\title{
Heterocyclic aromatic amines and colorectal cancer risk
}

Citation for published version (APA):

Moonen, H. J. J. (2003). Heterocyclic aromatic amines and colorectal cancer risk. [Doctoral Thesis, Maastricht University]. Datawyse / Universitaire Pers Maastricht. https://doi.org/10.26481/dis.20031211hm

Document status and date:

Published: 01/01/2003

DOI:

10.26481/dis.20031211hm

Document Version:

Publisher's PDF, also known as Version of record

\section{Please check the document version of this publication:}

- A submitted manuscript is the version of the article upon submission and before peer-review. There can be important differences between the submitted version and the official published version of record.

People interested in the research are advised to contact the author for the final version of the publication, or visit the DOI to the publisher's website.

- The final author version and the galley proof are versions of the publication after peer review.

- The final published version features the final layout of the paper including the volume, issue and page numbers.

Link to publication

\footnotetext{
General rights rights.

- You may freely distribute the URL identifying the publication in the public portal. please follow below link for the End User Agreement:

www.umlib.nl/taverne-license

Take down policy

If you believe that this document breaches copyright please contact us at:

repository@maastrichtuniversity.nl

providing details and we will investigate your claim.
}

Copyright and moral rights for the publications made accessible in the public portal are retained by the authors and/or other copyright owners and it is a condition of accessing publications that users recognise and abide by the legal requirements associated with these

- Users may download and print one copy of any publication from the public portal for the purpose of private study or research.

- You may not further distribute the material or use it for any profit-making activity or commercial gain

If the publication is distributed under the terms of Article $25 \mathrm{fa}$ of the Dutch Copyright Act, indicated by the "Taverne" license above, 


\title{
Heterocyclic aromatic amines and colorectal cancer risk
}

\author{
Harald J.J. Moonen
}


2003 Harald J.J. Moonen

Cover design: Harald Moonen | Mark Walravens

ISBN 90-5278-400-0

Production: Datawyse | Universitaire Pers Maastricht

Un The study presented in this thesis was performed at the Nutrition IIU IIII" and Toxicology Research Institute Maastricht (NUTRIM) which

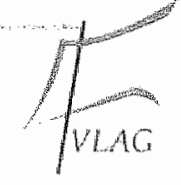
participates in the Graduate School VLAG (Food Technology, Agrobiotechnology, Nutrition and Health Sciences), accredited by the Royal Netherlands Academy of Arts and Sciences. 


\section{Heterocyclic aromatic amines and colorectal cancer risk}

\section{PROEFSCHRIFT}

ter verkrijging van de graad van doctor

aan de Universiteit Maastricht,

op gezag van de Rector Magnificus, Prof. dr. A.C. Nieuwenhuijzen Kruseman, volgens het besluit van het College van Decanen,

in het openbaar te verdedigen op donderdag 11 december 2003 om 14.00 uur

door

Harald Johan Joseph Moonen

geboren te Weert op 27 april 1974

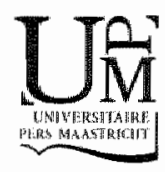




\section{Promotor:}

Prof. dr. J.C.S. Kleinjans

Co-promotor:

Dr. T.M.C.M. de Kok

\section{Beoordelingscommissie:}

Prof. dr. E.C.M. Mariman (voorzitter)

Prof. dr. M.J.A.P. Daemen

Dr. H. van Kranen (RIVM)

Prof. dr. F.C.S. Ramaekers

Prof. dr. I. Rietjens (Wageningen Universiteit)

Het verschijnen van dit proefschrift werd mede mogelijk gemaakt door de financiële steun van de Stichting Dr. Ir. J.H.J. van de Laar en Omnilabo International. 
"The difficulty in life is the choice" - George Moore 



\section{Contents}

CHAPTER I

General introduction and outline of the thesis

CHAPTER II

Methodologies for heterocyclic aromatic amine-DNA adduct analysis and determination of urinary 2-amino-1-methyl-6phenylimidazo[4,5-b]pyridine (PhIP) excretion levels

ChAPTER III

Generation of free radicals and induction of DNA adducts by activation of heterocyclic aromatic amines via different metabolic pathways in vitro

\section{CHAPTER IV}

Cyclooxygenase-mediated DNA adduct formation by heterocyclic aromatic amines in human adenocarcinoma colon cells

\section{CHAPTER V}

CYP1A2 and NAT2 genotype/phenotype relations and urinary excretion of 2-amino-1-methyl-6-phenylimidazo[4,5-b]pyridine $(\mathrm{PhIP})$ in a human dietary intervention study

\section{CHAPTER VI}

Relationship between the CYP1A2-164A $\rightarrow C$ polymorphism

(CYP1A2*1F) and risk for colorectal neoplasia in humans

\section{CHAPTER VII}

Summary \& general discussion

SAMENVATTING

DANKWOORD

CURRICULUM VITAE 



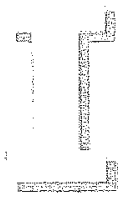

\section{Introduction}




\subsection{Colorectal cancer: etiological aspects}

\section{Facts and figures}

Of all common diseases in industrialized Westem countries, collorectal cancer (CRC) remains one of the most prevalent. In The Netherlands, approximately 8,600 new cases of CRC are diagnosed every year (1). In 2001, 3349 people died of colon cancer, which is about $9 \%$ of all cancer deaths in that year (2). For women, CRC is second only to breast cancer, while lung and prostate cancer are the only cancer types that exceed CRC rates in men.

Many factors can influence the development of CRC in humans. Genetic predisposition is an impontant risk factor, underlying inherited syndromes like familial adenomatous polyposis (FAP) and hereditary nonpolyposis colorectal cancer (HNPCC). FAP is characterized by the development of muitiple colorectall adenomas ( $>100$ ) at a very young age, caused by an inherited mutation in the APC gene, mostly leading to truncated APC proteins $(3,4)$. Patients with HNPCC show the tendency to early onset of CRC, without extensive polyposis. This syndrome is bellieved to be due to mutational Loss of DNA mismatch repair genes.

\subsubsection{Colorectal carcinogenesis: a genetic model}

The development of cancer is a highly complex process, to which many factors may contribute, including environmental and dietary factors as well as inherited and somatic mutations. However, the precise mechanism behind the development of colon cancer has not been completely clarified yet. Although the genetic model presented by Vogelstein has undergone some modifications and elaborations, it is still believed to provide a molecular basis for CRC development, describing the complex multi-stage process in which cells undergo subsequent alterations in genes that control cell growth and differentiation (Figure 1) (5-8). In the initiation phase of tumor development, the Adenomatous Polyposis Coli (APC) gene, located on chromosome $5 q$, is believed to play a major role. In the majority of colorectal cancers, one or two alleles of the APC gene may be inactivated by somatic mutation at an early stage of tumor development $(5,9,10)$, thus triggering a chain of other genetic alterations. As stated earlier, mutations in the APC gene are also responsible for the autosomal dominantly inherited syndrome called FAP.

The progression of tumors is believed to result from mutations in both oncogenes (K-ras) and tumor suppressor genes (on chromosomes $5 q, 17 p$ and $18 q)(11-13)$. In patients without polyposis, allelic losses involving chromosome $5 \mathrm{q} 21$ are the most frequent genetic alteration found in early adenomas $(5,9,14)$, while occurring with nearly the same frequency in more advanced tumors. Unchanged oncogenes or proto-oncogenes generally contribute to the normal growth regulation of cells in a positive manner, while mutated oncogenes can dominantly promote tumor development. The K-ras oncogene is mutated in approximately $50 \%$ of colorectal carcinomas and large adenomas, and these adenomas may have an imcreased risk of malignant progression (15). As the percentage of mutated K-ras genes is much lower in small adenomas (5), K-ras mutations are likely to occur in an early stage of colorectal carcinogenesis, during the conversion of small to large adenomas. Allelic losses in chromosomes $18 \mathrm{q}$ and $17 \mathrm{p}$ occur more frequently at later stages of tumorigenesis $(5,16)$. On chromosome $18 \mathrm{q}$, a common region af allelic loss was mapped, from which a candidate tumor suppressor gene was identified (17). Expression of this gene, termed DCC (deleted in colorectal cancer), is greatly reduced or absent in the majority of colorectal carcinomas. The common region of loss on chromosome $17 \mathrm{p}$ contains the gene encoding for $\mathrm{p} 53$, a protein that is believed to function as a tumor suppressor (18). 

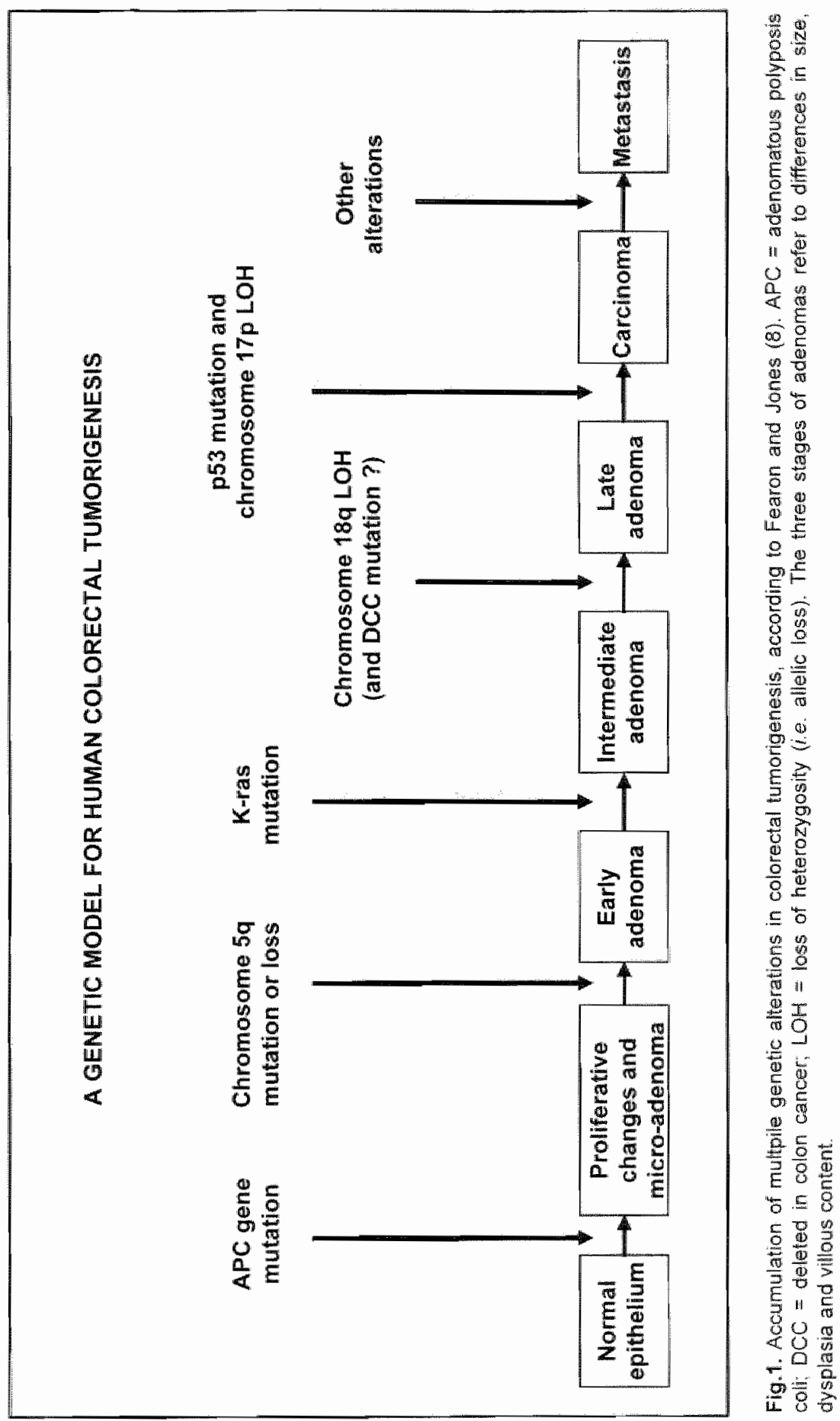
Without any other genetic alterations, mutations in the p53 gene are not common in carcinomas or adenomas. However, p53 point mutation in one allele coupled with the loss of the remaining wild-type allele, occurs frequently in later stages of the adenomacarcinoma cascade (19).

Although a preferred order in the timing of the specific events appears to exist, this order is not invariant. Moreover, accumulation of multiple genetic alterations seems more important than the order of the successive events. It is believed that at least four to five alterations in oncogenes or tumor suppressor genes are required for a malignant tumor to develop $(7)$.

\subsubsection{Environmental factors and CRC risk}

CRC incidence rates vary approximately 20 -fold worldwide, with high colon cancer rates found in North America, Australlia and Europe, and incidence being much lower in South America, Asia and Africa $(20,21)$. Interestingly, these rates were found to increase among groups that migrate from low-incidence to high-incidence areas $(22,23)$. Furthermore, CRC incidence increased over time within stable populations (24). These findings indicate that, besides the well-established genetic component $(25)$, environmental factors are important modulating factors in CRC risk. Moreover, nowadays environmental influences are believed to account for most of the variation in incidence rates. In 1981, Doll and Peto already estimated that approximately $90 \%$ of all colon cancer cases are due to environmental, and especially dietary, practices (26). In 1997, the World Cancer Research Fund (WCRF) together with the American Institute for Cancer Research (AICR), estimated that one-third of all cancer deaths are caused by the diet (27). In this perspective, the probable increased CRC risk associated with the consumption of red and processed meat seems very important and has gained much attention over the years.

\subsection{Relationship between meat consumption and CRC risk}

Although numerous studies have investigated the association between meat consumption and the risk for CRC (reviewed in 28), results are divergent and therefore, the relation remains controversial (e.g. 27,29-36). However, both red meat and processed meat are believed to be possible risk factors in the development of $\mathrm{CRC}$. In 1989, the National Acaderny of Sciences in the USA issued a report which implicated red meat as a causative factor in the etiology of CRC (37). Subsequently, a WCRF report concluded that "red meat probably increases risk and processed meat possibly increases risk of CRC", while a report from the Committee on Medical Aspects of Food and Nutrition Policy stated that "there is moderately consistent evidence from cohort studies of a positive association between the consumption of red or processed meat and risk of CRC" $(27,32)$. As a result, these groups of experts recommended a decrease in red meat consumption for Western populations in order to reduce CRC risk. Several hypothetical mechamisms have been proposed to link the intake of red meat to an increased risk of colon cancer. An interesting mechanism was described by Babbs (38), suggesting that high intake of red meat may increase fecal iron concentrations, thus leading to higher CRC risk via generation of hydroxyl radicals inducing oxidative DNA damage, which is a mutagenic lesion. Alternatively, Iransformation of meat constituents by reactive nitrogen species in the colon, resulting in DNAwbinding reactive metabolites, may increase cancer risk (39).

Most of the hypotheses, however, are related to the fatty acid content of red meat. Reddy suggested that dietary fat induces the excretion of bile acids, which can be converted to carcinogens or promotors by normal colonic bacteria (40). Indeed, high 
consumption of beef has been shown to increase concentrations of fecal bile acids (41). However, ather sources of fat have not been found to increase CRC risk, which may be explained in different ways (42). For example, red meat may contain specific fattly acids that are particularly harmful. Furthermore, more of the red meat fat may reach the large bowel, because it is less well digested or absorbed in the small intestine. Finally, nonlipid components of meat may be responsible for an elevated CRC risk. In this perspective, the formation of carcinogens, such as polycyclic aromatic hydrocarbons (PAH) and heterocyclic amines (HCA), during the cooking of meat may be of significant importance.

\subsection{Discovery and characterization of heterocyclic amines}

In 1939, Widmark firstly suggested the possible occurrence of "cancer-producing substances in fried meat", and demonstrated this by inducing carcinogenic effects in mouse skin by applying roasted horse meat extracts (43). In 1976. Sugimura wondered what might be in the smoke produced in the kitchen during cooking of fish and meat. He designed an apparatus to collect smoke particles, produced by broiling fish over a gas burner, on a glassufiber filter. After being dissolved with dimethyl sulfoxide the mutagenicity of the collected matter was tested in the Ames test, a sensitive and reliable assay using Salmonella typhimurium (44). Mutagenicity of the smoke condensate was demonstrated after metabolic activation with 59 -mix $(45,46)$. Furthermore, mutagenic activity was demonstrated in cooked fish and meat, and especially the surface of the cooked foods was found to be very mutagenic (46-48). As a result of these findings, research was initiated to characterize the substances in meat and fish responsible for its mutagenic activity.

A series of mutagenic compounds could be isolated from pyrolysates of amino acids and proteins and directly from cooked meat and fish by monitoring the mutagenic activity in Salmonella typhimurium strain TA98 with $\mathrm{S9}$ mix during purification. These compounds were found to be heterocycles with an amine functional group, and this class of mutagens thas since then been known as heterocyclic amines. The first HCA to be characterized were two umidazo-pyridine compounds, 3-amino-1,4-dimethyl-5Hpyrido[4,3-b]indole (Trp-P-1) and 3-amino-1-methyl-5H-pyrido[4,3-b]indole (Trp-P-2), which were isolated from a pyrolysate of tryptophan (49). From a pyrolysate of glutamic acid, two dipyrido-imidazole compounds were isolated, 2-amino-6-methyldipyrido-[1,2-a: $3^{\prime}, 2^{\prime}-d$-imidazole (Glu-P-1) and 2-aminodipyridol1,2-a: $\left.3^{\prime}, 2^{\prime}-d\right]$ imidazole (Glu-P-2) (50).

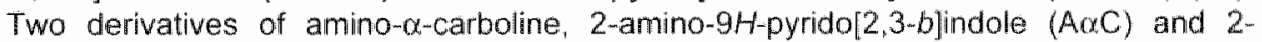
amino-3-methyl-9H-pyrido[2,3-blindole (MeAaC), were found in a pyrolysate of soybean globulin (51). A few years later other mutagens were isolated directly from cooked fish and meat. Two imidazoquinoline compounds, 2-amino-3-methylimidazo-[4,5-f]quinoline (IQ) and 2-amino-3,4-dimethylimi-dazo[4,5-f]quinoline (MelQ), were purified from broiled sun-dried sardines $(52,53)$, while 2-amino-3,8-dimethylimidazo[4,5-f]quinoxaline (MelOx) was found to be present in fried beef (54). In 1986, another major mutagen, 2-amino-1methyl-6-phenylimidazo[4,5-b]pyridine (PhIP) was isolated from fried beef (55). Everitually, all these HCA have been classified as non-1Q-and 10 -types. Their structures are depicted in Figures 2 and 3 , and their names, abbreviations, source of isolation and year of characterization are given in Table 1. Formation of non-1Q-type HCA occurs at temperatures above $300{ }^{\circ} \mathrm{C}$ and these HCA are classified as 'pyrolytic mutagens'. Because these temperatures are far higher than normal domestic cooking temperatures. these particular HCA are not commonly found in the Western diet. The IQ-type HCA are formed at temperatures below $300^{\circ} \mathrm{C}$ and are called 'thermic mutagens'. They possess a 2-amino-imidazo group fused to a quinoline ( $1 Q$ and MelQ), quinoxaline (MelQx) or pyridine (PhIP) ring and are referred to as amino-imidazo-azarenes (AIA). 
<smiles>Cc1c(N)nc(C)c2c1[nH]c1ccccc12</smiles>

TrP-P-1<smiles>Nc1ccc2nc3ccccn3c2n1</smiles>

Glu-P-2<smiles>Cc1nc(N)cc2[nH]c3ccccc3c12</smiles>

TrP-P-2<smiles>Nc1ccc2c(n1)[nH]c1ccccc12</smiles>

$\mathrm{A} \times \mathrm{C}$<smiles>Cc1cccn2c1nc1ccc(N)nc12</smiles>

Glu-P-1<smiles>Cc1cc2c(nc1N)[nH]c1ccccc12</smiles>

MeAaC

Fig.2. Structures of non-1Q-type heterocyclic amines.<smiles>Cn1c(N)nc2c3cccnc3ccc21</smiles>

$1 Q$<smiles>Cc1cc2ncccc2c2nc(N)n(C)c12</smiles>

MelQ<smiles>Cc1cnc2ccc3c(nc(N)n3C)c2n1</smiles>

Mellax<smiles>CN1C(N)=NC2N=CC(c3ccccc3)=CC21</smiles>

$\mathrm{Ph} \| \mathrm{P}$

Fig.3. Sitructures of IQ-type heterocyclic annines. 
Table 1. Chemical names, abbreviations, source and year of isolation for theterocyclic amines.

\begin{tabular}{|c|c|c|c|}
\hline Chemical name & Abbreviation & Source & Year \\
\hline $\begin{array}{l}\text { 3-amino-1,4-dimethyl-5H } \\
\text { pyrido[4,3-b]-indole }\end{array}$ & Trp-P-1 & $\begin{array}{l}\text { Tryptophan } \\
\text { pyrolysate }\end{array}$ & 1977 \\
\hline $\begin{array}{l}\text { 3-amino-1-methyl-5H- } \\
\text { pyrido }[4,3-b] \text { indole }\end{array}$ & Trpm $\mathrm{P}-2$ & $\begin{array}{l}\text { Tryptophan } \\
\text { pyrolysate }\end{array}$ & 1977 \\
\hline $\begin{array}{l}\text { 2-amino-6-methyldipyrido- } \\
{\left[1,2-a: 3^{\prime}, 2^{\prime}-d\right] \text {-imidazole }}\end{array}$ & Glu-P-1 & $\begin{array}{l}\text { Glutamic acid } \\
\text { pyrolysate }\end{array}$ & 1978 \\
\hline $\begin{array}{l}\left.\text { 2-aminodipyrido[1,2-a: } 3^{\prime}, 2^{\prime}-d\right] . \\
\text { imidazole }\end{array}$ & Glu-P-2 & $\begin{array}{l}\text { Glutamic acid } \\
\text { pyrolysate }\end{array}$ & 1978 \\
\hline 2-amino-9H-pyrido $[2,3$-b]indole & $\mathrm{A} \alpha \mathrm{C}$ & $\begin{array}{l}\text { Soybean globulin } \\
\text { pyrolysale }\end{array}$ & 1978 \\
\hline $\begin{array}{l}\text { 2-amino-3-methyl-9H-pyrido- } \\
{[2,3 \text {-b]indole }}\end{array}$ & $\mathrm{MeA} \alpha \mathrm{C}$ & $\begin{array}{l}\text { Soybean globulin } \\
\text { pyrolysate }\end{array}$ & 1978 \\
\hline $\begin{array}{l}\text { 2-amina-3-methylimidazo- } \\
{[4,5-f] q u i n o l i n e}\end{array}$ & $1 \mathrm{Q}$ & $\begin{array}{l}\text { Brolled sun-dried } \\
\text { sardine }\end{array}$ & 1980 \\
\hline $\begin{array}{l}\text { 2-amino-3,4-dimethylimidazo- } \\
{[4,5-f] \text {-quinoline }}\end{array}$ & MelQ & $\begin{array}{l}\text { Broiled sun-dried } \\
\text { sardine }\end{array}$ & 1980 \\
\hline $\begin{array}{l}\text { 2-amino-3,8-dimethylimidazo- } \\
{[4,5-f] \text {-quinoxaline }}\end{array}$ & Melax & Fried beef & 1981 \\
\hline $\begin{array}{l}\text { 2-amino-1-methyl-6- } \\
\text { phenylimidazo[4,5-b]-pyridine }\end{array}$ & PhIP & Fried beef & 1986 \\
\hline
\end{tabular}

The synthetic pathway of the class of HCA seems to involve Maillard reactions in the presence of creatine (56-58). This is in agreement with the fact that the formation of HCA only occurs in foods containing creatine (i.e. mostly meat and fish), and not in other types of foods. Figure 4 shows a possible pathway for the formation of la by the Maillard reaction, as proposed by Jagerstad ef al. (56). Other 1Q-type HCA are formed in a similar way.

In this pathway, creatinine is formed from creatine by cyclization and elimination of water, eventually forming the amino-imidazo part of the HCA molecule. Other parts of the molecule are possibly made up of Strecker degradation products like pyridine, formed in the Maillard reaction between hexase and an amino acid. Finally, linkage of the two parts of the molecule is believed to result from an aldol condensation involving a Strecker aldehyde. 


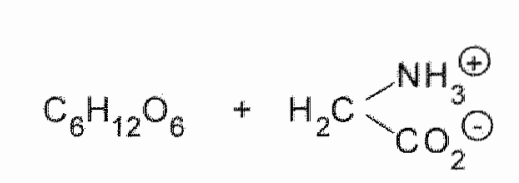

hexase

amino acid

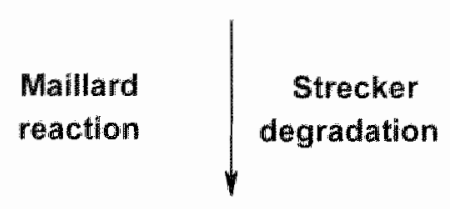

$\overbrace{\mathrm{CH}_{3}}+\mathrm{H}_{2} \mathrm{C}=\mathrm{O}+$

pyridine<smiles>CN(CC(=O)O)C(=N)N</smiles>

creatine

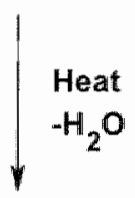<smiles>CN1CC(=O)N=C1N</smiles>

creatinine<smiles>Cn1c(N)nc2c3cccnc3ccc21</smiles>

$1 \mathrm{Q}$

Fig. 4. Suggested pathway for the formation of 10 .

The important role of creatine has been confirmed by investigators adding creatine to meat products before frying, thereby strongly increasing the total mutagenic activity (5962). The results of those studies suggest that the creatine content is a rate-limiting factor in food mutagen formation. Moreover, as suggested by the Jägerstad pathway in Figure 4 . creatine has indeed been demonstrated to form a part of the PhIP molecule by using radiolabelled creatine (63). Many other studies have supported the hypothesis on the precursors and intermediates as suggested by lägerstad (see 58). 
With respeci to other factors that influence the formation of HCA temperature and time of preparation are both very important. Several studies have described an increase in HCA formation due to higher temperatures $(64-66)$ or prolonged preparation times $(67,68)$. When using a model system of creatinine, glucose and a mixture of amino acids, Arvidsson et al. found the amount of formed HCA to level out after reaching a maxirnum after some time (69).

Alternatively, several factors have been found to inhibit the formation of HCA. The presence of antioxidants (70-72), marinating before cooking (73,74), and pre-treatment by microwaves (75) have all been found to reduce HCA formation im meat.

In general, the formation of HCA in meat and fish cooked by ordinary household methods results in concentrations in the $\mathrm{ppb}(=\mathrm{ng} / \mathrm{g}$ ) range, with PhiP being most abundantly present in cooked meat (76-78).

\subsection{Metabolic fate of HCA}

In humans, HCA are efficiently absorbed into the systemic circulation after ingestion; thus being almost completely bioavailable. With only $1-4 \%$ to be excreted unchanged in the urine, the majority of ingested HCA are subject to metabolization in the body. Like many other xenobiotics, HCA have to be metabolically activated in order to exert their mutagenic and carcinogenic properties. This is believed to occur via $\mathrm{N}$-oxidation to $\mathrm{N}$ hydroxy metabolites followed by $\mathrm{O}$-acetylation to form $\mathrm{N}$-acetoxy arylamines, the reactive metabolites that may form DNA adducts. These reactions are respectively catalyzed by hepatic cytochrome P4501A2 (CYP1A2) and N-acetyltransferase-2 (NAT-2), which are both polymorphic in humans. Figure 5 shows the proposed metabolic activation of HCA in relation to collon carcinogenesis (79).

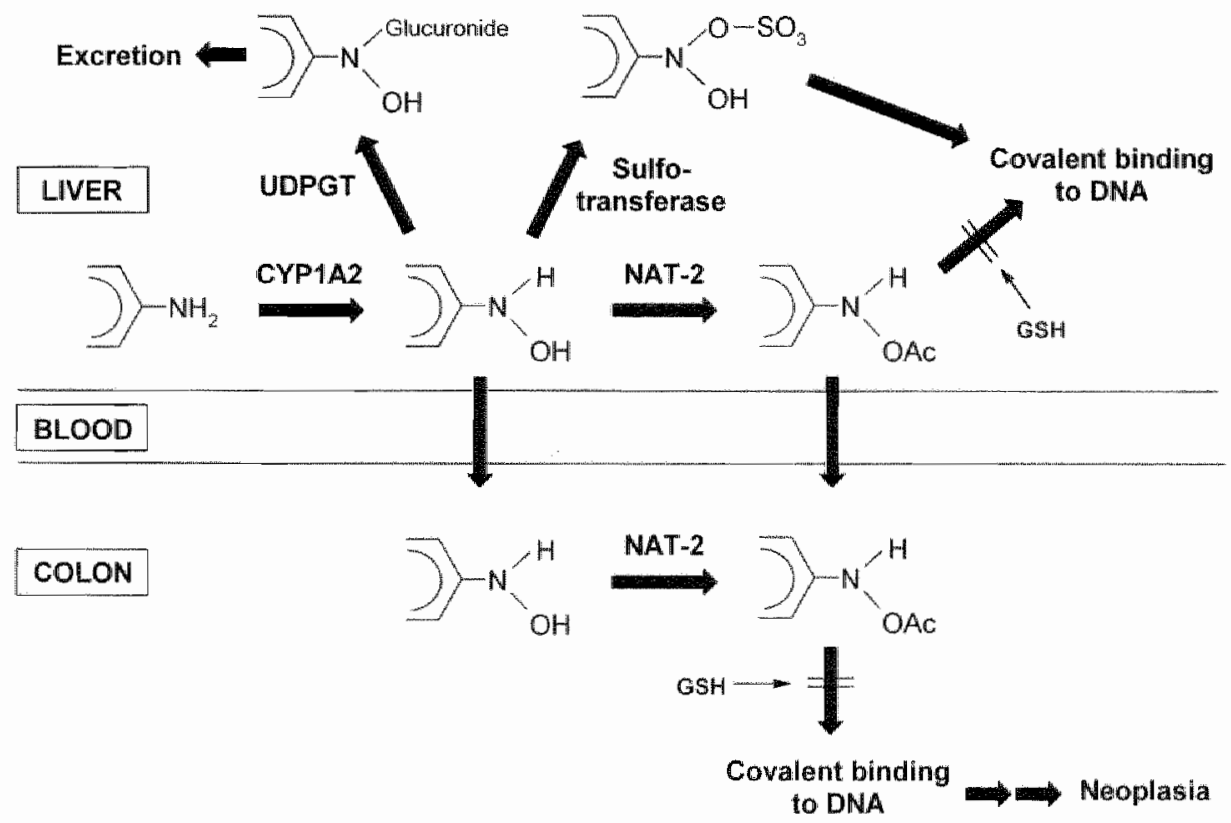

Fig. 5. Metabolic activation of PhIP and other HCA in collorectal carcinogenesis, as proposed by Kadlubar et al. (79). 
HCA have proven to be poor substrates for direct $N$-acetylation by NAT-2 (80). The Nhydroxy metabolites, however, are good substrates for the NAT-2 enzyme to undergo Oacetylation, either in the liver or in the colon after transportation via the blood stream. Alternatively, $N$-hydroxy metabolites may be subjected to glucuronidation and can thus be excreted in the urine, a detoxification step that is catalyzed by UDP glucuronosyltransferase (UDPGT). Another possibility is the formation of the sulfate ester from N-hydroxy-HCA by cytosolic sulfotransferase, a pathway that has also been found to occur in the human colon, rendering an ultimate carcinogenic species $(81)$. Both the N-hydroxy form and the $N$-acetoxy form can be transported via the bloodstream to extrahepatic tissues like the colon. This circulation of highly reactive intermediates through the bloodstream has been confirmed by Schut and Herzog, who found high PhIP.DNA adduct levels in rat lymphocytes after an oral dose of PhIP (82).

Biliary transport after glucuronidation, with subsequent deconjugation of the $N$ glucuronides, appears to be a detoxification route (83). For PhIP, detoxification in the liver is believed to be caused by reaction of glutathone with the $N$-acetoxy derivative, thus explaining the carcinogenic properties of PhIP in rat colon rather than in the liver (84). This detoxification step is further enhanced by glutathione-S-transferases, which may explain organ-specificity in HCA carcinogenicity (85). The esters that result from either acetylation or sulfatation, undergo spontaneous hydrolyzation to form an arylnitrenium ion, the ultimate reactive intermediate that can form covalently bound DNA adducts.

In contrast, another detoxification pathway involwes direct C-hydroxylation of $H C A$, resulting in non-mutagenic phenolic compounds like 4'-hydroxy-PhiP. These can subsequently undergo conjugation by phase $\|$ enzymes such as sulfotransferase, glutathione transferase or glucuronosyl transferase, that can be induced by vegetable extracts and green or black tea, which have been found to increase the detoxification reactions (86-88). The proposed pathway has been confirmed by several other investigators. For instance, Sawada and Kamataki found high reactivities for HCA in genetically engineered cells, stably expressing cytochrome P450 and $\mathrm{N}$ acetyltransferase (89). Furthermore, Boobis et al. demonstrated that the CYP1A2catalyzed primary conversion of HCA is the major metabolic route in humans (90). Next to CYP1A2, the isozymes CYP1A1 and, to a lesser extent, CYP1B1 could also play a role in extrahepatic PhIP metabolism in humans, with respect to the formation of 2 hydroxyamino-PhIP $\left(N^{2}-O H-P h P\right)$. Allhough the rate of formation of this mutagenic metabolite is clearly higher for CYP1A2 than for CYP1A1 and CYP1B1, the catalytic efficiency of $\mathrm{N}^{2}$.OH-PhlP production was found to be higher for CYP1A1 than for CYP1A2 (91).

Specific intestinal bacterial systems can also participate in the metabolic activation of HCA. Both HCA that reach the gut directly, and especially HCA and their metabolites that reach the gut via biliary transport, can be converted in this way $(92,93)$. 10 can be converted into the mutagenic 7 -hydroxy derivative $7-\mathrm{OH}-1 \mathrm{QQ}$ by normal microflora (94), while $N$-hydroxy $1 Q$ is formed by anaerobic microorganisms in the human small intestine (95). A major biliary metabolite of $1 \mathrm{Q}$ was identified as the non-mutagenic sulfamate derivative, $N$-(3-methylimidazo[4,5-f]quinolin-2-yl)sulfamic acid, the formation of which thus being an important detoxification pathway in the rat (96).

Another pathway, that may be of particular interest with respect to the carcinogenicity of HCA in extrahepatic tissues such as colon and rectum, involves oxidation of HCA catalyzed by the enzyme prostaglandin H synthase (PHS) (97). PHS is found in most mammalian tissues and has two distinct activities, cyclooxygenase (COX) and peroxidase. 
For COX, two isoforms are known; COX -1 is constitutively expressed in nearly all cells, while COX-2 can be induced in many cell types by a number of intracellular and extracellular stimuli $(98,99)$. Cyclooxygenase catalyzes the formation of prostaglandin $\mathrm{G}_{2}$ ( $P G G_{2}$ ) from the polyunsaturated falty acid arachidonic acid (AA), which is released from membrane phospholipids by phospholipases (100). The peroxidase moiety of PHS catalyzes the subsequent reduction of $\mathrm{PGG}_{2}$ to prostaglandin $\mathrm{H}_{2}(\mathrm{PGH})$, which is a precursor for several types of prostanoids, like prostaglandin $E_{2}\left(P G E_{2}\right)(97,101-103)$. During the conversion of $\mathrm{PGG}_{2}$ to $\mathrm{PGH}_{2}$, electron-donating cosubstrates are necessary to allow the peroxidase catalytic cycle to proceed. In turn, these cosubstrates are then converted to chemically reactive, electron-deficient metabolites (97). It is believed that HCA can serve as cosubstrates for PHS peroxidase, thus ondergoing one-electron oxidation, resulting in the formation of HCA free-radical metabolites that can bind covalently to DNA (104) (Figure 6).

A considerable amount of evidence indicates the involvement of $\mathrm{COX}-2$ in colorectal carcinogenesis. Many studies have demonstrated that colorectal adenocarcinomas show higher levels of COX-2 expression than the adjacent normal tissue (e.g. 105-107). Furthermore, inhibitors of cyclooxygenases have been found to substantially decrease colorectal cancer risk. For instance, continuous use of non-steroidal anti-inflammatory drugs (NSAIDs) like aspirin, which are known to inhibit both COX-1 and COX-2, has been correlated to a decreased CRC risk (108-112). This antineoplastic action is believed to result from the inhibition of isoform $\operatorname{COX}-2(113)$.

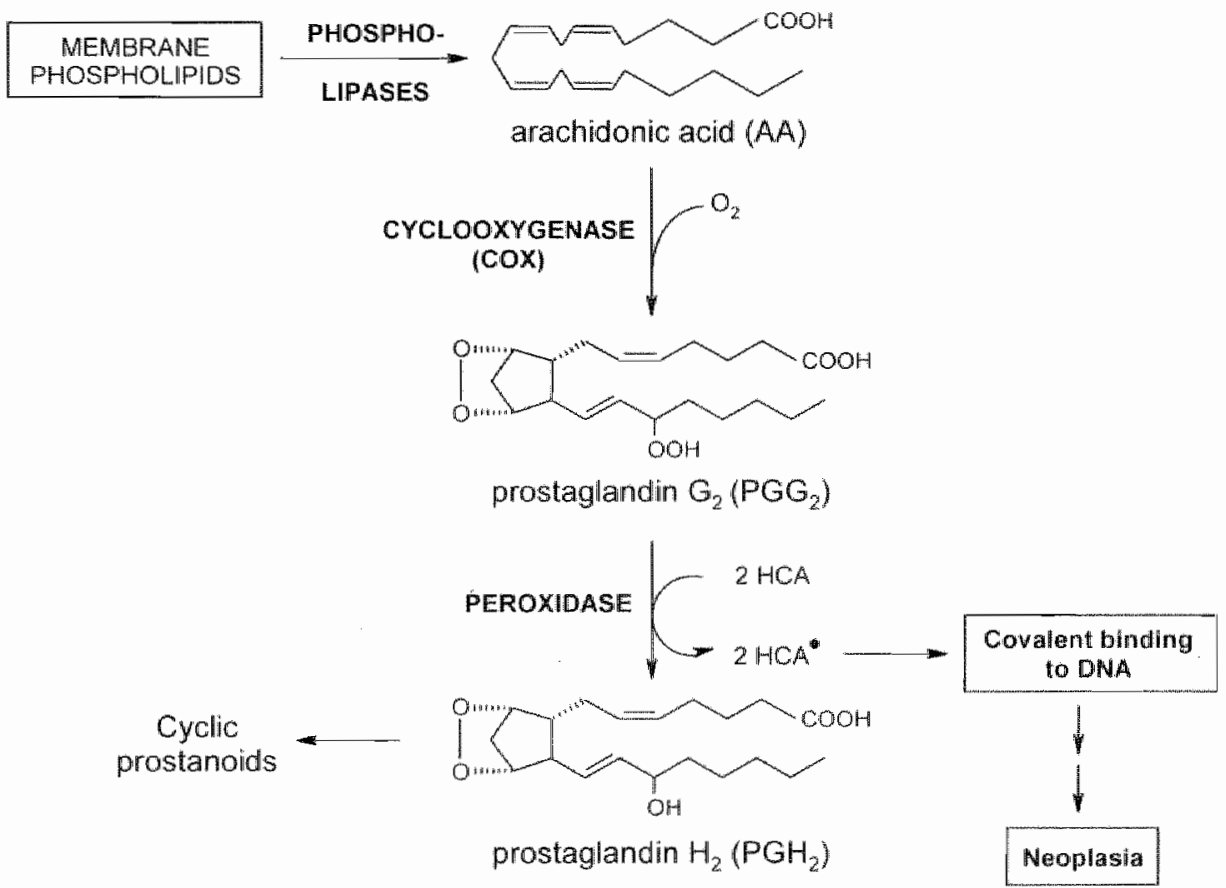

Fig. 6. Cooxidation of HCA during the PH5-catalyzed conversion of arachidonic acid to prostanoids. 


\subsection{DNA adduct formation by HCA}

Both the hepatic and the extrahepatic pathway lead to the formation of reactive HCA metabolites that may bind covalently to DNA, thus generating DNA adducts. It is generally belleved that the formation of DNA adducts is an essential step in the carcinogenic process, although the exact relationship is not fully understood $(114,115)$. Measurement of DNA adducts provides biologically relevant information on the ultimate result of exposure, absorption, distribution, metabolism, genetic susceptibility and DNA repair capacity. Because DNA adducts accur at wery low levels, very sensitive assays are necessary to detect and quantify these lesions. Of the different methods developed over the years, the ${ }^{32}$ P-postlabeling assay has been used most extensively. This technique involves the introduction of a radioactive label into the adduct, after it has been formed. Thus, DNA adducts can be regarded as biomarkers of potential mutagenicity and of cancer risk $(114,116)$. Using the ${ }^{32} \mathrm{P}$-postlabeling assay, adducts formed by HCA have been identified in rats (117-119), monkeys (120-122), dogs (79) and humans $(79,123,124)$. In humans, HCA-DNA adducts were predominantly found in colon and rectum tissues, and not in pancreas, liver or urinary bladder, indicating that the colorectal mucosa is the target tissue for HCA.

After oral administration of the corresponding HCA to rats, the highest levels of IQ- and MelQX.DNA adducts have been found in the liver, followed by kidney and heart; for PhIP, adduct levels were highest in colon, heart, lung and pancreas, and lowest in the liver (117-119,125). So far, various HCA-DNA adduct structures have been identified. All form a major adduct with the $C 8$ atom of guanine, while $1 Q$ and $M e l Q x$ also form a minor adduct with the $N^{2}$ atom of guanine $(120,122,126-129)$. Figure 7 shows the structures of the identified DNA adducts formed by $\mid Q$ and $P h I P$.<smiles>Cn1c(Nc2nc3c(=O)[nH]c(N)nc3n2C2CC(O)C(CO)O2)nc2c3cccnc3ccc21</smiles>

$d G-C 8-1 Q$<smiles>Cn1c(N)nc2c3cccnc3c(Nc3nc4c(ncn4C4OC5C4COC5(O)CO)c(=O)[nH]3)cc21</smiles>

$d G \cdot N^{2}-\| Q$<smiles>CN1C(Nc2nc3c(=O)[nH]c(N)nc3n2C2CC(O)C(O)(CO)O2)=NC2N=CC(c3ccccc3)=CC21</smiles>

dG-C8-PhIP

Fig.7. Structures of DNA adducts formed by $1 Q$ and PhIP. dG-C8-1Q, N-(deoxyguanosin-8-yl) $1 Q$; dG- $N^{2}-1 Q, 5$-(deoxyguanosin- $\left.N^{2}-y \mid\right)-1 Q ;$ d dG-C8-PhIP, $N$-(deoxyguanosin-8-yl)-PhIP. 
Other assays used to determine HCA-DNA adduct levels comprise GC-MS $(79,123), L C$ MS (130) and accelerated mass spectrometry (AMS) (131-133). The latter technique, which has shown to be very sensitive, has been used to detect PhIP.DNA adducts in normall human collorectal tissue after exposure to a dietary-relevant dose of the food mutagen (134). However, this assay is limited to the use of ${ }^{14} \mathrm{C}$-labeled substrates, and is therefore not applicable in standard human biomonitoring studies. Furthermore, by using the isolated compound, the food matrix effect in normal dietary exposure is not taken into account in these studies. As stated earlier, the 3zp-postlabeling assay, although less sensitive than AMS, has been used to detect HCA-DNA adducts in colon tissue, and may therefore be used in biomonitoring studies. Because the target tissues are usually not easily accessible alternative tissues are considered for biomonitoring purposes. In this perspective, peripheral blood lymphocytes may be used for biomonitoring HCA exposure and investigating the peripheral bioavailability of $\mathrm{HCA}$ in thumans. Although, for HCA-DNA adducts, such studies have not been described yet, the use of DNA adducts as biomarkers of exposure in peripheral blood lymphocytes was earlier described for another food carcinogen, the PAH benzo[a]pyrene (135).

Turteltaub ef al. investigated covalent DNA-binding for MelQX in the human colon using AMS, suggesting that humans may produce more DNA adducts per dose as compared to the rat (136). Furthermore, Lin et al. demonstrated that the human liver is more active with respect to $\mathrm{N}$-hydroxylation of aromatic amines by CYP4501A2 as compared to the rodent liver (137), thus leading to higher levels of reactive HCA intermediates per ingested dose. These findings indicate that humans seem more sensitive to genotoxic damage by HCA than rodents $(138,139)$, and suggest that extrapolation from rodent cancer data could lead to an underestimation of the risk for humans. In conclusion, it can be said that consumption of well-done meat results in HCA-DNA adduct formation in the colon, which may cause genetic alterations. These alterations can eventually lead to colorectal tumorigenesis, as described by the Vogelstein model in paragraph 1.1.1.

\subsection{Mutagenicity and carcinogenicity of HCA}

The AIA, with the exception of $\mathrm{PhIP}$, are among the most potent mutagenic compounds known in bacteria, as tested in the Ames assay $(140,141)$. Mutagenicities of the AIAs and some typical carcinogens in Salmonella Typhimurium strains TA98 and TA100 are summarized in Table 2.

Many studies in bacterial assays support the role of AIA-DNA adduct formation in mutagenesis (140-144). Malfatti et al. studied the efficiency of HCA.DNA adducts to form mutations in Salmonella Typhimurium TA98, showing that less than 25 adducts are required for one mutational event (ie. frameshift mutation) (145). Furthermore, Kerdar ef al. demonstrated for several AIAs that mutagenic potency was linearly related to higher adduct levels in bacterial DNA (143), thus indicating that quantitative rather than qualitative differences in DNA adduct levels determine mutagenicity differences among these AlAs.

Alternatively, in mammalian cell mutagenicity assays. AlA-DNA adducts have been found to primarily induce base substitution mutations in guanine, with $G \rightarrow T$ transversion mutations accurring most frequently $(146,147)$. In general, in in vitro studies, mutations induced by AIA-DNA adducts appear to be site-specific in mammalian genes, as demonstrated for PhlP by Shibutani et al. (148). 
Table 2. Mutagenic activities of IQ-type HCA in comparison with typical carcinogens in Salmonella Typhimurium TA98 and TA 100 (149).

Mutagenic activity (revertants/ $/ \mathrm{g}$ )

\begin{tabular}{lrr} 
Mutagen & TA98 & TA100 \\
\hline 10 & 433000 & 7000 \\
MelQ & 661000 & 30000 \\
IQx & 75000 & 1500 \\
MelQx & 145000 & 14000 \\
4,8-DiMelQx & 183000 & 8000 \\
7,8-DiMelQx & 163000 & 9900 \\
PhIP & 1800 & 120 \\
& & \\
2-Furyl-3-nitrofuryl-acrylamide & 6500 & 42000 \\
Aflatoxin B 1 & 6000 & 28000 \\
4-Nitroquinoline 1-axide & 970 & 9900 \\
Benzo[alpyrene & 320 & 660 \\
N-Nitrosodiethylamine & 0.02 & 0.15 \\
& & \\
& &
\end{tabular}

In vivo, AlAs have demonstrated to induce base substitution and/or deletion mutations in the lacl or lacZ genes of transgenic mice $(150-152)$, in colonic cells of mice $(153,154)$, and in mouse small intestine (155). In the transgenic mice, mutant frequency appears to depend on both the dose and the duration of exposure to AIAs $(156,157)$. It is not certain whether lacZ or lacl genes can predict the sites for chemical-induced carcinogenesis (156), although PhIP has been shown to induce a single-base deletion in the lacl gene in transgenic mice colon, which was characteristic of the single-base deletions found in the APC gene of rat colon tumors induced by PhIP (151). Other studies have also suggested that PhIP leaves a characteristic mutational fingerprint in the APC gene $(158,159)$.

In general, HCA are less carcinogenic as they are mutagenic, when compared with other compounds (160). Still, HCA have proven to be potent carcinogens in numerous animal studies. For rodents, carcinogenicity of HCA has been well documented $(160,161)$, showing that rats are generally more sensitive than mice. All of the AlAs that were found to be carcinogenic in rats and/or mice, form DNA adducts in these species (e.g. $83,84,129,162,163) . I Q$ and MelQx are hepatocarcinogens in rats and mice, both producing relatively high levels of DNA adducts in the liwer $(118,125,164,165)$. Alternatively. PhIP, which is not a hepatocarcinogen in adult rodents, has shown to form relatively low levels of DNA adducts in the liver as compared to extrahepatic tissues such as mammary gland, prostate and colon $(83,164,166,167)$. Similar findings were described in nonhuman primates, where hepatic adduct levels were found to be much higher for IQ than for MelQx, with IQ being a potent hepatocarcinogen, contrary to 
MelOx (121,168-170). Although these findings support the role of AlA-DNA adducts in carcinogenesis, the possible occurrence of relatively high adduct levels in non-target tissues, as well as the possible absence of elevated adduct levels in target tissues, contradict a simple relation between DNA-adducts and cancer $(123,163,164,171)$. The capacity of human tissues to activate AlAs varies widely between individuals $(168,172,173)$. The resulting variation in DNA adduct levels is suggested to be dependent on the balance between metabolic activation and deloxification ( 83 $85,174,175)$. Polymorphisms and differences in expression of genes involved in activation or detoxification, may thus influence genotoxicity $(176-478)$. For instance, high enzymatic activities for both CYP1A2 and NAT-2, which are key enzymes in HCA metabolism, have been associated with an elevated risk for colorectal cancer in humans $(79,179,180)$. Such important determinants of HCA metabolism have not been taken into account in the numerous epidemiological studies where HCA exposure is directly linked to CRC (see 28), leaving uncertainties about the internal HCA exposure and the biological fate of HCA in the human body. Moreover, accurate assessment of human HCA exposure appears to be difficult, mainly due to the complexicity of the food matrix, the low amounts of HCA present and the multi-step isolation procedure (181). Food questionnaires have often been used to estimate HCA exposure (182), but there are several flaws including bias, inconsistent reporting and day-to-day variation in diet (183). Therefore it is necessary to monitor HCA and their metabalic activation in the human body, using biomarkers of exposure and incorporating the role of relevant genetic polymorphisms and enzyme activities.

In general, it is believed that individual genetic susceptibility may play a major role in human cancer risk. There is substantial evidence that certain individuals are at a higher risk for cancer when exposed to heterocyclic amines, the magnitude of risk most likely ranging from 1 per 10,000 for the average person to greater than 1 in 50 for those ingesting large amounts of well-done muscle meats $(184)$.

\subsection{Outline of the thesis}

Many aspects concerning dietary HCA, their metabolism and the putative relation to human colorectal cancer risk, have been studied by other researchers who have amply provided insights into the features of these food-borne carcinogens. However, still many issues remain incompletely understood. With respect to the in vitro metabolic activation of HCA via different pathways, the extrahepatic pathway for HCA has been studied far less extensively as compared to the hepatic route. However, it is important to know the relative importance of either pathway, since both routes of activation, with their corresponding key enzymes and resulting reactive metabolites "may significantly contribute to the ultimate carcinogenic risk resulting from HCA exposure. Furthermore, interaction with other dietary factors, such as PUFA, may influence HCA metabolism.

As explained in paragraph 1.7, it is important to monitor the biological fate of HCA in humans. Although metabolic activation of HCA in relation to genetic polymorphisms and enzymatic activities for CYPAA2 and NAT-2 has been investigated in numerous studies, data on the relationship between the specific CYP1A2-164A $\rightarrow C$ polymorphism (CYP1A2*1F) and either biomarkers of exposure, such as urinary excretion of unmetabolized PhIP, or relative colorectall cancer risk are not available.

The aim of the present thesis is to further complete our understanding of the complex relationship between $\mathrm{HCA}$ and colorectal cancer risk in humans. 
Therefore, the research topics of the present thesis are:

- To study the relative importance of the hepatic and extrahepatic metabolic pathways for HCA by investigating the formation of intermediate and ultimate reactive metabolites resulting from the activation of HCA via these different routes in vitro.

- To investigate the cyclooxygenase-catalyzed formation of DNA adducts by HCA in COX-2 expressing human colon cells, and to study the effect of polyunsaturated faty acids and specific enzyme inhibitors on this DNA adduct forming capacity.

- To study the urinary excretion of PhIF as a biomarker of exposure, in relation to the dietary exposure and genetic polymorphisms and enzymatic activities for both CYP1A2 and NAT-2 in healthy volunteers.

- To investigate the influence of genetic polymorphisms and enzymatic activities for both CYP1A2 and NAT-2 on colorectal neoplasia risk in different risk groups of patients, as compared to healthy control subjects.

Chapter 2: This chapter describes the development and optimization of methods to determine different biomarkers of HCA intake used in this thesis. The ${ }^{32}$ P-postlabeling assay was used for detection and quantification of DNA adduct levels formed by PhIP and $1 \mathrm{Q}$. In order to assess urinary PhIP excretion levels, gas chromatography-mass spectrometry (GC-MS) was used.

Chapter 3: As described in paragraph 1.5, the metabolic activation of HCA to genotoxic species can proceed via two different pathways. In this chapter, the formation of reactive metabolites via either of both pathways was investigated in vitro. The ${ }^{32} \mathrm{P}$-postlabeling assay, as described in chapter 2, was used to assess HCA-DNA adducts levels resulting from either pathway, while the generation of free radical metabolites in the extrahepatic route was demonstrated using electron spin resonance (ESR) spectroscopy.

Chapter 4: The extrahepatic activation of HCA comprises cooxidation during the conversion of polyunsaturated fatty acids (PUFA) by the cyclooxygenase (COX) enzyme. DNA adduct formation by HCA was investigated in COX-2 expressing human colon cancer cells. Furthermore, the influence of PUFA and the effect of several specific enzyme inhibitors on the DNA adduct forming capacity by HCA was studied in these cells.

Chapter 5: To investigate the influence of genetic polymorphisms and enzyme activities on the metabolic process of HCA in humans, volunteers were exposed to a PhIP containing diet. Subjects were genotyped and phenotyped for the enzymes CYP1A2 and NAT-2. Urinary PhIP excretion levels were determined using GC-MS, as described in chapter 2 .

Chapter 6: Patients undergoing endoscopic examination were divided into groups at different risk for colorectal cancer, based on occurrence and size of colorectal adenomas. For these subjects, the influence of genotypic and phenotypic variations in CYP1A2 and NAT-2 on colorectal cancer risk was investigated, as compared to control subjects.

Chapter 7: The findings of all studies described in this thesis are discussed and summarized. 


\section{References}

1. Visser, O., Coebergh, J., Schouten, L., Van Dijck, J. (2001) Incidence of cancer in the Netherlands. In: Visser, $O$., Coebergh, J., Schouten, L., Van Dijck, J. (eds.), Vereniging van Integrale Kankercentra 86 . Utrecht, The Netherlands

2. Statistics Netherlands website: hittp:/Www cbs nllen/

3. Nishisho, I., Nakamura, Y., Miyoshi, $Y$., Miki, $Y$., Ando, H., Horii, A., Koyama, K., Utsunoniya, J., Baba, S., Hedge, P. (1991) Mutations of chromosome 5 q21 genes in FAP and colorectal cancer patients. Science 253, 665-669.

4. Joslyn, G., Carlson, M. "Thliveris, A. Albertsen, H., Gelbert, L., Samowitz, W., Groden, J., Stevens, J., Spirio, L., Robertson. M. el al. (1991) Identification of deletion mutations and three new genes at the familial polyposis locus. Cell $66,601-613$

5. Vogelstein, B., Fearan, E.R., Hamilton, S.R., Kern, S.E., Preisinger, A.C., Leppert, M., Nakamura, Y., White, R., Simits, A.M., Bos, J.L. (1988) Genetic alterations during colorectaltumor development. N Engl J Med 319, 525-532

6. Vogelstein, B., Fearon, E.R., Baker, S.J., Nigro, J.M., Kern, S.E., Hamilton, S.R., Bos, J., Leppert, M., Nakamura, Y., White, R. (1989) Genetic alterations accumulate during colorectal tumorigenesis. In: Cavenee, W., Hastie, N., Stanbridge, E. (eds.) Recessive ancagenes and tumor suppression, Cold Spring Harbor, New York.

7. Fearon, E.R., Vogelstein, B. (1990) A genetic model for colorectal tumorigenesis. Cell 61, 759767.

8. Fearon, E.R., Jones, P.A. (1992) Progressing toward a molecular description of colorectal cancer development. FASEB $J 6(-10), 2783-2790$.

9. Solomon, E., Voss, R., Hall, V., Bodmer, W.F., Jass, J.R., Jeffreys, A.J. Lucibello, F.C., Patel, I., Rider, S.H. (1987) Chromosome 5 allele loss in human colorectal carcinomas. Nature (London) 328, 616-619.

10. Powell, S.M., Zilz, N., Beazer-Barclay, Y., Bryan, T.M., Hamilton, S.R., Thibodeau, S.N., Vogelstein, B., Kinzler, K.W. (1992) APC mutations accur early during colorectal tumorigenesis. Nature 359, 235-237.

11. Bishop, J.M. (1987) The molecular genetics of cancer. Science 235, 305-311.

12. Weinberg. R.A. (1989) Oncogenes, antioncogenes, and the molecular bases of multistep carcinogenesis. Cancer Res 49, 3713-3721.

13. Weinberg, R.A. (1991) Tumor suppressor genes. Science 254, 1138-1146

14. Sasaki, M. Okamoto, M., sato, C., Sugio, K., Soejima, J., Iwama, T., Ikeuchi, T., Tanomura, A., Miyaki, M. Sasazuki, T. (1989) Loss of constitutional heterozygosity in colorectal tumors form patients with familial polyposis coli and those with non-polyposis colorectal carcinoma. Cancer Res $49,4402-4406$.

15. Muto. T., Bussey. H.J.R. Morson, B.C. (1975) The evolution of cancer of the colon and rectum. Cancer 36, 2251-2270.

16. Baker, S.J., Fearon, E.R., Nigro, J.M., Hamilton, S.R., Preisinger, A.C., Jessup, J.M. vanTuinen, P., Ledbetter, D.H., Barker, D.F., Nakanura, Y., White, R., Vogelsiein, B. (1987) Chromosome 17 deletions and p53 gene mutations in colorectal carcinomas. Science 244. 217.221

17. Fearon, E.R., Cho, K.R., Nigro, J.M., Kem, S.E. Simons, J.W., Ruppert, J.M. Hamilton, S.R., Preisinger, A.C. Thomas, G. Kinzler, K.W. Vogelstein, B. (1990) Identification of a chromosome $18 \mathrm{q}$ gene that is altered in colorectal cancers. Science $247,49-56$.

18. Levine, A.J., Momand, J., Finllay, C.A. (1991) The p53 tumor suppressor gene. Nafune (London) 351, 453-456.

19. Baker, S.J., Preisinger, A.C., Jessup, J.M., Paraskeva, C., Markowitz, S., Willson, J.K.V., Hamilton, S.R., Vogelstein, B. (1990) p53 gene mutations occur in combination with $17 \mathrm{p}$ allelic deletions as late events in colorectal tumorigenesis. Cavcer Res 50,7717.7722

20. Muir, C., Waterhouse, J., Mack, T., Powell, J., Whelan, S., Smans, M. et al. (1987) Cancer incidence in five continents. Lyon (France): International Agency for Research on Cancer.

21. Parkin, D.M. Muir, C.S. Whelan, S.L., Gao, J.T., Ferlay, J., Powell, J. (1992) Cancer incidence in five continents. Lyon (France): International Agency for Research on Cancer.

22. Haenszel, W., Kurihara, M. (1968) Studies of dapanese migrants. I. Mortality from cancer and other diseases among Japanese in the United States. I Natl Cancer Inst 40, 43-68.

23. McMichael, A.J., Giles, G.G. (1988) Cancer in migrants to Australia: extending the descriptive epidemiological data. Cancer Res $48,751-756$. 
24. Boyle, P., Zaridze, D.G. Simans, M. (1985) Descriptive epidemiology of colorectal cancer. Int a Cancer 36, $9-18$

25. Camnon-Albright, L.A., Skotnick, M.H., Bishop, D.T., Lee, R.G., Burt R.W. (1988) Common inheritance of $\$$ usceptibility to colonic adenomatous polyps and associated colorectal cancers. N Engl I Med 319,533-537.

26. Doll, R. Peto, $R$. (1981) The caluses of cancer quantitative estimates of avoidable risks of cancer in the United States loday. J Nati Cancer Inst 68, 1191-1308.

27. World Cancer Rlesearch Fund (1997). Food, nutrition, and the prevention of cancer: a global perspective. Washington, DC (USA): WCRF/AICR.

28. Norat, T., Riboll, E. (2001) Meal consumption and colorectal cancer: a review of epidemiological evidence. Nurr. Rew 59, 37-47.

29. Armstrong, B. Doll, R. (1975) Environmental factors and cancer incidence and mortality in different countries, with special reference to dietary practices. Int J Cancer 15, 617-631.

30. Potter, J.D. (1996) Nutrition and colorectal cancer. Cancer Causes Control 7, 127-146.

31. Cummings, J.H. Bingham, S.A. (1998) Diet and the prevention of cancer. BMJ 317, 16361640 .

32. Working Group on Diet and Cancer of the Committee on Medical Aspects of Food and Nutrition Policy. Nutritional aspects of the development of cancer (UK Department of Health: Report on Health and Social Subjects No. 148. London: HMSO.

33. Hill, M.J. (1999) Meat and cancer. Eur J Cancer Prev 8, 173-174.

34. Scheppach, W., Bingham, $S_{*}$ Boutron-Ruault, M.C., Gerhardsson de Verdier, M., Moreno, $V$., Nagengast, F. M., Reifen, R., Riboli, E., Sieitz, H.K., Wahrendorf, J. (1999) WHO consensus statement on the role of nutrition in colorectal cancer. Eur $J$ Cancer Prev 8, 57-62.

35. Truswell, A.S. (1999) Report of an expert workshop on meat intake and colorectal cancer risk convened in December 1998 in Adelaide, South Australia. Eur J Cancer Prev 8, 175-178.

36. Forman, D. (1999) Meat and cancer; a relation in search of a mechanism. Lancet 353, 686687.

37. National Academy of Sciences (1989) Diet and health. Washington, DC. National Acaderny Press.

38. Babbs, C.F. (1990) Free radicals and the etiology of colon cancer. Free Radic Biol Med 8 , $191-200$.

39. Lakshimi, V.M., Hsu, F.F., Zenser "T.V. (2002) Nitrosation and nitration of 2-amino-3methylimidazo[ $4,5-f]$ quinoline by reactive nitrogen oxygen species. Chem. Res. Toxicol. 15 , 1059-1068.

40. Reddy, B.S. (1981) Diel and excretion of bile acids. Cancer Res 41, 3766-3768.

41. Reddy, E.S., Hanson, D., Mangat, S., Mathews, L., Sbaschnig, M. Sharma, C. Simi, B. (1980) Effect of high-fat, high-beef diet and mode of cooking of beef in the diet on fecal bacterial enzymes and fecal bile acids and neutral sterols. J Nutr 110, 1880-1887.

42. Giovannucci, E. Willett, W.C. (1994) Dietary factors and risk of colon cancer. Ann Med 26, $443-452$

43. Widmark, E.M.F. (1939) Presence of cancer-producing substances in roasted food. Nature 143, 984

44. Ames, B.N.N. McCann, J., Yamasaki, E. (1975) Methods for detecting carcinogens and mutagens with the Salmonella/marnmalian-microsomal mutagenicity test. Mutat Res 31,347 364.

45. Suginura, T. Nagao, M., Kawachi, T., Honda, M., Yahagi, T., Seino, Y., Sato, S., Matsukura, N., Matsushima, T. Shirai, A., Sawamura, M., Matsumoto, H. (1977) Mutagen-carcinogens in food, with special reference to highly mutagenic pyrolytic products in broiled foods. In: Hiatt; H.H., Watson, J.D. Winsten, J.A. (Eds.) Origins of Human Cancer, Book C. Cold Spring Harbor Laboratory Press, New York, pp. 1561-1567.

46. Nagao, M., Honda, M., Seino, Y., Yahagi, T., Sugimura, T. (1977) Mutagenicities of smoke condensates and the charred surface of fish and meat. Cancer Lett 2, 221-226.

47. Commoner, B. Vithayathil, A.J., Dolara, P., Nair, S., Madyastha, P., Cuca, G.C. (1978) Formation of mutagens in beef and beef extract during cooking. Science 201, 913-916.

48. Sugimura, T. (2000) Nutrition and dietary carcinogens. Carcinogenesis 21, 387-395.

49. Sugimura, T., Kawachi, T., Nagao, M., Yahagi, T., Seino, Y., Okamoto, T., Shudo, K., Kosuge, T., Tsuji, K., Wakabayashi, K., litaka, Y.. Itai, A. (1977) Mutagenic principle(s) in tryptophan and phenylalanine pyrolysis products. Proc Jpn Acad 53, 58-61. 
50. Yamamoto, T., Tsuji, K., Kasuge, T., OKamoto, T., Shudo, K., Takeda, K. litakã, Y., Yamaguchi, K., Seino, Y., Yahagi, T., Nagao, M., Sugimuita, T. (1978) Isolation and structure determination of mutagenic substances in L-glutamic acid pyrolysate. Proc Jpn Acad 54B. $248-250$.

51. Yoshida, D., Matsumoto, T., Yoshimura, R.: Matsuzaki, T. (1978) Mutagenicity of amino- $\alpha-$ carbolines in pyrolysis products of soybean globullin. Biochem Biophys Res Commun 83,915 920.

52. Kasai, $H_{\text {., }}$ Yamaizumi, Z., Wakabayashi, K., Nagao, M., Sugimura, T., Yokoyama, S., Miyazawa ${ }_{\text {T. }}$., Spingarn, N.E.., Weisburger, J.H. Nishimura, S. (1980) Potent novel mutagens produced by broiling fish under normal conditions. Proc Jpn Acad 56B, 278-283.

53. Kasai, H. Yamaizumi, Z., Wakabayashi, K., Nagao, M., Sugimura, T., Yokoyama, S. Miyazawa, T., Nishimura, S. (1980) Structure and chemical synthesis of Mes 1 , a potent mutagen isolated from broiled fish. Chem Latt 11, 1391-1394.

54. Kasai, H., Yamaizumi, Z., Shiomi, T., Yokoyama, S., Miyazawa, T., Wakabayashi, K. Nagao, M., Sugimura, T. Nishimura, S. (1981) Structure of a potent mutagen isolated from fried beef. Chem Lett $4,485-488$.

55. Felton, J.S., Knize, M.G., Shen, N.H., Lewis, P.R., Andresen, B.D., Happe, J., Hatch, F.T. (1986) The isolation and identification of a new mutagen from fried ground beef: 2-amino-1methyl-6-phenylimidazo[4,5-b]pyridine (PhIP). Carcinogenesis 7, 1081-1086.

56. Jägerstad, M., Laser Reutersward, A., Olsson, R., Grivas, S., Nyhammar, T., Olsson, L., Dahlquist, A. (1983) Creat(in)ine and Maillard reaction products as precursors of mutagenic compounds: effects of various amino acids. Food Chem 12, 255-264.

57. Grivas, S. Nyhammar, T., Olsson, K., Jägerstad, M. (1985) Formation of a new mutagenic DiMelQx compound in a model system by heating creatinine, alanine and fiructose. Mutat Res $151,177-183$.

58. Skog. K. (1993) Cooking procedures and food mutagens: a literature review. Fd Chem Toxicol $3,655-675$.

59. Nes, L.F. (1986) Mutagen formation in fried meat emulsion containing various amounts of creatine. Mutat Res $175,145-148$.

60. Knize, M.G. Shen, N.H., Felton, J.S. (1988) A comparison of mutagen production in fried ground chicken and beef effect of supplemental creatine. Mutagenesis 3, 503-508.

61. Overvik, E., Kleman. M., Berg, I., Gustavsson, J.A. (1989) Influence of creatine, amino acids and water on the formation of the multagenic heterocyclic amines found in cooked meat. Carcinogenesis 10, 2293-23011.

62. Felton, J.S. Knize, M.G. (1991) Occurrence, identification, and bacterial mutagenicity of heterocyclic amines in cooked foods. Mutat Res 259, 205-217.

63. Felton, J.S., Knize, M.G. (1991) Mutagen formation in muscle meats and modell heating systems. In: Hayatsu, $\mathbb{H}$. (Ed.) Mutagens in food: detection and prevention. CRC Press, Boca Raton, FL, pp. 57-66.

64. Knize, M.G., Dolbeare, F.A., Carroll, K.L., Moore, D.H. II, Felton, J.S. (1994) Effect of cooking time and temperature on the heterocyclic amine content of fried beef patties. Fd Chem Toxicol $32,595-603$.

65. Skog. K., Steineck, G. Augustsson, K., Jägerstad, M. (1995) Effect of cooking temperature on the formation of heterocyclic amines in fried meat products and pan residues. Cancinogenesis $16,861-867$.

66. Solyakov. A. Skog. K. (2002) Screening for heterocyclic amines in chicken cooked in various ways. Fd Chem Toxicol 40, 1205-1211.

67. Sinha, R. Rothman, N., Brown, E.D. Salmon, C.P., Knize, M.G. Swanson, C.A., Rossi, S.C., Mark, S.D., Levander, O.A. Fellon, J.S. (1995) High concentrations of the carcinogen 2amino-1-methyll-6-phenylimidazo[4,5-b]pyridine (PhIP) occur in chicken but are dependent on the cooking method. Cancer Res 55, 4516-4519.

68. Knize, M.G., Salmon, C.P., Hopmans, E.C., Felton, U.S. (1997) Analysis of foods for heterocyclic aromatic amine carcinogens by solid-phase extraction and high-performance liquid chromatography. J Chromatogr A 763, 179-185.

69. Arvidsson, P., van Boekel, M.A.J.S., Skog, K., Jägerstad, M. (1997). Kinetics of fomation of polar heteracyclic amines in a meat model system. J Food Sci $62,911-916$.

70. Wang, Y.Y., Wuolo, L.L., Spinglarn, N.E., Weisburger, J.H. (1982) Formation of mutagens in cooked foods. $W$. The mutagen reducing effect of soy protein concentrates and antioxidants during frying of beef. Cancer Lett $16,179-89$. 
71. Barnes, W.S, Maher, JC., Weisburger, JH. (1983) High-pressure liquid chromatographic method for the analysis of 2-amino-3-methyl[4,5-flimidazo-quinoline, a mutagen formed during the cooking of food. I Agric Food Chem 31, 883-886.

72. Kikugawa, K. (1999) involvement of free radicals in the formation of heterocyclic amines and prevention by antioxidants. Cancer Let 143, 123-126.

73. Tikkanen, L.M. Latwa Kala, K.J.Heinio, R.L. (1996) Effect of commercial marnades on the mutagenic activity, sensory quality and amoumt of heterocyclic amines in chicken grilled under different conditions. Fol Chem Toxicol $34,725-730$.

74. Salmon, C.P., Knize, M.G. Feltor, J.S. (1997) Effects of marinating on heterocyclic amine ciarcinogen formation in grilled chicken. Fol Chem Toxicol 35, $433-441$.

75. Fellon, J.S. Fultz, E. Dolbeare, F.A. Knize, M.G. (1994) Effect of mierowave pretreatment on heterocyclic aromatic amine mutagens/carcinogens in fried beef patties. Fo Chem Toxicol 32", $897-903$

76. Felton, J.S. Knize, M.G., Shen, N.H., Andresen, B.D., Bjeldanes, L.F., Hatch, F.T. (1986) Identification of the multagens in cooked beef. Environ Health Perspect 67, 17-24.

77. Skog. K. Mugustsson, K., Steineck. G., Steniberg, M., Jagerstad, M. (1997) Polar and nonpolar heterocyclic amines in cooked fish and meat products and their corresponding pan pesidues. Fid Chen Toxicol 35, 555-565.

78. Skog, K.I., Johansson, M.A. Jagerstad, M.l. (1998) Carcinogenic heterocyclic amines in model systems and cooked foods: a review on formation, occurence and intake. Fd $\mathrm{Chem}$ Toxicol $36,879-896$.

79. Kadlubar, F.F., Kaderlik, K.R., Mulder, G.J., Lin, D., Butler, M.A., Teitel, C.E., Minchin, R.F. lleti, K.F., Friesen, M.D. Bartsch, H., Nagao, M., Esumi, H., Sugimura ,T. Lang, N.P. (1995) Metabolic activation and DWA adduct detection of PhIP in dogs, rats, and humans in relation to urinary bladder and colon carcinogenesis. In: Adamson, R.H., Gustafsson, J-A. Nobuyukil, I., Nagao, M. Sugimura, T. Wakabayashi, K. Yamazoe Y. (Eds.) Helerocyclic amines in cooked foods: possible human carcinogens. Princeton Scientific Publishing Co., Nu, pp. 207. 213.

80. Turesky, R.d., Lang. N.P., Butler, M.A., Teitel, C.H., Kadlubar, F.F. (1991). Metabolic activation of crarcinogenic theterocyclic aromatic amines by human fiver and colon. Carcinogenesis 12,18394845

81. Chow, H.-C., Lang. M.P., Kadlubar, F.F. (1995) Metabolic activation of N-hydroxy arylamines and $N$-hydroxy heterocyclic amines by human sulfotransferase(s). Cancer Res 55, 525-529.

82. Sichut, H.A.J., Herzog, C.R. (1992) Formation of DNA adducts of 2-amino-1-methyl-6phenylimidazo[4,5-b]pyridine (PhIP) in male Fischer-344 rats. Cancer Lett 67, 117-124.

83. Kaderlk, K.R., Minchin, R.F. Mulder, G.J., llett, K.F., Daugaard-Jenson, M., Teitel, C.H., Kadlubar, F.F. (1994) Metabolic activation pathway for the formation of DNA adducts of the carcinogen 2-amino-1-methyll-6-phenylimidazo[4,5-b]pyridine (PhIP) in rat extrahepatic tissues. Caucinogenesis 15, 1703-1709.

84. Kaderlik, K.P. Mulder, G.a., Shaddock, J.G., Casciano, D.A., Teitel, C.H. Kadlubar, F.F. (1994) Effect of glutathione depletion and inhibition of glucuronidation and sulfation on 2amimo-1-methyl-6-phenylimidazo[4,5-b]pyridine (PhIP) metabolism, PhIP-DNA adduct formation and unscheduled DNA synthesis in primary rat hepatocytes. Carcinogenesis 15, $1711-1716$.

85. Lin, D., Meyer, D.J., Ketterer, B. Lang, N.P., Kadlubar, F.F. (1994) Effects of human and rat glutathione S-transferases on the covatent DNA binding of the N-acetoxy derivatives of heterocyclic amine carcinogens in witro: a possible mechanism of organ specificity in their carcinogenesis. Cancer Res $54,4920 \times 426$.

86. Kurada, Y., Hara, Y. (1999) Antimutagenic and anticarcinogenic activity of tea polyphenols. Mutat Res $436,69.97$

87. Schwab, C.E. Huber, W.W., Parzefall, W. Hietsch, G. Kassie, F, Schulte-Hermann, R., Knasmuller, S. (2000) Search for compounds that inhibit the genotoxic and carcinogenic affects of heterocyclic aromatic amines. Crit Rev Toxicol 30, 1-69.

88. Wesburger, J.H. Chung, F.-L. (2002) Mechanisms of chronic disease causation by nutritional factors and tobacco products and their prevention by tea polyphenols. Fd Chem Toxicol 40 , $1145-1154$

89. Sawada "N. Kamataki, T. (1998) Genetically engimeered cells stably expressing cytochrome P450 and their application in mutagen assays. Mutat Ros $411,19-43$. 
90. Boobis, A.R., Lynch, A.M., Murray. S., de la Torre, R., Solans, A. Farre, M., Segura, J., Gooderham, N.J., Davies, D.S. (1994). CYP1A2-catalyzed conversion of dietary heterocyclic amines to their proximate carcinogens is their major route of metabolism in humans. Cancer Res 54, 89-94.

91. Crofts, F.G., Sutter, T.R., Strickland, P.T. (1998) Metabolism of 2-amino-1-methyl-6phenylimidazo[4,5-b]pyridine by human cytochrome P4501A1, P4501A2 and P4501B1. Carcinogenesis 19, 1969-1973.

92. Hayatsu, H. Hayatsu. T. (1993) Suppressing effect of Lactobacilus casei administration of urinary mutagenicity arising form ingestion of fried ground beef in the human. Cancer Lett 73. $173-179$.

93. Hirayama, K., Baranczewski, P., Alkerlund, J.-E., Midtwed, T., Möller, L., Rafter, J. (2000) Effects of human intestinal flora on mutagenicity of and DNA adduct formation from food and environmental mutagens. Carcinogenesis 21, 2105-2111.

94. Weisburger, J.H., Rivenson, A., Reinhardt, J., Aliaga, C., Braley, J., Dolan, L.M., Williams, G.M., Zang, E., Kingston, D.G.I. Bashir, M., Shu, Y.-Z., Wilkins, T.D., Van Tassell, R.L. (1994) Genotoxicity and carcinogenicity in rats and mice of 2-amino-3,6-dilhydro-3-rnethyl- $7 \mathrm{H}$ imidazolo[4,5-f]quinolin-7-one: an intestinal bacterial metabolite of 2-amino-3-methyl-3Himidazo[4,5-f]quinoline. J Natl Cancer Inst $86,25-30$.

95. Carman, R.J., Van Tassell, R.L., Kingston, D.G.I. (1988) Conversion of IQ, a dietary pyrolysis carcinogen to a direct mutagen by intestine bacteria of humans. Murat Res 206, 335-342.

96. Turesky, R.J., Skipper, P.L., Tannenbaum, S.R., Coles, B. Ketterer, B. (1986) Sulfamate formation is a major route of detoxification of 2-amino-3-methyl-imidazo[4,5-f]quinoline in the rat. Carcinogenesis $7,1483-1485$.

97. Marnett, L.J., Eling. T.E. (1983) Cooxidation during prostaglandin biosynthesis: A pathway for the metabolic activation of xenobiotics. In: Hodgson, E., Bend, J.R., Philpot, R.M. (Eds.) Reviews in biochemical toxicology val. 5. Elevier Press, New York, pp. 135-172.

98. Herschman, H.R. (1996) Prostaglandin synthase 2. Biochim Biophys Acta 1299, 125-40

99. Williams, C.W., DuBiois, R.N. (1996) Prostaglandin endoperoxide synthase: why two isoforms? Am I Phys 270, G393-G400.

100. Fischer. S.M. (1997) Prostaglandins and cancer. Frontiers in Bioscience 2, 482-500.

101. Eling, T.E., Boyd, J.A., Reed, G.A., Mason, R.P., Sivarajah, K. (1983) Xenobiotic metabolism by prostaglandin endoperoxide synthetase. Drug Motab Rev 14, 1023-1053.

102. Eling: T.E., Krauss, R.S. (1985) Arachidonic acid-dependent metabolism of chemical carcinogens and toxicants. Im: Marnett, L.J. (Ed.) Arachidonic Acid Metabolism and Tumor Initiation. Martinus Nijhoff Publishing, Boston, pp. 83-124.

103. Tapiero, H., Nguyen Ba, G., Couvreur, P., Tew, K.D. (2002) Polyunsaturated fatty acids (PUFA) and eicosanoids in human health and pathologies. Biomed Pharmacother 56,215 222.

104. Eling, T.E., Thompson, D.C., Foureman, G.L., Curtis, J.F., Hughes, M.F. (1990) Prostaglandin H synthase and xenobiotic oxidation. Annu Rev Pharmacol Toxicol 30, 1-45.

105. Mackawa, M., Sugano, K., Sano, H., Miyazaki, S., Ushiama, M., Fujita, SS, Gotoda, T, Yokota, T. Ohkura, H., Kakizoe, T., Sekiya, T. (1998) Increased expression of cyclooxygenase-2 to -1 in human colorectal cancers and adenomas, but not in hyperplastic polyps. Jpn J Clin oncol $28,421-426$.

106. Williams, C.S., Mann, M., DuBois, R.N. (1999) The role of cyclooxygenases in inflammation, cancer, and development. Oncogere 18,7908-7916

107. Williams, C., Shattuck-Brandt RL., DuBois, R.N. (1999) The role of COX-2 in intestinall cancer. Ann NY Acad Sci 889, 72-83.

108. Rosenberg, L., Paimer, J.R., Zauber. A.G., Warshauer, M.E., Stolley, P.D., Shapiro, S. (1991) A hypothesis: Nonsteroidal anti-inflammatory drugs reduce the incidence of large-bowel cancer. J Nath Cancer knst 83, 355 358.

109. Greenberg, E.R., Baron, J.A., Freeman, D.H. Jr., Mandel, J.S., Haile, R. (1993) Reduced risk of large-bowel adenomas among aspirin users. J Natl Cancer linst 85, 912-916

110. Giowannucci, E., Rimm, E.B., Stampier, M.J., Colditz, G.A., Ascherio, A. Witlett, W. C. (1994) Aspirin use and the risk for colorectal cancer and adenoma in male health professionalis. Ann intern Med 121, 241-246.

111. Giowannucci, E., Egan, K.M., Hunter, D.J., Stampfer, M.J., Colditz, G.A., Willett, W.C., Speizer, F.E. (1995) Aspirin and the risk of colorectal cancer in women. N Engl J Med 333 . $609-614$. 
112. Smalley, W., Ray, W.A. Daugherty, $\$$., Grifin, M.R. (1999) Use of nonsteroidal antiintlammatory drugs and incidence of colorectal cancer. Arch Intem Med 159, 161-160.

113. Vane, J.R., Boting, R.M. (1997) Mechanism of action of aspitin-like drugs. Semin Arthrins Fheur 26 (Suppl 1), 2, 10 .

14. Hemminki, $K_{2}$ (1993) DNA adducts, mutations and cancer Carchogenesis 14, $2007-2012$.

115. Schut H.A. Snydewine, E.G. (1999) DNA adducts of heterocycic amine food mutagens: implications for mutagenesis and carcinogenesis. Carcinogenesis 20, 353-368.

116. Schut, H.A.J. Shiverick, K.T. (1992) DNA adducts in humans dosimeters of exposure to environmental, occupational, or dielary genotoxins. FASEB \& 6, 2942-2951.

117. Takayama, K., Yamashita, K., Wakabayashi, K., Suginura, T. Nagao, M. (1989) DNA modification by 2-amino-1-methyl-6-phenylimidazo[4,5-b]pyridine (PhIP) in rats. Jpm $J$ Cancer Res $80,1145-1148$.

118. Yameshita, K. Adachi, M. Kato, S., Nakagama, H., Ochiai, M., Wakabayashi, K., Sato, S., Nagao, M., Sugimura, T. (1990) DilA adducts formed by 2-amino-3,8-dimethylimidazo[4,5fquinoxaline in rat liver: dose-response on chronic administration. Jon $J$ Cancer Res 81,470 476.

119. Schut, H.A.d. Herzog, C.H. (1992) Formation of DNA adducts of 2-amino-1-methyl-6phenylimidazo[4,5-b]pyridine (PhiP) in male Fischer 344 rats. Cancer Let 67, 117-124.

120. Snyderwine. E.G.; Yamashita, K., Adamson, R.H., Sato, S., Nagao, M., Sugimura, T., Thorgeirsison, S.S. (1988) Use of the P-postlabeling method to detect DNA adducts of 2 amino-3-methyl-imidazo[4,5-f]quinoline (lQ) in monkeys fed $1 \mathrm{Q}$ identification of the $\mathrm{N}$. (deoxyguanosin-8-yl) $1 \mathrm{Q}$ adduct. Carcinogenesis $9,1739-1743$.

121. Adamson, R.H., Thorgeirsson, U.P., Snyderwine, E.G., Thorgeirsson, S.S., Reeves. J., Dalgard. D.W. Takayama. S. and Sugimura, T. (1990) Carcinogenicity of 2-amino-3methylimidazo[4,5-f]quinoline in nonhumarn primates. Induction of tumors in three macaques. Jan J Caricer Res 81, 10-14.

122. Snyderwine, E.G., Davies, C.D. Nouso, K., Roller, P.P., Schut. H.A. . (1993) ${ }^{32}$ P-postlabeling alnalysis of 10 . MelQx and PhIP adducts formed in vitro in DNA and polynucleotides and found in vivo in thepatic DNA from IQ-, MellQx-and PhIP-treated monkeys. Carcinogenesis 14, 13891395.

123. Friesen. M. Kaderlk, K. Lin, D. Garren, L., Bartsch, H., Lang. N.P., Kadlubar, F.F. (1994) Analysis of DNA adducts of 2-amino-1-methyl-6-phenylimidazo[4,5-b]pyridine in rat and human tissues by alkaline hydrolysils and gas chromatographylelectron capture mass spectrometry: validation by comparison with ${ }^{32}$ P-postlabeling. Chem Res Toxicol 7, 733-739.

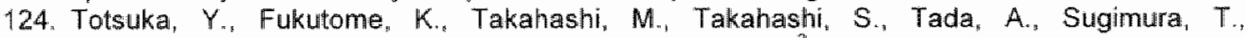
Wakabayashi, K. (1996) Presence of $N^{2}$-(deoxyguanosin-8-yl)-2-amino-3,8dimethylimidazo[4,5-f]quinoxaline (dG-C8-MelQx) in human tissues. Carcinogonosis 17,1029 1034.

125. Schut, H.A.J., Putman, K.L., Randerath, K. (1988) DNA adduct formation of the carcimogen 2amino-3-methylimidazo[4,5-f]quinoline in target tissues of the F-344 rat. Cancer Lett 41, 345 352 .

126. Turesky, R.J., Rossi, S.C., Welti, D.H., Lay, w.O. Ji, Kadlubar, F.F. (1992) Characterization of DNA adducts formed in vitro by reaction of N-hydroxy-2-amino-3-methylimidazo[4, 5 -fquinoline and $N$-hydroxy-2-amino 3,8-dimethylimidazo[4,5-f]quinoxaline at the $C 8$ and $N^{2}$ atoms of guanine. Chem Res Toxicol $5,479-490$

127. Lin, D. Kaderlik, K.R. Turesky, R.J. Miller, D.W. Lay, J.O.Nr Kadiubar, F.F. (1992) Identification of $N$-(deoxyguanosin-8-y)-2-amino-1-methylo-pheny/imidazo[4,5-b]pyridine as the major adduct formed by the food-bome carcinogen, 2-amino-1-methyl-6phenylimidazo[4,5-b]pyridine, with DNA. Chem Res Toxicol 5,691-697.

128. Turesky, R.J. Markovic, J. (1994) DNA adduct formation of the food carcinogen 2-aminom methylimidazo $4,5-f$ quinoline at the $C 8$ and $N^{2}$ atoms of guanine. Chem Res Toxicol 7,752 761.

129. Tada A, Ochiai, M., Wakabayashi, K. Nukaya, H. Sugimura, T., Nagao, M. (1994) Identification of $N^{2}$-(deoxyguanosin-8-yl)-2-amino-3,4-dimethylimidazo[4,5-f]quinoline (dG-C8MelQy as a major adduct formed by MelQ with nucleotides in witro and with DNA in wivo. Carcinogenesis $15,1275-1278$.

130. Crosbie, S.l., Murray, S., Boobis, A.R., Gooderham, N.J. (2000) Mass spectrometric detection and measurement of $\mathrm{N} 2-\left(2^{\prime}\right.$-deoxyguanosin-8-yl)PhIP adducts in DNA. JChrom. B 744, 55-64. 
131. Turteltaub, K.W. Felton, J.S., Gledhill, B.L., Vogel, J.S., Southon, J.R., Caffee, M.W. Finkel, R.C., Nelson, D.E., Proctor, I.D., Davis, J.C. (1990) Accelerator mass spectrometry in biomedical dosimetry: relationship between low-level exposure and covalent binding of heterocyclic amine carcinogens to DNA. Proc. Nath Acad Sci. USA 87, 5288-5292.

132. Turteltaub, K.W. Dingley, K.H. Curtis, K.D. Malfatti, M.A. Turesky, R.J., Garner, R.C., Felton, J.S., Lang. N.P. (1999) Macromolecullar adduct formation and metabolism of heterocyclic amines in humans and rodents at low doses. Cancer Lett. 143, 149-155.

133. Lang, N.P., Nowell, S. Malfatti, M.A.. Kulp, K.S. Knize, M.G., Davis, C., Massengill, J., Williams, S. Macleod, S., Dingley, K.H.. Felton, J.S., Turteltawb, K.W. (1999) In wiwo human metabolism of $\left[2{ }^{14} \mathrm{C}\right] 2$-amino-1-methyl-6-phenylimidazo[4,5-b]pyridine (PhIP) Cancer Lett. $143,135-138$.

134. Dingley, K.H. Curtis, K.D., Nowell, S. Felton, J.S., Lang, N..P., Turtellaub, K.W. (1999) DNA and protein adduct formation in the colon and blood of humans after exposure to a dietaryrelevant dose of 2-amino-1-methyl-6mphenylimidazo[4,5-b]pyridine. Cancer Epidemiol. Biomarkers Prev. $8,507-512$.

135. Van Maanen, J.M., Moonen, E.J., Maas, L.M., Kleinjans, J.C., Van Schooten, F.J. (1994) Formation of aromatic DNA adducts in white blood cells in relation to urinary excretion of 1hydroxypyrene during consumption of grilled meat. Carcinogenesis 15, 2263-2268.

136. Turteltaub, K.W., Mauthe, R.J., Dingley, K.H., Vogel, J.S., Frantz, C.E., Garner, R. C., Shen, N. (1997) MelQx-DNA adduct formation in rodent and human tissues at low doses. Mutat Res $376,243-252$.

137. Lin, D.-X., Lang, N.P., Kadlubar, F.F. (1995) Species differences in the biotransformation of the food-borne carcinogen 2-amino-1-methyl-6-phenylimidazo[4,5-b]pyridine by hepatic microsomes and cytosols from humans, rats and mice. Drug Metab Disposit 23, 518-524.

138. Mckimnom, R.A., Burgess, W.M., de La, P., Hall, M., Abdull-Aziz, Z., McManus, M.E. (1992) Metabolism of food-derived heterocyclic amines in human and rabbit tissue P4503A proteins in the presence of flavonoids. Cancer Res $52,2108 \mathrm{~s}-2113 \mathrm{~s}$.

139. Garner, R.C., Lightfoot, T.J., Cupid, B.C., Russell, D., Coxhead, J.M., Kutschera, W., Priller, A., Rom, W. Steier, P., Alexander, D.J., Leveson, S.H., Dingley, K.H., Mauthe, R.J., Turteltaub, K.W. (1999) Comparative biotransformation studies of MelQx and PhIP in animal models and humans. Cancer Lett 143, 161-165.

140. Wakabayashi, K.. Nagao, M., Esumi, H., Sugimura, T. (1992) Food-derived mutagens and carcinogens. Cancer Res 52 (Suppl.), 2092s-2098s

141. Felton, J.S., Knize, M.G., Dolbeare, F.A., Wu, R. (1994) Mutagenic activity of heterocyclic amines in cooked foods. Enwiron Health Perspect 102 (Suppl. 6), 201-204.

142. Ford, G.P., Griffin, G.R. (1992) Relative stabilities of nitrenium ions derived from heterocyclic amine food-carcinogens: relationship to mutagenicity. Chem Biol Interact 81, 19-33.

143. Kerdar, R.S., Dehner, D., Wild, D. (1993) Reactivity and genotoxicity of arylnitrenium ions in bacterial and mammalian cells. Toxicol Lett $67,73 m 85$.

144. Suzuki, A. Kushida, $H_{\text {. }}$ Iwata, H. Watanabe, M., Nohmi, T., Fujita, K., Gonzalez. F.J., Kamataki, T. (1998) Establishment of Salmonella tester strain highly sensitive to mutagenic heterocyclic amines. Cancer Res 58, 1833-9838.

145. Malfatti, M.A., Shen, N.H., Wu, R.W. Turteltaub, K.W., Felton, J.S. (1995) A carrelation of Salmonella mutagenicity with DNA adducts induced by the cooked-food mutagen 2-amino-1mthyl-6-phenylimidazo[4,5-b]pyridine. Mutagenesis 10,425-431.

146. Carothers, A.M. Yuan. W. Hingerty, B.E., Broyde, S., Grunberger, D. Snydenwine, E.G. (1994) Mutation and repair induced by the carcinogen 2-(hydroxyamino)-1-methyl-6phenylimidazol4,5-b]pyridine (N-OH-PhIP) in the dihydrofolate reductase gene of Chinese hamster ovary cells and conformational modeling of the dG-C8-PhIP adduct in DNA. Chem Res Toxicol 7, 209-218.

147. Morgenthaler, P.-M.L., Holzhauser, D. (1995) Analysis of mutations induced by 2-amino-1methyl-6-phenylimidazo[4,5-b]pyridine (PhIP) in human lymphoblastoid cells. Carcinogenesis 16, 713 718 .

148. Shibutani, S. Fernandes, A., Suzuki, N., Tan, X., Johnson, F. Grollman. A.P. (1998) Sitespecific mulagenesis studies of 2-amino-4-methyl-6-phenylimidazo[4,5-b]pyridine (PhlP). derived DNA adduct in mammalian cells. In: Proceedings of the International Workshop on Heterocyclic Aromatic Amines, Graz, Austria, April 23-24. 
149. Sugimura, T. Wakabayashi, K. (1990) Mutagens and carcinogens in food. In: Pariza, M.M., Aeschbacher, HU., Felton, J.S., Sato, S. (Eds.) Mutagens and Carcinogens in the Diet. WileyLiss, Inc., New York, pp. 1-18

150. Davis, C.D., Dacquel, E.J., Schut, H.A.J., Thorgeirsson, S.S., Snyderwine, E.G. (1996) in wivo mutagenicity and DNA adduct levels of heterocyclic amines in Muta ${ }^{\text {rM }}$ mice and c-mychlacZ double transgeric mice. Mutat Res 356, 287-296.

151. Okonogi, $H_{\text {.; }}$ Ushijima, $T$., Zhang, X.B., Heddle, J.A., Suzuki, T., Sofuni, T., Felton, J.S., Tucker, J.D., Sugimura, T., Nagao, M. (1997) Agreement of mutational characteristics of heterocyclic amines in Vacl of the Big Bue mouse with those in tumor related genes in rodents. Carcinogenesis 18, 745-748.

152. Ryu, D.Y., Weider, V.S., Davis, C.D., Schut, H.A.J., Thorgeirsson, S.S., Snyderwine, E.G. (1998) In wivo mutagenicity and hepatocarcinogenicity of MelQx in transgenic C57Bl/acZ (MutaMice) and double transgenic c-myc/lacZ mice. Proc Am Assoc Cancer Res 39, 633.

153. Dolara, P., Caderni, G., Bianchini, F. Tangamelli, E. (1986) Nuclear damage of colon epithelial cells by the food carcinogen 2-amino-3-methylimidazo[4,5-ffquinoline $(10)$ is modulated by dietary lipids. Mular Res $175,255-258$.

154. Bird, R.P. Bruce, W.R. (1986) Effect of dietary fat levels on the susceptibility of colonic cells to nucleardamaging agents. Nutr Cancer 8, 93-100.

155. Brooks, R.A., Gooderham, N.J., Zhao, K., Edwards, R.J., Howard, L.A., Boobis, A.R. Winton, D.J. (1994) 2-Amino-1-methyl-6-phenylimidazo[4,5-b]pyridine is a potent mutagen in the mouse small intestine. Cancer Res 54, 1665-1671.

156. Lynch. A.M., Gooderham, N.J., Boobis, A.R. (1996) Organ distinctive mutagenicity in Muta ${ }^{\text {TM }}$ mouse after short-term exposure to PhIP. Mutagenesis 11, 505-509.

157. Zhang, X.B., Felton, J.S., Tucker, J.D., Urlando, C., Heddle, J.A. (1996) Intestinal mutagenicity of two carcinogenic food mutagens in transgenic mice: 2-amino-1-methyl-6-phenylimidazo[4,5b]pyridime and amino[a]carboline. Carcinogenesis 17, 2259-2265.

158. Toyota, M., Ushijima, T., Kakiuchi, H., Canzian, F., Watanabe, M., Imai, K., Sugimura, T., Nagao, $M$ (1996) Genetic alterations in rat colon tumors induced by heterocyclic amines. Cancer Suppl 77, 1593-1597.

159. Nagiao, M., Ushijima, T., Toyota, M. Inoue, R., Sugimura, T. (1997) Genetic changes induced by heterocyclic amines. Mutat Res 376, 161-167.

160. Hatch, F.T. Knize, M.G. Moore, D.H., Felton, J.S. (1992) Quantitative correlation of mutagenic and carcinogenic potencies for heterocyclic amines from cooked foods and additional aromatic amines. Mutat Res 271, 269-287.

161. Stavric, B. (1994) Biological significance of trace levels of mutagenic heterocyclic aromatic amines in human diet: a critical review. Fd Chem Toxic 32, 977-994.

162. Turesky, R.J., Markovic, J., Aeschlimann, J.-M. (1996) Formation and differential removal of $\mathrm{C8}$ and $\mathrm{N}^{2}$-guanine adducts of the food carcinogen 2-amino-3-methylimidaza[4,5-f]quinoline (1Q) in the liver, kidney and colorectum of the rat. Chem Res Toxicor 9, 397-402.

163. Friesen, M.D. Cummings, D.A., Garren, L., Butler, R., Bartsch, H., Schut, H.A.J. (1996) Validation in rats of two biomarkers of exposure to the food-bome carcinogen 2-amino-1. methyl-6-phenyllimidazo[4,5-b]pyridine (PhIP): PhIP-ONA adducts and urinary PhIP. Carcinogenesis 17, 67-72.

164. Schut, H.A.d. Herzog, C.R., Cummings, D.A. (1994) Accumulation of DNA adducts of 2amino-3-methylimidazo[4,5-f]quinoline (1Q) in tissues and white blood cells of the Fischer $\mathrm{F}$ 344 rat after multiple oral dosing. Carcinogenesis $15,1467-1470$.

165. Hirose, M. Wakabayashi, K., Ochiai, M., Kushida, H., Sato, H., Sugimura, T., Nagao, M. (1995) Formation and removal of DNA adducts in the liver of rats chronically fed the foodborme carcinogen, 2amino-3,8-dimethylimidazo[4,5-f]quinoxaline. Jpn J Cancer Res 86,516522.

166. Shirai, T., Sano, M., Tamano, S., Takahashi, S. Hirose, M. Futakuchi, M. Hasegawa, R. Imaida, K., Matsumoto, K., Wakabayashi, K., Sugimura, T., Ito, N. (1997) The prostate: a target for carcinogenicity of 2-amino-1-methyl-6-phenylimidazo[4,5-b]pyridine (PhIP) derived form cooked foods. Cancer Res 57, 195-198.

167. Snyderwine, E.G., Davis, C.D., Schut, H.A.J., Roberts-Thomson, S.J. (1998) Proliferation. development and DNA adduct levels in the mammary gland of rats given 2-amino-1-methyl-6phenylimidazo[4,5-b]pyridine (PhIP) and a high fat diet. Carcinogenesis 19, 1209-1215.

168. Davis, C.D. Schut, H.A.J., Adamson, R.H. Thorgeirsson, U.P., Thorgeirsson, S.S., Snyderwine, E.G. (1993) Mutagenic activation of IQ. PhIP and MelQx by hepatic microsomes 
from rat, monkey and man: low mutagenic activation of MelQx in cynomolgus monkeys in vitro reflects low DNA adduct levels in wivo. Carcinogenesis 14, 61-65.

169. Adamson, R.H., Takayama, S., Sugimura, T., Thorgeirsson, U.P. (1994) induction of hepatocellular carcinoma in nonhuman primates by the food mutagen 2 amino-3methylimidazo[4,5-fquinoline. Emwiron Health Perspect 102, 190-193.

170. Thorgeirsson, S.S., Davis, C.D., Schut, H.A.J., Adamson, R.H., Snydenwine, E.G. (1995) Piossible relationship between tissue distribution of DNA adducts and genotoxicity of foodderived theterocyclic amines. In: Adamson, R.H., Gustafsson, J.-A., Ito, N., Nagao, M. Sugimura, T., Wakabayashi, $K$., Yamazoe, $Y$. (Eds.) Heterocyclic amines in cooked foods: possible human carcinogens. Princeton Scientific Publishing, Princeton, NJ, pp. 85-92.

171. Cummings, D.A., Schut, H.A.J. (1994) Remowal of DNA adducts of 2-amino-1-methyl-6phenylimidazo[4,5-b]pyridine (PhIP) in the male Fischer-344 rat. Carcinogenesis 15, 2623. 2628 .

172. Boobis, A.R., Gooderham, N.J., Edarwds, R.J., Murray, S., Lynch, A.M., Yadollah-Farsani, M. Davis, D.S. (1996)Enzymic and interindividual differences in the human metabolism of theterocyclic amines. Arch Toxicol 18 (Suppl), 286-302.

173. Turesky, R.J., Constable, A., Richoz, J., Varga, N., Markovic, J., Martin, M.V., Guengerich, F.P. (1998) Activation of heterocyclic aromatic amines by rat and human liver microsomes and by purified rat and human cytochrome P450 1A2. Chem Res Toxicol 11, 925-936.

174. Nerurkar, P.V., Schut, H.A.J., Anderson, L.M., Riggs, C.W., Snyderwine, E.G., Thargeirsson, S.S. Weber, W.W., Rice, J.M., Levy G.N. (1995) DNA adducts of 2-amino-3imethylimidazo[4,5-f]quinoline $(\mathrm{IQ})$ in colon, bladder and kidney of congenic mice differing in Ah responsiveness and Nacetyltransferase genotype. Cancer Res $55,3043-3049$.

175. Nerurkar, P.V., Schut, H.A., Andersom, L.M., Riggs, C.W., Formwald, L.W., Davis, C.D.n Snyderwine, E.G., Thorgeirssan, S.S. Weber, W.W. Rice, J.M. Levy, G.N. (1996) Ahr locus phenotype in congenic mice influences hepatic and pulmonary DNA adduct levels of 2-amino3-methylimidazo[4,5-1]quinoline in the absence of cytochrome $P 450$ induction. Mol Pharmacof $49,874-81$

176. Kadlubar, F.F. (1994) Biochemical individuality and its implications for drug and carcinogem metabolism: recent insights form acetyltransferase and cytochrome P4501A2 phenotyping and genotyping in humans. Drug Merab Rev 26, 37-46

177. Purewal, M., Fretland, A.J., Schut, H.A., Hein, D.W., Wargovich, M.J. (2000) Association between acetylator genotype and 2-amino-1-methyl-6-phenylimidaza[4,5-b]pyridine (PhIP) DNA adduct formation in colon and prostate of inbred Fischer 344 and Wistar Kuyoto rats. Cancer Lett $149,53-60$.

178. Frandsen, $H_{.}$Alexander, J. (2000) Nwacetyltransferase-dependent activation of 2. hydroxyamino-1-methyll-6-phenylimidazo[4,5-b]pyridine: formation of 2-amino-1-methyl-6-15hydroxy)phenylimidazo[4,5-b]pyridine, a possible biomarker for the reactive dose of 2-amino1-methyl-6-phenylimidazo[4,5-b]pyridine. Carcinogenesis 21, 1197-1203.

179. Kadlubar, F.F., Butler, M.A., Kaderlik, K.R., Chou, H.-C., Lang, N.P. (1992) Polymorphisms for aromatic arnine metabolism in humans: relevance for human carcinogenesis. Enwiron Health Perspect 98, 69-74.

180. Lang. N.P., Butler, M.A., Massengill, J.P. Lawson, M., Stotts, R.C., Hauer-Jensen, M. Kadlubar, F.F. (1994) Rapid metabolic phemolypes for acetyltransferase and cytochrome P4501A2 and putative exposure to food-borne heterocyclic amines increase the risk for colorectal cancer or polyps. Cancer Epidemiol Biomarkers Prew 3, 675-682.

181. Skog, K. (2002) Problems associated with the determination of heterocyclic amines in cooked foods and human exposure. Fol Chem Toxico 40, 1197-1203.

182. Augustsson, K., Skog, K., Jägerstad, M., Dickman, P.W., Steineck, G. (1999) Dietary heterocyclic amines and cancer of the colon, rectum, bladder, and kidney: a population-based study. Lancet 353, 703-707.

183. Alexander, J., Reistad, R., Hegstad, S., Frandsen, H., Ingebrigtsen, K., Paulsen, U.E., Becher, G. (2002) Biomarkers of exposure to heterocyclic amines: approaches to improve the: exposure assessment. Fd Chem Toxicol 40, 1131-1137.

184. Felton, J.S. Malfatti, M.A., Knize, M.G., Salmon, C.P., Hopmans, E.C., Wu, R.W. (1997) Health risks of heterocyclic amines. Mutat Res 376, 37-41. 


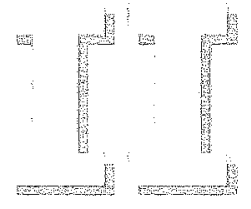

Methodologies for heterocyclic aromatic amine-DNA adduct analysis and determination of urinary 2-amino-1-methyl-6phenylimidazo- $[4,5-b]$ pyridine (PhIP) excretion levels

Harald J.J. Moonen Edwin J.C. Moonen Jos C.S. Kleinjans Theo M.C.M. de Kok

Partially based on Journal of Chromatography B 778(1-2), 345-354 (2002) 


\section{Introduction}

In our daily life we are continuously exposed to genotoxic chemicals that may interact with cellular DNA to form DNA adducts. Unless these adducts are removed by DNA repair systems, they may lead to mutations as a consequence of misreplication. There is convincing evidence that mutations in relevant target sequences, such as oncogenes or tumor suppressor genes, are associated with the carcinogenic process (1). From this, it stands to reason that accurate methods are necessary to measure human exposure to these environmental mutagens with high specificity and sensitivity. The development of extremely sensitive analylical methods for detecting DNA adduct levels in the range of 1 per $10^{8}$ to $10^{10}$ normal nucleotides, offered the opportunity to use DNA adduct measurements as a quantitative tool in exposure and risk assessment. The advantage of using DNA adduct measurements in mutagen-exposed humans compared to environmental monitoring data in the context of risk assessment, is that these biomarkers integrate several aspects that determine the actual risk, including differences in exposure levels, absorption, distribution, metabolic (in)activation, genetic susceptibility and DNA repair capacity. Although there is still some debate on the biological significance of DNA adducts and the interpretation of adduct levels in terms of health risk (2.3). Tang et al. demonstrated that smoking-related DNA adducts in white blood cells significantly predict the risk for lung cancer in humans (4). There is however consensus. that the use of adduct data in risk extrapolation has the greatest value when adduct structures have been characterized and the role of adduct removal and biological relevance of specific adducts are understood $(2,5)$. As described in Chapter 1 of this thesis, for heterocyclic aromatic amines ( $\mathrm{HCA})$, the role of DNA adducts in carcinogenesis is supported by many studies. The most widely applied method for DNA adduct measurements is the ${ }^{32} \mathrm{P}$-postlabeling assay, originally developed and described over 20 years ago $(6,7)$. Since then, the number of studies using postlabeling techniques has beem continuously growing, and the technique was greatly improved. The main improvement comprised the insertion of enrichment steps, allowing the selection of modified nucleotides among normal nucleotides $(8,9)$. The general outline of the assay is as follows: [1] enzymatic digestion of DNA into 3'-mononucleotides; [2] adduct enrichment to enhance the sensitivity of the assay; [3] kinase-mediated phosphorylation of the adduct nucleotides with $\left[\gamma^{32}\right.$ P]ATP of high specific radioactivity to form $\left[5^{\prime}-{ }^{32} \mathrm{P}\right]-3^{\prime}$ biphosphates, and [4] chromatographic resolution of the labeled adducts (which are modified nucleoside $3^{\prime \prime}-5^{\prime}$-biphosphates) and their quantification.

Different modifications of the basic procedure have been applied, depending on the specific adduct under analysis. More specifically, for HCA-DNA adducts, several different methods have been described. With respect to the labeling conditions, next to the standard method (7), the intensification (i.e. ATP-deficient) method (10) has been used in many studies. The standard method comprises the use of a molar excess of AT ${ }^{32} \mathrm{P}$. thus labeling adducted and normal nucleotides to the same extent. With this method, an enrichment step is performed prior to the labeling to increase the relative amount of adducted nucleotides in the labeling mixture. The intensification method is performed under ATP-deficient conditions and is based on the principle of preferential labeling. meaning that adducted nucleotides are ${ }^{32}$ P-labeled rather than normal nucleotides. Furthermore, different methods have been described with respect to enrichment procedures and extra digestion steps after the labeling. The occurrence of large interlaboratory variations in HCA-DNA adduct analysis was demonstrated in an extensive interlaboratory trial (11). Therefore, it was important to determine the most optimal protocol in our laboratory, before the ${ }^{32} \mathrm{P}$-postlabeling technique could be used in our studies. 
Another way of investigating bioactivation of HCA in humans is by determination of parent compounds and/or metabolites that are excreted in the urine. These compounds may also be used as biomarkers of exposure. However, since the majority of the dose has been found to be excreted within the first 18 hours, it is only the recent exposure that is reflected in urine excretion levels (12). In order to determine the potential health risk associated with the HCA 2-amino-1-methyl-6-phenylimidazo[4,5-b]pyridine (PhIP), several studies have been conducted on the metabolism and disposition of this compound in humans. Urinary excretion of unmetabolized PhIP was related to the dose received in well-done meat meals $(13,14)$. Bioavailability of PhIP in humans was further demonstrated by the presence of PhIP conjugates in urine, although no information about specific metabolic pathways was obtained in this way $(15,16)$. Also, in these studies, significant differences in excretion levels were observed between individuals, which may be due to variations in activities of enzymes responsible for the bioactivation of HCA. These enzymes, cytochrome P4501A2 (CYP1A2) and N-acetyltransferase 2 (NAT2), display polymorphic distribution in humans, and variabilities in their metabolic activities may influence cancer risk susceptibility $(17,18)$. Boobis et al. found a 4 -fold increase of urinary PhIP excretion levels in human subjects after administration of the CYP1A2 inhibitor furafylline (19). This study also showed that CYP1A2-mediated metabolism accounted for appraximately $70 \%$ of the ingested dose. Recently, Stillwell at al. found an association between urinary excretion of the $N^{2}$-glucuronide conjugate of PhIP and CYP1A2 activity, but not NAT2 activity in humans (20). These findings indicate that the metabolic fate of PhIP in humans strongly depends on CYP1A2 enzymatic activity, which shows interindividual differences.

Thus, monitoring HCA and their metabolites in urine can provide an overall view in assessing bioactivation and detoxification pathways $(21,22)$. For this purpose, gass chromatography-mass spectrometry (GC-MS) is often used because of its high sensitivity and specificity, which are necessary to measure low levels in complex matrices. This assay generally comprises four steps: [1] urine hydrolysis, in which the HCA metabolites are quantitatively cleaved to liberate the parent compound; [2] extraction and possible clean-up; [3] derivatization of the polar HCA in order to make them volatile for GC; [4] GC-MS analysis. For each of these steps, several different procedures and modifications have been described (e.g. 13,14,23-25).

To be able to incorporate the use of DNA adducts and urinary HCA excretion as biomarkers of activation and exposure risk in our studies, we had to introduce and optimize the ${ }^{32}$ P-postlabeling assay for HCA-DNA adducts and the GC-MS assay for urinary HCA in our laboratory.

\section{Materials and methods}

\section{Chemicals and enzymes}

2-Amino-3-methylimidazo[4,5-f]quinoline (IQ), 2-amino-1-methyl-6-phenylimidazo[4,5b]pyridine (Ph|P'), 2-hydroxyamino-1-methyl-6-phenylimidazo[4,5-b]pyridine (N-OH-PhIP) and $\left[{ }^{2} \mathrm{H}_{3}\right]$ PhIP were obtained from Toronto Research Chemicals (Toronto, Canada). The DNA adduct standards for both $1 Q$ and PhlP were kindly provided by Dr. Herman Schut, Department of Pathology, Medical College of Ohio, Toledo, Ohio, USA. Spleen phosphodiesterases I and II were obtained from Worthington Biochemical Co. (Lakewood, NJ). T4 polynucleotide kinase was from Amersham (Braunschweig, Germany). PEl-cellulose plates were from Macherey-Nagel (Düren, Germany) and ${ }^{32} \mathrm{P}_{-}$ ATP with a specific activity of $-7000 \mathrm{Ci} / \mathrm{mm}$ ol was obtained from $1 \mathrm{CN}$ (Meckenheim, Germany). Heptafluorobutyric acid anthydride (HFBAA) was from Supelco (Bellefonte, PA, USA); 1-methyl-3-nitro-1-nitrosoguanidine (MNNG), 3,5-bis(trifluoromethyl)benzyl 
bromide (TFMB-Br), pentafluorobenzyl bromide (PFB-Br) and disopropylethylamine from Aldrich (Steinheim, Gemany). B-glucuronidaselarylsulfatase was purchased from Boehringer-Mannheim (indianapolis, IN, USA). All other chemicals were from Sigma Chemical Company (St. Louis, MO).

32 P-POSTLABELING METHODS

\section{DNA extraction}

DNA was extracted with equal wolumes of phenol, phenol/chloroform/isoamylalcohol (25:24:1) and chloroform/isoamylalcohol. Subsequently, DNA in the aqueous phase was precipitated by addition of sodium acetate ( $\mathrm{pH} 6.0)$ and $96 \%$ ethanol ( $4{ }^{\circ} \mathrm{C}$ ). After drying, DNA was dissolved in $2 \mathrm{mM}$ Tris and the final DNA concentration was determined spectrophotometrically at $260 \mathrm{~mm}$.

\section{DNA hydrolysis}

DNA hydrolyzation was investigated by using different methods, as described by Gupta et al. (7), Wohlin et al. (26) and Phillips et al. (11). An alternative procedure was based on the protocol provided by Dr. Schut (Medical College of Ohio, Toledo, OH, USA), which was upscaled in terms of DNA and enzyme quantity. $15 \mu \mathrm{g}$ of DNA was hydrolyzed in air at $38^{\circ} \mathrm{C}$ during 3.5 hours by $2.5 \cup$ micrococcal nuclease and $15 \mu \mathrm{g}$ of spleen phosphodiesterase, in a reaction mixture containing $10 \mathrm{mM}$ sodium succinate $(\mathrm{pH}$ $6.0)$ and $5 \mathrm{mM} \mathrm{CaCl}$.

\section{Adduct enrichment}

The butanol enrichment procedure we used was described by Wohlin et al (26). To the DNA digest, $1 \mathrm{mM}$ ammonium formate $(\mathrm{pH} 3.5)$ and $10 \mathrm{mM}$ tetrabutyl ammonium chloride (TBA) were added. The mixture was extracted twice with water-saturated butanol, and the combined butanol phases were back-extracted twice with $0.1 \mathrm{mM}$ butanol-saturated ammonium formate.

\section{P-postlabeling analysis}

Based on the methods described by Gupta et al. (7) and Randerath ef al. (10), the labeling reaction was performed under standard or adduct-intensification conditions, respectively. For the intensification method, the protocol from Dr. Schut was used. Briefly, hydrolysed DNA $(15 \mu \mathrm{g})$ was incubated with [ $\gamma^{32}$ P]ATP $(225 \mu \mathrm{Ci}, 32 \mathrm{pmoll})$, kinase buffer (180 $\mathrm{mM}$ bicine, $90 \mathrm{mM} \mathrm{MgCl}, 90 \mathrm{mM}$ dithiothreitol $4.5 \mathrm{mM}$ spermidine) and polynucleotide kinase $(0.45 \mathrm{U})$ for $40 \mathrm{~min}$ at $37^{\circ} \mathrm{C}$.

\section{Nuclease $P_{1}$ hydrolysis}

After the labeling reaction, zinc chloride, sodium acetate and hydrochioric acid were added, followed by NP, according to the method described by Pfau et al. (27). The mixture was incubated for 45 minutes.

\section{Nuclease $P_{1}+$ phosphodiesterase / hydrolysis}

After the labeling reaction, the mixture was incubated with $\mathrm{HCl}$ and sodium citrate buffer containing $\mathrm{NP}_{1}$ for $10 \mathrm{~min}$ at $37^{\circ} \mathrm{C}$, as described by Fukutome et al. (28). Subsequently, the mixture was incubated with Tris and an aqueous solution of PDE I for $30 \mathrm{~min}$ at 37 ${ }^{\circ} \mathrm{C}$.

Separation of adducts by thin layer chromatography (TLC) and adduct analysis The reaction mixture was spotted on a PEl-cellulose thin layer plate $(10 \times 10 \mathrm{~cm})$ with a wick of Whatman no. 1 paper $(10 \times 23 \mathrm{~cm})$ stapled to the top. After owernight elution of 
the plates in the D1 direction with 1 MI sodium phosphate buffer (pH 6.5), the wicks were cut off and discarded. Elution in the D2 direction was performed with $5.3 \mathrm{M}$ lithium formate, $8.5 \mathrm{M}$ urea $(\mathrm{pH} 3.5)$ and elution in the $\mathrm{D} 3$ direction with $1.2 \mathrm{M}$ lithium chloride, $0.5 \mathrm{M}$ Tris, $8.5 \mathrm{M}$ urea ( $\mathrm{pH}$ 8.0). Finally, the plates were eluted with $1.7 \mathrm{M}$ sodium phosphate ( $\mathrm{pH} 6.0$ ) overnight onto a wick of Whatman paper mo. 1 (D4); again the wicks were cut off and discarded. Immediately before elutions D2-D4, the plates were predeveloped with water to $\sim \mathrm{cm}$ from the bottom edge. Following each elution, the plates were washed twice with water and dried. Adduct spots on the chromatograms were located by a storage phosphor imaging technique (Molecular Dynamics, Sunnyvale, CA) (29), using a screen exposure time of $4-24$ hours.

To evaluate the hydrolysis process and to determine the exact amount of DNA analyzed, a diluted aliquot of normal nucleotides was derived from the sample under analysis, and labeled with ${ }^{32}$ P-ATP $(50 \mu \mathrm{Ci})$ using PNK. Individual nucleotides were separated from unused $32 \mathrm{P}$ and unspecifically labeled material by monodirectional TLC in $0.12 \mathrm{M}$ sodium phosphate $(\mathrm{pH} 6.8)$

\section{GC-MS METHODS}

\section{Intemal standard}

$\left.{ }^{2} \mathrm{H}_{3}\right] \mathrm{PhIP}$, dissolved in methanol, was used as the internal standard, which was added to the urine sample before hydrolysis.

\section{Urine hydrolysis}

For chemical hydrolysis, either acid or alkaline conditions are applied. The alkaline hydrolysis used $\mathrm{NaOH}$ concentrations of $0.5 \mathrm{M}(30)$ or $1 \mathrm{M}(25)$, while $1 \mathrm{M}(14,31)$ or $6 \mathrm{M}$ (32-34) $\mathrm{HCl}$ was used for acid hydrolysis. Alternatively, urine samples were enzymatically hydrolyzed by B-glucuronidase/arylsulphatase $(20,35)$.

\section{Extraction and clean-up}

Hydrolyzed urine samples were made alkaline by addition of sodium carbonate and then extracted twice with ethyl acetate. The organic extract was evaporated to dryness, resolved in $\mathrm{HCl}$ and washed wice with hexane. The acidic solution was made alkaline by adding sodium carbonate, and was subsequently extracted twice with ethyl acetate. The extract was evaporated to dryness before derivatization.

\section{Derivatization procedure}

Different methods describing the derivatization of HCA were explored. Sample extracts were incubated with either 3,5-bis(trifluoromethyl) benzyl bromide and disopropylethylw amine (e.g. $13,20,30,36)$, pentafluorobenzyl bromide and disopropylethylamine $(23,25$, 37,38 ), or heptafluorabutyric acid anhydride and diazomethane $(14,24)$.

\section{Clean-up after derivatization}

Several investigators have applied the cleanup procedure after the derivatization reaction $(13,25,36)$. Based on these methods, the sample was taken to dryness and resolved in $\mathrm{HCl}$. The solution was washed twice with hexane and made alkaline by addition of sodium carbonate. Finally, the sample was extracted wice with ethyl acetate and evaporated to dryness before GC-MS analysis.

\section{GC-MS analysis}

The dried samples were dissolved in isooctane and the volume was reduced to $10 \mu$ by evaporation under a stream of $\mathrm{N}_{2}$. For the analysis, $1 \mu$ of the isooctane solutions were splitlessly injected into a HP5890 Series II gas chromalograph (Hewlett-Packard, 
Portland, Oregon, USA), injector temperature $250^{\circ} \mathrm{C}$, using a $30 \mathrm{~m}$, i.d. $0.25 \mathrm{~mm}$, film thickness 0.25 um CP-SilBCB-MS column (Varian. Harbor City, CA. USA). Helium was used as the carrier gas at a column head pressure of 20 p.s.1. The temperature of the $\mathrm{GC}$ oven was $200^{\circ} \mathrm{C}$ for $0.5 \mathrm{~min}$, then rising to $300^{\circ} \mathrm{C}$ at $20^{\circ} \mathrm{C} / \mathrm{min}$, where it was held for 2 min. The GC column ended inside the ion source of the double focusing mass spectrometer of reversed geometry (Jeolm SX102A, JEOL Ltd., Tokyo, Japan), which was operated in either the negative ion chemical ionization (NICl) or the electron ionization (El) mode, and mass resolution was varied between 1,000 and 10,000. Using El, the base peaks $\left(M-C_{3} F_{7}\right)^{*}$ of PhlP $(\mathrm{m} / \mathrm{z}=265.1089)$ and $\left[{ }^{2} \mathrm{H}_{3}\right] \mathrm{PhIP}(\mathrm{m} / \mathrm{z}=268.1277)$ were recorded by selective ion monitoring (SIM).

\section{Results}

${ }^{32} \mathrm{P}$-POSTLABELHNG ANALYSIS

All results, obtained by the various assays, were compared in terms of sensitivity and clarity of adduct patterns. For DNA hydrolysis, the methods by Gupta, Wohlin and Phillips were equally effective, as evaluated by monodirectional TLC of individual nucleotides. The best result, however, was obtained by the method of Schut. The butanol enrichment procedure was appllied in the standard postlabeling assay, leading to better results as compared to the assay in which an enrichment step was omitted. This was not the case for NP1 and PDE I hydrolysis after the labeling reaction, where no improvement was observed. However, application of the slightly modified adduct intensification assay resulted in the most optimal adduct sensitivity. Thus, after exploring all the different methods and modifications described, the ${ }^{32} \mathrm{P}$-postlabeling method most suitable for application in our studies, was found to be the adduct intensification method by Dr. Schut. This means that no enrichment procedure or extra hydrolysis step was used in the eventual protocol. Figure 1 shows adduct standard patterns for both PhIP and $1 Q$, obtained by this method. The detection limit for this assay was 1 adduct $/ 10^{8}$ normal nucleotides.
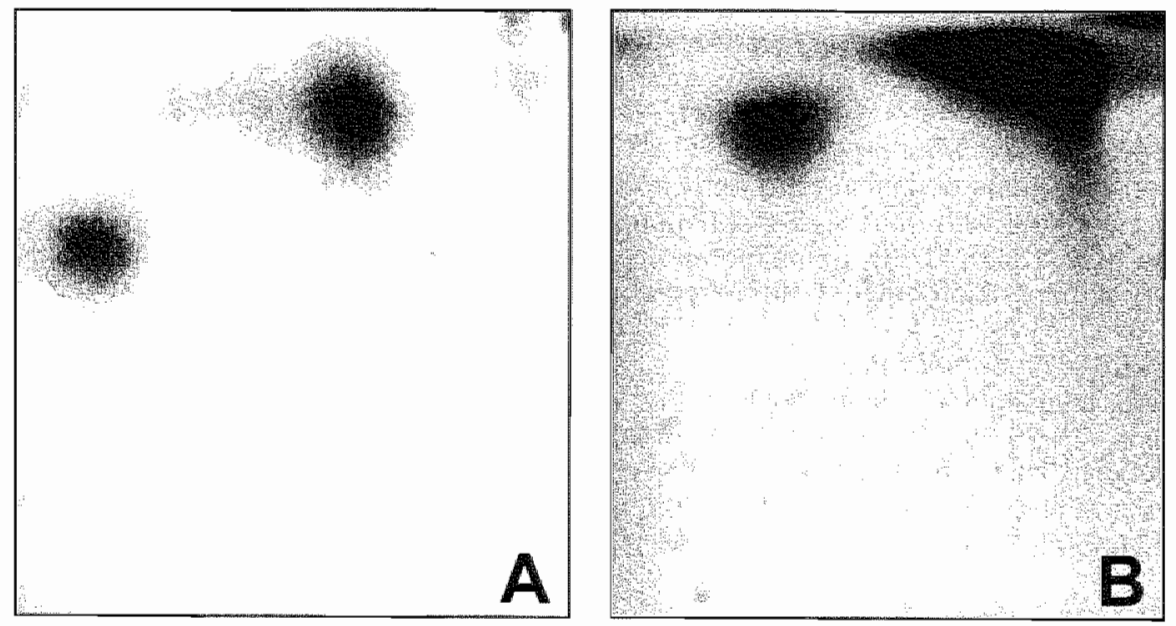

Fig. 1. DNA adduct standard profiles for (A) PhIP and (B) IQ, with modification levels of 1 adduct per $10^{6}$ nucleotides and $1 /$ adduct per $10^{7}$ nucleotides, respectively. Adduct profiles were obtained using the ${ }^{32}$ P.postlabeling method described by Dr. Schut. 
Enzymatic hydrolysis appeared to be effective and most useful, avoiding salt precipitations that were experienced when performing a chemical hydrolysis. The clean up procedure with $\mathrm{HCl}$ was best applied in combination with the orgaric solvent extraction and thus before the derivatization procedure, also avoiding salt precipitations that were formed when the clean-up was performed after the derivatization. For the derivatization, the two-step procedure described by Reistad ef al. (14), Using HFBAA and diazomethane for subsequent acetylation and methylation, was found to be most effective. In the eventual GC-MS analysis, the $\mathrm{EI}$ mode was preferred to $\mathrm{NICl}_{\text {, nendering }}$ the best signal-noise ratio when the mass spectrometer was set at a mass resolution of 10,000 . Thus, the most optimal assay in our laboratory setting was determined after comparing all different procedures and modifications.

Measured under these circumstances, the limit of detection for PhIP in urine was approximately $5 \mathrm{pg} / \mathrm{ml}$. Figure 2 shows both a chromatogram and a mass spectrum for urinary PhIP, as obtained by the ultimate assay used in our studies.
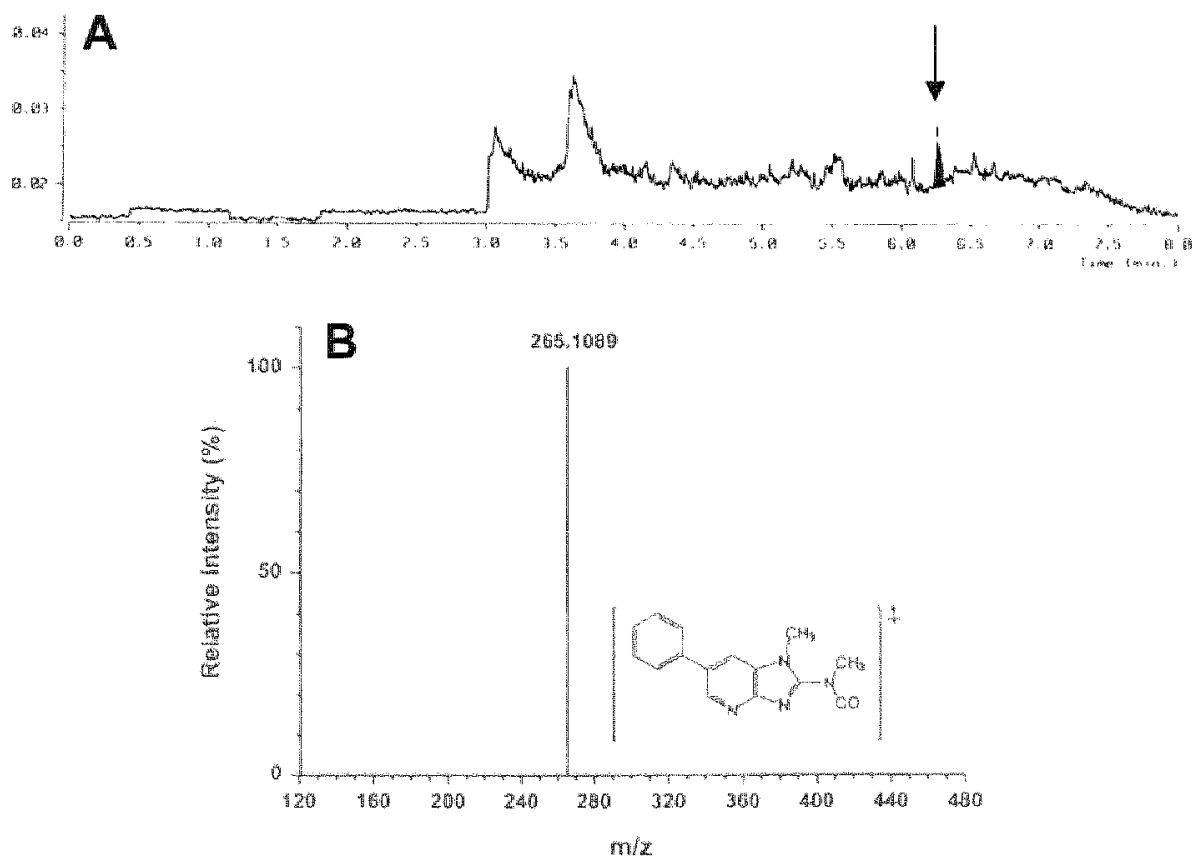

Fig. 2. (A) Chromatogram of a urine sample containing PhiP, which is indicated by the arrow; (B) Spectrum and structure of the PhIP ion in the HRE mode, using selected ion monitoring.

Next to the parent compound, similar conditions were used to investigate the detection of $\mathrm{N}$-OH-PhIP in urine, using the same assay that was described for 4'-OH-PhIP (14). Although the standard compound could be readily derivatized and measured using this assay, the metabolite could not be detected in human urine. 


\section{Discussion}

In order to monitor the biological fate of heterocyclic aromatic amines in the human body, the use of sultable biomarkers of exposure, actiwation and risk is important. Covalent binding of reactive HCA metabolites to DNA, as well as the urinary excretion of $\mathrm{HCA}_{4}$ can be used for this purpose. In our laboratory. we explored several modifications of ${ }^{32} \mathrm{P}$. postlabeling methods, described for DNA adducts formed by PhIP and IQ. using TLC to separate labeled adducts. Variations in DNA hydrolysis protocols mainly comprised differences in enzyme concentrations and incubation time, except for the Schut protocol. Contrary to the other methods, where DNA was digested in a waterbath of $37^{\circ} \mathrm{C}$, in this method the incubation was performed in air at $38^{\circ} \mathrm{C}$. Hydrolysis was evaluated by monodirectional TLC analysis of individual nucleotides, demonstrating that the Schut method was most effective, showing better nucleotide patterns and less background disturbance as compared to the other assays.

If the labeling reaction is performed under standard conditions, usually an enrichment step is introduced. NP, selective digestion (i.e. dephosphorylation) of normal 3'nucleotides enriches the sample in adducts, and is the most commonly used enrichment procedure. The dephosphoryllated normal nucleotides are no longer substrates for kinase and will not be labeled. However, since HCA-DNA adducts are sensitive to NP, digestion (39), butanol extraction was used for enrichment of these adducts. This method mainly recovers hydrophobic adducts, which are transferred into the organic phase, while the normal nucleotides remain in the aqueous phase. Compared to postlabeling without an enrichment step, butanol enrichment prior to labeling resulted in higher recovery of adducts and less background radiation, due to a relatively higher concentration of adducts and less unspecifically labeled material. The adduct intensification (ATPdeficient) method has been employed in numerous studies to recover DNA adducts induced by HCA (e.g. 23,26,28,40-43). Some investigators found patterns of multiple spots after postlabeling, and suggested that some of these spots were those of undigested adducted di- or oligonucleotides. Therefore, additional digestion steps were introduced after the labeling reaction, leaving onlly adducted mononucleotides to be separated by TLC $(27,28,44,45)$. Nuclease $P_{1}$ or a combination of nuclease $P_{1}$ and phosphodiesterase I were used for this purpose. In our study, incubation with these enzymes after postlabeling did not result in any noticeable improvement, indicating that DNA was already digested completely, not leaving di- or oligonucleotides to be labeled. Eventually, the adduct intensification method proved to be the most sensitive assay, and thus the most suitable method for application in our studies. Using this method, no enrichment steps or additional digestive steps were applied. Although lower detection limits have been reported for HCA-DNA adduct analysis using TLC- ${ }^{32}$ P-postlabeling in some studies $\left(e . g .28\right.$; detection limit $\left.1 / 10^{10}\right)$, we were able to detect these adducts at a level of 1 per $10^{6}$ nucleotides after optimization of the assay in our laboratory. Based on DNA-adduct levels formed by polycyclic aromatic hydrocarbons (PAH) in peripheral blood lymphocytes of humans after ingestion of PAH-containing hamburgers (46), we expect our detection limit to be adequate for DNA adduct measurements in our human studies. Especially in the colon, adduct levels are expected to be relatively high due to high metabolic activity. Techniques such as accelerated mass spectrometry (AMS), although much more sensitive with detection limits as low as 1 adduct per $10^{12}$ nucleotides, are not applicable in human biomonitoring studies due to the use of ${ }^{14} \mathrm{C}$ labeled substrates $(47,48)$. On the ather hand, one might raise the question whether such low adduct levels can still be regarded as biologically relevant.

With respect to the GC-MS method to detect urinary PhIP levels, also different modifications were investigated. Although acidic conditions are most often used for hydrolyzation purposes, this method resulted in salt precipitations when reducing the 
volume by evaporation, thus disturbing the assay. Therefore, enzymatic hydrolysis, not leading to any such side effects, became our method of choice. For the same reason, the $\mathrm{HCl}$ clean-up was performed in combination with the organic solvent extraction, as described by several other investigators (23,37). Applying the clean-up step after derivatization led to salt precipitation, possibly sodium carbonate. Alternatively, omission of the clean-up procedure was investigated as described by Friesen ef al. (38), leading to many disturbing peaks and high noise signals in the chromatograms.

The derivatization procedure was tested in three different ways, using derivatization chemicals with either five (PFB-Br), six (TFMB-Br) or seven (HFBAA) fluor atoms. Although the two-step procedure using HFBAA and the carcinogenic and explosive diazomethane has not been used by many other investigators, this method was found to be the most optimal because of various chromatographic difficulties that were experienced when applying either of the other two methods. For the GC-MS analysis, the high resolution El-mode (HREI) was adapted from Reistad ot al. (14), who also applied the HFBAA/diazomethane derivatization for determination of urinary HCA. With this method, higher selectivity and sensitivity were obtained than with the use of chemical ionization. The detection limit for PhIP measurement under these optimal conditions was $5 \mathrm{pg}$ PhIP per $\mathrm{ml}$ urine, which is in agreement with the detection limit that was described in the original study (14), from which our protocol was adapted. Next to the parent compound, similar conditions were used to investigate the detection of $\mathrm{N}-\mathrm{OH}-\mathrm{PhIP}$, one of the major metabolites of PhIP in the rat, in human urine. Although the standard compound could be readily derivatized, the metabolite was not detectable in urine. This was thought to be due to the clean-up procedure, during which the hydroxy-group might be lost. Therefore, our attention was focused on the analysis of unmetabolized PhIP in urine.

In conclusion, we succeeded in developing suitable methods for the detection of HCADNA adducts and urinary excretion of PhIP in our laboratory "which were to be used in our studies to monitor the biological fate of these food carcinogens in the human body.

\section{References}

1. Hemminki, K., Dipple, A. Shuker, D.E.G. Kadlubar, F.F., Segerback, D., Bartsoh, H. (Eds.) (1994). DNA Adducts: Identification and Biological Significance. IARC Scientific Publication No. 125. IARC, Lyon.

2. Nestmanin, R.R., Bryant, D.W. Carr, C.J. (1996) Toxicological significancie of DNA adducts: summary of discussions with an expert panel. Reg Toxicol Phammaol $24,9-18$.

3. Vineis, P. Perera, F. (2000) DNA adducts as marker's of exposure to carcinogens and risk of cancer. Int J Cancer 88, 325-328.

4. Tang, D., Phillips, D.H., Stampter, M., Mooney, L.A., Hsu, y., Cho, S., Tsai, M. Y., Ma, J., Cole, K.J. She M.N., Perera, F.P. (2001) Association between carcinogen-DNA adductio in white blood cells and lung cancer risk in the physicians health study. Camcer Res 61, 6708-6712.

5. Van Delft, J.H., Baan, R.A., Roza, L. (1998) Biological effect markers for exposure to carcinogenic compound and their relevance for isk assessment. Crit Rew Toxicol $28,477-510$

6. Randerath, K., Reddy, M.V., Gupta, R.C. (1981) 32P-labeling test for DNA damage. Proc Natl Acad Sci USA 78, 6126-6129.

7. Gupta, R.C., Reddy, M.V. Randerath, K. (1982) 32.postlabeling anallysis of non-radioactive aromatic carcimogen-DNA adducts. Carcinogenesis 3, 1081-1092.

8. Gupta, R.C. (1985) Enhanced sensitiwity of ${ }^{32}$ P-postlabeling analysis of aromatic caircinogenDNA adducts. Cancer Res 45, 5656-5662

9. Reddy, M.Y. Randerath. K. (1986) Nuclease P,-mediated enthancement of sensitivily of ${ }^{32}$. postlabeling lest for structurally diverse DNA adducts. Carcinogenesis $7,1543-1551$

10. Randerath, E., Agrawal, H.P., Weaver, JA, Bordelon, C.B., Randerath. KK, (1985) "P. postlabeling analysis of DNA adducts persisting for up to 42 weeks in the $s k i n$, epidermis and 
dermig of mice treated topically with 7,12-dimethylbenzla]lanthracene. Carcinogenesis 6,1117 . 126

11. Phillips, D.H. Castegnaro, M. (1999) Standardization and valtidation of DNA adduch postlabelling truthods: repont of interlaboratory trials and production of recommended protocols. Mutagensais $14,301-315$.

12. Kulp. K.S., Knize, M.G., Malfatti, M.A., Samon, C.P., J.S. Felton (2000) Identification of urine metabolites of 2 -amino- 1 -methyl-6uphenylimidazo[4,5-b]pyridine following consumption of a single cooked chicken meal in humans. Carcinogemesis 21, 2065-2072

13. Lynch, A.M., Knize. M.G., Boobis, A.P., Gooderham, N.J., Davies, D.S., Murray, S. (1992). Intra and interindividual variability in systemic exposure in humans to 2-amino-3,8dimethylimidazo[4.5-f]gunoxaline and 2-amino-1-methyl-6-phenylimidazol4,5-b]pyridime, carcinogens present in cooked beef. Cancer Res 52,6216-6223.

14. Reistad, R. Rossland, O.J. Latwa-Kala, K.J., Rasmussen, T., Vikse, R., Becher, G.; Alexander, J. (1997) Heterocyclic aromatic amines in human urine following a fried meat meal. Fol Chem Toxic $35,945-955$.

15. Stillwell, W.G., Kidd, L.C.R., Wishnok, J.S. Tannenbaum, S.R., Sinha, R. (1997) Urinary excretion of unmetabolized and phase $\|$ conjugates of 2 -amina- $\|$-methyl-6-phenylimidazo[4,5-b]pyridine and 2-amino-3,8-dimethylimidazo[4,5-f|quinoxaline in humars: relationship to cytochrome P4501A2 and N-acetylttansferase activity. Cancer Res 57, 3457-3464.

16. Kidd, L.R. Stilwell, W.G., Yu, M.C., Mishnok, J.S., Skipper, P.L. Ross, R.K. Henderson, B.E. Tannenbaum, S.R. (1999), Ulïnary excretion of 2-amino-1-methyl-6-phenylimidazo[4,5blpyridine (PhlP) in White, Africar-American and Asian-American men in Los Angeles County. Cancer Epidemiol Biomarkers Prev 8, 439-445.

17. Caporaso, N., Landi, M.T., Vineis, P. (1991) Relevance of metabolic polymorphisms to human carcinogenesis: evaluation of epidemiologic evidence. Pharmacogenelics 1, 4-19.

18. Kadlubar, F.F., Butler, M.A., Kademtik, K. R., Chou, H.-C., Lang. N.P. (1992) Polymorphisms for aromatic amine metabolism in humans: relevance for human carcinogenesis. Enwron Health Perspect $98,69-74$

19. Boobis, A.R., Lynch, A.M., Murray, S. de la Torre, R., Solans, A., Farre, M., Segura. J.., Gooderham, N.J., Davies, D.S. (1994) CYP1A2-catalyzed conversion of dietary heterocyclic amines to their proximate carcinogens is their major route of metabolism in humans. Cancer Res 54, 89.94.

20. Stillwell, W.G., Simha, R. Tannenbaum, S.R. (2002) Excretion of the $N^{2}$-glucuronide conjugate of 2-hydroxy-1-methyl 16 phenylimidlazo $[4,5-b]$ pyridine hn urine and its relationship to CYP1A.2 and NAT2 activity levels in humans. Cavoinogenesis 23,831-838.

21. Stillwell, W.G., Turesky, R.J. Sirha, R. Skipper, P.L." Tannenbaum, SR. (1999) Biomonitoring of heterocyclic aromatic amine metabolites in human urine. Cancer Lett 143 145-148.

22. Stillwell, W.S., Skipper, P.L., Tannebaum, S.R. (2000) Biomonitoring: methods and analysis. In: Nagao, M., Sugimura, T. (Eds.) Food Bonne Carchogens: Heterocyclic Amines. John Wiley \& Sons Lid., Chichester, pp. 319-331.

23. He, Y.H., Friesen, M.D., Ruch, R.d. Schul, H.A.J. (2000) Indole-3-carbinol as a chemopreventive agent in 2-amino-1-methyl-6-phenylimidazo[4,5-b]pyridine (PhIP) carcinogenesis: inhibition of PhIP.IDNA adduct formation, acceleration of PhIP metabolism, and induction of cylochrome P450 in Female F344 rats. Fo' Chem Toxicol 38, 15-23.

24. Murray, S., Lake, B.G. Gray, S., Edwards, A.J., Springall, C., Bowey. E.A., Willamson, G. Boobis, A.R. Gooderham, N.J. (2001) Effect of cruciferous vegetable consumption on theterocyclic aromatic amine metabolism in man. Carcinogenesis 22, 1413-1420.

25. Friesen, M.D., Rothman, N., Strickland, P.T. (2001) Concentration of 2-amino-1-methyl-6phenylimidazo(4,5-b)pyridine in urine and alkali-hydrolyzed urine after consumption of charbroiled beel. Cancer Lot $173,43-51$

26. Wohlin, P., Zeisig, M., Gustafsson, لd-A. Möller, L. (1996) ${ }^{32}$ P-HPLC analysis of DNA adducts formed in vitro and in wivo by 2 amino-1-methyl-6-phenylimidazo[ 4,5 b]pyridine and 2-amino3.4,8-trimethyl-3H-imidazo[4,5-f]quinoxaline, utilizing an improved adduct enrichment procedure. Chem Res Toxicol $9,1050-1056$.

27. Piau, W. Brockstedt, U, Söhren, Kn. D., Marquardt, H. (1994) ${ }^{32}$ P-postlabelling anallysis of DNA adducts formed by food-derived heterocyclic amines: evidence for incomplete hydrolysis and a procedure for adduct pattern simplification. Carcinogenesis 15, 877-882. 
28. Fukutome, K., Ochiai, M., Wakabayashi, K., Watanabe, S. Sugimura, T., Nagao, M. (1994) Detection of guanine-C8-2-amino-1-methyl-6-phenylimidazo[4,5-b]pyridine adduct as a single spot on thin-layer chromatography by modification of the "2P-postlabeling method. Jpm $f$ Cancer Res 85, 113-117.

29. Reichert, W.L., Stein, J.E., French, B.E.; Goodwim, P., Varanasi, U. (1992) Storage phosphor imaging technique for detection and quantitation of DNA adducts measured by the ${ }^{32} \mathrm{P}_{\text {. }}$ postlabeling assay. Carcinogenesis $13,1474-1479$.

30. Crosbie, S.J. Murray, S., Boobis, A.R., Gooderham, N.J. (2000) Mass spectrometric detection and measurement of $N^{2}-(2$-deoxyguanosin-8-yil)PhIP adducts in DNA. J Chrom $B 744,55-64$.

31. Tannenbaum, S.R., Stillwell, W.G., Ji, H. Skipper, P.L., Yu, M.C. Ross, R.K., Henderson, B.E., Turesky, R.J. Gross, G.A. (1995) MelQx (2-amino-3,8-dimethylimidazo[4,5 f]quinoxaline): metabolism in humans and urinary metabolites in human populations. Princess Takamatsu Symp 23, 197-206.

32. Stillwell, W.G., Turesky, R.J, Gross, G.A. Skipper, P.L., Tannenbaum, S.R. (1994) Human urinary excretion of sulfamate and glucuronide conjugates of 2-amino-3,8-dimethylimidazo[4,5ffquinoxaline (MelQx). Cancer Epidemiol Biomarkers Prev 3, 399-405.

33. Ji, H., Yu, M.C., Stillwell, W.G. Skipper, P.L., Ross, R.K., Henderson, B.E., Tannenbaum, S.R. (1994) Urinary excretion of 2-amimo-3,8-dimethylimidazo[4,5-1] quinoxaline (MelQx) in white, black, and Asian men in Los Angeles Country. Cancer Epidemiol Biomarkers Prev 3. 407-411.

34. Sinha, R., Rothman, N., Mark, S.D., Murray, S., Brown, E.D., Levander, O.A. Davies, D.S., Lang, N.P., Kadlubar, F.F., Hoover, R.N. (1995) Lower levels of 2-amino-3,8dimethylimidazo(4,5-f)quinoxaline (MelQX) in humans with higher CYP1A2 activity. Carcinogenesis 16, 2859-2861.

35. Dietrich, C.G., de Waart, D.R., Ottenhoff, R., Bootsma, A.H., van Gennip, A.H., Elferink, R.P. (2001) Mrp2-deficiency in the rat impairs biliary and intestinal excretion and influences metabolism and disposition of the food-derived carcinogen 2-amino- 1 -methyl-6-phenylimidazo. Carcinogenesis 22,805-811.

36. Murray, S., Gooderham, N.J., Boobis, A.R., Davies, D.S. (1989) Detection and measurement of MeIQx in human urine after ingestion of a cooked meat meal. Carcinogenesis 10, 763-765.

37. Friesen, M.D., Garren, L., Bereziat, J.C. Kadlubar, F.F. Lin, D. (1993) Gas chromatographymass spectrometry analysis of 2-amino-1-methyl-6-phenylimidazo[4,5-b]pyridine in urine and feces. Environ Health Perspect 99, 179-181.

38. Friesen, M.D., Cummings, D.A., Garren, L., Butler, R., Bartsch, H., Schut, H.A. (1996) Validation in rats of two biomarkers of exposure to the food-borne carcinogen 2-amino-1methyl-6-phenylimidazo[4,5-b]pyridine (PhIP): PhIP-DNA adducts and urinary PhIP. Carcinogenesis $17,67-72$.

39. Izzotti, A. (1998) Detection of modified DNA nucleotides by postlabeling procedures. Toxicol Math 8, 175-205.

40. Zu. H., Schut, H.A.J. (1991) Sex differences in the formation and persistence of DN.A adducts of 2-amino-3-methylimidazo[4,5-fiquinoline (IQ) in CDF, mice. Carcinogenesis $12,2163-2168$

41. Schut, H.A.J., Herzog, C.R. (1992) Formation of DNNA adducts of 2-aminome-methyl-6phenylimidazo[4,5-b]pyridine (Ph|P) in male Fischer-344 rats. Cancer Lett 67, 117-124.

42. Cummings, D.A., Schut, H.A.J. (1994) Removal of DNA adducts of 2-aminom 1-methyl-6. phenylimidazo[4,5-b]pyridine (PhIP) in the male Fischer-344 rat. Carcinogenesis 15, 26232628.

43. Schut, H.A.J, Yao, R. (2000) Tea as a potential chemopreventive agent in PhIP carcinogenesis; effects of green tea and black tea on PhIP.DNA adduct formation in female F.. 344 rats. Nutr Cancer $36,52-58$.

44. Tada, A. Ochiai, M. Wakabayashi. K., Nuyaka, H., Sugimura, T. Nagao. M. (1994) Identification of $\mathrm{N}$-(deoxyguanosin-B-yl)-2-amino-3,4-dimethylimidazol4.5-fiquinoline (dG-C8 MelQ) as a major adduct formed by MelQ with nucleotides in vifro with DNA in wivo. Carcinogenesis 15, 1275-1278.

45. Ochiai, M., Nakagama, H. Turesky. R. J., Sugimura, T., Nagao, M. (1999) A new modification of the ${ }^{32}$ P-postlabeling method to recover IQ-DNA adducts as mononucleotides. Mutagenesis $14,239-242$

46. Van Maanen, J.M., Moonen, E.J., Maas, L.M., Kleinjans, J.C. Van Schooten, F. J. (1994) Formation of aromatic DNA adducts in white blood cells in relation to urinary excretion of 1. hydroxypyrene during consumption of griled meat Carcinogenesis 15, 2263-2268. 
47. Tuteltaub, K.W., Fetron, J.S., Gledhil, BL., Vogel, J.S. Southon, J.F., Caffee, M.W., Finkel, R.C. Felson, D.E., Proctor, I.D., Davis, J.C. (1990) Accelerator mass spectrometry in biomedical dosimetry: relationship between low-level exposure and cowalent bindimg of heterocychic amine carcinogens lo DNA. Proc Nall ACad Sci USA $87,5288-5292$.

48. Tutellaub, K.W., Dingley, KH., Curtis, K.D. Malfatti, M. A. Turesky, R.J., Garmer, R.C., Felton, J.S., Lang. N.P. (1999) Macromolecular adduct formation and metabolism af heterocycic amines in humans and rodents at low doses. Cancer Let $143,149-155$. 


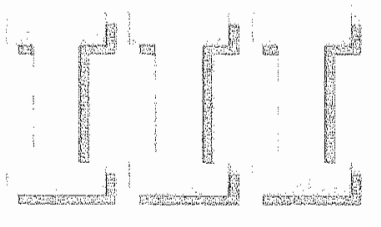

\title{
Generation of free radicals and induction of DNA adducts by activation of heterocyclic aromatic amines via different metabolic pathways in vitro
}

\author{
Harald J.J. Moonen \\ Jacob J. Briedé \\ Jan M.S. van Maanen \\ Jos C.S. Kleinjans \\ Theo M.C.M. de Kok
}

Molecular Carcinogenesis 35, 196-203

(2002) 


\section{Abstract}

Foodmerived heterocyclic aromatic amines (HCA) have proven to be carcinogenic in both rodents and nonhuman primates. For the metabolic activation of $\mathrm{HCA}$, two different metabolic pathways are suggested. The hepatic pathway proceeds via a 2 -step process involving N-hydroxylation by CYP1A2 and subsequent O-acetylation by NAT2. An alternative pathway may be of particular interest in extrahepatic tissues and proceeds via one-electron oxidation catalyzed by prostaglandin $H$ synthase (PHS), rendering free radical metabolites. In this studly, we investigated the metabolic activation of two HCA, 2amino-3-methylimidazo[4,5-f]quinoline (IQ) and 2-amino-1-methyl-6-phenylimidazo[4,5b]pyridine (PhIP), by two different enzyme systems in vitro, generating different primary and secondary reactive metabolites. Rat liver $\$ 9$-mix or PHS was used as the activating system, representing the hepatic and extrahepatic pathway, respectively. Electron spin resonance (ESR) spectroscopy demonstrated that both $1 \mathrm{Q}$ and $\mathrm{PhlP}$ exert inhibiting effects on the PHS-mediated formation of hydroxyl radicals during the conversion of arachidonic acid to prostaglandins. Evidence for the formation of HCA free radicals is presented in an indirect way by the formation of glutathione-derived thiyl radicals, using purified PHS as the activating system. Activation by S9-mix did not result in the formation of detectable radical metabolites "showing that the wo metabolic routes primarily lead to the formation of different metabolites. In all ESR experiments, $\| Q$ appears more effective as compared to PhIP.

On the contrary. DNA adduct analysis by means of ${ }^{32}$ P-postlabeling showed similar adduct patterns for $\mathrm{S} 9$ and $\mathrm{PHS}$ in single and double stranded salmon testes DNA after incubation with $\mathrm{PhIP}$, indicating the ultimate formation of a common reactive intermediate. For $1 Q_{x}$ activation by PHS led to an additional adduct spot that was not present after S9-activation. Furthermore, activation of $1 \mathrm{Q}$ resulted in higher adduct levels as compared to PhIP for both activation pathways. Overall, adduct levels were higher in single stranded DNA as compared to double stranded DNA. Our results show that the hepatic and extrahepatic pathways result in different primary metabolites, while the ultimate formation of a similar reactive intermediate for PhIP, possibly an ary/nitrenium ion, suggests that both pathways could play an important role in the onset of carcinogenesis. 


\section{Introduction}

Heterocyclic aromatic amines (HCA) form a class of compounds that was first isolated and characterized by Sugimura et al. in 1977 (1). This class of compounds appeared highly mutagenic in the Ames mutagenicity assay after activation by both rat liver $\$ 9$ (13 ) and prostaglandin $H$ synthase $(4,5)$. Furthermore, HCA have proven to be carcinogenic in both rodents (6-8) and nonhuman primates (9)).

The bioactivation of HCA is hypothesized to occur via $\mathrm{N}$-oxidation to $\mathrm{N}$-hydroxy metabolites followed by $\mathrm{O}$-acetylation to form $\mathrm{N}$-acetoxy arylamines. These steps are catalyzed by hepatic cytochrome P4501A2 (CYP1A2) and colonic N-acetyltransferase 2 (NAT2), respectively. $N$-acetoxy arylamines are then further converted to chemically reactive nitrenium ions, ultimately leading to the formation of DNA adducts.

An alternative pathway, which may be of particular interest concerning the carcinagenicity of HCA in extrahepatic tissues such as colon and rectum, proceeds via one-electron oxidation catalyzed by prostaglandin H synthase (PHS) (10). PHS occurs in most mammalian tissues and features two distinct enzyme activities, namely cyclooxygenase (COX) and peroxidase. COX catalyzes the incorporation of molecular oxygen into arachidonic acid rendering a hydroperoxy endoperoxide, prostaglandin $\mathrm{G}_{2}$ $\left(P G_{2}\right)$. Subsequent reduction of $P G G_{2}$ by the peroxidase activity of $P H S$ yields the corresponding alcohol, prostaglandin $\mathrm{H}_{2}\left(\mathrm{PGH}_{2}\right)$ (Figure 1), which is further converted to other prostanoid metabolites (10-12).

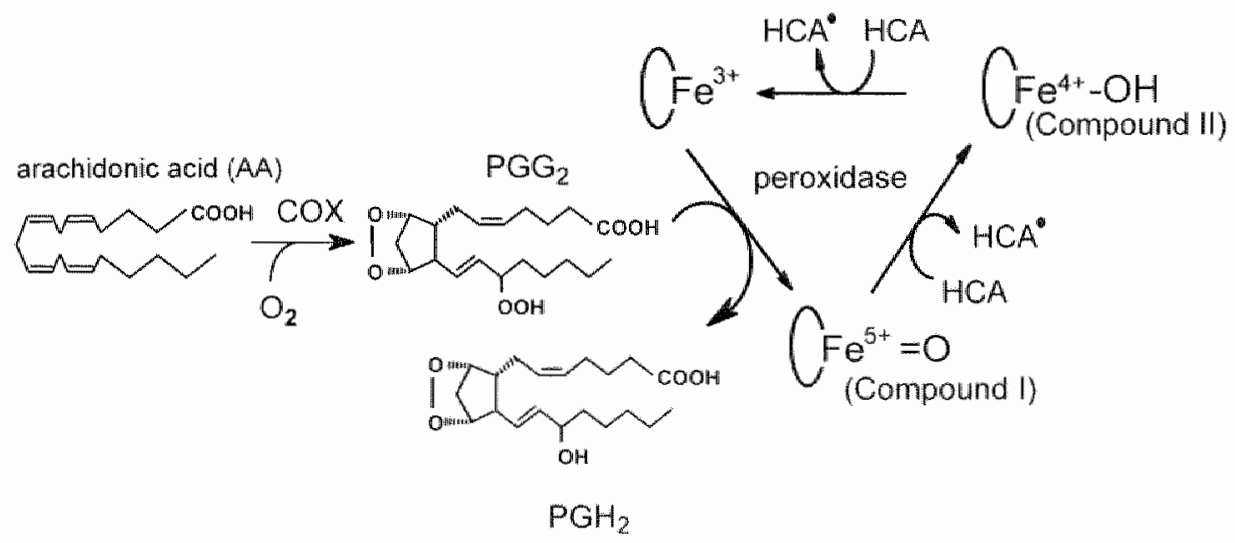

Fig. 1. Generation of HCA free radical metabolites during peroxidase-catalyzed reduction of prostaglandin $\mathrm{G}_{2}\left(\mathrm{PGG}_{2}\right)$ to prostaglandin $\mathrm{H}_{2}\left(\mathrm{PGH}_{2}\right)$. Cyclooxygenase (COX) and peroxidase are the two distinct activities of the enzyme prostaglandin H synthase (PHS).

For the reduction of $\mathrm{PGG}_{2}$ to $\mathrm{PGH}_{2}$, reducing cofactors are required by PHS peroxidase in order to catalyze this reaction. Such cosubstrates donate single electrons to the peroxidase, while in turn being converted to chemically reactive, electron deficient metabolites (10).

The peroxidase catalytic cycle is also shown in Figure 1, starting with the resting PHS enzyme containing heme iron in the +3 oxidation state. By reducing the hydroperoxide 
$\left(\mathrm{PGG}_{2}\right)$ to the corresponding alcohol $\left(\mathrm{PGH}_{2}\right)$ an iron-Oxo complex (Compound I) is formed. in which the iron is in the formal oxidation state of +5 . Compound I can be reduced by a single electron from an appropriate cosubstrate, thereby generating another iron-oxo complex (Compound II) in which the iron is in the +4 oxidation state. Finally, the ground state of the enzyme is regenerated by a second single electron reduction, while in turn another cosubstrale molecule is oxidized $(10,13)$.

It is generally assumed that HCA can be suitable cosubstrates for PHS peroxidase (Figure 1), thereby undergoing one-electron oxidation leading to the formation of HCA free radical metabolites producing DNA adducts (14). Indirect evidence for the formation of 2-amino-3-methylimidazo[4,5-f]quinoline (IQ) free radical metabolites by ram seminal vesicles was earlier described by Petry et al. (15). More recently. Wolz et al. (16) described the formation of identical IQ-DNA adduct patterns in hepatocytes, ovine seminal vesicle cells and Salmonella typhimurium after metabolic activation by either PHS or monooxygenases. However, in this study no adducts were found in isolated DNA after incubation with $1 \mathrm{Q}$ activated by either of these enzyme systems.

In this study, we investigated the relative capacity of CYP-VS. PHS-mediated pathways to generate reactive metabolites from both $1 Q$ and 2 -amino-1-methyl-6-phenylimidazo$[4,5-b]$ pyridine (PhIP), and present evidence that both compounds are capable of forming adducts in isolated DNA after activation via either hepatic or extrahepatic pathways, represented by $\mathrm{S} 9 \mathrm{mix}$ and pure PHS, respectively. Furthermore, to our knowledge the combination of ESR spectroscopy and ${ }^{32} \mathrm{P}$-postlabeling was never used before to investigate the mechanisms behind the metabolic activation of both $1 \mathrm{Q}$ and PhIP by two different enzyme systems.

\section{Materials and methods}

\section{Chemicals and enzymes}

2-Amino-3-methylimidazo[4,5-f]quinoline (IQ) and 2-amino-1-methyl-6-phenylimidazo[4,5-b]pyridine (PhIP) were obtained from Toronto Research Chemicals (Toronto, Canada). The DNA adduct standards for both $\| Q$ and PhHP were kindly provided by Dr. Herman Schut, Department of Pathology, Medical College of Ohio, Toledo, Ohio, USA. Purified prostaglandin $H$ synthase (PHS) was purchased from Oxford Biomedical Research (Oxford, MI). Spleen phosphodiesterase II was obtained from Worthington Biochemical Co. (Lakewood. NJ). T4 polynucleotide kinase was from Amersham (Braunschweig, Germany). PEI-cellulose plates were from Macherey-Nagel (Düren, Germany) and ${ }^{32}$ P.ATP with a specific activity of $-7000 \mathrm{Ci} / \mathrm{mmol}$ was obtained from ICN (Meckemheim, Germany). Glutathione, charcoal and ethanol were purchased from Merck (Darmstadt, Germany). All other chemicals were from Sigma Cinemical Company (St. Louis, MO).

\section{Electron spin resonance spectroscopy}

Electron spin resonance (ESR) studies were performed at room temperature using a Bruker EMX 1273 spectrometer equipped with an ER $4119 \mathrm{HS}$ high sensitivity cavity and $12 \mathrm{~kW}$ power supply operating at $X$ band frequencies. The following instrument conditions were used: scan range, $60 \mathrm{G}$; center magnetic field, $3490 \mathrm{G}$; modulation amplitude, $1.0 \mathrm{G}$; microwave power, $50 \mathrm{~mW}$; receiver gain, $10^{5}$; modulation frequency. $100 \mathrm{KHz}$; microwave frequency, $9.85 \mathrm{GHz}$ : time constant, $40.96 \mathrm{~ms}$; scan time, $20.97 \mathrm{~s}$ " number of scans, 50. 5,5-Dimethyl-1-pyrroline N-Oxide (DMPO) was used for trapping hydroxyl radicals and was purified in nitrogen flushed milli $Q$ water by mixing with 30 $\mathrm{mg} / \mathrm{ml}$ charcoal during $20 \mathrm{~min}$ at $35^{\circ} \mathrm{C}$. This procedure was used three times to remove background ESR signals. Finally, the concentration of DMPO was determined 
spectrophotometrically at $234 \mathrm{~mm}$. Incubation mixtures (total volume 200 ul) consisted of HCA $(0.25,0.50$ or $1.0 \mathrm{mM})$ and DMPO $(100 \mathrm{mM})$ in the absence or presence of glutathione (1 mM) and one of the following enzyme systems. (1) PHS (1 U/ul), hematin (5 $\mu \mathrm{M})$ and arachidonic acid $(0.2 \mathrm{mM})$ or (2) phenobarbital induced rat liver $59 \mathrm{mix}$ (equivalent to $0.3 \mathrm{mg}$ protein/incubate). After $15 \mathrm{~min}$ of incubation at $37^{\circ} \mathrm{C}$. ESR spectra were recorded using $100 \mu$ capillary glass tubes. Quantitation of the spectra (in arbitrary units) was performed by peak integration using the WIN-EPR spectrum manipulation program. Simulation spectra were generated using the WIN-EPR SimFonia spectral simulation program.

\section{Induction of HCA-DNA adducts}

Stock solutions of salmon testes DNA in 2 mM Tris were used for all experiments. Single stranded DNA was obtained by denaturation of double stranded DNA at $100^{\circ} \mathrm{C}$ for 5 minutes, immediately followed by chilling in ice-water. Both single stranded and double stranded DNA $(100 \mu \mathrm{g})$ were incubated in duplo during 1 hour at $37^{\circ} \mathrm{C}$ with either $1 \mathrm{mM}$ PhIP or $0.5 \mathrm{mM} \| \mathrm{Q}$ and one of the following enzyme systems: (1) PHS (200 U), hematin $(5 \mu \mathrm{M})$ and arachidonic acid $(80 \mu \mathrm{M})$ or $(2)$ phenobarbital induced rat liver $\$ 9 \mathrm{mix}$ (equivalent to $0.3 \mathrm{mg}$ protein/incubate). The total volume of the incubation mixtures was $0.5 \mathrm{~mL}$.

\section{Extraction and hydrolysis of DNA}

The incubation mixture was extracted with equal volumes of phenol, phenol/chloroform/isoamylalcohol $(25: 24: 1)$ and chloroform/isoamylalcohol. DNA in the aqueous phase was precipitated by addition of 0.1 volumes of $1 \mathrm{M}$ sodium acetate $(\mathrm{pH}$ 6.0) and 2 vol of $96 \%$ ethanol $\left(4^{\circ} \mathrm{C}\right.$ ). After drying, DNA was dissolved in $2 \mathrm{mM}$ Tris and the final DNA concentration was determined spectrophotometrically at $260 \mathrm{~nm}$.

DNA was hydrolyzed at $38^{\circ} \mathrm{C}$ during 3.5 hours in a total volume of $42 \mu$ containing 15 $\mu \mathrm{g}$ DNA, $10 \mathrm{mM}$ sodium succinate $(\mathrm{pH} 6.0), 5 \mathrm{mM} \mathrm{CaCl}, 2.5 \mathrm{U}$ micrococcal nuclease and $15 \mathrm{\mu g}$ of spleen phosphodiesterase.

\section{${ }^{32}$ P-Postlabeling and TLC analyses of HCA-DNA adducts}

Based on the method described by Randerath al. (17), the labeling reaction was performed under adduct-intensification conditions, thus preferentially ${ }^{32}$ P-labeling the HCA-DNA adducts (18). Hydrolysed DNA (15 $\mu \mathrm{g})$ was incubated with $\left[\gamma^{32}\right.$ PJATP $(225$ $\mu \mathrm{Ci}, 32$ pmol), kinase buffer (180 $\mathrm{mM}$ bicine, $90 \mathrm{mM} \mathrm{MgCl}, 90 \mathrm{mM}$ dithiothreitol, $4.5 \mathrm{mM}$ spermidine) and polynucleotide kinase $(0.45 \mathrm{U})$ in a total volume of $62 \mu \mathrm{l}$ for 40 min at 37 ${ }^{\circ} \mathrm{C}$. The reaction mixture was spotted on a PEI-cellullose thin layer plate $(10 \times 10 \mathrm{~cm})$ with a wick of Whatman no. 1 paper $(10 \times 23 \mathrm{~cm})$ stapled to the top. After overnight elution of the plates in the D1 direction with $1 \mathrm{M}$ sodium phosphate buffer $(\mathrm{pH} 6.5)$ the wicks were cut off and discarded. Elution in the D2 direction was performed with $5.3 \mathrm{M}$ lithium formate, $8.5 \mathrm{M}$ urea $(\mathrm{pH} 3.5)$ and elution in the $\mathrm{D} 3$ direction using $1.2 \mathrm{M}$ lithium chloride, $0.5 \mathrm{M}$ Tris, $8.5 \mathrm{M}$ urea $(\mathrm{pH} \mathrm{8.0}$ ). Finally. the plates were eluted with $1.7 \mathrm{M}$ sodium phosphate ( $\mathrm{pH} \mathrm{6.0)}$ overnight onto a wick of Whatman paper no. 1 (D4); again the wicks were cut off and discarded. Immediately before elutions D2-D4, the plates were predeveloped with water to $\sim 1 \mathrm{~cm}$ from the bottom edge. Following each elution, the plates were washed twice with water and dried. Adduct spots on the chromatograms were located by a storage phosphor imaging technique (Molecular Dynamics. Sunnyvale, CA) (19), using a screen exposure time of 4 hours. 


\section{Statistical methods}

Differences between ESR signal peak areas were analyzed by the Mann-Whitney nonparametric two-sample test. Spearman rank correlation coefficients were determined between HCA concentrations and ESR signal peak areas.

\section{Results}

Generation of reactive oxygen species during HCA metabolism

HCA are believed to be oxidized by PHS via a one-electron mechanism, in which free radical metabolites are formed. Therefore, we attempted to detect HCA free radicals using ESR spectroscopy, both in a direct manner (i.e. without any spin trap) and by forming a spin adduct with the spin trap DMPO. Neither of these approaches led to an additional signal or an increase in the ESR control signal (data not shown). The control signal (in absence of any HCA) is a typical hydroxyl radical spectrum (DMPO-OH. Figure 2A). probably due to reactive oxygen species (ROS) that are formed in the PHScatalyzed metabolism of arachidonic acid (20-23).

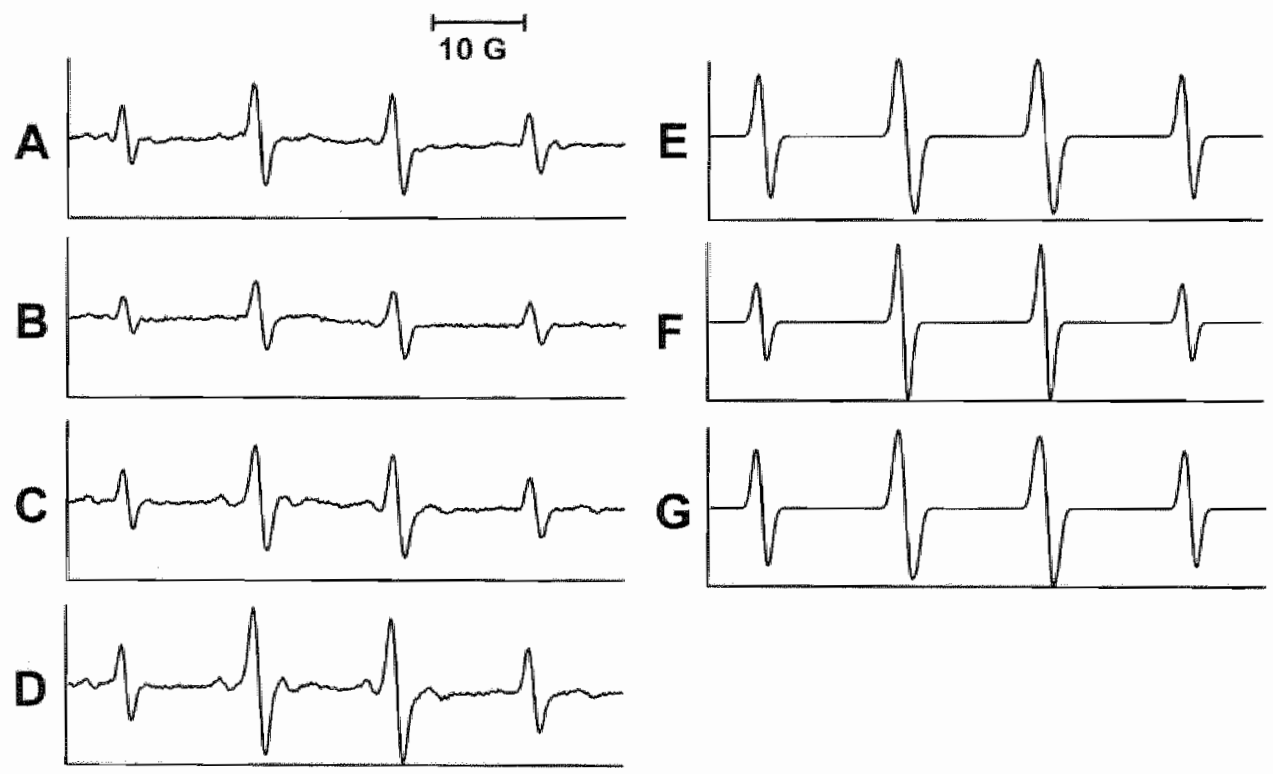

Fig. 2. Formation of spin adducts from oxygen radicals and thiyl radicals, measured by means of electron spin resonance spectroscopy. $A$, contral incubation without $I Q$ and glutathione. $B$, with 250 $\mu M$ IQ. $C$, same as in $A$ but with $1 \mathrm{mM}$ glutathione. D, same as in $C$ but with $250 \mu M$ IQ. Es computer simulation of the spectrum for the thiyl radical spin adduct (DMPO-GS) with hyperfine splitting

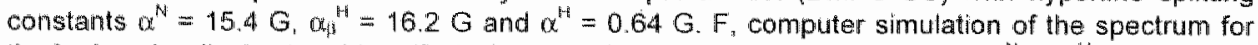
the hydroxyl radicall spin adduct (DMPO-OH) with hyperfine splitting constants $\alpha^{\mathrm{H}}=\alpha_{\mathrm{f}}^{\mathrm{H}}=14.9 \mathrm{G} . \mathrm{G}^{\mathrm{H}}$ computer simulation of the combination of spectra $E+F$.

Addition of $1 Q$ led to a decrease in the control signal (Figure 2B), indicating a decrease in the amount of ROS formed. This declining effect was found to be concentration 
dependent (Figure 3, Speaman rank correlation coefficient $p=0.65, p=0.021$ ). For $1 \mathrm{Q}_{\text {}}$ the difference bewween the decreased signal and its corresponding control was statistically significant for all concentrations $(P<0.05$ ). This effect was not clearly demonstrated for PhIP, although the ESR signal was slightly inhibited at a concentration of $0.5 \mathrm{mM}$. Thus, inhibition of the DMPO-OH signal appeared to be much weaker for PhIP as compared to IQ (Figure 3), the difference between PhIP and IQ being nearly statistically significiant $(P=0.05)$ for both $0.25 \mathrm{mM}$ and $0.5 \mathrm{mM}$. When $S 9$-mix was used as the activating system, no ESR signal could be detected in the absence or presence of a spin trap (data not shown).

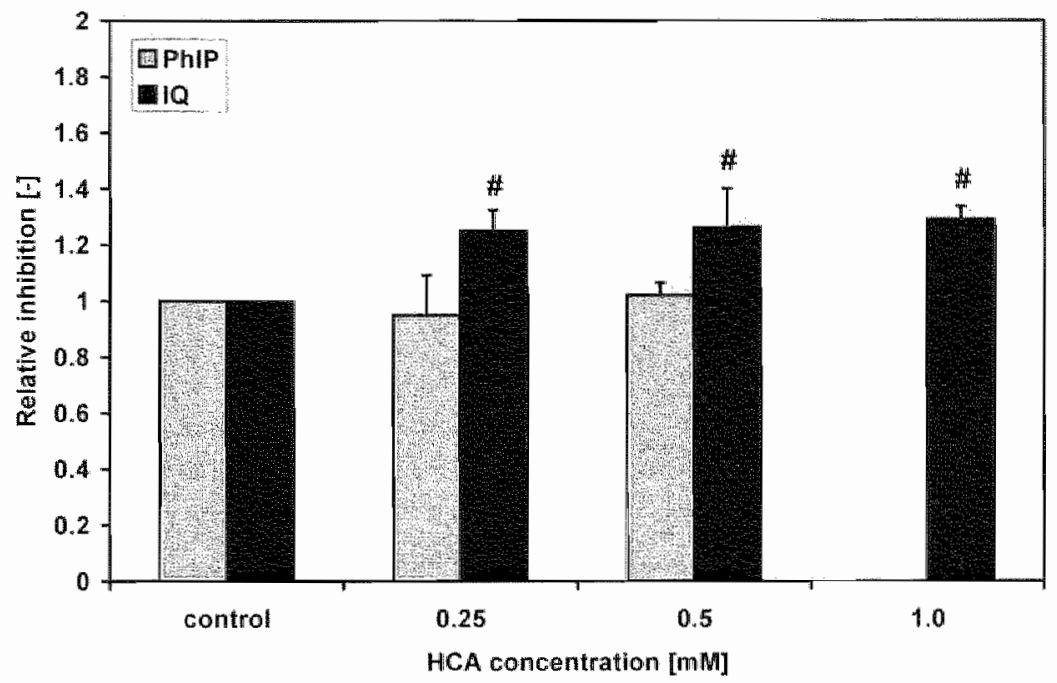

Fig. 3. Decrease of oxygen radical formation during the PHS-catalyzed conversion of arachidonic acid by addition of $1 Q$ and PhIP. measured by means of electron spin resonance spectroscapy. Contral experiments were performed without HCA. Values shown are averages $(n=3)$ with standard deviation; indicates a statistically significant difference as compiared to control $(P<0.05$, Mann-Whitney).

\section{Formation of HCA radical metabolites}

Since no direct evidence for the formation of HCA free radicals was observed, an alternative method was used to obtain indirect evidence. This method described by Petry et al. (15), is based on the fact that HCA free radicals are reduced by glutathione (24), while in turn glutathione is oxidized to form a thiyl radical. Because glutathione itself is relatively unaffected by PHS (21), the formation of thiyl radicals in presence of HCA indicates the formation of HCA free radical metabolites. These thiyl radicals form detectable spin adducts with the spin trap DMPO, leading to an ESR signal that is superimposed on the ESR spectrum of DMPO $=\mathrm{OH}$, thus giving a combined spectrum of thiy! radicals (DMPO-GS) and hydroxyl radicals (DMPO-OH).

As can be seen in Figure $2 C$, the addition of glutathione does not affect the control signal (Figure 2A), confirming that glutathione itself is a poor substrate for PHS. However, after incubation with $0.25 \mathrm{mMIQ}$ an increased ESR signal is obtained (Figure 2D). Since this spectrum matches the computer simulation of the combined spectrum of DMPO-GS and DMPO-OH (Figure 2G), it indicates the formation of thiyl radicals and thus the oxidation 
of 12 , leading to $1 \mathrm{Q}$ free radical metabolites. The formation of thiyl radicals after incubation with 10 proceeds in a concentration-dependent manner (Figure 4, Spearman rank correlation coefficient $\rho=0.87$ at level of $P=0.01$ ), showing statistically significant differences for all three concentrations as compared to their corresponding controls ( $P<$ $0.05)$.

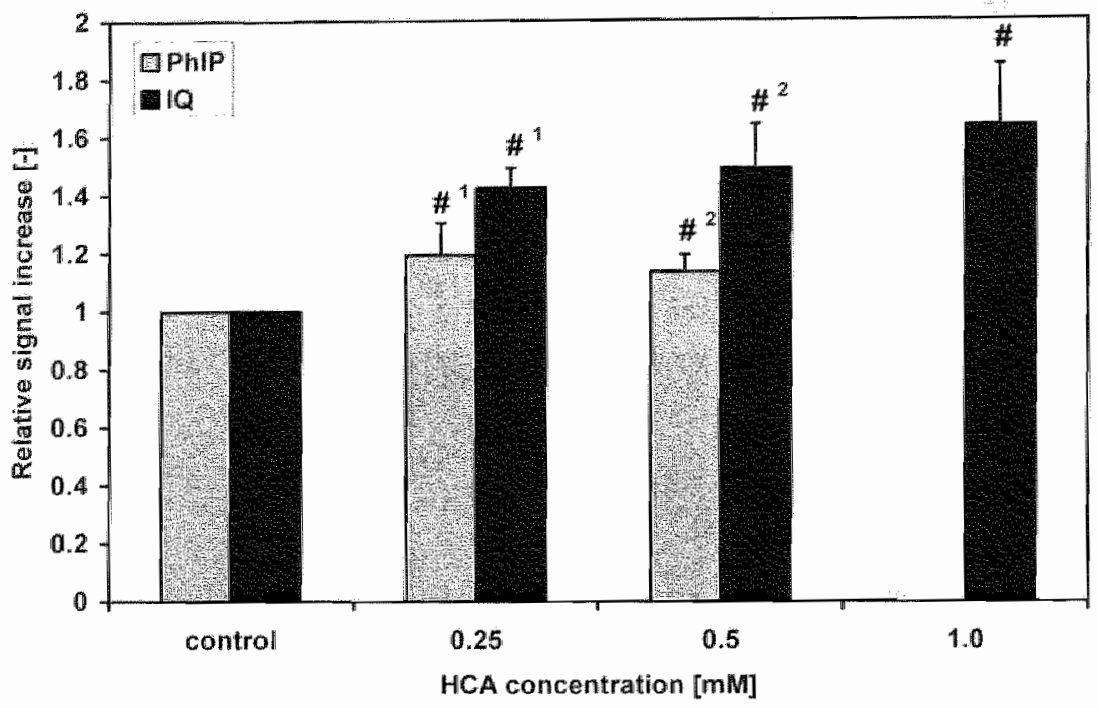

Fig. 4. Thiyl radical formation during oxidation of $1 Q$ and PhIP. Control experiments were performed without HCA. Values shown are averages $(n=3)$ with standard deviation; \# indicates a statistically significant difference as compared to control $(P<0,05$, Mann-Whitney). indicates a significant difference between $0.25 \mathrm{mM} \mathrm{PhlP}$ and $0.25 \mathrm{mM} / Q$ and $\#^{2}$ indicates a significant difference between $0.5 \mathrm{mM}$ PhIP and $0.5 \mathrm{mMlO}(\mathrm{P}<0.05$, Mann-Whitney).

For PhiP, the same effect could be demonstrated (ESR spectra not shown), although there was no clear concentration-dependent relation and the signals showed no statistically significant differences as compared to the corresponding controls (Figure 4). In view of the poor solubility of PhiP in any organic solvent, incubation concentrations could not be further increased. Finally, the effect of PhIP on thiyl formation was significantly smaller as compared to $\mathrm{IQ}(\mathrm{P}<0.05)$. When S9-mix was used as the activating system, no ESR signal could be detected in the absence or presence of a spin trap (data not shown).

\section{Formation of HCA-DNA adducts}

Using the ${ }^{32}$ P-postlabeling technique, DNA adducts were observed after incubation of both 10 and PhIP with single stranded or double stranded salmon testes DNA. HCA were activated by either S9-mix or PHS, representing the hepatic and extrahepatic metabolic pathway, respectively. For $1 \mathrm{Q}, \mathrm{S} 9$-activation leads to a multiple-adduct pattern for both single stranded and double stranded DNA (Figures 5A and $5 \mathrm{~B}$, respectively), matching the pattern of the IQ-DNA adduct standard (Figure 5E). However, for double stranded DNA, adduct spots 1 and 2 are both less intense than those in the single stranded DNA sample. In the case of PHS-activation, the profile of $1 Q$ adducts shows a pattern that is 
slightly different from that after S9-activation. Besides the fact that adduct spots 1 and 2 are both less intense as compared to S9-activation. PHS-activation leads to an additional adduct spot (nr 3, Figures 5C and 5D). Also, single stranded DNA adducts ane formed to a greater extent than double stranded DNA adducts after PHS-activation.

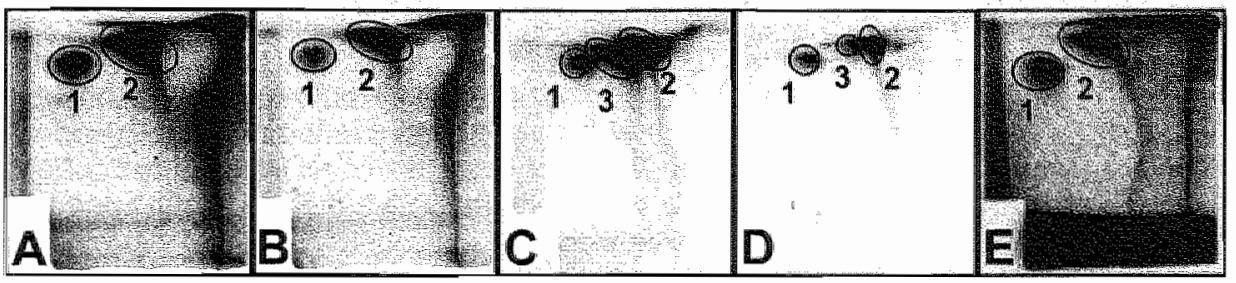

Fig 5. Autoradiographic profiles of $1 Q-D N A$ adducts, obtained by ${ }^{32} P$-positlabeling after activation by rat liver S9-mix or prostaglandin H synthase (PHS). IQ was incubated in the presence of (A) single stranded saimon testes DNA and S9-mix or (B) double stranded salmon testes DNA and S9-mix or (C) single stranded saimon testes DNA and PHS or (D) double stranded salmon testes DNA and PHS. Panel (E) shows the profile of the IQ-DNA adduct standard with a modification level of 1 adduct per $10^{6}$ normal nucleotides.

For PhIP, activation by two different enzyme systems leads to similar adduct profiles in single stranded DNA. When activated by S9-mix, the profile for single stranded DNA consists of three distinct adduct spots (Figure 6A), as is also the case for the PhIP.DNA adduct standard (Figure 6E). Incubation with double stranded DNA leads to only one adduct spot (Figure 6B), which is less intense than the matching spot in Figure 6A. For both single and double stranded DNA, the adduct profiles obtained after PhIP-activation by PHS (Figures $6 C$ and $6 \mathrm{D}$ ) are similar to the profiles in Figure $6 \mathrm{~A}$ and $6 \mathrm{E}_{\text {" }}$ again showing more intense spots for the single stranded DNA adducts.

Although the results from the ESR measurements show that different metabolic pathways initially lead to the formation of different reactive metabolites, the formation of similar DNA adduct profiles for PhIP indicates the ultimate formation of a common reactive metabolite. Furthermore, DNA adducts are formed more efficiently in single stranded DNA as compared to double stranded DNA for both enzyme systems. Comparison of the two heterocyclic amines shows that the activation of $1 \mathrm{Q}$ leads to higher adduct levels as compared to PhIP at lower incubation concentrations for both activating systems.

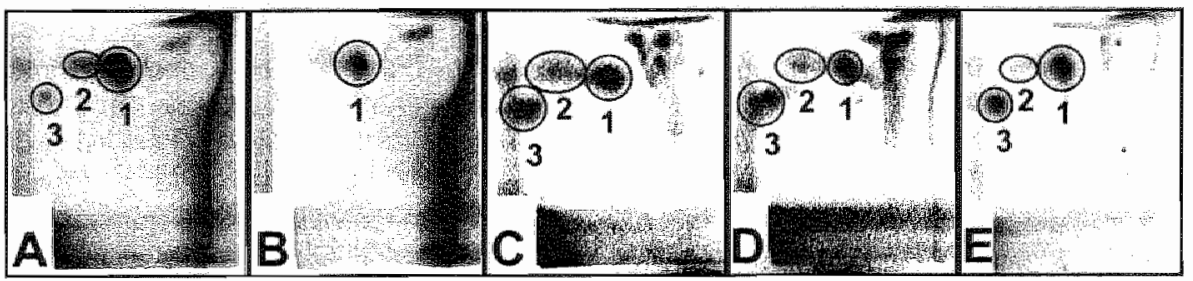

Fig. 6. Autoradiographic profiles of PhIP.DNA adducts, obtained by ${ }^{32}$ P-postlabeling after activation by rat liver S9-mix or prostaglandin H synthase (PHS). PhIP was incubated in the presence of (A) single stranded salmon testes DNA and S9-mix or (B) double stranded salmon testes DNA and S9. mix or (C) single stranded salmon testes DNA and PHS or (D) double stranded salmon testes DNA and PHIS. Panel (E) shows the profile of the PhIP-DNA adduct standard with a modification level of 1 adduct per $10^{7}$ normall nucleotides. 


\section{Discussion}

The activation of dietary HCA can proceed via different metabolic pathways. Apart from the extensively studied hepatic patrway, there is also an extrahepatic pathway in which free radicals are believed to play a crucial role. Formation of $1 Q$ free radicals was demonstrated indirectly by Pelry et al. (15). proving that this metabolic pathway proceeds via one-electron mechanism. Furthermore, this study showed an inhibiting effect of 10 on both the cyclooxygenase and hydroperoxidase activity of ram seminal vesicles, measured as the inhibition of molecular oxygen incorporation into arachidonic acid and phenylbutazone, respectively. So far, no study has been described in which both thepatic and extrahepatic pathways are investigated with regard to the activation of $I Q$ and $P$ hIP in wifro, measured by both ESR spectroscopy and ${ }^{32} \mathrm{P}$-postlabeling.

In our study, an inhibiting effect on the PHSimediated formation of oxygen radicals during the conversion of arachidonic acid to $P G H_{2}$ was demonstrated for both $I Q$ and PhIP. using ESR spectroscopy and purified PHS rather than ram seminall vesicles. Addition of $1 \mathrm{Q}$ to the control incubation mixture caused a decrease of the ESR control signal (Figure 2B) in a concentration-dependent way, whereas the effect of PhIP was. much weaker and not concentration-dependent (Figure 3). This difference between $1 Q$ and PhIP was nearly statistically significant $(P=0.05$, Figure 3 ) and is probably due to structure-related properties. Although both $1 \mathrm{Q}$ and PhiP belong to the HCA subclass of aminoimidazoazarenes (AIAs), for $1 Q$ the 2-aminoimidazo moiety is fused to a quinoline ring, while for PhIP this group is fused to a pyridine ring. A structure-activity relationship for HCA was also suggested by Felton et al. (25), with respect to mutagenic potency in the Ames test, in which $1 \mathrm{Q}$ turned out to be far more mutagenic as compared to PhIP (26).

The ESR control signal consisting of a typical DMPO-OH spectrum (Figure 2A), can be explained by the generation of reactive oxygen species during the PHS-catalyzed conversion of arachidonic acid to $\mathrm{PGH}_{2}$ (20-23) These species could be both hydroxyl $(\mathrm{OH})$ and superoxide $\left(\mathrm{O}_{2}^{\circ}\right)$ radicals. Both radical species form detectable spin adducts with the spin trap DMPO, but since the superoxide radical forms an unstable spin adduct that decomposes to a hydroxyl radical spin adduct within several minutes (27), the final ESR spectrum (i.e after 15 minutes of incubation) is identical with the DMPO-OH signal. Inhibition of this signal means that less oxygen radical spin adducts are formed. This may be due to either a competition between the generation of reactive oxygen species and the oxidation of HCA, or reaction of HCA with the generated oxygen radicals. Either of these mechanisms would lead to the formation of HCA free radicals. However, we were not able to detect a spin adduct directly formed by any HCA free radicals, probably due to their extreme instability or reactivity (12). The exact mechanism behind these findings, however, remains unclear.

In order to obtain evidence for the formation of PHS-catalyzed oxidation products of HCA, an indirect approach was necessary. As explained earlier, glutathione can be used to reduce the obtained $\mathrm{HCA}$ free radicals, and in turn be oxidized to its thiyl radical (GS) (24). This thiyl radical can then form a stable spin adduct with DMPO, which is detectable by means of ESR spectroscopy. Indeed, after addition of glutathione to the incubation mixture, IQ caused an increase in the ESR signal (Figure 2D). This increase was concentration-dependent and was statistically significant $(P<0.05$ ) for all three concentrations tested (Figure 4). The obtained ESR signal is a combination of 2 spectra, namely those of DMPO-OH (control signal) and DMPO-GS overlapping eachother, as can be seen in the computer simulation of the combined spectrum (Figure 2G). For PhIP, the effect was significantly weaker as compared to $1 Q$, although the increase was sill statistically significant as compared to the corresponding control (Figure 4). Overall for the ESR experiments it can be concluded that IQ shows a much stronger effect as 
compared to PhIP, both for the decrease in oxygen radical generation and the fomation of thiyl radicals. As mentioned earlier, this is most likely due to molecular structure differences. Since no ESR signal could be generated after activation of HCA by S9-mix with or without addition of glutathione, these results provide evidence for the formation of different primary metabolites by both $1 \mathrm{Q}$ and PhlP after activation by different metabolic pathways.

The formation of DNA adducts by $1 Q$ after bioactivation by monooxygenases (MFO) on PHS was earlier described by Wolz et al. (16), suggesting that both activation pathways ultimately result in the same DNA-binding species (arylnitrenium ion), leading to identical DNA adduct profiles in the ${ }^{32} \mathrm{P}$-postlabeling assay. The primary metabolites, however, were found to be different for the two pathways $(28,29)$. The ulitimate formation of a nitrenium ion as a common reactive intermediate for both metabolic poutes was also suggested in other studies $(30,31)$. So far, no adducts were found after incubation of PHS-activated HCA with isolated DNA. This was explained by the fact that the primary metabolites had to undergo a secondlary metabolic step before ultimate DNA-binding species would be obtained (29). In our study, we compared the two different metabolic activation pathways in order to investigate whether different metabolites would be gemerated, rendering different adduct patterns in salmon testes DNA. In contrast to Wolz et al. (16), we found that HCA-DNA adducts can be generated in isolated DNA after both PHS-and S9-activation, demonstrating that no additional metabolic step is necessary for the formation of ultimate genotoxic species. Although only one of three adduct spots was detected in double stranded DNA after S9-activation (Figure 6B), for PhIP similair adduct profiles are obtained for both PHS- and S9-activation (Figures 6A, 6C and 6D). This indicates the formation of a common reactive metabolite, as suggested in other studies $(29,30)$. For $1 \mathrm{Q}$, adduct patterns are different for PHS as compared to S9. While the pattern resulting from 59 -activation is identical to the standard pattern (Figure 5E) for both single stranded and double stranded DNA (Figures 5A and 5B), the profile obtained after PHS-activation shows an additional adduct spot (nr. 3 in Figures 5C and 5D). Although the influence of species differences for the different enzyme systems cannot be ruled out, this spot may be due to the formation of DNA adducts by 10 free radical intermediates that are not yet converted to the suggested common intermediates (nitrenium ions), which are known to form different adducts to DNA than do free radical intermediates (28). The formation of a higher amount of radicals by $I Q$ as compared to PhIP (Figure 4) may explain the presence of $I Q$ radicals after 1 hour of incubation, in contrast to the apparent absence of PhIP radicals. Future research will focus on identification of this spot.

Furthermore, for both $I Q$ and PhIP and for both activating systems, higher adduct levels are found in single stranded DNA as compared to double stranded DNA. This can be expected, since the reactive HCA metabolites do not experience any sterical hinder from a complementary DNA strand, thus able to form covalent bonds at greater ease as compared to double stranded DNA. Finally, IQ shows to have a greater adduct forming capacity, since IQ-DNA adducts are formed at higher levels than PhIP-DNA adducts, at an IQ-concentration only half that of PhIP $(0.5 \mathrm{mM}$ vs. $1 \mathrm{mM})$. In confilimation of our ESR data, these findings once again suggest that the structural differences between $1 Q$ and PhIP have great impact on their ability to form reactive metabolites. This could also be the explanation for the much higher mutagenic potential of $1 Q$ as compared to PhIP $(25)$. In summary, our study has shown that metabolic activation of HCA via different pathways primarily leads to the formation of different reactive metabolites in witro, with $\mid Q$ exerting greater overall effects as compared to PhIP. Furthermore, our results show that activation via different metabolic routes ultimately leads to the formation of a common reactive genotoxic intermediate for $P$ hIP, whille for $1 Q$ an additional adduct spot is generated after PHS-activation, thus proving that no additional metabolic conversion is 
necessary in order to obtain genotoxic species from both PhIP and $1 Q$. Therefore, PHScatalyzed activation of HCA should be taken into account when investigating the activation of HCA to genotoxic metabolites in vivo, especially in extrahepatic tissues. Further studies on the formation of HCA-DNA adducts in both human colon cell ines and animals could provide more clarity with regard to the relative importance of both metabolic pathways in human carcinogenesis.

\section{Acknowledgements}

The authors would like to thank Dr Herman Schut for providing the DNA adduct standards and for his advice in the 32 P-postlabeling assay.

This article was dedicated to our co-author, $\mathrm{dr}$. Jan wan Maanen, who died unexpectedly on November 5.2002.

\section{References}

1. Sugimura, T. Nagao, M., Kawachi, T., Honda, M. Yahagi, T., Selno, Y., Sato, S., Matsukura N., Matsushima, T. Shirai, A. Sawamura, M., Matsumoto, H. (1977) Mutagen-carcinogens in food, with special reference to highly mutagenic pyrolytic products in broiled foods. In: Hiatt, H.H. Watson, J.D. Winsten, J.A. (eds.) Origins of Human Cancer, Book C. Cold Spring Harloor Laboratory Press, New York, pp. 1561-1567.

2. Sugimura, T., Kawachi, T. Nagao, M., Yahagi, T., Seino, Y., Okamoto, T., Shudo, K., Kasuge,

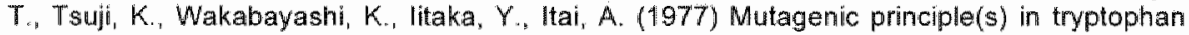
and phenylalanine pyrolysis products Proc lpon Acad 53, 58-61.

3. Sugimura, T., Sato, S. (1983) Mutagens-Carcinogens in foods. Cancer Res (suppl) 43, 2415s$2421 \mathrm{~s}$

4. Robertson, 1.G.C., Sivanajah, K., Eling, T.E., Zeiger, E. (1983) Activation of some aromatic amines to mutagenic products by prostaglandin endoperoxide symthetase. Cancer Res 43 , 476-480.

5. Wild, D. Degen, G.H. (1987) Prostaglandin H synthase-dependent mutagenic activation of Ineterocyclic aromatic anines of the LQ-type. Carcinogenesis $8,541-545$.

6. Esumi, H., Ohgaki, H., Kohzen, E., Takayama, S., Sugimulra, T. (1989) Induction of lymphoma in CDF mice by the food mutagen, 2-amino-1-methyl-6-phenylimidazo[4,5-b]pyridine. Jpn $J$ Cancer Res 80, 1176-1178.

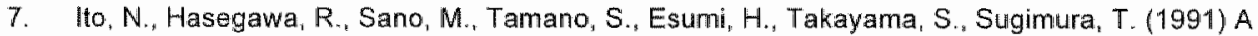
new colon and mammary carcinogen in cooked food, 2-amino-1-methyl-6mphenylimidazo[4,5bjpyridine (PhlP). Carcinogenesis 12, 1503-1506.

8. Ohgalki, H4. Takayama, S. Sugimura, T. (1991) Carcinogenicities of heterocyclic amines in cooked food. Mutation Res 259, 399-410.

9. Adamson, R.H., Thorgeirsson, L.P., Snyderwine, E.G. Thorgeirsson, S.S., Reeves, J. Dalgard, DW. Takayama, S. and Sugimura, T. (1990) Carcinogenicity of 2amino-3 methylimidazo[4,5-f]quinoline in nonhuman pringates. Induction of tumors in three macaques. upn J Cancer Ros 81, 10-14.

10. Marriet, L.J., Eling. T.E. (1983) Cooxidation during pirostaglandin biosynthesis: a pathway for the metabolic activation of xenobiotics. In. Hodgson, E., Bend, J.R. Philpot, R.M. (eds.) Reviews in Biochemical Toxicology 5. Elsevier Press, New York, pp 135-172.

11. Eling. T.E.,Boyd, A.A., Reed, G.A.,Mason, R.P., Siwarajah, K, (1983) Xenobiotic metabolism by prostaglandin endoperoxide synthetase. Drug Metab Rev 14, 1023-1053

12. Eling. T.E. Krauss, R.S. (1985) Arachidonic acid-dependent metabolism of chemical carcinogens and toxicants. In: Marnett, L. . (ed.) Arachiolonic Acrid Metabolsm and Tumor Initiation. Martinus Nijhoff Publishing. Boston, pp. 83 124 .

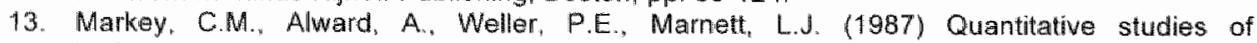
hydroperoxide reduction by prostaglandin H synthase. J Biof Chem 262, 6266-6279.

14. Eling, T.E., Thompson. D.C., Foureman, G.L., Curtis, J.F., Mughes M.F. (1990) Prostaglandin H synthase and xemobiotic oxidation. Annu Rew Pharnacol Toxicol 30, $1-45$. 
15. Petry. T.W. Josephy. P.D., Pagano, D.A., Zelger, E., Knecht, K.T., Eling. T.E. (1989) Prostaglandin hydroperoxidase-dependent activation of heterocyclic aromatic amines. Carcinogenesis 10, 2201-2207.

16. Wolz, E. Pfau, W., Degen, G.H. (2000) Bioactivation of the food mutagen 2-amino-3-methylimidazo[4,5-f]quinoline (IQ) by prostaglandin-H synthase and by monooxygenases: DNA adducts analysis. Food Chem Toxicol 38, 513-522.

17. Randerath, E., Agrawall, H.P. Weaver, J.A., Bordelon, C.B., Randerath, K. (1985) "P. postlabeling analysis of DNA adducts persisting for up to 42 weeks in the skin, epidermis and dermis of mice treated topically with 7,12-dimethylbenz[a]anthracene. Carcinogenesis 6,1117 1126 .

18. De Kok, T.M.C.M. Moonen. H.J.J., van Defft, J., van Schooten, F.J. (2002) Methodologies for DNA adduct analysis and biomonitoring of environmental and occupational exposures. $J$ Chrom B 778, 345-354.

19. Reichert, W.L., Stein, J.E., French, B.E., Goodwin, P., Varanasi, U. (1992) Storage phosphor imaging technique for detection and quantitation of DNA adducts measured by the " $p$. postlabeling assay. Carcinogenesis 13, 1474-1479.

20. Cerutti, P.A. (1985) Prooxidant states and tumor promotion. Science 227, 375-381.

21. Halliwell, B. (1987) Oxidants and human disease: some new concepts. FASEB J1, 358-364.

22. Marnett, L.J. (1992) Aspirin and the potential role of prostaglandins in colon cancer. Cancer Res 52, 5575-5589.

23. Kasprzak, K. (1996) Oxidative DNA damage in metal-induced carcinogenesis. In: Chang, L. (ed.) Toxicology of Metals. CRC Lewis Publishers, Boca Raton, pp. 299-320.

24. Eling, T.E., Curtis, J.F., Harman, L.S., Mason, R.P. (1986) Oxidation of gluthathione to its thiyl free radical metabolite by prostaglandin $H$ synthese. J Biol Chem 261, 5023-5028.

25. Felton, J.S. Knize, M.G., Hatch, F.T., Tanga, M.J., Colvin, M.E. (1999) Heterocyclic amine formation and the impact of structure on their mutagenicity. Cancer Lett 143, 127-134.

26. Sugimura, T., Wakabayashi, K. (1990) Multagens and carcinogens in food. In. Pariza. M.W., Aeschbacher, H.U., Felton, J.S., Sato, S. (eds.) Mutagens and carcinogens in the diet. WileyLiss, New York, pp. 1-18.

27. Halliwell, B., Gutteridge, J.M.C. (1985) Free radicals in biology and medicine. Oxford University Press, New York.

28. Krauss, R.S., Eling. T.E. (1985) Formation of unique arylamine DNA adducts from 2 aminofluorene activated by prostaglandin $\mathrm{H}$ synthase. Cancer Res $45,1680-1686$.

29. Wolz, E., Wild, D., Degen, G.H. (1995) Prostaglandin-H synthase mediated metabolism and mutagenic activation of 2-amino-3-methylimidazo[4,5-f]quinoline (IQ). Arch Toxical 69, 171 179.

30. Degen, G.H., Wolz, E., Wild, D. (1994) Prostaglandin $H$ synthase dependent activation of the food-borne mutagen 2-amino-3-methylimidazo[4,5-flquinoline (lQ). In: Eyer, P. (ed.) Metabolic aspects of cell toxicity. Mannheim: BI Wissenschaftsverlag, Mannheim, pp. 95-107.

31. Williams, J.A., Stone, E.M., Millar, B.C. Hewer, A., Phillips, D.H. (2000) Pathways of heterocyclic amine actiwation in the breast: DNA adducts of 2-amino-3-methylimidazo[4,5. fquinoline (IQ) formed by peroxidases and in human mammany epithelial cells and fibroblasts. Mutagenesis $15,149-154$. 


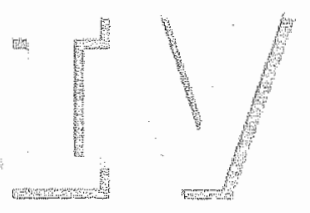

\title{
Cyclooxygenase-mediated DNA adduct formation by heterocyclic aromatic amines in human adenocarcinoma colon cells
}

\author{
H.J.J. Moonen ${ }^{1}$ \\ Y.E.M. Dommels ${ }^{2}$ \\ M. van Zwam ${ }^{2}$ \\ M.H.M. van Herwijnen ${ }^{1}$ \\ J.C.S. Kleinjans ${ }^{1}$ \\ G.M. Alink ${ }^{2}$ \\ T.M.C.M. de Kok ${ }^{1}$ \\ ${ }^{1}$ Department of Health Risk Analysis and Toxicology, \\ University of Maastricht. \\ ${ }^{2}$ Department of Toxicalogy, \\ Wageningen University, Wageningen
}

Submitted for publication 


\section{Abstract}

Dietary heterocychic aromatic amines (HCA) and polyunsaturated fatty acids (PUFA) are both believed to play a role in colon carcinogenesis, and are both substrate for the enzyme cyclooxygenase (COX). In HCA-7 cells, highly expressing isoform COX-2, we investigated DNA adduct formation by the HCA 2-amino-1-methyl-6-phenylimidazo[4,5b]pyridine (PhIP) and 2-amino-3-methylimidazo[4,5-f]quinoline (IQ). Furthermore, we studied the role of $\mathrm{COX}, \mathrm{COX}-2$ in particular, and cytochrome P4501A2 (CYP1A2) by using the specific enzyme inhibitors indomethacin (IM), NS-398 and phenethyl isothiocyanate (PEITC), respectively. Finally, the influence of the PUFA arachidonic acid $(A A, 20: 4 n-6)$ and eicosapentaenoic acid (EPA, 20:5n-3) on HCA-DNA adduct formation was investigated.

COX-mediated formation of prostaglandin $E_{2}\left(P G E_{2}\right)$ from linoleic acid (LA, 18:2n-6) showed that HCA-7 cells can convert $\angle A$ into AA. Alternatively, EPA was found to compete with AA for COX. Strongly decreased $\mathrm{PGE}_{2}$ levels by addition of IM demonstrated involvement of COX in PUFA metabolism. Both IM and NS-398 inhibited adduct formation by HCA to nearly the same extent, indicating involvement of COX-2 rather than COX-1, while CYP1A2 activity in HCA-7 cells was demonstrated by addition of PEITC. Overall, inhibiting effects were stronger for PhIP than for IQ. Finally, HCA-DNA adduct formation was stimulated by addition of PUFA, although high PUFA concentrations partly reduced this stimulating effect. These results show that $C O X$, and COX-2 in particular, can play a substantial role in HCA activation, especially in extrahepatic tissues like the colon. Furthermore, the obvious interactions between PUFA and $\mathrm{HCA}$ in $\mathrm{COX}-2$ expressing cancer cells may be important in modulating colorectal cancer risk. 


\section{Introduction}

Heterocyclic aromatic amines (HCA) form a class of compounds to which humans are exposed daily through their diet. HCA are present in the ng/g range in meat and fish cooked by ordinary household methods $(1,2)$ and they are believed to play a role in the development of colon cancer. For the metabolic activation of $\mathrm{HCA}$, two different pathways have been described, both leading to the formation of HCA-DNA adducts (3). Of these two pathways, the hepatic activation by cytochrome P450 1A2 (CYP1A2) and $\mathrm{N}$-acetyltransferase 2 (NAT2) has been studied most extensively. The alternative, extrahepatic pathway involves the enzyme cyclooxygenase (COX) and comprises cooxidation of HCA during the metabolic conversion of polyunsaturated fatty acids (PUFA) (Figure 1), leading to the formation of free radical HCA metabolites that can undergo secondary reactions and subsequently bind to DNA (4).

PUFA form essential ingredients of the human diet, since the essential PUFA linoleic acid (LA; 18:2n-6) and onolenic acid (ALA; 18:2n-3) cannot be synthesized endogenously $(5,6)$. By contrast, PUFA are aiso believed to play a role in colorectal cancer (e.g. 7-9). Longer chain, more unsaturated fatty acids like arachidonic acid (AA: 20:4n-6) and eicosapentaenoic acid (EPA; $20: 5 n-3$ ) can be derived from linoleic acid and $\alpha$-linolenic acid, respectively, by desaturation and elongation enzymes (10). Thus, there are two families of PUFA, named $n-6$ and $n-3$ fatty acids based on the position of the first double bond counted from the methyl end of the carbon chain. Special interest in these different fatty acids emerged from observations that colon cancer incidence is generally low in Eskimos in Greenland and Alaska as compared to Western populations (11). Eskimos mainly consume fish, whales and seals, thus ingesting predominantly $n-3$ fatty acids (6). The influence of PUFA on the development of colorectal cancer was further substantiated by Japanese emigrants, showing a progressive increase in cancer development upon moving to the United States. This phenomenon is believed to be caused by a westernization of the diet, thus shifting from food containing mainly $n-3$ fatty acids (e.g. fish) to food containing mainly $n-6$ fatty acids (e.g. meat and fat) (12). Also, numerous animal experiments confirmed beneficial effects of $\mathrm{n}-3$ fatty acids, contrary to $n-6$ fatty acids (13-15). Nowadays, with reglard to the dietary intake of PUFA, it is bellieved to be important to determine the $(n-6)$ to $(n-3)$ ratio rather than only the absolute level of each fatty acid family (16). Studies investigating the mechanisms behind these findings demonstrated involvement of the enzyme cyclooxygenase (COX), which has two active sites. The cyclooxygenase moiety catalyzes the conversion of $A A$ into prostaglandin $\mathrm{G}_{2} \quad\left(\mathrm{PGG}_{2}\right)$ and EPA into prostaglandin $\mathrm{G}_{3}$ (PGG3), while the endoperoxidase moiety catalyzes the subsequent reduction of $\mathrm{PGG}_{2}$ to prostaglandin $\mathrm{H}_{2}$ ( $\mathrm{PGH}$ ) and $\mathrm{PGG}_{3}$ to prostaglandin $\mathrm{H}_{3}\left(\mathrm{PGH}_{3}\right)$ (Figure 1), which are precursors for several prostaglandins, thromboxanes and prostacyclins $(5,6,17)$

Ot these products, prostaglandin $E_{2}\left(P G E_{2}\right)$ has been found to exert pro-carcinogenic effects by reducing the apoptotic rate and by increasing cell proliferation and cell motility in colon cancer cell lines (18-20). There are two distinct isoforms of cox, the constitutively expressed COX-1 and the inducible COX-2. Numerous studies have demonstrated an increased $\mathrm{COX}_{-2}$ expression in collorectal adenocarcinomas as compared to normal adjacent colonic tissue (e.g. 21-23). Thus, next to the metabolic activation of HCA, catalyzing the conversion of PUFA to prostaglandins represents another way in which COX may contribute to the development of colorectal cancer. Various studies have described the interaction between fatty acids and HCA. For instance, $n-3$ fitty acids have been found to inhibit the formation of HCA-induced DNA adducts in mice and rats (24-27). Furthermore, fatty acids have demonstrated to counteract the mutagenic effects of HCA in bacterial assays (28. 30 ). 


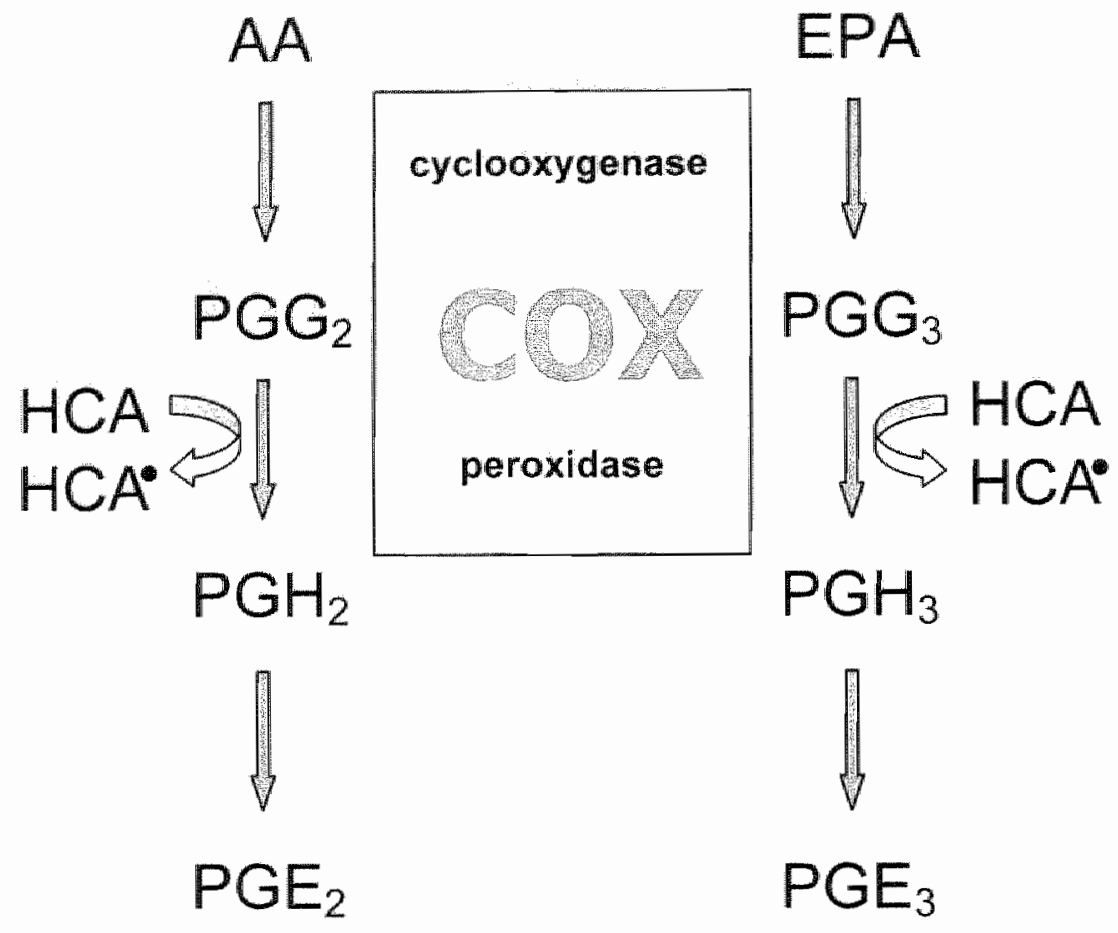

Fig. 1. Schematic representation of the conversion of $A A(n-6)$ and $E P A,(n-3)$ by the cyclooxygenase and peroxidase moieties of the COX enzyme and the concomitant oxidation of HCA, leading to the formation of HCA radical metabolites.

Similar to HCA, n-3 and n-6 fatty acids are not only substrate to COX but also to CYP1A2 $(31,32)$. One way of PUFA to exert their chemo-preventive effect could be through affecting the catalyic activity or synthesis of CYP1A2, suggested by Schut (24). Thus, several studies have described an inhibiting effect of PUFA on DNA-adduct formation from both 2-amino-1-methyl-6-phenylimidazo[4,5-b]pyridine (PhIP) and 2amino-3-methylimidazo[4,5-f]quinoline (IQ) in rodents. To our knowledge, similar experiments have not yet been performed in human colon adenocarcinoma cells in vitro. In this study, we investigaled the metabolic activation and DNA adduct forming capacity of the HCA PhIP and $1 \mathrm{Q}$ in the human colon adenocarcinoma cell line HCA-7, which shows high constitutive COX-2 expression. Furthermore, the role of $\mathrm{COX}-2$ in adduct formation by PhIP and IQ in HCA-7 cells was confirmed by using indomethacin (IM). NS398 and phenethyl isothiocyanate (PEITC) as selective inhibitors for COX, COX-2 and CYP1A2, respectively. Finally, we studied the influence of the PUFA AA $(n-6)$ and EPA $(n-3)$ on HCA-DNA adduct formation in these cancer cells. 


\section{Materials and methods}

\section{Chemicals and enzymes}

Bovine serum albumin (BSA; essential fatty acid-free), arachidonic acid (AA), eicosapentaenoic acid (EPA), linoleic acid (LA), indomethacin (IM). NS-398, phenetyl isothiocyanate (PEITC), 3-(4,5-dimethylthiazol-2-yl)-2,5-diphenyltetrazolium bromide (MTT) and micrococcal inuclease (MN) were obtained from Sigma Chemical Company (St Louis, MO, USA). Triton X-100 and dimethylsulfoxide (DMSO) were purchased from Merck AG (Darmstadt, Germany). 2-Amino-1-methyl-6-phenylimidazo[4,5-b]pyridine (PhIP) and 2-amino-3-methylimidazo[4,5-f]quinoline (IQ) were obtained from Toronto Research Chemicals (Downsview, Ontario, Canada). The DNA adduct standards for both IQ and PhIP were kindly provided by Dr. Herman Schut, Department of Pathology. Medical College of Ohio, Toledo, Ohio, USA. Cell culture medium, fetal calf serum (FCS), sodium-pyruvate, trypsin and penicilin/streptomycin were purchased from Life Technologies (Breda, the Netherlands). Cell culture flasks were from Costar (Cambridge. MA, USA). Spleen phospho-diesterase II (SPD) was obtained from Worthington Biochemical Co. (Lakewood, Nل, USA). T4 polynucleotide kinase (PNK) was from Amersham (Braunschweig, Germany). Polyethyleneimine (PEl) cellulose plates were from Macherey-Nagel (Düren, Germany) and ${ }^{32}$ P-ATP with a specific activity of -7000 $\mathrm{Ci} / \mathrm{mm}$ ol was obtained from ICN (Meckenheim, Germany).

\section{Cell culture}

Human colonic adenocarcinoma cells (HCA-7) were kindly provided by Dr. S. Kirkland (University of London, England). Cells were grown in $10 \%$ FCS-containing Dulbecco's modified Eagle's medium (DMEM), supplemented with $0.11 \mathrm{~g} / \mathrm{L}$ sodium pyruvate, Glutamax-1, $4500 \mathrm{mg} / \mathrm{L}$ gluicose and pyridoxin. During the postlabel experiments, the medium was also supplemented with $2 \%$ penstrep $(100 \mathrm{U} / \mathrm{ml}$ penicillin $\mathrm{G}$ and $100 \mu \mathrm{g} / \mathrm{ml}$ streptomycin sulphate). Cells were cultured in a $5 \% \mathrm{CO}_{2} / 95 \%$ air atmosphere at $37{ }^{\circ} \mathrm{C}$. For subculture, cells were treated with $0.25 \%$ trypsin $(w / v)$ in phosphate buffered saline (PBS) after they had reached $70-90 \%$ confluence. Cells were cultured in $75 \mathrm{~cm}^{2}$ culture flasks (Costar, Cambridge, MA, USA). All experiments were carried out within 25 passages.

\section{Prostaglandin production}

A PGE enzyme immunoassay kit (Amersham Pharmacia Biotech UK, Buckinghamshire. England) was used for quantification of $P G E_{2}$ levels. Cells were plated at a concentration of $1.25 \times 10^{5}$ cells $/ \mathrm{ml}$ in $500 \mu$ of medium into 24 well tissue culture plates and cultured at $37^{\circ} \mathrm{C}$ with $5 \% \mathrm{CO}_{2}$. The medium was removed after 24 hours and replaced by $500 \mu 1$ fresh serum-free medium for one hour. This medium was supplemented with $1 \mathrm{mg} / \mathrm{ml}$ fatty acid-free BSA and the indicated (non-cytotoxic) concentrations of AA, EPA and IM, and pre-incubated for 30 minutes at $37^{\circ} \mathrm{C}$ before addition to the cells. AA, EPA and IM were dissolved in ethanol with a maximum final solvent concentration of $0.5 \%$ in the medium. The medium was collected after one hour and $P G E_{2}$ levels were determined according to the standard EIA kit protocol. The detection limit of the assay was approximately $20 \mathrm{pg} / \mathrm{ml}$. PGE levels are expressed as nanograms. $P_{\text {GE }}$ per $\mathrm{ml}$ medium or as mean percentages of control values (set as 100\%).

\section{Cytotoxicity analysis by LDH leakage}

Leakage of the enzyme lactate dehydrogenase ( $\mathrm{LDH})$ in culture medium was used as an indicator of cytotoxicity, since leakage of this enzyme occurs when cells burst (33). The enzyme catalyses the conversion of pyruvate and NADH into lactate and NAD+. respectively. The decline of $\mathrm{NADH}$ is proportional to the enzyme activity and can be 
measured spectrophotometrically. Cells were plated at a concentration of $5 \times 10^{4}$ cells/ml in $200 \mu$ of medium into 96 wells tissue culture plates and cultured at $37^{\circ} \mathrm{C}$ with $5 \%$ $\mathrm{CO}_{2}$. After 24 hours, the medium was replaced by $100 \mu$ fresh serum-free medium. supplemented with $1 \mathrm{mg} / \mathrm{ml}$ fatty acid-free BSA and the indicated concentrations PhIP or $1 \mathrm{Q}$, and pre-incubated for 30 minutes at $37{ }^{\circ} \mathrm{C}$ before addition to the celis. HCA were dissolved in DMSO with a final solvent concentration of $0.2 \%$ in the medium. After 24 hours of incubation, the medium was removed and transferred to another 96 wells tissue culture plate. $100 \mu 1$ of $0.5 \%$ Triton $X-100$ in $50 \mathrm{mM}$ potassium phosphate buffer $(\mathrm{pH} 7.5)$ was added to the cells for lysis. Subsequently, NADH and sodium pyruvate were added and LDH activity was determined by monitoring the decrease in NADH concentration at $340 \mathrm{~nm}$ using a Spectramax spectrophotometer (Molecular Devices Co., Sunnyvale, CA. USA). Cytotoxicity is expressed as LDH activity in the medium as a percentage of the total LDH activity in both cells and medium, corrected for the background leakage from control cells.

\section{Cytotoxicity analysis by MTT colorimetric assay}

The MTT assay was performed as described by Mosmann (34). The assay is based on the activity of mitochondrial dehydrogenase in viable cells, converting MTT to a blue formazan dye. Cells were plated into 96 wells tissue culture plates at $1 \times 10^{4}$ cells/100 $\mu l$ and cultured at $37{ }^{\circ} \mathrm{C}$ with $5 \% \mathrm{CO}_{2}$. After 2 days, fresh medium was added to each well. At confluence, test compounds were added and incubated for $24 \mathrm{~h}$ at $37{ }^{\circ} \mathrm{C}$ in $5 \% \mathrm{CO}_{2}$. Both PEITC and NS-398, inhibitors of respectively CYP1A2 and COX-2, were dissolved in DMSO with a final solvent concentration of $0.5 \%$ in the medium. Subsequently, $25 \mu$ l of MTT dissolved in sterile PBS was added. After an incubation period of $3 \mathrm{~h}\left(37^{\circ} \mathrm{C}, 5 \%\right.$ $\mathrm{CO}_{2}$ ), the medium was replaced by $200 \mu \mathrm{LMSO}$. Formazan crystals were dissolved by gently shaking the plate (1 $\mathrm{min}$ ), and absorption was read at $540 \mathrm{~nm}$ using a microplate reader (Biorad, Hercules, CA, USA). Cytotoxicity is expressed as the percentage of viable cells after exposure to the test compound.

\section{Induction of HCA-DNA adducts}

Cells were plated at a concentration of $1.8 \times 10^{5}$ cells $/ \mathrm{ml}$ in $5 \mathrm{ml}$ of medium into $25 \mathrm{~cm}^{2}$ culture flasks. After 24 hours, the medium was removed and replaced by $5 \mathrm{ml}$ of fresh serum-free medium. This medium was supplemented with $1 \mathrm{mg} / \mathrm{ml}$ fatty acid-free BSA and varying concentrations of PhIP, IQ, AA, EPA, IM, NS-398 and PEITC, and preincubated for 30 minutes at $37{ }^{\circ} \mathrm{C}$ before addition to the cells. After 24 hours of incubation, the cells were harvested and DNA was isolated for ${ }^{32}$ P-postlabeling purposies. For PhIP and IQ, used concentrations (50 and $25 \mu \mathrm{M}$, respectively) were determined from the linear part of the corresponding dose-response curve (data not shown).

\section{DNA extraction and hydrolysis}

After proteinase $K$ digestion of the cells, DNA was extracted with equal volumes of phenol " phenol/chloroform/isoamylalcohol $(25: 24: 1)$ and chloroform/isoamylalcohol. Subsequently, DNA in the aqueous phase was precipitated by addition of 0.1 volumes of $1 \mathrm{M}$ sodium acetate $(\mathrm{pH} 6.0)$ and 2 vol of $96 \%$ ethanol $\left(4^{\circ} \mathrm{C}\right)$. After drying. DNA was dissolved in $2 \mathrm{mM}$ Tris and the final DNA concentration was determined spectrophotometrically at $260 \mathrm{~nm}$.

$15 \mu \mathrm{g}$ of DNA was hydrolyzed at $38^{\circ} \mathrm{C}$ during 3.5 hours in a total volume of $42 \mu l_{\text {, }}$ containing $10 \mathrm{mM}$ sodium succinate $(\mathrm{pH} 6.0), 5 \mathrm{mM} \mathrm{CaCl}, 2.5 \mathrm{U} \mathrm{MN}$ and $15 \mu \mathrm{g}$ of SPD. 
32 P.Postlabeling and TLC analysis of HCA-DNA adducts

Based on the method described by Randerath et al (35), the labeling reaction was performed under adduct-intensification conditions, thus preferentially ${ }^{32}$ Pulabeling the

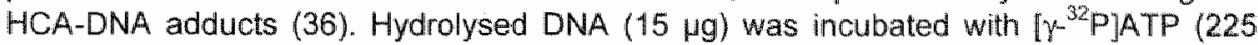
$\mu \mathrm{Ci}, 32 \mathrm{pmol}$ ), kinase buffer (180 $\mathrm{mM}$ bicine, $90 \mathrm{mM} \mathrm{MgCl}, 90 \mathrm{mM}$ dithiothreitol, $4.5 \mathrm{mM}$ spermidine) and PNK (0.45 U) in a total volume of $62 \mu \mathrm{l}$ for 40 min at $37^{\circ} \mathrm{C}$. The reaction mixture was spotted on a PEl-cellulose thin layer plate $(10 \times 10 \mathrm{~cm})$ with a wick of Whatman no. 1 paper $(10 \times 23 \mathrm{~cm})$ stapled to the top. After overnight elution of the plates in the D1 direction with $1 \mathrm{M}$ sodium phosphate buffer $(\mathrm{pH} 6.5$ ) the wicks were cut off and discarded. Elution in the D2 direction was performed with $5.3 \mathrm{M}$ lithium formate. $8.5 \mathrm{M}$ urea $(\mathrm{pH} 3.5)$ and elution in the $\mathrm{D} 3$ direction using $1.2 \mathrm{M}$ lithium cliloride, $0.5 \mathrm{M}$ Tris, $8.5 \mathrm{M}$ urea $(\mathrm{pH} 8.0)$. Finally, the plates were eluted with $1.7 \mathrm{M}$ sodium phosphate $(\mathrm{pH} \mathrm{6.0)}$ overnight onto a wick of Whatman paper no. 1 (D4); again the wicks were cut off and discarded. Immediately before elutions D2-D4, the plates were predeveloped with water to $-1 \mathrm{~cm}$ from the bottom edge. Following each elution, the plates were washed twice with water and dried. Adduct spots on the chromatograms were located and quantified using a storage phosphor imaging technique (Molecular Dynamics, Sunnyvale, CA) (37), with a screen exposure time of 24 hours. The detection limit was approximately 5 adducts per $10^{9}$ normal nucleotides.

\section{Statistical analysis}

Correlations ( $R^{2}$-values) were determined using trend line analysis in Microsoft Excel. Differences in $\mathrm{PGE}_{2}$ levels and differences in DNA adduct levels were callculated using $95 \%$ confidence intervals.

\section{Results}

\section{Cytotoxicity of HCA and enzyme inhibitors}

In the LDH leakage assay, compounds are considered to be cytotoxic when the relative LDH activity in the medium exceeds $10 \%$. Both PhIP and 10 did not exert cytotoxic effects up to a concentration of $100 \mu \mathrm{M}$ (data not shown). Using the MTT assay. compounds were assigned cytotoxic when the resulting cell viability was less than $90 \%$. For PEITC, concentrations higher than $2.5 \mu \mathrm{M}$ were cytotoxic, while exposure to NS-398 did not result in cytotoxic effects up to a concentration of 100 uM (data nol shown). In further experiments, only non-cytotoxic concentrations were used.

\section{$P G E_{2}$ production}

$\mathrm{PGE}_{2}$ levels in the medium of HCA-7 cells strongly increased after exposure to $10 \mu \mathrm{M}$ $\mathrm{AA}$ for 1 hour, and a clear dose response relationship was observed (Figure $2 ; R^{2}=$ 0.93). Exposure to EPA resulted in a dose dependent decrease in PGE production (Figure $2 ; \mathbb{R}^{2}=0.96$ ), with a maximum decrease of approximately $30 \%$ for the highest EPA concentration tested $(80 \mu M)$. When the cells were exposed to both $A A$ and EPA, $\mathrm{PGE}_{2}$ levels also decreased in a concentration dependent manner for all concentrations tested (Figure 2; $R^{2}=0.85,0.97,0.99$ and 0.88 for $10,20,40$ and $80 \mu M A A$, respectively). Exposing the cells to IM resulted in a dose dependent decrease of $P \mathrm{GE}_{2}$ production, with an inhibition of almost $60 \%$ after 24 hours of incubation with $500 \mu \mathrm{M} \mathrm{IM}$ (Figure $3 ; R^{2}=0.99$ for 1 hour; $R^{2}=0.89$ for 24 hours). 


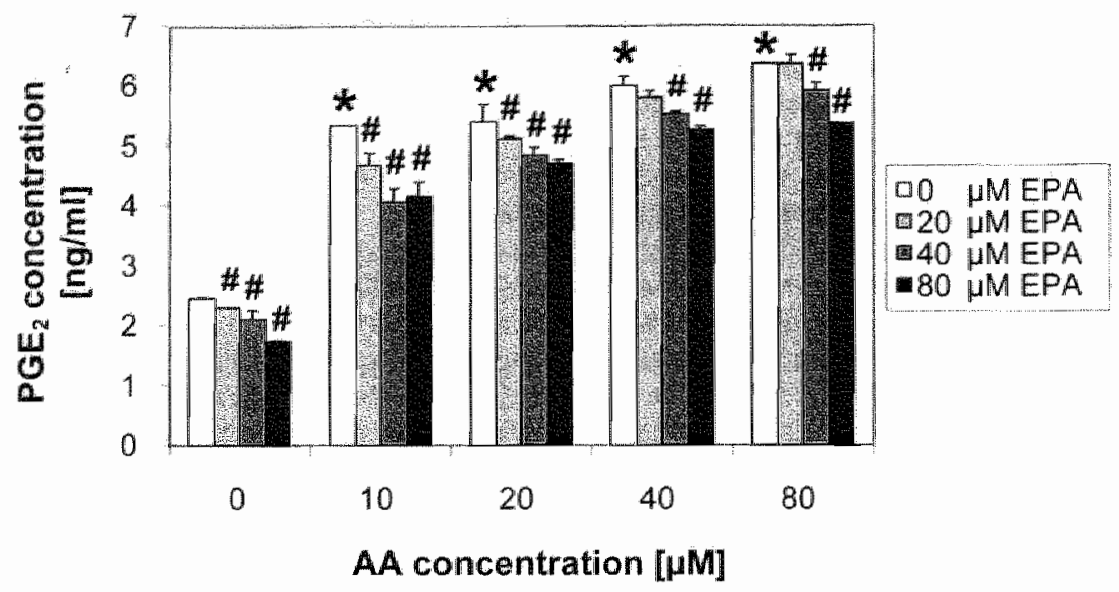

Fig. 2. Effect of $A A$ and EPA (alone or in combination) on the production of $P G E_{2}$ in $H C A-7$ cells after 1 hour. Results are expressed as mean values $(n=2) \pm$ standard error * indicates a statistically significant difference as compared to control $(0 \mu \mathrm{M} A \mathrm{AA})(\mathrm{P}<0.05)$. \# indicates a significant difference as compared to the corresponding control $(0 \mu M$ EPA) $(P<0.05)$.

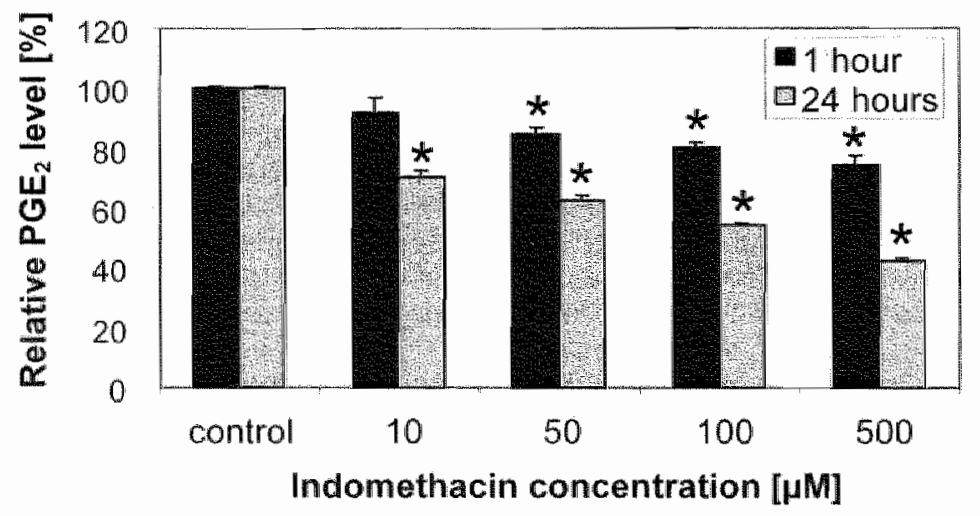

Fig. 3. Effect of indomethacin on PGE: production in HCA-7 cells after 1 hour and after 24 hours. Results are expressed as mean values $(n=2) \pm$ standard error. * indicates a statistically significant difference as compared to control $(P<0.05)$. 
Figure 4 shows that addition of LA also led to an increase in PGE production, although the obtained concentrations were significantly lower as compared to AA-induced PGE. production for all concentrations tested $(P<0.05,95 \%$ confidence interval). Furthermore, all $P G E_{2}$ concentrations were significantly lower after 1 hour of incubation as compared to 24 hours of incubation ( $P<0.05,95 \%$ confidence interval), contrary to PGE 2 production after exposure to AA under the same conditions. These results indicate that HCA-7 cells are likely to convert LA into AA.

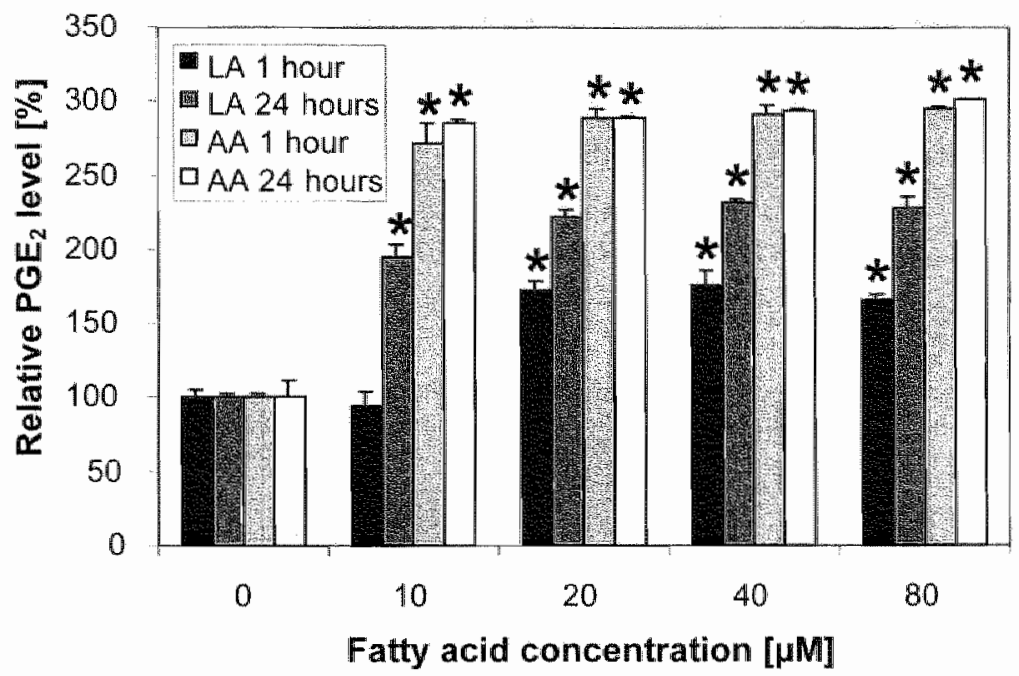

Fig. 4. Effect of LA vs. AA on PGE 2 production in HCA-7 cells after 1 hour and after 24 hours. Results are expressed as mean values $(n=2) \pm$ standard error. * indicates a statistically significant difference as compared to corresponding control $(P<0.05)$.

Effect of fatty acids and enzyme inhibitors on DNA adduct formation by HCA

Figure 5 shows the effect of both fatty acids AA and EPA on the DNA adduct forming capacity of $I Q$ and $P h I P$. For $\| Q$, a clear dose reponse relationship was observed up to concentrations of $60 \mu \mathrm{M}$ for both fatty acids (Figure $5 \mathrm{~A}_{i} \mathrm{R}^{2}=0.86$ for $A \mathrm{~A}^{2} \mathrm{R}^{2}=0.94$ for EPA). However, not all induced adduct levels were significantly different from the corresponding control level, due to relatively large standard deviations. This stimulating effect was reduced by exposure to $80 \mu \mathrm{M}$ of either fatty acid.

For PhIP, EPA appeared to have a stronger effect on adduct formation as compared to AA (Figure $5 B$ ). High concentrations of PUFA also led to a decrease in PhIP adduct levels, although with PhIP this effect was already observed with $60 \mu M$ of either fatty acid. Overall, increase of DNA adduct levels by addition of PUFA was stronger for IQ as compared to PhIP. 

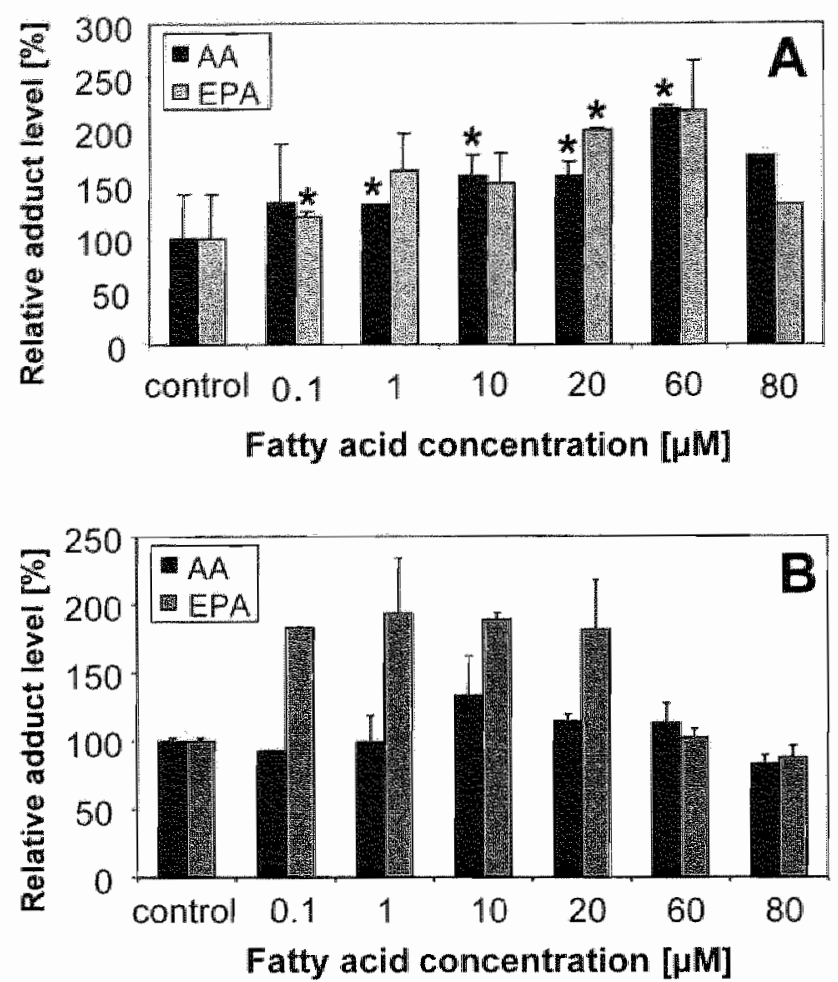

Fig. 5. Effect of $A A$ and EPA on the formation of DNA adducts by (A) $1 Q$ and (B) PhIP in HCA-7 cells after 24 hours. Results are expressed as mean values $(n=2) \pm$ standard error, with the axception of the $80 \mu \mathrm{M}$ levels (single measurements). * indicates a statistically significant difference as compared to the corresponding control level $(P<0.05)$.

IM strongly inhibited adduct formation by PhIP. while for IQ this effect was only significant at a high concentration (Figure 6).

The enzyme inhibitors PEITC and NS-398 both showed an inhibiting effect on DNA adduct formation by $1 \mathrm{Q}$ and PhIP (Figure 7). For both heterocyclic amines, the inhibiting effects of PEITC and NS-398 were dose dependent when the inhibitors were added separately, in general leading to statistically significant differences as compared to the control level. Simultaneous exposure to both inhibitors did not result in a further significant decrease of DNA adduct levels. Both PEITC and NS-398 exerted stronger inhibiting effects for PhIP than for IQ. Overall, for PhIP the inhibiting effect of both IM and NS-398 were stronger as compared to PEITC. For $1 Q$, the effects of PEITC and NS-398 were both stronger as compared to $I M$. 

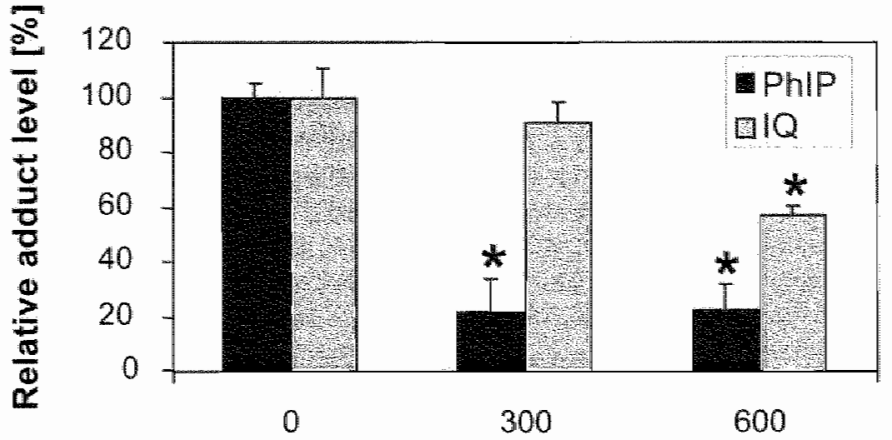

Indomethacin concentration [ $\mu \mathrm{M}]$

Fig. 6. Effect of indomethacin on DNA adduct formation by PhIP and IQ in HCA-7 cells after 24 hours. Results are expressed as mean values $(n=2) \pm$ standard error. * indicates a statistically significant difference as compared to control level $(P<0.05)$.

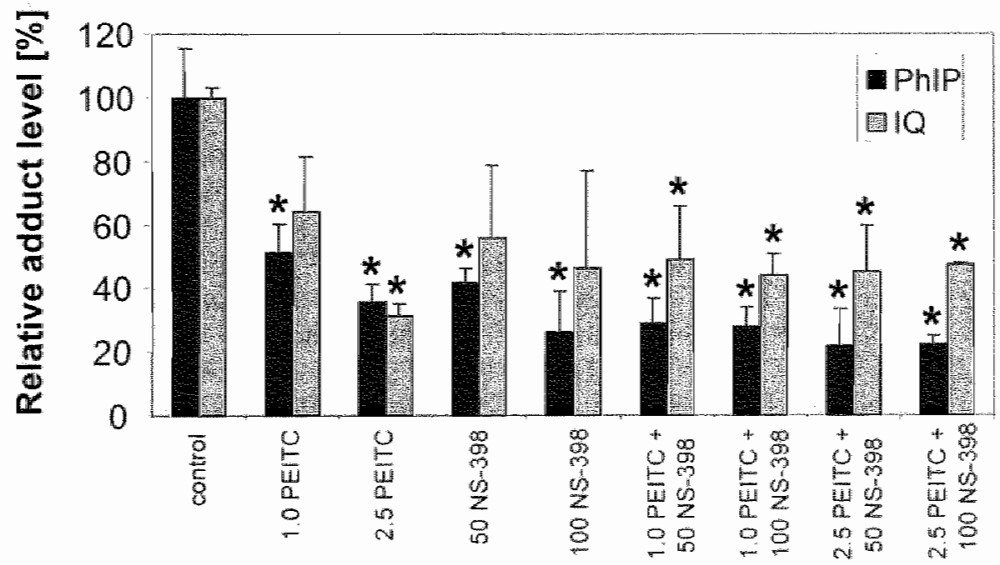

\section{Enzyme inhibitor concentration $[\mu \mathrm{M}]$}

Fig. 7. Effect of enzyme inhibitors PEITC and NS-398 on DNA adduct formation by PhIP and IQ in HCA- 7 cells after 24 hours. Results are expressed as mean values $(n=2) \pm$ standard error.

*indicates a statistically significant difference as compared to control level $(P<0.05)$. 


\section{Discussion}

Heterocyclic aromatic amines and polyunsaturated fatty acids are commonly ingested daily in the human diet. Furthermore, they both form classes of compounds that are believed to play a role in the development of colorectal cancer in humans. Thus far, several investigators have studied the interaction between PUFA and HCA in rodents, in which both $n-3$ and $n-6$ fatty acids were found to inhibit DNA adduct formation by HCA (24-27). However, the molecular mechanisms behind the interactive effects of HCA and PUFA remain to be established. HCA are known to be metabolized via both a hepatic and an extrahepatic pathway (3). The latter involves the enzyme COX, which is also important in the conversion of PUFA (Figure 1). Because of this analogy, in our study we investigated the COX-mediated pathways for both classes of compounds in HCA-7 cells, which highly express COX-2. Furthermore, selective enzyme inhibitors were used to investigate the relative importance of specific enzyme systems.

Figure 2 shows that the addition of relatively small amounts of AA results in a very strong increase in $\mathrm{PGE}_{2}$ production after 1 hour of incubation demonstrating highly expressed levels of COX-2 in these cells. By addition of higher concentrations of $\mathrm{AA}$, a clear dose response relationship was abserved $\left(R^{2}=0.93\right)$. When the cells were exposed to only $E P A$, a clear dose dependent decrease in $P G E_{2}$ production was found (Figure $2, R^{2}=$ 0.96). This can be explained by the fact that EPA has been shown to act as a competitive inhibitor for prostaglandin synthesis by $A A(17,38-41)$, leading to the formation of $\mathrm{PGE}_{3}$ rather than $\mathrm{PGE}_{2}$ (Figure 1). Moreover, EPA is believed to inhibit the activity of $\mathrm{COX}(39)$ and the expression of $\mathrm{COX}-2(42)$, thus leading to the formation of less prostaglandins overall. Figure 2 also shows that HCA-7 cells produce large amounts of $\mathrm{PGE}_{2}$ endogenously, as described earlier by Coffey et al. (43). Simultaneous exposure of the cells to $A A$ and EPA led to an EPA dose dependent decrease in PGE production for each AA concentration tested, demonstrating the competition between $A A$ and EPA. When the general COX inhibitor IM was added to the medium of the cellis, the endogenously produced $\mathrm{PGE}_{2}$ levels were significantly decreased (Figure 3 ) and inhibition was strongly dependent on incubation time. The maximum inhibition measured was approximately $60 \%$ and was induced by an IM concentration of $500 \mu \mathrm{M}$ after 24 hours, thus demonstrating the involvement of $\mathrm{COX}$ in the AA-derived production of $P G E_{2}$ in these cells. In contrast to our findings, COX-independent mechanisms for IM were suggested in some studies. Smith et al. (44) suggested a COX-2 independent mechanism of action for IM. Moreover, IM-induced apoptosis was even found to occur in cells lacking both COX isoforms (45), possibly by activation of a receptor that is associated with apoptosis in human colorectal cancer cell lines $(46,47)$.

In 1983, Nemoto and Takayama suggested that the number of carbon double bonds in PUFA molecules might determine their capacity to inhibit the metabolic activation of carcinogens by mixed-function oxidases in rat hepatic $\$ 9$ fractions (48). By comparing the influence of $\angle A(2, C=C$ bonds) and $A A(4 C=C$ bonds) on the metabolic activation of HCA, we wanted to investigate whether this effect could be observed in HCA-7 cells. However, although $1 \mathrm{HCA}-7$ cells have been investigated and characterized extensively (49-51), it was unknown whether these cells have the capacity to convert LA into AA in witro. Figure 4 shows the effect of LA vs. AA on the production of PGE 2 after 1 hour and after 24 hours. As can be seen, addition of LA led to an increase in PGE 2 production, with significantly higher levels after 24 hours as compared to after 1 hour, contrary to the equal levels resulting from AA exposure. Since LA is not a direct substrate for COX, these findings demonstrate that HCA-7 cells can convert LA into AA, eventually leading to the formation of $P G E_{2}$. Thus, addition of $L A$ is likely to result in a similar response as the addition of $A A$, although $P G E_{2}$ levels induced by $L A$ exposure were significantly lower as compared to AA exposure after both 1 hour and 24 hours. As a consequence, 
LA cannot be used to investigate the influence of the number of carbon double bonds on the metabolic activation of carcinogens in these cells.

The influence of AA and EPA on DNA adduct formation by $1 Q$ and PhP is shown in Figure 5. For $1 Q$, the adduct level was dosemdependently increased by addition of both $\mathrm{AA}$ and EPA up to concentrations of $60 \mu \mathrm{M}$ (Figure 5A). Similar results were found for PhIP up to concentrations of $20 \mu \mathrm{M}$, although the effect of EPA was clearly stronger as compared to AA (Figure $5 \mathrm{~B}$ ). These effects can be explained by the fact that the addition of fatty acids stimulates the expression of COX-2, thus generating more HCA metabolites in the co-oxidation process during the conversion of fatty acids to prostaglandins, eventually leading to an increase in adduct formation. However, when the cells were exposed $1080 \mu \mathrm{M}$ of AA or EPA. IQ-DNA adduct levels were found to decrease. Although these levels were determined in single experiments, the decline in adduct level was obwious for both fatty acids. For PhIP, this inverting effect was already found after exposure to $60 \mu \mathrm{M}$ of either fatty acid. These latter results are in agreement with those found in most animal studies, where fatty acids showed a decreasing effect on HCA adduct formation (24-27). Several possible explanations have been suggested by other investigators, that may also apply to the results reported here. Hayatsu et al. suggested a limitation in cellular HCA uptake due to the presence of high concentrations of fatty acids, leading to the formation of micelles entrapping the HCA molecules (29). Another interesting explanation was provided by Corey et al., who described inhibition of COX activity by EPA (39). In our study, this would then also apply to AA. Altematively, in the presence of such high concentrations of PUFA, it could be hypothesized that HCA radical metabolites are scavenged by PUFA molecules before binding covalently to DNA. Next to interference in COX-mediated pathways, decrease in HCA-DNA adduct formation may also be due to interactions between PUFA and cytochrome P450 enzymes. Josyula and Schut suggested that $n-3$ fatty acids may affect the synthesis or catalytic activity of cytochromes P450 1A1 and 1A2 (27). Furthermore, various studies described the possible modulation of several cytochromes P450 by dietary fish oil, although specific effects on isoforms $1 A 1$ and $1 A 2$ remain unknown $(52,53)$. Finally, competition between the fatty acids and HCA for the same site of the cytochrome P450 enzyme can be ruled out, as demonstrated by Hô et al. (54).

In a previous study, we demonstrated that HCA can be metabolized in vitro via CYP1A2and COX-mediated pathways, both resulting in the formation of DNA adducts (3). In the present study, exposure of HCA-7 cells to both PhIP and IQ was firstly found to result in the formation of adducis. Furthermore, different selective enzyme inhibitors were used to investigate specific metabolic routes in these cells. Figure 6 shows the inhibiling effect of IM on the formation of DNA adducts by both PhIP and IQ. For PhIP, adduct levels decreased to approximately $20 \%$ of the control level after incubation with $300 \mu \mathrm{M} I \mathrm{M}$, while addition of $600 \mu \mathrm{M}$ showed no further decreasing effect. This could indicate that the remaining adducts are formed by cytochrome $P 450$ catalyzed pathways, or that the inhibiting effect of $I M$ may not be strong enough to totally inhibit the COX activity in these cells. In contrast, $300 \mu M$ of $I M$ did not effect the IQ adduct level. Although the highest IM concentration significantly reduced the adduct level, the effect was clearly less pronounced as compared to the effect on PhIP adduct formation.

NS-398 was used to inhibit COX-2, as this non-steroidal anti-inflammatory drug (NSAID) is reported to be highly specific for this COX isoform (55). For CYP1A2 inhibition we used PEITC, an isothiocyanate naturally occurring in cruciferous vegetables (56). As shown in Figure 7, both NS-398 and PEITC inhibited DNA adduct formation by HCA in a dose dependent manner, although for $1 \mathrm{Q}$ only $2.5 \mathrm{\mu M}$ PEITC led to a statistically significant decrease. When both inhibitors were used simultaneously, decreases in adduct levels were significantly different from control levels for all combinations tested ( $P$ $<0.05)$. Although the exact cytochrome P450 isozyme activities for HCA-7 cells are not 
known, these results indicate that the cells contain both CYP1A2 and COX-2 enzyme activity. However, cytochrome P450 activity in these cells may not be limited to isoform CYP1A2, since PEITC is also known to inhibit CYP1A1 activity (57). Furthermore, PhIP is known to be converted to the N-hydroxy derivative by both CYPTA2 and CYP1A1 (5861). Remarkably, inhibition of DNA adduct formation by IM (Figure 6) was scarcely stronger as compared to inhibition by NS-398. This indicates involvement of mainly COX-2 and not COX-1, although involvement of the latter isoform cannot be ruled oul completely. Similar findings were described by Wiese et al. who found that metabolic activation of PhIP by COX-2 was clearly stronger as compared to COX-1, indicating a difference in substrate specificity (62). Furthermore, in that study the activation of $1 Q$ by COX was found to be very minimal, while in our study a decrease in $I Q$ activation by addition of a selective COX-2 inhibitor appeared to be measured, although not statistically significant. Interestingly, Zhang et al. found anti-proifferative effects of NS398 in embryo fibroblasts without any expression of $\mathrm{COX}-1$ and $\mathrm{COX}-2$, demonstrating a COX-independent mechanism of action for NS-398 (45). In agreement with these findings, Smith et al. suggested that NS-398 can exert anti-proliferative effects via both COX-2-dependent and-independent pathways in human colorectal cancer cells (44). while Elder et al. demonstrated COX-2-independent induction of apoptosis by NS-398 in different human colorectal cancer cell lines (63). However, the exact COX-2-independent mechanism of action of NS-398 remains unknown. Overall Figures 6 and 7 show that the effects of the inhibitors were stronger for $\mathrm{Ph} P \mathrm{P}$ than for IQ. This could be due to the fact that $I Q$ has a greater DNA adduct forming capacity as compared to PhIP (3), thus. being relatively less sensitive for partial inhibition of either enzymatic pathway.

In summary, our present findings in HCA-7 cells for the first time show that these cells are capable of converting the essential fatty acid LA into AA, a precursor for many biologically active compounds. Next to high concentrations of endogenously produced $P G E_{2}$, adldition of $A A$ led to a further increase in $P G E_{2}$ production, while inhibition of $\mathrm{PGE}_{2}$ production by EPA showed that this $n-3$ fatty acid competes with $A$ A for the COX enzyme.

Furthermore, we demonstrated that both $I Q$ and PhIP can readily form DNA adducts in these cells, while inhibition of adduct formation by specific enzyme inhibitors demonstrated the involvement of both COX-2 and CYP450 in the metabolic activation of the two HCA. Finally, simultaneous exposure to PUFA and HCA led to an increase of HCA-DNA adduct formation, an effect that was reduced by high concentrations of PUFA. Remarkably, no opposite effects were found for $n-3$ versus $n-6$ fatty acids in this perspective. In general, COX-catalyzed pathways can play an important role in the metabolic activation of xenobiotics like HCA, especially in extrahepatic tissues such as the colon. This might explain the decreased CRC risk that has been demonstrated after use of the NSAID aspirin, which is a COX inhibitor (64). Furthermore, one might speculate that the interaction between PUFA and HCA also applies in vivo and may therefore influence the risk for development of colorectall cancer.

\section{References}

1. Skog, K, Augustsson, K., Steineck, G., Stenberg. M., Jagerstad, M. (1997) Polar and nonpolar heterocyclic amines in cooked fish and meat products and their corresponding pan residues. Fo Chem Toxico 35,555-565.

2. Skog, K.I., Johansson, M.A., Jagerstad, M.I. (1998) Carcinogenic heterocycilc amines in model systems and cooked foods: a review on formation. occurence and intake. Fd Chem Toxicol 36. $879-896$. 
3. Moonen, H.J.J., Briedé, J.J. Van Maanen, J.M.S., Keinjans, J C.S., De Kok, T.M.C.M. (2002) Generation of free radicals and induction of DNA adducts by activation of heterocyclic aromatic amines via different metabolic pathways in vitro. Mol Carcinog 35, 196-203.

4. Wolz, E., Wild, D., Degen, G.H. (1995) Prostaglandin-H synthase mediated metabolism and mutagenic activation of 2-amino-3-methyl-imidazo[4,5-f]quinoline (\|Q). Arch Toxicol 69, 171179.

5. Innis, S.M. (1994) Essential dietary dipids. In: Ziegler. E.E. Filer, L.J. Jr. (eds.) Present knowledge in nutrition. ILSI Press, Washington DC, pp. 58-66.

6. Gurr, M. (1993) Fats. In: Garrow, J.S., James, W.P.T. (eds.) Human nutrition and dietotics Churchill Livingstone, London, pp. 77-102.

7. Wynder, E.L., Kajitani, T. Ishikawa, S., Dodo, H. Takano, A. (1969) Environmental factors of cancer of colon and rectum II. Japanese epidemiologicall data. Cancer (Phila.) 23, 1210-1220.

8. Miller, A.B., Howe, G.R. Jain, M. (1983) Food items and food groups as risk factors in a casecontrol study of diet and colon cancer. Int J Cancer $32,155-162$.

9. Giovannucci, E., Willett, W.C. (1994) Dietary factors and risk of colon cancer. Am Med 26. $443-452$.

10. Dommels, Y.E.M., Alink, G.M., van Bladeren, P.J., van Ominen, B. (2002) Dietary n-6 and n-3 fatty acids and colorectal carcinogenesis: results from cultured colon cells, animal models and human studies. Enwiron Toxicol Pharmacol 12, 233-244

11. Blot, W.J., Lanier, A., Fraumeni, J.F. Jr., Bender, T.R. (1975) Cancer mortality among Alaskan natives, 1960-69. I Natl Cancer inst 55, 546-554.

12. Lee, J.A. (1976) Recent trends of large bowel cancer in Japan compared to United States and England and Wales. Int J Epidemiol 5, 187-194.

13. Reddy, B.S., Burill, C. Rigotty, J. (1991) Effects of diets high in and 3 and acids on initiation and postinitiation stages of colon carcinogenesis. Cancer Res 51, 487-491.

14. Oshima, M., Takahashi, M. Oshima, H., Tsutsumi, M. Yazawa, K., Sugimura, T., Nishimura, S., Wakabayashi, K., Taketo, M.M. (1995) Effects of docasahexaenoic acid (DHA) on intestinal polyp development in Apc ${ }^{4716}$ knockout mice. Carcinogenesis 16, 2605-2607.

15. Takahashi, M. Fukutake, M., Isoi, T., Fukuda, K., Sato, H., Yazawa, K, Sugimura, T., Wakabayashi, K. (1997) Suppression of azoxymethane-induced rat colon carcinoma development by a fish oil component, docosahexaenoic acid (DHA). Carcinogenesis 18, 13371342.

16. Tapiero, H., Nguyen Bia, G., Couvreur, P., Tew, K.D. (2002) Polyunsaturated fatty acids (PUFA) and eicosanoids in human health and pathologies. Biomed Pharmacofher 56, 215222.

17. Fischer, S.M. (1997) Prostaglandins and cancer. Frontiers in Bioscience 2, 482-500.

18. Sheng, H., Shao, J., Morrow, J.D., Beauchamp, R.D., DuBois, R.N. (1998) Modulation of apoptosis and Bel-2 expression by prostaglandin $\mathrm{E}_{2}$ in human colon cancer cells. Cancer Res $58,362-366$

19. Sheng. H., Shao, J., Washington, M.K., DuBois, R.N. (2001) Prostaglandin $E_{2}$ increases growth and motility of colorectal carcinoma cells. J Biol Chem 276, 18075-18081.

20. Mutoh, M. Watanabe, K., Kitamura, T., Shoji, Y., Takahashi, M., Kawamori, T. Teani, K., Kobayashi, M., Maruyama, T., Kobayashi, K. Ohuchida, S., Sugimoto, Y., Narumiya, S., Sugimura, T., Wakabayashi, K. (2002) Involvement of prostaglandin E receptor subtype EP in colon carcinogenesis. Cancer Res 62, 28-32.

21. Kargman, S.L., ONeill, G.P., Vickers, P.J., Evans, J.F., Mancini, J.A., Jothy, S. (1995) Expression of prostaglandin $\mathrm{G} / \mathrm{H}$ synthase-1 and -2 protein in human colon cancer. Cancer Res 55, 2556-2559.

22. Sano, H. Kawahito, Y., Willder, R.L., Hashiramoto, A. Mukai, S., Asai, K., Kimura, S., Kato, H., Kondo, M. Hla, T. (1995) Expression of cyclooxygenase-1 and -2 in human colorectal cancer. Cancer Res 55, 3785-3789.

23. DuBois, R.N. Radhika, A., Reddy, B.S., Entingh, A.J. (1996) Increased cyclooxygenase-2 levels in carcinogen-induced rat colonic tumors. Gastroenterology $410,1259-1262$.

24. Schut, H.A.J. (1994) Dietary moduliation of DNA adduct formation of the food mutagen 2amino-3-methyl-imidazo[4,5-f]quinoline in the male Fischer 344 rat. Environ Health Persp $102 s 6,57-60$.

25. Schut, H.A.J., Cummings, D.A., Smale, M.H. Josyula, S. Friesen, M.D. (1997) DNA adducts of heterocyclic amines: formation, removall and inhibition by dietary components. Mut Ries 376 . $185-194$. 
26. Schutt, H.A.J., Wang, C-L., Twining. L.M. Earle, K.M. (1997) Formation and persistence of DNA adducts of 2-amino-3-methy-imidazo[4.5-ffquinoline (IQ) in CDF1 mice fed a high wa 3 fatty acid diet. Mut Res 378, 23-30.

27. Josyula. S. Schut, H.A.J. (1999) Dietary omegam 3 fatty acids as potential inhibitors of carcinogenesis: effect on DNA adduct formation of 2-amino-1-methyl-6-phenylimidazo[4,5blpyridine (PhIP) in mice and rats. Fol Chem Toxic 37, 287-296.

28. Hayatsu, H., Arimolo, S., Togawa, K. Makita, M. (1981) Inhibitor of the ether extracts of human feces on activities of mutagens: inhibition by oleic and linoleic acids. Mut Res 81, 287293.

29. Hayatsu, H. Arimoto, S., Negishi, T. (1988) Dietary inhibitors of mutagenesis and carcinogenesis: Mut Res 202, $429-446$.

30. Ho, T.A., Coutts, T.M., Rowland, IR., Alldrick, A.J. (4992) Inhibition of the metabolism of mutagens occurring in food by arachidonic acid. Mut Res $269,279-284$.

31. Kupfer, D. (1982) Endogeneous substrates of monooxygenases: fatty acids and prostaglandins. In: Schenkman, J.B., Kupfer, D. (eds.) Hepatic cytochrome P450 monooxygenase system. Pergamon Press, Oxford, UK, pp. 157-187.

32. Bylund, J., Kunz. T. Valmsen, K., Oliw, E.H. (1998) Cytochiromes P450 with bisallylic hydroxylation activity on arachidonic and linoleic acids studied with human recombinant enzymes and with human and rat liver microsomes. $J$ Phamacol Exp Ther 284, 51-60.

33. Mitchell. D.B., Santone, K.S., Acosta, D. (1980) Evaluation of cytotoxicity in cultured cells by enzyme leakage. J Tissue Cult Methods 6, 113 116.

34. Mosmann, T. (1983) Rapid colorimetric assay for cellular growth and survival: application to proliferation and cytotoxicity assays. J Immunol Methods 65, 55-63.

35. Randerath, E. Agrawall, H.P., Weaver, J.A., Bordelon, C.B., Randerath, K. (1985) ${ }^{32}$ Ppostlabeling analysis of DNA adducts persisting for up to 42 weeks in the skin, epidermis and dermis of mice treated topically with 7,12-dimethylbenz[a]anthracene. Carcinogenesis 6,1117 1126.

36. De Kok, T.M.C.M., Moonen, H.J.J., van Delft, J., van Schooten, F.J. (2002) Methodologies for DNA adduct analysis and biomonitoring of environmental and occupational exposures. J Chrom $B 778,345-354$.

37. Reichert, W.L., Stein, J.E., French, B.E., Goodwin, P., Varanasi, U. (1992) Storage phosphor imaging technique for detection and quantitation of DNA adducts measured by the ${ }^{32} \mathrm{P}$ postlabeling assay. Carcinogenesis 13, $1474-1479$.

38. Croft, K.D., Beilin, L.J., Vandongen, R., Metews, S.E. (1984) Dietary modification of fatty acid and prostaglandin biosynthesis in the rat. Effect of variations in the level of dielary fat. Biochim Biophys Acta 795, 196-207.

39. Corey. E.J., Chih, C., Cashman, J.R. (1984) Docosahexaenoic acid is a strong inhibitor of prostaglandin but not leukotriene biosynthesis. Proc Natl Acad Sci USA 80, 3581-3584.

40. Needleman, P., Raz, A. Minkes, M.S., Ferrendelli, J.A. Sprecher, H. (1979) Triene prostaglandins: prostacyclin and thromboxane biosynthesis and unicque biological properties. Proc Nall Acad Sci USA 76, 944-948.

41. Lands, W.E., Le Tiellier, P.E., Rome, L.H., Vanderhoek. J.Y. (1973) Inhibition of prostaglandin biosynthesis. Adw Bioscience 9, 15-28.

42. Singh, J. Hamid, R., Reddy. B.S. (1997) Dietary fat and colon cancer: modulation of cyclooxygenase -2 by types and amount of dietary fat during the postinitiation stage of colon carcinogenesis. Cancer Res 57, 3465-3470.

43. Coffey, R.J., Hawkey, C.J., Damstrup, L., Graves-Deal, R., Daniel, V.C.. Dempsey, P.J., Chinery, R., Kirkland, S.C., DuBois, R.N., Jetton, T.L., Morrow, J.D. (1997) Epidermal growth factor receptor activation induces nuclear targeting of cyclooxygenase-2, basolateral release of prostaglandins, and mitogenesis in polarizing colon cancer cells. Proc Nall Acad Sci 94, $657-662$.

44. Smith, M.-L.. Hawcroft, G. Hull, M.A. (2000) The effect of non-steroidal anti-inflammatory drugs on human colorectal cancer cells: evidence of different mechanisms of action. Eur $J$ Cancer $36,664-674$.

45. Zhang, X., Morham, S.G., Langenbach, R., Young, D.A. (1999). Malignant transformation and anti-neoplastic actions of nonsteroidal anti-inflammatory drugs (NSAIDs) on cyclooxygenasenull embryo fibroblasts. J Exp Med 190, 451-459. 
46. Lehmann, J.M., Lenhard, J.M., Oliver, B.B., Ringold, G.M., Kliewer, S.A. (1997). Peroxisome proliferator-actiwated receptors $\alpha$ and $\gamma$ are activated by indomethacin and oher non-steroidal anti-inflammatory drugs. J Biol Chem 272, 3406-3410

47. Brockman, J.A. Gupta, R.A. DuBois, R.N. (1998). Activation of PPARy leads to inhibition of anchorage-independent growth of human colorectal cancer cells. Gastroenterology 115.1049 1055.

48. Nemoto, N.. Takayama, S. (1983) Effects of unsaturated fatty acids on metabolism of benzo(a)pyrene in an NADPH-fortified rat liver microsomal system. Carcinogenesis 4, 12531257.

49. Kirkland, S.C. (1985) Dome fromation by a human colonic adenocarcinoma cell line (HCA-7). Cancer Res 45, 3790-3795.

50. Henderson, R.M. Ashford, M.L., MacVinish, L.J, Cuthbert, A.W. (1992) Chloride channels and anion fluxes in a human colonic epithelium (HCA-7). Br J Pharmacol 106, 109-114.

51. Kirkland, S.C., Henderson, K., Liu, D., Pignatelli, M. (1995) Organisation and gel contraction by human colonic carcinoma (HCA-7) sublines grown in 3-dimensional collagen gel Int $J$ Cancer 60, 877-882.

52. Anderson, K.E., Kappas, A. (1991) Dietary regulation of cytochrome P450. Ann Rev Nutrit 11. $141-167$.

53. Yang, C.S., Brady, J.F., Hong, J.-Y. (1992) Dietary effects on cytochromes P450 xenobiotic metabolism and toxicity. FASEB $/ 6,737-744$.

54. Hô, T.A., Alldrick, A.J., Rowland, I.R. (1992) Effect in vitro of arachidonic acid, eicosapentaenoic acid and docosahexaenoic acid on the hepatic activation of dietary genotoxins by rat post-mitochondrial fractions. Fa Chem Toxio 30, 853-858.

55. O'Neill, G.P., Kennedy, B.P., Mancini, J.A., Kargman, S., Ouellet, M., Yergey, J., Falgueyret, J.P. Cromlish. W.A. Payette, P., Chan" C.C. et al. (1995) Selective inhibitors of COX-2. Agents Actions Suppl 46, 159-168.

56. Diana, G.C., Daxenbichler, M.E., Van Etten, C.H., Kwolek, W.F., Williams, P.H. (1987) Glucosinolates in cruciferous vegetables: broccoli, Brussels sprouts, cauliflower, collards, kale, mustard green and kohirabi. I Am Soc Hort Sci 112.173-178.

57. Thapliyal, R., Maru, G.B. (2001) Inhibition of cytochrome P450 isozymes by curcumins in vitro and in vivo. Fd Chem Toxic 39, 54\%-547.

58. Holme, J.A., Wallin, H., Brunborg, G., Søderlund, E.J., Hongslo, J.K., Alexander, J. (1989) Genotoxicity of the food mulagen 2-amino-1-methyl-6-phenylimidazo[4,5-b]pyridine (PhIP): formation of 2-hydroxamino-PhIP, a directly acting genotoxic metabolite. Carcinogenesis 10 , 13.89-1396.

59. Buonarati "M.H., Felton, J.S. (1990) Activation of 2-amino-1-methyl-6-phenylimidazo[4,5b]pyridine (PhIP) to mutagenic metabolites. Carcinogenesis 11, 1133-1138

60. Turteltaub, K.W., Knize, M.G., Buonarati, M.H. McManus, M.E., Veronese, M.E., Mazrimas, J.A., Felton, J.S. (1990) Metabolism of 2-amino-1-methyi-6-phenylimidazo[4,5-b]pyridine (PhIP) by liver microsomes and isolated rabbit cytochrome P450 isozymas. Carcinogenesis $11,941-946$.

61. Shimada, T., Guengerich, F.P. (1991) Activation of amimo-a-carboline, 2-amino-1-methyl-6phenylimidazo[4,5-b]pyridine, and a copper phthalocyanine cellulose extract of cigarette smoke condensate by cytochrome P450 enzymes in rat and human liver microsomes. Cancer Res 51, 5284-5291.

62. Wiese, F.W. Thompson, P.A. Kadlubar, F.F. (2001) Carcinogen substrate specificity of human COX-1 and COX-2. Carcinogenesis 21, 5 10.

63. Elder, D.J.E., Halton, D.E., Hague, A., Paraskeva, C. (1997) Induction of apoptotic cell death in human colorectal carcinoma cell lines by a cyclooxygenase-2 (COX-2)-selective nonsteroidal anti-inflammatory drug: independence from COX-2 protein expression. Clin Cancar Res 3.1679-1683.

64. Heath, C.W. Thun, M.J., Greenberg, E.R., Levin, B., Mameth, L.J. (1994) Nonsteroidal antiinflammatory drugs and human cancer. Cancer $74,2885-2888$ 


\title{
CYP1A2 and NAT2 \\ genotype/phenotype relations and urinary excretion of 2-amino-1- methyl-6-phenyl-imidazo- $[4,5-b]$ pyridine (PhIP) in a human dietary intervention study
}

\author{
Harald J.J. Moonen \\ Edwin J.C. Moonen \\ Lou Maas \\ Jos C.S. Kleinjans \\ Theo M.C.M. de Kok
}




\begin{abstract}
Heating of protein-rich food like meat results in the formation of a class of food mutagens calted heterocyclic aromatic amines (HCA), which are metabolically activated by cytochrome P4501A2 (CYP1A2) and N-acetyltransferase 2 (NAT2). Respective genes encoding for these enzymes, display polymorphic distribution in the human population and are thus believed to cause interindividual differences in cancer risk susceptibility. The present study investigated genotype/phenotype correlations for both CYP1A2 and NAT2. Furthermore, the influence of dietary exposure and CYP1A2 and NAT2 genotypes and phenotypes on urinary PhIP excretion levels was examined in 71 human volunteers. The subjects were exposed to a PhIP containing diet, and urinary PhIP concentrations were measured by means of GC-MS. The CYP1A2-164A $\rightarrow C$ polymorphism (CYPIA2*1F) and the NAT2 genotype were determined using PCR-RFLP. For NAT2, genotypes were divided into two categories (fast or slow). Subjects were phenotyped for both CYP1A2 and NAT2 by HPLC analysis of urinary caffeine metabolites.

Urinary PhIP excretion levels were found to reflect recent dietary exposure levels in human volunteers. Urinary caffeime metabolite ratios were significantly different between the wa NAT2 genotypes, whereas for CYP1A2, the apparent difference in metabolic ratios between the genotypes was statistically non-significant. For the first time, significant correlations were found between the CYP1A2*1F polymorphism and urinary PhIP excretion levels. This indicates that slow oxidizers excrete relatively high amounts of urinary PhIP as compared to fast oxidizers, implying that the latter group may be at higher risk for genotoxic damage due to higher doses of reactive PhIP metabolites in the systemic circulation. These results indicate that the CYP1A2*1F polymorphism could play a role in human cancer risk susceptibility.
\end{abstract}




\section{Introduction}

Diet represents a substantial part of all environmental conditions to which humans are exposed daily. Moreover, dietary exposure to mutagenic agents is believed to play a major role in the initiation process of carcinogenesis at various target sites in the human body, including the colon $(1,2)$. Part of this mutagenic exposure is due to the fact that humans prepare their food at high temperatures prior to consumption. During the cooking process, numerous compounds can be formed, some of which are genotoxic. In 1977. Sugimura and co-workers described the occurrence of strongly mutagenic compounds in cooked meat and fish, leading to the discovery of a class of compounds nowadays known as heterocyclic aromatic amines (HCA) (3). So far, nineteen different HCA have been identified, with 2-amino-1-methyl-6-phenylimidazo[4,5-b]pyridine (PhIP) being most abundantly present in cooked meat $(4,5)$. To exert their ultimate mutagenic/carcinogenic properties, HCA have to be metabolically activated, which can proceed via different pathways (6). In relation to colon carcinogenesis, the main steps in the metabolic activation of HCA via the hepatic pathway are $N$-hydroxylation and $O$ acetylation, catalyzed by cytochrome P4501A2 (CYP1A2) and N-acetyltransferase 2 (NAT2), respectively (7). HCA have proven to be poor substrates for direct $N$-acetylation by NAT2 (8). Multiple genes encoding for biotransformation enzymes such as CYP1A2 and NAT2, display polymorphic distribution in the human population and these enzyme activities are therefore liable to interindividual variation, leading to a specific metabolizing capacity profile for each person. Also, urinary excretion of unmetabolized PhIP may reflect these interindividual differences in HCA metabolism, as described earlier in other studies (9-11). In general, it is assumed that, as a consequence of these interindividual differences in biaactivating carcinogens, genetic polymorphisms cause variations in cancer risk susceptibility between individuals. Furthermore, while NAT2 activity is expressed constitutively (12), the activity of CYP1A2 is inducible by environmental factors, including the diet $(13,14)$. With respect to NAT2, subjects can be designated either 'slow' or 'fast' acetylators, depending on their ability to acetylate many different kinds of substrates, including HCA.

For CYP1A2, several polymorphisms in the encoding gene have been described $(15-17)$. The $-164 \mathrm{~A} \rightarrow \mathrm{C}$ polymorphism ( $\mathrm{CYP} 1 \mathrm{~A} 2^{*} \mathrm{AF}$ ) is one of the most common in Caucasians and can be used in the routine assessment of the CYP1A2 genotype (18). Moreover, this pollymorphism appears to be associated with differences in the inducibility of CYP1A2 (17). However, it has to be noted that, in general, solely genotyping cannot be used to predict enzymatic activities (i.e. phenotypes). In this respect it is of relevance that both high CYP1A2 activity and high NAT2 activity have been associated with a higher risk for developing colon cancer in humans $(12,19)$. Moreover, thigh CYP1A2/NAT2 activities were found to correlate with an elevated CRC risk in individuals preferring well-done meat $(20,21)$.

Therefore, in this study we investigated the correspondence between genotypes and phenotypic activities for CYP1A2 and NAT2. For this, CYP1A2 and NAT2 phenolypes were determined by caffeine administration, which provides valid estimates of the enzyme activities (22). Next, we exposed humain volunteers to a PhIP containing diet and assessed urinary PhIP excretion as a function of CYP1A2 and NAT2 genotypes and phenotypes and dietary exposure. Since HCA are far better substrates for CYP1A2 than for NAT2, we hypothesize that interindividual variations in HCA metabolism are dominated by the CYP1A2 genotype/phenotype rather than by the NAT2 genotype/phenotype. 


\section{Materials and methods}

\section{Chemicals and enzymes}

2-amino-1-methyl-6-phenylimidazo[4,5-b]pyridine (PhIP) and $\left[{ }^{2} \mathrm{H}_{3}\right] \mathrm{PhIP}$ were purchased from Toronto Research Chemicals (Downsview, Ontario, Canada). Heptafluorobutyric acid anhydride (HFBAA) was from Supelco (Bellefonte, PA, USA); 1-methy-3-nitro-1nitrosoguanidine (MNNG) from Aldrich (Steinheim, Germany). Biglucuronidaselarylsulfatase was purchased from Boehringer-Mannheim (Indianapolis, UN, USA). Extrelut 20 columns and Extrelut refill material were from Merck (Darmstadt, Germany). Bond-Elut propylsulfonic acid (PRS) cartridges $(500 \mathrm{mg})$ and Bond-Elut $\mathrm{C}_{18}$ cartridges $(100 \mathrm{mg})$ were obtained from Varian (Harbor City, CA, USA). Taq polymerase was from Amersham (Braunschweig, Germany). 1-Methyluric acid (1U), 1-methylxanthine (1X). 1,7-dimethyluric acid (17U) and $\mathrm{N}$-acetaminophen were from Sigma (St. Louis, MO, USA). 5-Acetylamino-6-formylamino-3-methyluracil (AFMU) was a gift from Dr. R. Fumeaux, Nestlé Research Center, Lausanne, Switzerland. Other chemicals were of HPLC - or analytical grade.

\section{Protocol}

7 t healthy, non-smoking, female volunteers participated in this study. Ages ranged from 17 to 34 years. Participants were asked to consume a daily portion of $140 \mathrm{~g}$ of chicken for 10 consecutive days instead of their habitual lunch, while further maintaining their normal dietary habits. Subjects were assigned at random to either the high dose group ( $\mathrm{n}$ $=35$ ) or low dose group $(n=36) .24$ hr urine samples were collected 4 days before and 7 days after the intervention period, while during this period, $24 \mathrm{hr}$ urine samples were collected at all 10 days; the volumes were recorded and samples were stored at $-20^{\circ} \mathrm{C}$. Blood samples were collected from each individual for genotyping purposes. All participants gave their informed consent after being informed on the study aim and instructed about the procedure. This study was approved by the Medical Ethical Committee of the Academic Hospital in Maastricht.

\section{Preparation of meat}

Before frying, the boneless and skinless chicken breasts, purchased in one batch from a local supermarket, were cut into small pieces. Since two different dases of PhlP were to be compared in the intervention, two different cooking procedures were applied. For the low dose samples, meat was panfried at $200^{\circ} \mathrm{C}$, just until done. For the high dose group, after panfrying, the meat was oven-broiled at $250^{\circ} \mathrm{C}$ for $16 \mathrm{~min}$.

\section{Extraction of HCA from prepared meat samples}

Prepared meat samples were extracted and analysed by HPLC using the procedure described by Gross and Gruter (23) with minor modifications (24). Briefly, 3.5-g samples were homogenized in $1 \mathrm{M} \mathrm{NaOH}$ and mixed with Extrelut diatomaceous earth to fill an Extrelut 20 column. The HCA were eluted with $40 \mathrm{ml} 5 \%$ toluene in dichloromethane onto coupled Bond-Elut PRS columns. The PRS cartridges were washed with $6 \mathrm{ml} 0.1 \mathrm{~N}$ $\mathrm{HCl}, 15 \mathrm{ml} 40 \%$ methanol in $0.1 \mathrm{~N} \mathrm{HCl}$ to remove apolar heterocyclic amines, and $2 \mathrm{ml}$ water; then the PRS cartridges were coupled to Bond-Elut $C_{18}$ cartridges. The HCA were transfierred to the $\mathrm{C}_{18}$ cartridges with $20 \mathrm{ml}$ ammonium acetate $(0.5 \mathrm{M}, \mathrm{pH} 8.0)$, and the $\mathrm{C}_{18}$ columns were subsequently eluted with $10 \%$ ammonia in methanol. The eluate was evaporated to dryness at $50^{\circ} \mathrm{C}$ under $\mathrm{N}_{2}$, dissolved in $200 \mu /$ methanol and transferred to autosampler vials with inserts. 
HPLC

HPLC separation of the HCA was performed as described by Gross and Griter (23), on a TSK gel ODS80-TM column (TosaHaas, Montgomeryville, PA, USA, $220 \mathrm{~mm} \times 4.6 \mathrm{~mm}$ i.d.) with a mobile phase of $0.01 \mathrm{M}$ triethylamine phosphate (TEAP. $\mathrm{pH} 3.6)($ solvent $\mathrm{A}$ ) and acetonitrile (solvent $B$ ). A linear gradient $(5-15 \% \mathrm{~B}$ from $0-10 \mathrm{~min} ; 15-25 \% \mathrm{~B}$ from $10-20 \mathrm{~min} ; 25-55 \% \mathrm{~B}$ from $20-30 \mathrm{~min}$ ) was used at a flow rate of $1 \mathrm{~m} / \mathrm{mmin}$. Samples were analysed on a Gynkotek P580A HPLC system (Supelco. Bellefonte, PA. USA) with a Spark SP830 autosampler (Spark Holland. Emmen, The Netherlands) and a Perkin EImer LS-30 programmable fluorescence detector (Perkin Elmer, Foster Cily, CA. USA). Excitation/emission wavelengths were $315 / 390 \mathrm{~nm}$ for PhIP. For quantification, the standard addition method was used, taking incomplete analyte recovery into account. The different HCA were identified based on retention times.

\section{Enzymatic hydrolysis of urine}

Urine samples were allowed to thaw at room temperature. After mixing, a $5 \mathrm{ml}$ alliquot was transferred to a glass tube and $200 \mathrm{pg}$ of [ $\left.^{2} \mathrm{H}_{3}\right] \mathrm{PhIP}$ internal standard, dissolved in $100 \mu \mathrm{l}$ of methanol, was added. After addition of $3 \mathrm{ml}$ of $1 \mathrm{M}$ acetate buffer $(\mathrm{pH} \mathrm{4.9}), 20$ $\mu l$ of enzyme mix, consisting of $\beta$-gllucuronidase $(2000 \mathrm{U})$ and arylsulfatase $(16000 \mathrm{U})$. was added to the mixture. For hydrolysis, $\mathrm{pH}$ was adjusted to $4.9-5.1$ with $1 \mathrm{M} \mathrm{HCl}$ and samples were incubated at $37^{\circ} \mathrm{C}$ avernight.

\section{Extraction of PhlP from urine}

The extraction method was adapted from Lynch et al. (9). The hydrolysates were neutralized with $2.5 \mathrm{ml}$ of $1 \mathrm{M}$ sodium carbonate and subsequently extracted twice with 5 $\mathrm{ml}$ of ethyl acetate. The combined organic layers were evaporated to dryness at $40^{\circ} \mathrm{C}$ under $\mathrm{N}_{2}$ and the residues were dissolved in $200 \mu \mathrm{l}$ of $0.1 \mathrm{M} \mathrm{HCl}$. After extraction with 2 $\times 750 \mu \mathrm{l}$ hexane, the aqueous phase was made alkaline with $100 \mu \mathrm{l}$ of $1 \mathrm{M}$ sodium carbonate and extracted with $2 \times 750 \mu$ l ethyl acetate. The combined organic extract was again evaporated to dryness at $40^{\circ} \mathrm{C}$ under a stream of $\mathrm{N}_{2}$.

\section{Derivatization procedure}

Derivatization procedures were adapted from Reistad et al. (10). The dried samples were dissolved in $100 \mu$ lethyl acetate, which had been dried over calcium hydricle In order to derivatize the extracted HCA, $30 \mu \|$ of freshly made trimethylamine- $\mathrm{HCl}$ (TMA) and $30 \mu \mathrm{l}$ of HFBAA were added and after $1 \mathrm{hr}$ at $40^{\circ} \mathrm{C}$ the samples were dried at $40^{\circ} \mathrm{C}$ under $\mathrm{N}_{2}$ and the residue was dissolved in $100 \mu$ li ethyl acetate. which had been dried over calcium hydride. The acelylated HCA were subsequently $N$-methylated by addition of $200 \mu$ of freshly made diazomethane, which was repeated after 30 min. Diazomethane was generated from MNNG by dissolving it in $1 \mathrm{ml}$ of distilled water and $5 \mathrm{ml}$ of hexane and adding $1 \mathrm{ml}$ of $5 \mathrm{M} \mathrm{NaOH}$ dropwise. The methylated samples were left at room temperature overnight.

\section{Analysis of urinary PhIP by GCMS}

The dried samples were dissolved in $300 \mu /$ isooctane and the solutions were transferred to a glass vial with insert. The volume was reduced to $10 \mu$ by evaporation under a stream of $\mathrm{N}_{2}$. For the analysis, $1 \mu$ of the isooctane solutions were splitlessly injected into a HP5890 Series II gas chromatograph (Hewlett-Packard, Portland, Oregon "USA), injector temperature $250^{\circ} \mathrm{C}$, using a $30 \mathrm{~m}$, i.d. $0.25 \mathrm{~mm}$, film thickness $0.25 \mu \mathrm{m} \mathrm{CP}$. Sil8CB-MS column (Varian. Harbor City, CA, USA). Helium was used as the carrier glas at a column head pressure of 20 p.s.t. The temperature of the $\mathrm{GC}$ oven was $200^{\circ} \mathrm{C}$ for $0.5 \mathrm{~min}$, then rising to $300^{\circ} \mathrm{C}$ at $20^{\circ} \mathrm{C} / \mathrm{min}$, where it was held for $2 \mathrm{~min}$. Under these conditions, the retention time for the HFBAA derivative of PhIP was $6.0 \mathrm{~min}$. 
The $\mathrm{GC}$ column ended inside the ion source of the double focussing mass spectrometer of reversed geometry (Jeol-SX102A, JEOL Ltd., Tokyo, Japan), which was operated in the electron ionization (El) mode, with an bonizing energy of $70 \mathrm{eV}$ and an ion source temperature of $220^{\circ} \mathrm{C}$, and set at a mass resolution of 10,000 . The base peaks (M$\left.\mathrm{C}_{3} \mathrm{~F}_{\mathrm{y}}\right)^{*}$ of PhIP $(\mathrm{m} / \mathrm{z}=265.1089)$ and $\left.\mathrm{I}^{2} \mathrm{H} \mathrm{B}\right] \mathrm{PhIP}(\mathrm{m} / \mathrm{z}=268.1277)$ were recorded by selective ion monitoring (SIM). The limit of detection for PhIP was approximately $5 \mathrm{pg} / \mathrm{ml}$.

\section{Genotyping}

The NAT2 genotyping procedure was adapted from the method described by Doll et al. (25). After proteinase $K$ digestion, genomic DNA was extracted from peripheral blood lymphocytes with phenol-chloroform and precipitated with cold ethanol. For NAT2 genotyping, approximately $0.5 \mu \mathrm{g}$ of DNA was amplified by polymerase chain reaction (PCR) in the presence of $0.5 \mu \mathrm{g}$ of each of the NAT2 specific primers 5 ATGGACATTGAAGCATATITTGAAAGAATT-3' and '5'-AAGGGTTTATTTTGTTCCTTATTCTAAAT-3, $0.2 \mathrm{mM}$ of each INTP, $1.1 \mathrm{U}$ of Taq polymerase and PCR buffer composed of $50 \mathrm{mM} \mathrm{KCl}, 1.5 \mathrm{mM} \mathrm{MgCl}_{2}$ and $10 \mathrm{mM} \mathrm{Tris-HCl}(\mathrm{pH} \mathrm{9.0)}$ in a total volume of $50 \mu \mathrm{l}$. A PTC-200 PCR system (MJ Research, Watertown, MA, USA) was used to denaturate the mixture at $94^{\circ} \mathrm{C}$ for $3 \mathrm{~min}$ and to subsequently subject it to 30 cycles of $94{ }^{\circ} \mathrm{C}$ for $0.5 \mathrm{~min}, 55^{\circ} \mathrm{C}$ for $1 \mathrm{~min}$ and $72{ }^{\circ} \mathrm{C}$ for $0.5 \mathrm{~min}$. Finally, incubation at $72^{\circ} \mathrm{C}$ for 5 min was performed for complete extension. An aliquot of $10 \mu$ of the $895-b p$ PCR product was then subjected to RFLP analysis. Nucleotide substitutions at ${ }^{191} A, A^{4344} C$ and $C^{4 A 11} T$ were detected by digestion with the restriction enzymes $M s p l(10 U)$ and $K p n l$ (10 U) at $37^{\circ} \mathrm{C}$ for $3 \mathrm{~h}$, nucleotide substitutions at $\mathrm{G}^{580} \mathrm{~A}$ and $\mathrm{G}^{857} \mathrm{~A}$ by digestion with Taql $(10 \mathrm{U})$ and $\mathrm{BamHI}(10 \mathrm{U})$ at $37^{\circ} \mathrm{C}$ for $3 \mathrm{~h}$ and then at $65{ }^{\circ} \mathrm{C}$ for $3 \mathrm{~h}$ (restriction enzymes from Promegla, Madison, WI, USA). DNA fragments were separated on a $5 \%$ acrylamide $(29: 1)$ gel by electrophoresis at $30 \mathrm{~V}$ for $16 \mathrm{~h}$. Following electrophoresis, the gel was stained with ethidium bromide and DNA fragments were visualized and photographed under UV light. Each individual was classified as a rapid acetylator when possessing 1 or 2 NAT2* 4 alleles or as a slow acetylator when possessing 2 NAT2*5, NAT $2^{*} 6$ or NAT2 ${ }^{*} 7$ alleles $(26,27)$.

For CYP1A2 genotyping, we used the method described by Christiansen et al. (28). Genomic DNA was amplified by PCR using the primers 5'-GGAAGGTATCAGCAGAAAGCC-3" and 5'-GGCTCATCCTTGACAGTGCC-3" to give a 626-bp product. The total volume of the PCR reaction mixture was $50 \mu$ and contained $100 \mathrm{ng}$ of genomic DNA, $0.8 \mu \mathrm{M}$ of both primers (Eurogentec, Seraing, Belgium), $1 \mathrm{U}$ of Platinum Taq Polymerase (Invitrogen, Groningen, The Netherlands), $0.2 \mathrm{mM}$ of each dNTP and PCR buffer consisting of $10 \mathrm{mM}$ Tris $-\mathrm{HCl}(\mathrm{pH} 9.0), 1.5 \mathrm{mM} \mathrm{MgCl}$ and $50 \mathrm{mM} \mathrm{KCl}$. The mixture was denaturated at $95^{\circ} \mathrm{C}$ for $5 \mathrm{~min}$, followed by 35 cycles of $94^{\circ} \mathrm{C}$ for $0.5 \mathrm{~min}, 62^{\circ} \mathrm{C}$ for 0.5 min and $72{ }^{\circ} \mathrm{C}$ for $0.5 \mathrm{~min}$, and a terminal extension at $72{ }^{\circ} \mathrm{C}$ for $10 \mathrm{~min}$. Following $P \mathrm{PR}_{\text {, }}$ the presence of the C/A polymorphism was detected by incubating a $20 \mu l$ aliquot of the PCR product with $1 \mathrm{U}$ of the restriction enzyme Apal (Roche Diagnostics, Mannheim, Germany) at $30^{\circ} \mathrm{C}$ for $1 \mathrm{~h}$, cleaving the C alleles into two fragments of 181 and $445 \mathrm{bp}$. The digestion products were electrophoresed at $100 \mathrm{~V}$ for $2 \mathrm{~h}$ in a $2 \%$ agarose gel containing ethidium bromide and visualised under UV light. Subjects were categorized into one of three possible genotypes: $\mathrm{A} / \mathrm{A}, \mathrm{C} / \mathrm{A}$ or $\mathrm{C} / \mathrm{C}(i . \mathrm{e}$, fast, intermediate or slow oxidizers, respectively).

\section{Phenoryping by caffeine administration}

Urinary caffeine metabolites were measured by a procedure described by Krul and Hageman (29), with minor modifications. The subjects refrained from the consumption of products containing methylxanthine for 48 hours before and for the duration of the test. After consumption of one cup of coffee containing approximately $95 \mathrm{mg}$ of caffeine, the 
Subjects collected a urine sample at $t=5 \mathrm{~h}$ which was immediately stored at $-20^{\circ} \mathrm{C}$ until analysis. For analysis, a $200 \mu$ aliquot (pH adjusted to 3.5 with $1 \mathrm{MHCl}$ ) was saturated with $120 \mathrm{mg}$ of ammonium sulphate and $200 \mu \mathrm{l}$ of the internal standard. N-acetaminophen (150 mg/l), was added. After extraction with $6 \mathrm{ml}$ of chloroform: isopropanol $(4: 1)$, the organic phase was removed, gently evaporated to dryness under $N_{2}$ at $40-45$ ${ }^{\circ} \mathrm{C}$ and resuspended in $1 \mathrm{ml}$ of $0.05 \%$ acetic acid. A $20 \mu$ volume of the sample was injected onto a Hypersil $5 \mu \mathrm{m}$ ODS MPLC collumn $(15 \mathrm{~cm} \times 4.6 \mathrm{~mm}$ i.d.) from Phase Separations (Deeside, UK), eluted with $33 \%$ acelic acidtetrahydrofuran:acetonitrile: milliQ-water $(1: 2.5: 44: 952.5, \mathrm{w} / \mathrm{v})$ at a flow rate of $1 \mathrm{ml} / \mathrm{min}$, and monitored by UV absorbance at $280 \mathrm{~nm}$ using an Axxiom 717-993 UV detector (Separations Analytical Instruments, Hendrik Ido Ambacht, The Netherlands). The identities of the caffeine metabolites AFMU, $1 \mathrm{U}, 1 \mathrm{X}$ and $17 \mathrm{U}$ were determined by retention time.

Cytochrome P4501A2 (CYP1A2) activity was calculated from the molar ratio 5acetylamino-6-formylamino-3-methyluracil (AFMU) + 1-methylxanthine (1X) + 1-methyluric acid (1U)/ 1,7-dimethyl uric acid (17U) and $N$-acetyltransferase 2 (NAT2) activity from the molar ratio AFMU/1X.

\section{Statistical methods}

Differences in urinary PhIP levels within and between groups were analyzed using the Student's t-test or Mann-Whitney nonparametric two-sample test. Differences in caffeine metabolite ratios between different genotypes were calculated using the Student"s t-test for NAT2; in the case of CYP1A2, the Kruskal-Wallis test was used. Stepwise multiple linear regression models were used to examine the effect of CYP1A2 gemotypes and phenotypes, NAT2 genotypes and phenotypes and dietary exposure levels on the urinary PhIP excretion levels in human wolunteers on the various observed moments. In these models, NAT2 genotype and NAT2 phenotype were analyzed as dichotomous variables ( slow $=0$; fast $=1$ ), as well as the dietary PhIP exposure level (low dose $=0$; high dose $=1$ ). The CYP1A2 polymorphism (CYP1A2*1F) was analyzed as a trimodal variable $(C / C=0 ; C / A=1 ; A / A=2)$ and the CYP1A2 phenotype as a continuous variable. Significance was accepted at $P<0.05$. Finally, PhIP levels in chicken breast samples were compared using the Mann-Whitney test.

\section{Results}

NAT2 phenotypes were determined by the urinary molar ratio AFMU/1X, which ranged from 0.20 to 1.85 . When the molar ratios were plotted as logarithmically modified values, the frequency distribution showed a bimodal distribution with a bireakpoint at 0.6 for the ratio AFMU/1X (data not shown). This is in agreement with the findings in other studies $(30,31)$. Hence, all subjects showing a ratio of 0.6 or higher were designated fast acetylatiors, all others were designated slow acetylators. In our study population, 35 individuals $(49 \%)$ were designated fast acetylators. CYP1A2 phenotypes were determined by the urinary molar ratio (AFMU $+1 X+1 U \mathrm{y} / 17 \mathrm{U}$, which ranged from 0.47 to 6.10 and showed a normal distribution when plotted as logarithmical values (data not shown)

NAT2 genotyping showed a population distribution of 37 slow vs. 34 fast acetylators ( 52 $\%$ vs. $48 \%$ ). For CYP1A2, 41 subjects had the AlA genotype (58\%), whereas 28 subjects had the $\mathrm{C} / \mathrm{A}$ genotype $(39 \%)$ and only 2 were homozygous $\mathrm{C} / \mathrm{C}(3 \%)$.

When comparing individual genotyping results with caffeine-metabolite phenotyping, for NAT2 there was $79 \%(56 / 71)$ overall concordance between genotype and phenotype. For the slow and fast acelylators, concordance was $80 \%(29 / 36)$ and $77 \%(27 / 35)$, respectively. The distribution of phenotype ratios within each genotype is shown in 
Figures $1 A$ and $1 B$. As can be seen, for NAT2 the bimodal phenotypic distribution can be clearly distinguished by the genotype, the difference beween the phenotype distributions. for the two different genotypes being highly statistically significant $(P<0.001$, t-test). In the case of CYPAA2, the phenotypic caffeine ratios for the $\mathrm{C} / \mathrm{C}$ genotype appear to be different from the ratios for the other genotypes (Figure 1B). However, due to the small number of subjects in that group $(n=2)$, the difference was not found to be statistically significant $(P=0.104$. Kruskat-Wallis).

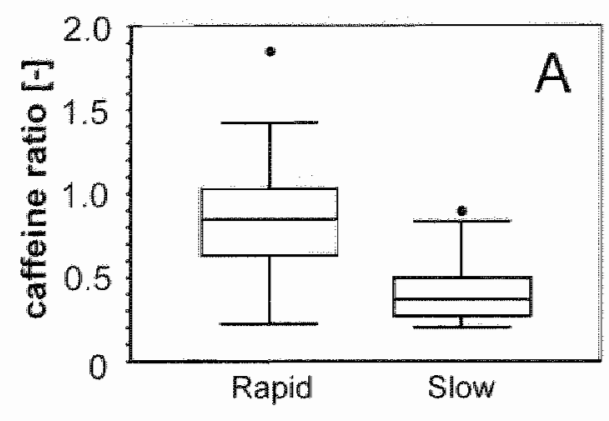

NAT2 genotype

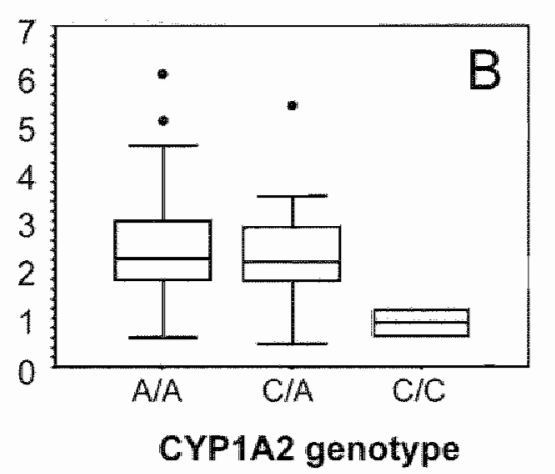

Fig. 1. Distribution of caffeine metabolite phenotypes categorized into genotypes for (A) NAT2 and (B) CYP1A2 denotes outlying values.

The determined levels of PhlP in chicken breast for the low dose group and the high dose group are $1.7 \pm 0.6 \mathrm{ng} / \mathrm{g}$ and $7.4 \pm 2.0 \mathrm{ng} / \mathrm{g}$, respectively (mean $\pm \mathrm{s} . \mathrm{e.m}$.), showing a statistically significant difference between the doses $(P<0.01)$. Urinary excretion levels of PhIP were determined before the intervention period, on days 1,5 and 9 during the intervention period, and 1 week after the intervention period.

Figure 2 shows 24 hr urinary PhlP excretion levels of both the high dose group $(n=35$ ) and the low dose group $(n=36)$. Before and after the intervention period, PhiP excretion levels are equal in both groups. During intervention, the amount of PhIP excreted in urine is higher in the high dose group as compared to the low dose group, with a statistically significant difference on day $5(P<0.05)$. For the low dose group, only the urinary PhIP excretion on day 9 was significantly different from the amount measured before the intervention, while for the high dose group, the difference was statistically significant at all observed moments during the intervention period $(P<0.05)$. 


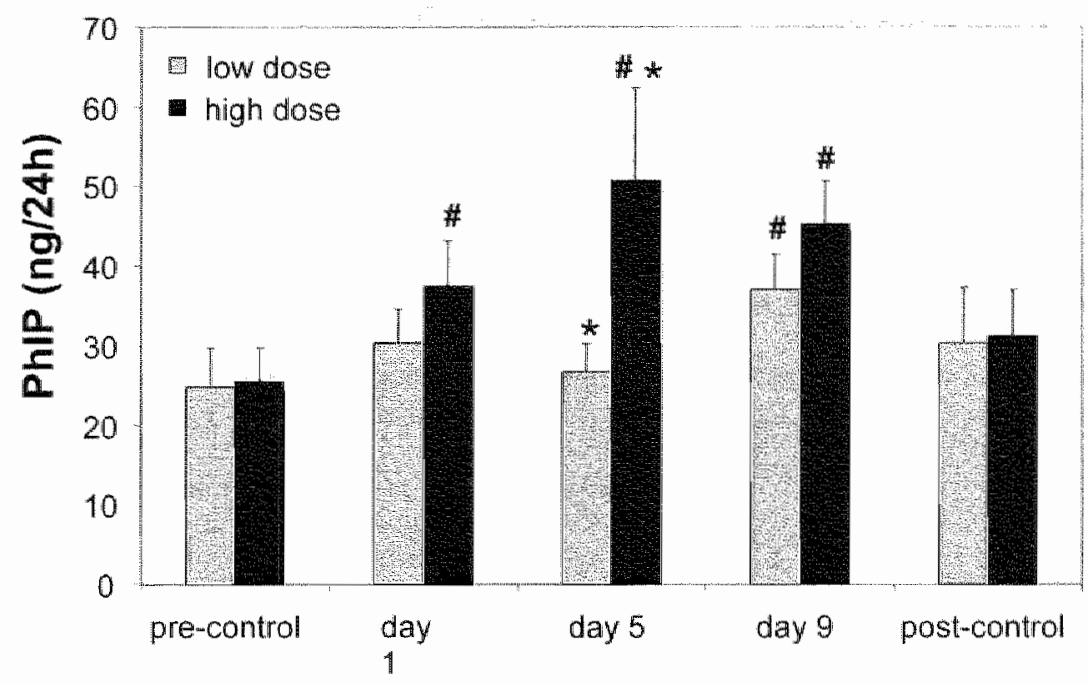

Fig. 2. 24 hr urinary excretion levels of PhIP; comparison between high and low dose groups.

* indicates a significant difference between the groups; \# indicates a statistically significant difference as compared to corresponding pre-control value $(P<0.05$, Student t-test).

The relationship between urinary PhIP excretion levels and the respective parameters CYP1A2 polymorphism (CYP1A2*1F). CYP1A2 phenotype, NAT2 genotype, NAT2 phenotype and PhIP exposure was tested in a stepwise multiple linear regression model. The parameters that were significantly correlated to the urinary PhIP excretion levels on the various abserved moments, as well as their corresponding P-values and standardized regression coefficients, are presented in Table 1. For the pre-control values, only the NAT2 genotype showed a significant influence, indicating that fast acetylators excreted higher amounts of urinary PhIP as compared to slow acetylators. On both day 5 and day 9 , the CYP1A2-164A $\rightarrow$ C polymorphism (CYP1A2*1F) was significantly correlated to the urinary $P$ hil excretion $(P=0.025$ and $P=0.028$. respectively), thus indicating that slow oxidizers (i.e. C/C genotype) excreted higher amounts of urinary PhIP as compared to fast oxidizers.

However, when the two $\mathrm{C} / \mathrm{C}$ genotypes were excluded from the analysis, these correlations were no longer found to be significant. Furthermore, on day 5 , the PhIP dose showed a significant effect on the urinary PhIP amount $(\beta=0.258)$. On day 1 and in the post-control values, no significant correlations were found. Overall, no relationship was found between urinary PhIP excretion levels and phenotypic differences between individuals. 
Table 1. Parameters significantly correlated to urinary PhIP excretion, and their corresponding Pvalues and regression coefficients (B).

\begin{tabular}{lccc}
\hline $\begin{array}{l}\text { Observed } \\
\text { moment }\end{array}$ & $\begin{array}{c}\text { Parameter significant in } \\
\text { stepwise multiple regression }\end{array}$ & P-value & $\beta$ \\
\hline $\begin{array}{l}\text { Premcontrol } \\
\text { Day 1 }\end{array}$ & NAT-2 genotype & 0.025 & 0.266 \\
Day 5 & none & - & - \\
& CYP1A2*1F polymorphism & $0.025^{\circ}$ & 0.260 \\
Day 9 & CYP1A2*1F polymorphism & $0.026^{*}$ & 0.258 \\
Post-contro & none & 0.028 & 0.261 \\
\hline
\end{tabular}

"overall P-value $=0.009$

\section{Discussion}

The metabolic activation of HCA is catalyzed by enzymes that are polymorphic in humans, leading to interindividual differences in metabolizing capacity. This may result in significant differences in cancer risk susceptibility between individuals. However, it is not only genetic variation in a human population that plays a role in the eventual cancer risk. Prior to the exposure to dietary HCA, food preparation methods determine the amount of HCA to be ingested. Due to individual dietary and cooking preferences, intake of HCA varies widely from day to day. In our study, we investigated the impact of the genotype/phenotype relationship for both CYP1A2 and NAT2 on PhIP metabolism in a dietary human intervention. In these subjects, the influence of the CYP1A2-164A $\rightarrow C$ polymorphism (CYP1A2*1F), the CYP1A2 phenotype, the NAT2 genotype and phenotype and the supplemented PhIP exposure on the urinary PhIP excretion was measured.

The distribution of NAT2 phenotypes was bimodal, with $49 \%$ fast and $51 \%$ slow acetylators. This ratio is representative for a Caucasian population, generally comprising $50-60 \%$ slow acetylators (32). CYP1A2 phenotypes were determined using the urinary ratio (AFMU $+1 X+1 U$ )/17U, showing a normal distribution. Although other molar ratios are also used for determining the CYP1A2 activity, this ratio has shown to give a reliable indication of caffeine clearance in humans $(33-35)$.

Genotyping results for both NAT2 (48\% fast ws. $52 \%$ slow acetylators) and CYP1A2 (58 $\% \mathrm{~A} / \mathrm{A}, 39 \% \mathrm{C} / \mathrm{A}$ and $3 \% \mathrm{C} / \mathrm{C}$ ) also showed representative distributions for a Caucasian population. For NAT2, the apparent relative discordance between genotype and phenolype (21\%) is somewhat higher as compared to findings in other studies (36-38) and may be explained by the fact that an observed phenotype cannot be simply linked to a well-defined genetic polymorphism. Figure $1 \mathrm{~A}$ presents the distribution of NAT2 phenotype ratios within each of the NAT2 genotypes, showing that the bimodal nature of the phenotypic distribution can be clearly distinguished by the genotype. For the CYP1A2 genotypes (Figure 1B), an apparent difference in phenotype ratios was found between the $\mathrm{C} / \mathrm{C}$ genotype and the other genotypes, although it was not statistically significant due to the small number of subjects. 
Like for many other enzymes, the relation between genotype and phenotype is not straightforward, since the eventual metabolizing capacity (i.e. phenotype) may be influenced by many other factors. In the case of CYP1A2, the enzyme activity is not only determined genetically, but can also be induced by environmental factors such as smoking and diet (14) and even by polymorphisms in other genes such as CYP1A1 and glutathione S-transferase M1 (GSTM1) (39). Another complicating factor is that many other enzymes can be involved in the metabolic conversion of HCA (e.g., CYP1A1. CYP1B1, CYP2C9) $(40,41)$, each with their own specific activities. Eventually, it is the phenotype that determines the metabolic outcome of the exposure to xenobiotics like HCA.

The two different cooking methods produced significantly different levels of PhIP in chicken, showing that the formation of heterocyclic aromatic amines in meat is strongly influenced by the preparation method, as also described in other studies (42-45). The difference in ingested PhIP levels was reflected in the urinary excretion when comparing the high and low dose group (Figure 2), although most differences were not statistically significant. For the high dose group, however, the PhIP levels found were significantly higher than the control value for all days measured, while for the low dose group, this was only the case for day 9 (Figure 2). Thus, urinary leveis of unmetabolized PhllP clearly reflect differences in dietary PhIP exposure. The use of urinary HCA as biomarkers of exposure has been widely accepted, especially since it is believed that the use of dietary questionnaires may result in inaccurate estimates of HCA exposure $(46,47)$. Because of the rapid excretion and short half-life of HCA in the body, only shortterm exposure can be determined by measurement of urinary HCA levels (48).

Multiple linear regression showed that the urinary PhIP excretion was significantly correlated to the CYP1A2-164A $\rightarrow C$ polymorphism (CYPAA2*1F) on wo observed moments during the intervention period. These observations are in agreement with the hypothesis that the primary HCA metabolism is dominated by CYP1A2 rather than by NAT2. This can be explained by the fact that the first step in the hepatic metabolic activation of PhIP in humans proceeds predominantly via $N$-hydroxylation, which is catalyzed almost entirely by CYP1A2 (49). Furthermore, although NAT2 may also metabolize PhIP directly by $\mathrm{N}$-acetylation, HCA have proven to be poor substrates for NAT2. Therefore, the contribution of NAT2 to the primary conversion of PhIP is negligible (8). Thus, CYP1A2 mainly determines the amount of unmetabolized PhIP. Similar findings were described earlier for another HCA, 2-amino-3,8-dimethylimidazo[4,5$f \mid$ quinoxaline (MelQx) (27). Also, a significant influence of the PhIP dose on the urinary excretion was found on day 5 of the intervention period. Surprisingly, this correlation was non-significant on the other observed moments during intervention. It should be noted that the found correlations were highly influenced by the two $\mathrm{C} / \mathrm{C}$ genotypes. To substantiate our findings, a larger number of $\mathrm{C} / \mathrm{C}$ genotypes should be included in the study.

In contrast to the findings of Stillwell et al. (50), no correlations were found between the CYP1A2 caffeine ratios and the urinary PhIP excretion levels on any day. As stated earlier, this can be explained by the fact that the CYP1A2 enzymatic activity can be influenced by many other factors, resulting in a large range of metabolic ratios within a group of test subjects. Moreover, because of its inducibility, CYP1A2 enzyme activity is subject to intraindividual variation in course of time. Also, no correlation was found between NAT2 phenotypes and PhIP excretion levels. The latter was also found by Stillwell et al. (50), and is in agreement with the earlier diescribed finding that HCA are poor substrates for direct $N$-acetylation by NAT2.

The apparent absence of CYP1A2 genotype influence on interindividual variability in CYP1A2 metabolic activity would be in agreement with findings in other studies $(17,51,52)$. 
In conclusion, our results show that the amount of unmetabolized PhIP in human urine clearly reflects the recent exposure to dietary HCA. Therefore, urinary PhIP levels can be used as biomarkers of short-term exposure in humans. Although the CYP1A2-164A $\rightarrow C$ polymorphism (CYP1A2*1F) does not appear to explain the variability in CYP1A2 metabolic activity in our study population. the significant correlations found between the studied CYP1A2 genotype and the urinary PhIP excretion indicate that this polymorphism could play a role in cancer risk susceptibitity in humans.

\section{References}

1. Giovannucci, E. and Willett, W. (1994). Dietary factors and risk of colon cancer. Arn Med 26 , $443-452$.

2. Potter, J.D. (1999), Colorectal cancer: molecules and populations. J Nati Cancer inst 91, 916932.

3. Sugimura, T., Nagad, M. Kawachi, T., Honda, M., Yahagi, T., Seino, Y., Sato, S., Matsukura, N., Matsushima, T., Shirai, A., Sawamura, M. Matsumoto, H. (1977) Mutagien.carcinogens in food, with special reference to highly mutagenic pyrolytic products in broiled foods. In: Hiatt, H.H. Watson, J.D. Winsten, J.A. (eds.) Origins of Human Cancer, Book C. Cold Spring Harbor Laboratory Press, New York, pp. 1561.1567.

4. Felton, J.S., Knize, M.G., Shen, N.H., Lewis, P.R., Andresen, B.D., Happa, J. and Hatch, F.T. (1986). The isolation and identification of a new mutagen from fried ground beef: 2-amino-1methyl-6-phenylimidazo[4,5-b]pyridine (PhIP). Carcinogenesis 7, 1081-1086.

5. Skog, K.I., Johansson, M.A., Jagerstad, M.l. (1998). Carcinogenic heterocyclic aromatic amines in model systems and coked foods: a review on formation, occurrence and intake. Fd Chem Toxic 36, 879-896.

6. Moonen, H.J.J., Briedê, J.J., wan Maanen, J.M.S., Kleinjans, J.C.S., de Kok, T.M.C.M. (2002) Generation of free radicals and induction of DNA adducts by activation of heterocyclic aromatic amines via different metabolic pathways in vitro. Mol Carcinog 35, 196-203.

7. Kadlubar, F.F., Kaderlik K.R., Mulder, G.J., Lin, D., Butler, M.A., Teitel, C.E., Minchin, R.F., llett, K.F., Friesen, M.D., Bartsch, H. Nagao, M., Esumi, H., Sugimura, T., Lang, N.P. (1995) Metabolic activation and DNA adduct detection of PhIP in dogs, rats, and humans in relation to urinary bladder and colon carcinogenesis. In: Adamson, R.H., Gustafsson, J.-A., Nobuyuki, I., Nagao, M., Sugimura, T., Wakabayashi K., Yamazoe, Y. (eds.) Heterocyclic amines in cooked foods: possible human carcinogens. Princeton Scientific Publishing Co. Nل, pp. 207-213.

8. Turesky, R.J., Lang. N.P., Butler, M.A., Teitell, C.H., Kadlubar, F.F. (1999) Metabolic activation of carcinogenic heterocyclic aromatic amines by human liver and colon. Carcinogenesis 12, $1839-1845$.

9. Lynch, A.M., Knize, M.G., Boobis, A.R., Gooderham, N.J., Davies, D.S., Murray, S. (1992) Intra- and interindividual variability in systemic exposure in hurnans to 2 -amino-3,8dimethylimidazo[4,5-1]quinoxaline and 2-amino-1-methyl-6-phenylimidazo[4,5-b]pyridine, carcinogens present in cooked beef. Cancer Res 52, 6216-6223.

10. Reistad, R., Rossland, O.J. Latva-Kala, K.J., Rasmussen, T., Vikse, R.. Becher. G., Alexander, J. (1997) Heterocyclic aromatic amines in human urine following a fried meat meal. Fd Chem Toxic 35, 945-955.

11. Friesen, M.D., Rothman, N., Strickland, T. (2001) Concentration of 2-amino-1-methyl-6phenylimidazo[4 $[5-b]$ pyridine (PhIP) in urine and alkali-hydrolyzed urine after consumption of charbrolled beef. Cancer Lett 173, 43-51

12. Kadlubar, F.F., Butler, M.A., Kaderlik, K.R., Chou, H.-C., Lang, N.P. (1992) Polymorphisms for aromatic amine metabolism in humans: relevance for human carcinogenesis. Environ Hoath Perspect 98, 69-74.

13. Sinha, R., Rothman, N. Brown, E., Mark, S. Hoover, R., Caporaso, N. Levander, O., Knize, M. Lang. N., Kadlubar, F. (1994). Pan-fried meat containing high levels of heterocyclic aromatic amines but low levels of polycyclic aromatic hydrocarbons induces cytochrome P4501A2 activity in humans. Cancer Res 54, 6154-6159.

14. Landi, M.T., Sinha, R., Lang, N.P., Kadlubar, F.F. (1999). Human cytochrome P4501A2. In: Vineis, P., Malats, N. Lang. M., d'Errico, A.. Caporaso, N., Cuzik, J., Boffetta, P. (eds.) 
Metabolic Polymorohisms and Susceptibilty to Cancer. ARC Scientifo Publications No. 148 LARC, Lyon, pp. 173-195.

15. Macleod, S.L., Tang, Y-M. Yokoi, T, Kamataki, T., Doublin, S., Lawson, B. Massengll, J. Kadlubar, F.F. Lang. N.P. (1998) the role of a recently discovered genetio polymorphism un the regulation of the human CYP1A2 gene. Proc Am Assoc Cancer Res 39, 396-396.

16. Nakajima, M. Yokoi, T., Mizutani, M., Kinoshita, M., Funayama, M., Kamataki, T. (1999) Genetic polymorphism in the 5'flanking region of human CYP1A2 gene: effect on the CYP1 A2 inducibility in humans. J Blochem $125,803-808$.

17. Sachse. C., Brockmöller, J., Bauer, S., Roots, 1. (1999) Functional significance of a $C \rightarrow A$ polymorphism in intron I of the cylachrome P450 CYP1a2 gene tested with caffeine. Br I Cho Pharmacol $47,445-449$

18. Sachse, C., Bhambra, U. Smith, G. Lightfoot, T.J., Barrett J.H. Scollay d, Gamer, R.C... Boobis, A.R., Wolf, C.R., Gooderham, N.J. (2003) Polymorphisms in the cytochrome P450 CYP1A2 gene (CYP1A2) in colorectal cancer patients and controls: allele frequencies, linkage disequillbrium and influence on caffeine metabolism. $\mathrm{Br} J$ Clin Phamacol $55,68-76$.

19. Lang. N.P., Butter, M.A., Massengill, J.P. Lawson, M., Stotts, R.C., Hauer-Jensen, M." Kadlubar, F.F. (1994) Rapid metabolic phenotypes for acetyltransterase and cytochrome P4501A2 and putative exposure to food-borne heterocyclic amines increase the risk fot collorectal cancer or polyps. Cancer Epidemiol Biomarkers Prev 3, 675-682.

20. Le Marchand, L., Hankin, J.H. Wikens, L.R., Pierce, L.M., Franke, A. Kolonel, L.N., Seifried, A. Custer, L.J., Chang, W., Lum-Jones, A., Donlon, T. (2001) Combined effects off well-done red meat, smoking, and rapid $N$-acetyltransferase 2 and CYP $A 2$ phenotypes in increasing collorectal cancer risk. Cancer Epidemiol Biomank Prew 10,1259-1266

21. Le Marchand, L. Hankin, J.H., Plerce, L.M., Sinha, R., Nerurkar, P.V., Franke, A.A., Wilkens, L.R. Kolonel, L.N. Donlon, T., Seifried, A., Custer, L.J., Lum-Jones, A., Chang, W. (2002) Well-done red meat, metabolic phenotypes and collorectal cancer in Hawaii. Mutat Res 506$507,205-214$.

22. Fuhr, U., Rost, K.L., Engelhardt, R., Sachs, M., Liermann, D., Belloc, C., Beaune, P. Janezic, S., Grant, D., Meyer, U.A., Staib, A.H. (1996) Evaluation of caffeine as a test drug for CYP1A2, NAT2 and CYP2E1 phenotyping in man by in wivo versus in vitro correlations. Pharmacogenetics 6. 159-176.

23. Gross, G.A., Gruter, A. (1992) Quantitation of mulagenic/carcinogenic heterocyclic amines in food products. J Chromatogr 592, 271-278

24. Knize, M.G., Sinha, R., Rothman, N., Brown, E.D., Salmon, C.P., Levander; O.A., Cumningham, P.L., Felton, J.S. (1995) Heterocylic amine content in fast-food meat products. Fd Chem Toxic 33, 545-551.

25. Doll, M.A., Fretland, A.J., Deitz, A.C., Mein, D.W. (1995) Determination of human NAT2 acetylator genotype by restriction fragment-length polymorphism and allele-specific amplification. Anal Brochem 231, 413-420.

26. Vatsis, K.P., Weber, W.W., Bell, D.A., Dupret, J., Price Evans, D.A.,Grant, D.M.,Hein, D.W.; Lin, H.w., Meyer, U. H. Relling, M.V., Sim, E., Suzuki, T., Yamazae, V. (1995) Nomenclature for N-acetylltransferases. Pharmacogenetios $5,1-17$.

27. Sintha, R. Caporaso, N. (1997) Heterocyclic amines, cytochome P4501A2, and N. acetylliansferase: issues. involved in incorporating putative genetic susceptibility markers into epidemiologicall studies. Ann Epidemiol 7, 350-356.

28. Christiansen, L., Bygum, $A_{x}$ Jensen, $A$. Thomsen, K., Brandrup $F$. Horder, M., Petersent, N.E. (2000) Association between CYP1A2 polymorphism and susceptibility to porphyria cutanea tarda. Hum Genet 107,612-614.

29. Krul. C., Hageman, G. (1998) Analysis of urinary caffeine metabolites to assess biotransformation enzyme activities by reverse-phase high-performance liquid chromalography, $J$ Chrom $B$ 709, 27-34.

30. Grant. D.M. Tang, B.K. Kalow, W. (1984) A simple test for acelylator phenotype using calfeine. Br I Clin Pharmacol 17, 459-464.

31. Butler, M.A. Lang, W.P., Young, J.F., Caporaso, N.E., Vineis. P., Hayes, R.B., Teitel, C.H. Massengill, J.P., Lawsen, M.F. Kadiubar, F.F. (1992) Determination of CYP1A2 and acetylator phenotypes in several human populations by analysis of caffeine urinary metabolites. Pharmacogenetics $2,116-127$.

32. Beli D.A., Taylor, J.A., Butler, M.A., Stephens, E.A. Wiest, J., Brubaker, L.H., Kadlubar F.F. Lucier, G.W. (1993) Gemotype/phenotype discordance for human arylamine $M$ 
acetyltransferase (NAT2) revealy a new slow-acetylator allele common in African-Americans. Carcinogenesis 14, 1689-1692.

33. Campbell, M.E. Spielberg. S.P. Kalow. W. (1987) A urinary metabolite ratio that reflects systemic caffente clearance. Chin Pharmacol Ther 42, 157-165.

34. Vistisen, K, Loft. S., Poulsen. HE. (1991) Cytochrome P450 1 A2 activity in man measured by caffeine metabolism: effect of smoking, broccoli and exercise. Adv Exp Med Biol 283, 407-411.

35. Tang. B.K. Zhou, Y. Kadar, D., Kalow, W. (1994) Caffeine as a probe for CYP1A2 activity. potantial irfluence of renal factors on urinary phenotypic trait measurements. Pharmacogenatios $4,1,17-124$.

36. Gross, Mi. Krusselbrink, T., Anderson, K., Lang, N., McGovern. P, Delongchamp, R.. Kadubar, F. (1999) Distribution and concordance of N-acetyltransferase genotype anct phenotype in an American population. Cancer Epidemiol Biomarkers Prev 8, 683-692.

37. Blum, M. Demierre. A. Grant, D.M., Heim, M. Meyer, U.A. (1991) Molecular mechantism of slow acetylation of drugs and carcinogens in humans. Proc Nati Acad Sci USA 88, 5237-5241.

38. Smith, C.A., Wadelius, M., Gough, A.C., Harrison, D.J., Wol, C.R., Rane, A. (1997) A simplified assay for the aylamine N-acetyltransferase 2 polymorphism vaildated by phenotyping with isoniazid. Med Genet 34,758-760.

39. MacLeod. S., Sinha, R., Kadlubar, F.F. Lang, N.P. (1997) Polymorphisms of CYP1A1 and GSTM1 influence the in vivo function of CYP1A2. Mut Res 376, $135-142$.

40. Crofts, F.G. Sutter, T.R. Strickland, P.T. (1998) Metabolism of 2-amino-1-methyl-6phenylimidaza[4,5-blpyridine by human cytochrome P4501A1, P4501A2 and P450181. Carcinogenesis 19, 1969-1973.

41. Eisenbrand, G. Tang. W. (1993) Food-borne heterocyclic amines. Chemistry, fiomation. occurrence and biological activities. A literature review. Toxicology 84, 1-82.

42. Knize, M.G., Dolbeare, F.A., Carroll, K.L, Moare, D.H. II, Felton, J.S. (1994) Effect of cooking time and temperature on the heterocyclic amine content of fried beef patties. Fd Chem Toxic 32, 595-603.

43. Skag, K. Steineck, G., Augustsson, K. Jägerstad, M. (1995) Effects of cooking temperature on the formation of heterocyclic amines in fried meat products and pan residues. Carcinogenesis 16, 861-867.

44. Salmon, C.P. Knize, M.G., Felton, J.S. (1997) Effects of marinating on hetterocyclic amine carcinogen formation in grilled chicken. Fd Chem Toxic 35, 433-441

45. Solyakov, A. Skog, K. (2002) Screening for heterocyclic aromatic amines in chicken cooked in warious ways. Fol Chem Toxic 40, 1205-1211.

46. Knize, M.G., Kulp. K.S., Salmon, C.P., Keating. G.A., Felton, J.S. (2002) Factors affecting human heterocyclic amine intake and the metabolism of PhIP. Mut Res 506-507, 153-162

47. Skog, K. (2002) Problems associated with the determination of heterocyclic amines in cooked foods and human exposure. Fd Chem Toxic 40, 1197-1203.

40. Alemander, J., Reistad, R. Hegstad, S., Frandsem, H., Ingebrigtsen, K., Paulsen, J.E., Becher, G. (2002) Biomarkers of exposure to heterocychlic amines: approaches to improve the exposure assessment. Fo Chem Toxic 40, $1131-1137$

49. Boobis, A.R., Lynch, A.M. Murray, S., de la Torre, R., Solans, A. Farrè, M. Segura, J. Gooderham, N.J., Davies, D.S. (1994) GYP1A2matalyzed conversion of dietary heterocyclic amines to their proximate carcinogens is their major route of metabolism in humans. Cancor Ras 54, 89.94

50. Stillwell, W.G. Simha, R., Tannenbaum, S.R. (2002) Excretion of the $\mathrm{N}^{2}$.glucuronide conjugate of 2-hydroxyamino-1-methyl-6-phenylimidazo[4,5-b]pyridine in urine and its relationship to CYP1A2 and NAT2 activity levels in humans. Carcinogenesis $23,834-838$

51. Huang, J.D., Guc, W.C., Lail, M.D., Guo, Y.L., Lambert, G.H. (1999) Detection of a novel cytochrome P-450 1A2 polymorphism (F21L) in Chinese. Drug Metab Dispos 27, 98-101.

52. Chevalier, D., Cauffiez, C.. Allorge, D., Lo-Guidice, J.M., Lhermitte, M., Lafitte, J.d., Broly, F. (2001) Five noven natural allelic wariants $-951 \mathrm{~A}>\mathrm{C}, 1042 \mathrm{G}>\mathrm{A}$ (D348N), 1156A>T (1386F), $1216 \mathrm{~S}>\mathrm{A},(\mathrm{C} 406 \mathrm{Y})$ and $1291 \mathrm{C}>\mathrm{T}(\mathrm{C} 431 \mathrm{Y})$ - of the human CYP1A2 gene in a French Caucasian population. Hum Mut 17, 355-356. 


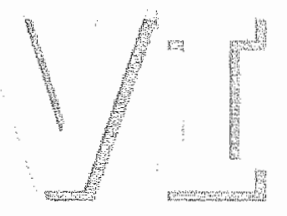

\title{
Relationship between the CYP1A2-164A $\rightarrow$ C polymorphism (CYP1A2*1F) and risk for colorectal neoplasia in humans
}

\author{
Harald J.J. Moonen ${ }^{1}$ \\ Leopold G.J.B. Engels ${ }^{2}$ \\ Jos C.S. Kleinjans ${ }^{1}$ \\ Theo M.C.M. de Kok ${ }^{1}$
}

1Department of Health Risk Analysis and Toxicology,
University of Maastricht
'Department of Gastroenterology,
Maasland Hospital, Sittard

Submitted for publication 


\section{Abstract}

Colorectal cancer (CRC) is one of the most common malignancies in Western countries; and is believed to be strongly related to dietary factors. More specifically, the intake of processed meat and of the formed heterocyclic aromatic amines (HCA) herein, is believed to play an important role in the etiology of CRC. HCA are metabolically activated by the enzymes cytochrome P4501A2 (CYP1A2) and $N$-acetyltransferase 2 (NAT2). Respective genes encoding for these enzymes, show polymorphic distribution in the human population. These polymorphisms lead to variations in metabolic activities and may thus cause interindividual differences in cancer risk susceptibility. High activities for both CYP1A2 and NAT2 are hypothesized to be related to an elevated CRC risk. In the present study, we investigated the influence of genotypic and phenotypic variations for CYP1A2 and NAT2 on the risk for colorectal neoplasia.

The study population comprised 94 individuals at different risk of developing CRC as assessed by coloscopy, who were phenotyped for both enzymes using urinary caffeine metabolite ratios. Furthermore, subjects were genotyped for polymorphisms of NAT2 and CYP1A2-164A $\rightarrow$ C (CYP1A2*1F) by means of PCR-RFLP.

Using logistic regression analysis, significant associations were found between the CYP $1 A 2 * 1 F$ polymorphism and the risk of colorectal neoplasia when comparing different risk groups or combinations of risk groups. Of all other variables, only age was found to be significantly associated to risk of colorectal neoplasia.

These results indicate that the CYP1A2*1F polymorphism could play a role in colorectal cancer risk susceptibility in humans. Further study in larger populations is necessary to substantiate and extend these findings. 


\section{Introduction}

Colorectal cancer remains one of the most common malignancies in Westem populations. In The Netherlands, more than 8000 persons are diagnosed with colon cancer each year. In a global perspective, colon cancer incidence varies widely between different regions (1). High rates are found in North America and northern Europe, while rates are lower in southern Europe and much lower in Asia and Africa. Furthermore, colon cancer rates have been found to increase in groups migrating from low- to highincidence regions (2). Thus, although an important risk factor is formed by genetic predisposition, leading to hereditary forms of colon cancer (3), these findings indlicate that environmental factors probably account for most of these distinct rate variations. Some 20 years ago, Doll and Peto already estimated that environmental mostly dietary factors could account for $90 \%$ of the human colorectal cancer risk (4). In numerous studies, an association was found between the intake of processed meat and risk of colon adenoma (e.g. 5,6) or colon cancer (e.g. 7.8). In this perspective, the formation of heterocyclic aromatic amines (HCA) during the processing of meat is considered to be of significant importance. Since their discovery in the 1970s, HCA have found to be highly mutagenic in bacteria, as well as carcinogenic in rodents (9) and non-human primates (10). More specifically, the HCA 2-amino-1-methyl-6-phenylimidazo[4,5-b]pyridine (PhIP) has proved to be a colon carcinogen in rats (11). This might implicate that the mutagenic HCA may induce early mutations in the human colorectal tumorigenesis model as proposed by Vogelstein (12). In humans, HCA are efficiently absorbed into the systemic circulation after ingestion, thus being almost completely bioavaillable. However, in order to interact with DNA, HCA are unactive until metabolized, which can proceed via different pathways (13). In the hepatic pathway, successive metabolic steps comprise $\mathrm{N}$-oxidation and O-acetylation, which are catalyzed by cytochrome P4501A2 (CYP1A2) and Nacetyltransferase 2 (NAT2), respectively (14). These enzymes are encoded by genes that are polymorphic in humans, thus leading to interindividual differences in enzyme activities. Polymorphism in NAT2 results in a "Slow' or 'fast' acetylator phenotype, depending on the ability to $N$-acetylate $H C A$ and other substrates. With respect to CYP1A2, several polymorphisms have been characterized in the past few years (15-17). Of these, the CYP1A2-164A $\rightarrow C$ polymorphism (CYP1A2*1F) is very common in Caucasians and is expected to result in a decreased capacity to activate HCA. Furthermore, the polymorphism appears to be related to variations in CYP1A2 inducibility (17). In this way, the CYP1A.2* $1 F$ polymorphism may underlie to large interindividual differences in CYP1A2 phenotype.

It is assumable that these differences in bioactivating capacity may implicate variations in cancer risk susceptibility between individuals. However, besides genetic constitution, many other factors may affect enzyme activities. For instance, the CYP1A2 enzymatic activity can be influenced by environmental factors such as smoking and diet (18), but also by endogenous factors like gene-gene interactions (19). Analyzing both genotypes and phenotypes therefore provides complementary information on genetic impact. To obtain valid estimates of actual NAT2 and CYP activities, individuals are usually phenotyped using urinary caffeine metabolites (20).

In order to evaluate the role of CYP1A2 and NAT2 genotypes and phenotypes in CRC risk, we designed a case-control study with 3 risk groups based on occurrence and size of colorectal adenomas. In these subjects, we investigated CYP1A2 and NAT2 genotype/phenotype relations and their influence on the relative risk for developing colorectal neoplasia. 


\section{Materials and methods}

\section{Chemicals and enzymes}

1-Methyluric acid (1U), 1-methylxanthine (1X), 1,7-dimethyluric acid (17U), N-acetaminophen and proteinase $K$ were from Sigma (St. Louis, MO, USA). 5-Acetylamino-6formylamino-3-methyluracil (AFMU) was a gift from Dr. R. Fumeaux, Nestle Research Center, Lausanne. Switzerland. Taq polymerase was purchased from Amersham (Braunschweig. Germany). Other chemicals were of HPLC- or analytical grade.

\section{Design and study population}

A case-control study was designed to evaluate the roles of genotypes and metabolic phenotypes in the risk to develop colorectal neoplasia. The study population consisted of 94 individuals of Caucasian origin ( 58 men and 36 women, mean age $59 \pm 12$ years, range 29-82 years), who had to undergo endoscopic examination at the Maasland Hospital in Sittard (The Netherlands) between February 1999 and July 2002, and who agreed to participate in this study. Previous history of colorectal cancer or intraabdominal surgery were excluding criteria. During colonoscopy, rectal biopsies were taken from normal colon epithelium for DNA adduct analysis. Subjects were assigned to three different risk groups, based on the occurrence and size of adenomas (21). The low-risk control group comprised subjects showing no neoplastic or other abnormal bowel conditions. Subjects with small colorectal adenomas (diameter $<1 \mathrm{~cm}$ ) were assigned to the medium-risk group, and those with large colorectal adenomas (diameter $\geq 1 \mathrm{~cm}$ ) and/or colorectal carcinomas in situ were assigned to the high-risk group. All participants gave their informed consent after being informed on the study airm and instructed about the procedure. This study was approved by the Medical Ethical Committee of the Maasland Hospital in Sittard.

\section{${ }^{32}$ P-postlabeling}

HCA-DNA adduct analysis in biopsies was performed by means of ${ }^{32} \mathrm{P}$-postlabeling under adduct-intensification conditions, as described in detail elsewhere (13).

\section{Genotyping}

The NAT2 genotyping procedure was adapted from the method described by Doll et al. (22), leading to a classification of slow and fast acetylators (23). For CYP1A2 genotyping, we used the method described by Christiansen et al. (24), and subjects were calegorized into one of three possible genotypes: $\mathrm{AlA}, \mathrm{C} / \mathrm{A}$ or $\mathrm{C} / \mathrm{C}$.

\section{Phenotyping by caffeine administration}

The urinary caffeine metabolites AFMU, $1 U, 1 X$ and $17 \cup$ were determined by HPLC analysis as described by Krul and Hageman (20). Cytochrome P4501A2 (CYP1A2) activity was calculated from the molar ratio (AFMU $+1 X+1 U$ )/17U and $N$ acelyltransferase 2 (NAT2) activity from the molar ratio AFMU/X.

\section{Statistical analysis}

Differences between phenotypic caffeine ratios for the different genotypes, age and smoking status were tested using the nonparametric Mann-Whitney two-sample test (NAT2) or the Kruskal-Wallis multi-sample test (CYP1A2). To assess the influence of age, smoking status, the CYP1A2 $1 \mathrm{~F}$ polymorphism, the CYP1A2 phenotype and the NAT2 genotype and phenotype on the CRC risk, logistic regression models were used. Because the CYP1A2 and NAT2 metabolic activity ratios appeared to be normally distributed, both phenotypes were introduced as continuous variables in the logistic regression models. Furthermore, the NAT2 genotype was analyzed as a dichotomous 
variable (Slow vs. fast) and the CYPIA2 IF polymorphism as trimodal variable (CIC. C/A or A/A). Finally, different models were constructed to compare two risk groups or combinations of risk groups, thus enabling binary logistic regression.

\section{Results}

The total research population comprised 94 persons. Of these individuals, $19(20 \%)$ were classified as low-risk control patients, showing no neoplastic bowel conditions upon endoscopic examination. Of the 75 patients, $37(49 \%)$ were classified as medium wisk subjects, whereas the resulting $38(51 \%$ ) were assigned to the high-risk group (see Table 1 for demographic details). Of the latter group 6 patients were diagnosed with a carcinoma in situ, however not showing any infiltration into colon mucosa.

${ }^{32} \mathrm{P}$-postlabeling analysis of colon biopsies did not lead to any detectable levels of HCADNA adducts. The urinary AFMU/1X molar ratio (i.e. NAT2 phenotype) ranged from 0.08 to 3.29. CYP1A2 phenotypes were determined using the urinary caffeine metabolite ratio (AFMU $+1 X+1 U) /(17 U)$, which ranged from 1.44 to 14.24 within the study population. Plotted as logarithmic values, the frequency distributions of the phenotypic ratios over the whole study population showed normal distributions for both CYP1A2 and NAT2 (Figure 1). CYP1A2 metabolic activities did not differ significantly between smokers and non-smokers $(P=0.07$; Student's t-test). Furthermore, neither CYP1A2 nor NAT2 metabolic activities were influenced by age. NAT2 genotyping resulted in a population distribution of 54 slow and 40 fast acetylators $(57 \%$ and $43 \%$, respectively). For CYP1A2, 49 subjects had the A/A genotype (fast oxidizers; $52 \%$ ), 38 subjects had the C/A genotype (intermediate oxidizers; $40 \%$ ) and 7 were homozygous $\mathrm{C} / \mathrm{C}$ (slow oxidizers; $8 \%$ ).

Table 1. Study population demographics.

Group

\begin{tabular}{|c|c|c|c|}
\hline & \\
\hline & $\begin{array}{l}\text { Low-risk } \\
(n=19)\end{array}$ & $\begin{array}{c}\text { Medium-risk } \\
\quad(n=37)\end{array}$ & $\begin{array}{l}\text { High-risk } \\
(n=38)\end{array}$ \\
\hline Mean age ( $\pm \mathrm{SD}$ ) & $48( \pm 11)$ & $61( \pm 12)$ & $62( \pm 9)$ \\
\hline Smaking subjects $(\%)$ & $5(26 \%)$ & $10(27 \%)$ & $3(8 \%)$ \\
\hline $\begin{array}{l}\text { Mean size of adenomas } \\
\text { removed }(\mathrm{cm} \pm \mathrm{SD})\end{array}$ & - & $0.5( \pm 0.3)$ & $1.1( \pm 0.9)$ \\
\hline $\begin{array}{l}\text { Mean \# of polypectomies } \\
\text { per patient }( \pm S D)\end{array}$ & $\infty$ & $1.8( \pm 1.0)$ & $1.6( \pm 0.8)$ \\
\hline
\end{tabular}



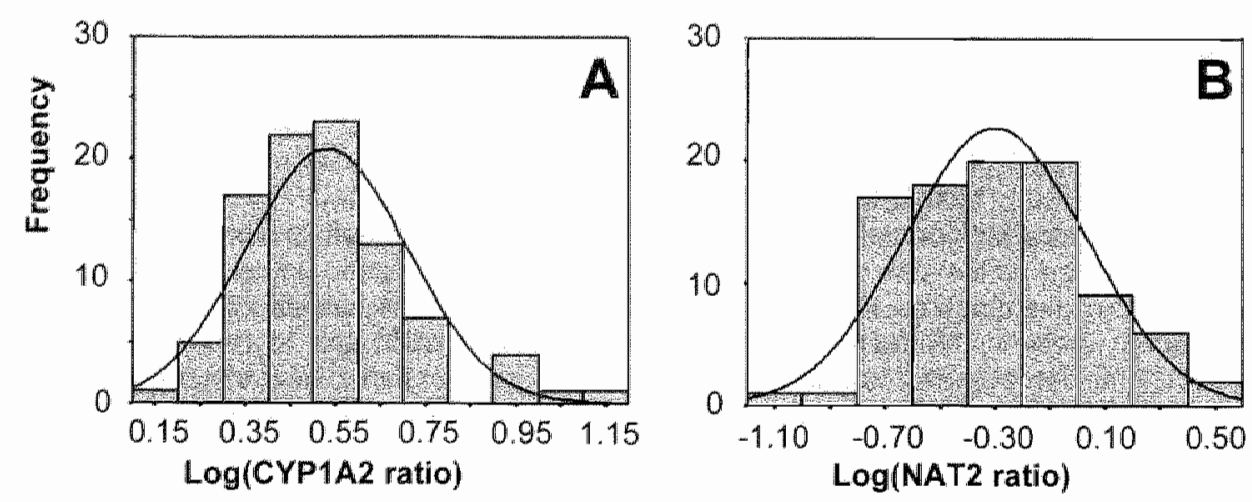

Fig. 1. Frequency distributions for the logarithmic values of the (A) CYP1A2 and (B) NAT2 urinary caffeine metabolite ratios.

The distributions of phenotypic values within the different genotype groups is presented in box-plot graphs (Figure 2). For CYP1A2 (Figure 2A), the difference between the phenotypic caffeine ratios was not significant $(P=0.063$; Kruskal-Wallis), due to a small number of extreme values (i.e. cases with walues more than 3 interquartile ranges from the upper edge of the box; cases not shown in Figure 2A). When these extremes were omitted from the analysis, the difference turned out highly significant ( $P=0.02$; KruskalWallis). Figure 2B shows the distribution of NAT2 phenotypic caffeine ratios between the two different NAT2 genotypes, the difference being highly statistically significant $(P=$ 0.002 ; Student's twtest). In general, the catalytic activities of both enzymes could be well related to the corresponding genotypes.

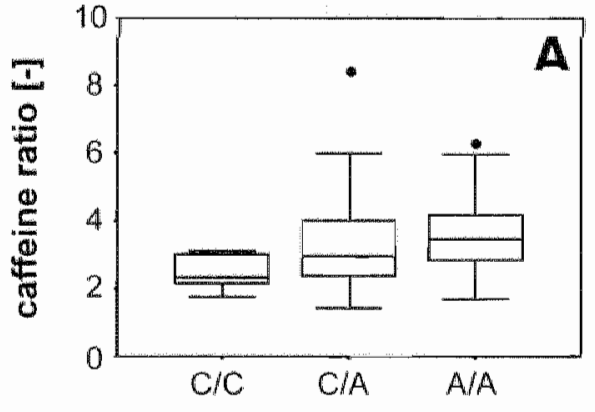

CYP1A2 genotype

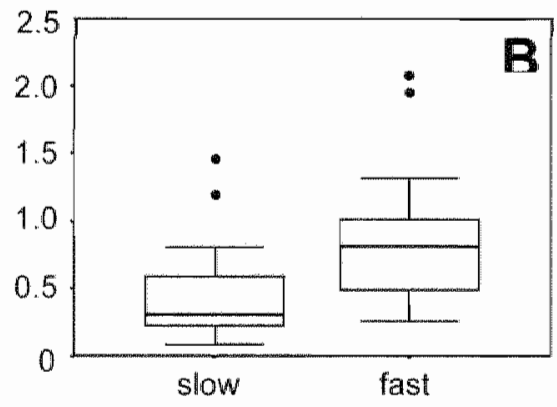

NAT2 genotype

Fig. 2. Distribution of caffeine metabolite phenofypes categorized into genotypes for (A) CYP1A2. and (B) NAT2: inndicates outlying values. 
The association between the risk for colorectal neoplasia and the respective parameters age, smoking status, CYP1A2*1F polymorphism, CYP1A.2 phenotype, NAT2 genotype and NAT2 phenotype was tested in a logistic regression model. For the different analyses, most relevant parameters that appeared correlated to the CRC risk are presented in Table 2, with their corresponding P-values and odds ratios (OR). There was no statistically significant association between the risk for colorectal neoplasia and the smoking status, CYP1A2 phenotype. NAT2 phenotype or the NAT2 genotype in any of the various regression models. Furthermore, interaction terms including different phenotypes or genotypes appeared not to be significant variables in explaining CRC risk (data not shown). However, comparison of these different models showed that both age and the CYP1A2-164A $\rightarrow C$ polymorphism (CYP1A2* $1 F$ ) were significant variables in the analysis (Table 2). The negative correlation coefficient for the CYP1A2*1F polymorphism indicates that the risk for developing colorectal neoplasia decreases when one or both of the CYP1A2 alleles possess the mutation. More specifically "comparison between the combined high-/medium-risk group and the low-risk group showed a significant association with age $(P<0.001, O R=1.1[95 \% C l, 1.0-1.2])$ and a non-significant association with the CYP1A2*1F polymorphism $(P=0.073, O R=2.0[95 \% \mathrm{Cl}, 0.9-4.4])$. For the low-risk group versus the medium-risk group only age was found to be a significant variable $(P=0.005, O R=1.1[95 \% \mathrm{Cl}, 1.0-1.2])$. When comparing the highrisk group with either the low-risk group or the combined medium-/low-risk group, age was only found to be a significant variabie in the first analysis. $(\mathbb{P}=0.002$ and 0.07 , with ORs of $1.1\left[95 \% \mathrm{Cl}_{1} 1.0-1.2\right]$ and $1.0[95 \% \mathrm{Cl}, 0.99-1.1]$, respectively), while the CYP1A2*1F polymorphism was of significant influence in both cases $(P=0.017$ and 0.038 , with ORs of $3.7[95 \% \mathrm{Cl}, 1.3-10.7]$ and $2.2[95 \% \mathrm{Cl}, 1.0-4.6]$, respectively).

Table 2. Results of logistic regression analysis, showing most relevanit parameters that appear correlated to risk for colorectal neoplasia.

\begin{tabular}{lcccc}
\hline $\begin{array}{l}\text { Dependent } \\
\text { variable }\end{array}$ & $\begin{array}{c}\text { Independent } \\
\text { variable }\end{array}$ & $\beta$ & OR $(95 \%$ CI) & P-value \\
\hline Low vs. (medium + high) risk & $\begin{array}{c}\text { CYP1A2 } \\
\text { age } 1 \mathrm{~F}\end{array}$ & $\begin{array}{r}-0.711 \\
0.089\end{array}$ & $\begin{array}{l}2.0(0.9-4.4) \\
1.1(1.0-1.2)\end{array}$ & $\begin{array}{c}0.073 \\
\text { Low vs. medium risk }\end{array}$ \\
Low vs. high risk & age & 0.074 & $1.1(1.0-1.2)$ & 0.005 \\
& CYP1A2*1F & -1.303 & $3.7(1.3-10.7)$ & 0.017 \\
& age & 0.123 & $1.1(1.0-1.2)$ & 0.002 \\
Low + medium) vs. high risk & CYP1A2*1F & -0.783 & $2.2(1.0-4.6)$ & 0.038 \\
& age & 0.037 & $1.0(0.99-1.1)$ & 0.070 \\
\hline
\end{tabular}

\section{Discussion}

The polymorphic nature of genes encoding for key enzymes in the metabolic activation of HCA in humans, is believed to result in interindividual differences in metabolizing potential. In this way, genetic polymorphisms may lead to differences in cancer risk susceptibility between individuals. Here, the influence of the CYP1A2-164A $\rightarrow C$ 
polymorphisim (CYPIA2*1F), the CYP1A2 phenotype and the NAT2 genotype and phenotype on the risk for development of colorectal adenomas was studied in a case control setting, using logistic regression models.

Development of colorectal adenoma and cancer is known to occur more frequently at higher age. Therefore, it is not surprising that in this study, significant associations were found between age and CRC risk. However, to our knowledge, so far only one study investigated the relation between the CYP1A2 $1 \mathrm{~F}$ polymorphism and CRC risk but no significant association was found (25). In contrast to these findings, our analysis is the first to clearly show a risk reducing influence of the CYP1A2*1F polymorphism on colorectal neoplasia risk, despite our relatively small study population. Because almost all colorectal cancers arise from preexisting adenomas (12), both adenorna patients and cancer patients were included in our study, and were divided into different risk groups. For the CYP1A2 $2^{\text {ty }} \mathbb{F}$ polymorphism, statistically significant associations were found when comparing the high-risk group to the low-risk or to the combined low-/medium-risk group, with odds ratios of $3.7(95 \% \mathrm{Cl}, 1.3-10.7)$ and $2.2(95 \% \mathrm{Cl}, 1.0-4.6)$, respectively. Furthermore, there was an association of borderline significance when comparing the low-risk group to the combined medium-thigh-risk group, the odds ratio being $2.0195 \%$ $\mathrm{Cl}, 0.9-4.4)$. These findings indicate that individuals carrying the CYP1A2-164A/A constellation are at higher risk for producing mutagenic HCA metabolites, which may induce an early mutation in the sequence of the Vogelstein model for colorectal tumorigenesis (12). Thus, these subjects are at higher risk for developing colorectal neoplasia as compared to those with a C/A or C/C genotype.

The CYP1A2 phenotypic activity was not found to be correlated to the CRC risk, despite the significant association between CYP1A2 genotypes and phenotypes when omitting extreme values. High CYP1A2 activities have previously also not been found to correlate to CRC risk $(26,27)$. In our study, CYP1A2 activities did not differ significantly between smokers and non-smokers and CRC risk was not influenced by smoking status.

With respect to NAT2 genotyping, a positive relationship between fast acetylators and $\mathrm{CRC}$ was found in only one study (28). Our results are therefore in agreement with most other studies (e.g. 29,30), showing no significant association between the NAT2 genotype and risk of colorectal neoplasia (data not shown). Severall studies have found a significantly elevated CRC risk for individuals who possess both high NAT2 and CYP1A2 activities $(31,32)$, whereas other studies have not (26). Furthermore, some studies found a significant association between high NAT2/CYPUA2 activities and CRC in individuals who preferred well-done red meat $(27,33)$. Alternatively, patients with the hereditary familial adenomatous polyposis (FAP) syndrome showed lower NAT2 activities and higher CYP1A2 activities as compared to control subjects (34). In our study, we used logistic regression models to investigate the influence of genotypic and phenotypic variations in CYP1A2 and NAT2 on the risk of colorectal neoplasia. High CYPAA2 and NAT2 phenotypic expressions were neither independently nor interactively significantly correlated to CRC risk (data not shown).

The CYP1A2*1F polymorphism is a very common single nucleotide polymorphism (SNP) of the CYP1A2 gene, which has been associated with altered phenolypic activity in smokers $(15,17)$. Recently, we found a significant association between the CYP1A2 SNP and urinary excretion levels of the HCA 2-amino-1-methyl-6-phenylimidazo[4,5-b]pyridine (PhIP) in a human dietary intervention study, demonstrating that high CYP1A2 activity leads to increased bioactivation of PhIP, thus leaving less of the unchanged HCA to be excreted in urine (submitted for publication). Although the CYP1A2 $1 F$ polymorphism is located in a non-coding region (intron 1) of the CYP1A2 gene, it may effect CYP1A2 phenotypic activity due to modification of a target sequence for the binding of regulatory proteins (15). Unfortunately, in the present study we were not able to identify HCA-DNA 
adducts in polyps biopsies, apparently due to lack of sufficient sensitivity of the postlabeling assay.

The frequency distributions for both CYP1A2 and NAT2 enzymatic activities showed normal distributions when plotted as logarithmic values (Figure 1). For NAT2, this is contrary to mast other studies using urinary caffeine metabolites to assess metabolic activity, where the AFMU/1X ratios showed a bimodal (e.g. 26,28) or even a trimodal distribution (35). This could be due to the relatively small study population in our sudy. Genotyping results showed population distributions that were comparable to those in Caucasian populations in other studies $(17,36)$. Although NAT2 phenotypic ratios were found to be significantly different for the two genotypes, the NAT2 phenotype was introduced as a continuous variable in the logistic regression analysis, in view of the apparently normal distribution when plotted as logarithmic values (Figure 1B). In several studies, associations were found between high NAT2 enzymatic activities and susceptibility to colorectal neoplasia (e.g. 37), but other studies failed to demonstrate such a relationship $(26,38)$.

For CYP1A2, the nearly significant difference in phenotypic ratios for the different genotypes reached a high degree of significance when the extreme values were omitted from the analysis. Although the expression of CYP1A2 enzymatic activity can be influenced by many ather factors, such as smoking, diet (18) and polymorphisms in other genes (19), we confirm a borderline significant association between CYP1A2 genotypes and phenotypes. These findings are contrary to those of Sachse et al. who found no association between the CYP1A2*1F polymorphism and the CYP1A2 phenotype, using a slightly different urinary caffeine metabolite ratio to assess the phenotype (39). The caffeine metabolite ratio used in our study, [(AFMU + $1 X+$ $1 \mathrm{U}) / 17 \mathrm{U}]$, has proved to give a reliable indication of caffeine clearance in humans $(40)$.

In conclusion, for the first time a significant association between the CYP1A2-164A $\rightarrow \mathrm{C}$ polymorphism and the risk of colorectal neoplasia in a human study population is described.

These results are in agreement with the hypothesis that genetically susceptible subgroups are particularly at risk with respect to the development of colorectal adenomas, possibly due to increased capacity of wild types of bioactivating HCA into their ultimate carcinogenic metabolites. Unfortunately, we could not quantify levels of HCA binding to DNA of colon biopsies, in order to evaluate this test hypothesis. As our results demonstrate that the CYP1A2-164A/A genotype is quite common occurring at 52 $\%$ in the general population, in order to reduce overall colon cancer risk, it makes sense to avoid exposure to food ingredients such as HCA which require bioactivation for becoming mutagenic.

\section{Acknowledgement}

The authors would like to thank Dr. W. Vos from the Pathology department of the Maasland Hospital in Sittard for his kind cooperation in this study.

\section{References}

1. Parkin, O.M., Whelan, S.L., Ferlay, J., Raymond, L., Young, J. (eds.) (1997) Cancer Incidence in Five Continents. IARC Scientific Publications vol VII 143, IARC, Lyon.

2. McMichael, A.J., Giles, G.G. (1988) Cancer in migrants to Australia: extending the descriptive epidemiollogical data. Cancer Res 48, 751-756.

3. Cannon-Abright, L.A.. Skolnick, M.H., Bishop, D.T. Lee R.G., Burt, R.W. (1988) Common inheritance of susceptibility to colonic aderomatous polyps and associated colorectal cancers N Engl J Med 319, 533-537 
4. Doll, $R$, Peto, $R$. (1981) The causes of cancer: quantitative estimates of avaidable risks of cancer in the United States today. N Wal Cancer Inst 66, 1191-1308.

5. Giovannucci, E., Stampter, E.J, Colditz, G., Rimm, E.B., Nillett, W.C. (1992) Relationship of diet to risk of colorectal adenoma in men. J Nati Cancer Inst 84, 91-98.

6. Kono, S., Imanishi, K. Shinchi, K., Wanai, F. (1993) Relationship of diet to small and large adenomas of the sigmoid colon. Jpn J Cancer Res 84, 13-19.

7. Goldbohm, R.A. vain den Brandt, P.A. wan theer P., Brants H.A., Dorant, E., Sturmans, F., Hermus, R.J. (1994) A prospective cohort study on the relation between meat consumption and the risk of colon cancer. Cancer Res 54,718-723.

B. Giovannucci, E. Rimm, E.B. Stampfer, M.J., Colditz, G.A., Ascherio, A., Willett, W.C. (1994) Intake of fat, meat and fiber in relation to risk of colon cancer in men. Cancer Res 54,2390 . 2397

9. Nagao, N., Ushijima, T., Watanabe, N., Okochi, E, Ochiai, M., Nakagama, H., Sugimura, T. (2002) Studies on mammary carcinogenesis induced by a heterocycic amime 2-amino-1methyl-6-phenyllimidazo[4,5-blpyridine, in mice and rats. Erviron Mol Mutagen 39, 158-164.

10. Adamson. R.H. Thorgeirsison, U.P., Snyderwine, E.G. Thorgeirsson. S.S. Reeves, J. Dalgard, D.W. Takayama, S., Sugimura $T$. (1990) Carcinogenicity of 2-amino-3. methylimidazol4,5-fiquinoline in monhuman primates: induction of tumors in three macaques. Jpn $J$ Cancer Res 81, 10-14.

11. Ochiai, M., Ogawa, K., Walkabayanstu, K., Sugimura, T., Nagase, S., Esumi, H., Nagao, M. (1991) Induction of intestinal aidenocarcinomas by 2-amino-1-methyl-6-phenylimidazo[4,5b]pyridine in Niagase analbuminemic rats. Jpn $/$ Cancer Res $82,363-366$.

12. Vagelstein, B., Fearon, ER., Hamilton, S.R. Kern, S.E., Preísinger, A.C., Leppert, M., Nakamulra, $Y$., White, R., Smits, A.M., Bos, J.L. (1988) Genetic alterations during colorectaltumor development. N Engl J Med 319,525-532.

13. Moonen, H.J.J., Briedé, J.J., wan Malanen, J.M.S., Kleinjans, J.C.S., de Kok. T.M.C.M. (2002) Generalion of free radicals and induction of DNA adducts by activation of heterocyclic aromatic amines wial different metabolic pathways in witro. Mol Carcinog 35, $\$ 96-203$.

14. Kadlubar, F.F., Kaderlik, K.R., Mulder, G.J., Lin, D., Butler, M.A., Teitel, C.E., Minchinn R.F.n lett, K.F. Friesen, M.D., Bartsch, H., Nagao, M., Esumi, H., Sugimura, T., Lang. N.P. (1995) Metabolic actwation and DNA adduct detection of PhIP in dogs, rats, and humans in relation to urinary bladder and colon carcinogenesis. In: Adamson, R.H., Gustafsson, J.A., Nobuyuki "I. Nagao, M. Sugimura, T., Wakabayashi, K., Yamazoe, Y. (Eds.) Heterocyclic amines in cooked foods: possible human carcimogens. Princeton Scientific Publishing Co. NJ, pp. 207213.

15. MacLeod, S.L., Tang, Y-M. Yokoi, T., Kamataki, T., Doublin, S., Lawsom, B., Massengill, J., Kaduluar, F.F., Lang. N.P. (1998) The role of a recently discovered genetic polymorphism in the regulation of the human CYP1A2 gene. Froc Am Assoc Cancer Res 39, 396-396.

16. Nakajima, M., Yokoi ${ }_{\text {i }}$., Mizutani, M., Kinoshita, M. Funayama, M., Kamataki, T. (1999) Genetic polymorphism in the 5 -flanking region of human CYP1A2 gene: effect on the CYP1A2 inducibility in humans. J Brochem 125, 803-808.

17. Sachse: C. Brockmöller, J., Bauer, S. Roots, 1. (1999) Functional significance of a $C \rightarrow A$ polymorithism in untron I of the cytochrome P450 CYP1A2 gene tested with caffeine. Br J Chn Phamacol $47,445-449$

18. Landi, M.7., Sinha, R., Lang. N.P. Kadubar, F.F. (1999) Human cytochrome P450142. Im: Vineis, P., Malats, N., Lang. M., d'Erico, A. Caporaso, N., Cuzik, J., Boffetta, P. (Eds.) Metabolic Polymorphisms and Susceptibility to Cancer. IARC Scientific Publications 148. 173195.

19. Macleod, S., Sinha, R., Kadlubar, F.F., Lang, N.P. (1997) Polymorphisms of CYP1A1 and GSTM1 influence the in vivo function of CYP1A2. Mut Res 376, 135-142

20. Krul, C. Mageman, G. (1998), Amalysis of urinary caifeine metabolites to assess biotransformation enzyme activities by reversemphase high-performance liquid chromatography. I Chrom $3709,27,34$.

21. De Kok, T.M.C.M., Van Faassen, A., Glinghammar, B., Pachen, D.M.F.A., Eng, M., Rafter, J.d., Baeten, C.G.M.I., Engels, L.G.J.B., Kleinjans, J.C.S. (1999) Bile acid concentrations, cytotoxicity, and pH of fecal water from patients with colorectal adenomas. Dig Dis Sci 44 , $2218 \cdot 2225$. 


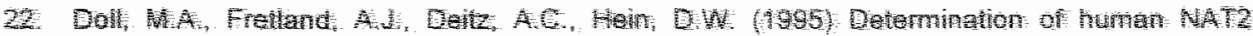

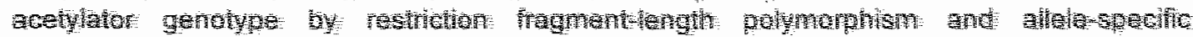

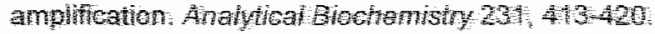

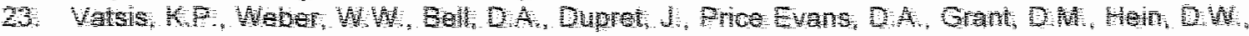

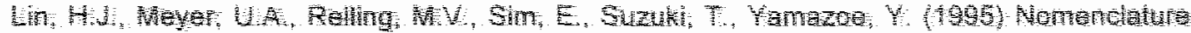

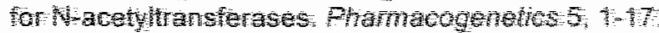

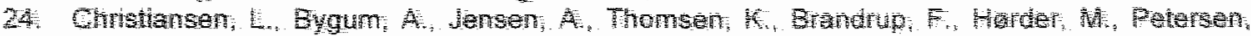

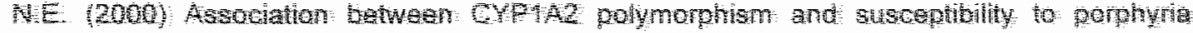

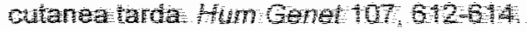

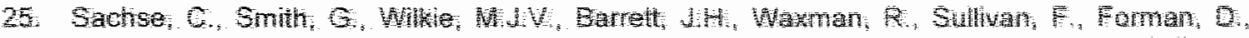

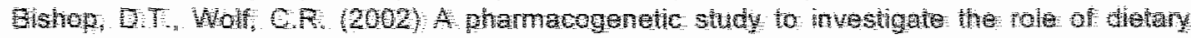

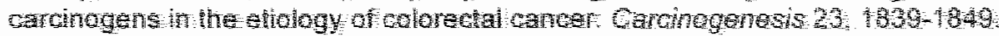

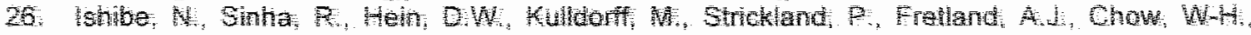

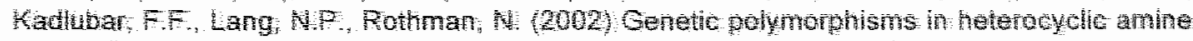

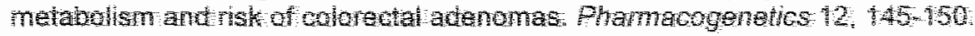

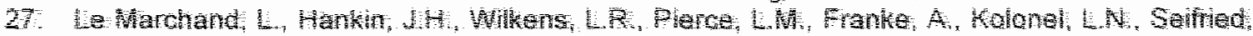

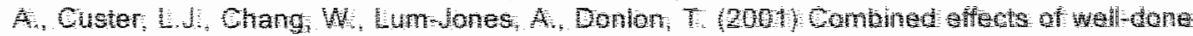
red meat amoking and rapid Hacetyltransferase 2 and CYPtA2 phenotypes in increasing

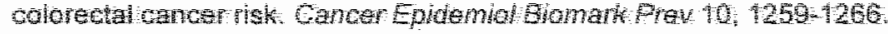

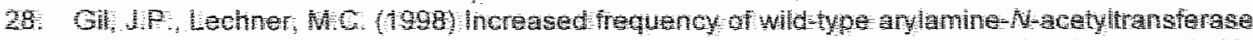

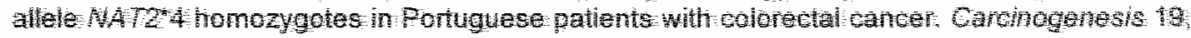
374

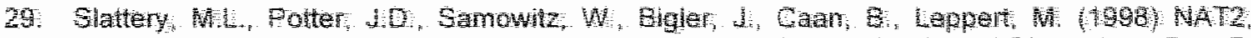

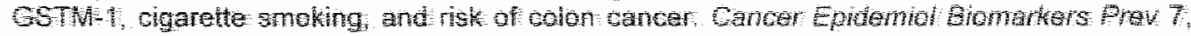
$1079-804$

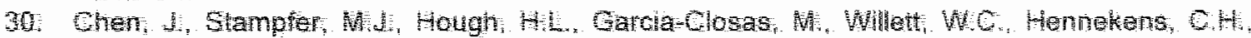

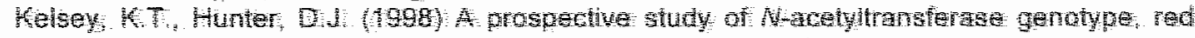
meat intake, and risk of colorectalcancer Cancer Res 58 ; 307-1.

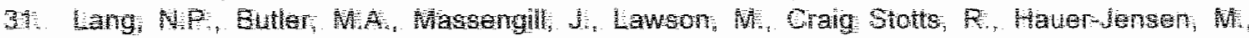

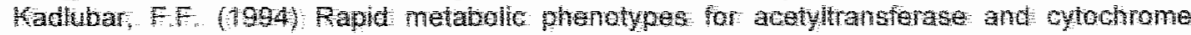

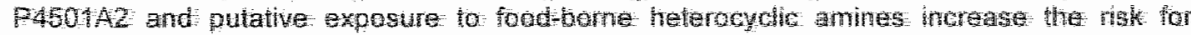

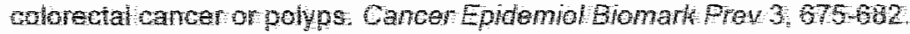

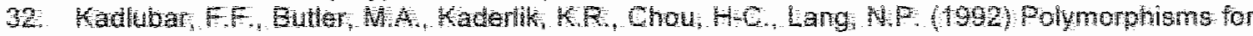
aromatic amine metabolism in tumang: relevance for human carcingenesgis. Environ Health Perspect 98, 68.74:

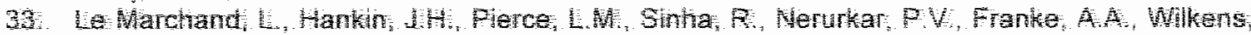

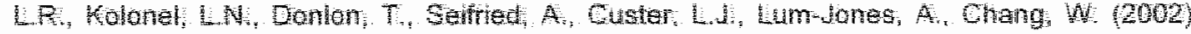

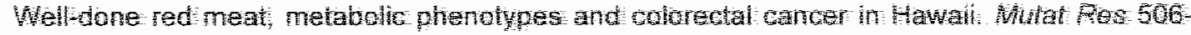
507, 205-214.

34. Spigelman, A.D., Farmer, K.C., Oliwer, S., Nugent, K.P., Bennett, P.N., Notarianni, L.J., Dobrocky, P., Phillips, R.K. (1995) Caffeine phenotyping of cytochrome P4501A2, Nacetyltransferase, and xanthine oxidase in patients with familial adenomatous polyposis. Gut $36,251-254$

35. Grant, D.M., Tang. B.K., Kallow, W. (1984) A simple test for acelylator phenotype using caffeine. Br J Clin Parmac 17, 459-464.

36. Hein, D.W., Doll, M.A., Fretland, A.J., Leff, M.A., Webb, S.J., Xiao, G.H., Devanaboyina, U-S., Nangju, N.A., Feng, Y. (2000) Molecular genetics and epidemiology of the NAT1 and NAT2 acetylation polymorphisms. Cancer Epidemiol Biomark Prev 9, 29-42

37. Probst-Hensch. N.M. Haile, R.W. Ingles, S.A., Longnecker, M.P..Han, C.Y., Lin, B.K., Lee, D.B., Sakamota, G.T., Franskl, H.D. Lee, E.R., Lin, H.J. (1995) Acelylation polymorphisms and prevalence of colorectal adenomas. Cancer Res 55, 2017-2020.

38. Potter, J.D., Bigler, J., Fosdick, L., Bostick, R.M., Kampman, E., Chen, C., Louís, T.A., Grambsch, P. (1999) Colorectal adenomatous and hyperplastic polyps: smoking and Nacetyltransferase 2 polymorphisms. Cancer Epidemiol Biomark Prev 8, 69-75.

39. Sachse, C., Bhambra, U., Smith, G.. Lightfoot, T.J, Barrett, J.H., Scollay, J., Garner, R.C., Boobis, A.R., Wolf, C.R., Gooderham, N.J. (2003) Polymorphisms in the cytochrome P450 CYP1A2 gene (CYP1A2) in colorectal cancer patients and controls: allele frequencies, linkage disequilibrium and influence on caffeine metabolism. Br J Clin Pharmacol 55, 68-76. 


\section{CHAPTER WI}

40. Vistisen, K, Loft, $S_{i}$ Poulsen, H.E. (1991). Cytochrome P450 1 A2 activity in man measured by caffeine mietabolism: effect of smoking, brocicoli and exercise. Adv Exp Med Biol 283, 407-411. 


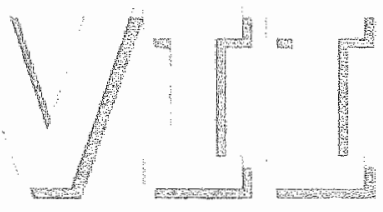

\section{Summary \& general discussion}


It is undisputed that humans are daily exposed to a large variety of genotoxic compounds. A substantial part of this exposure can be attributed to the diet, and there is convincing evidence that the intake of certain food compounds may contribute to cancer risks. More specifically, the intake of red and processed meat is believed to be related to colon cancer risk.

According to the Vogelstein model, the development and progression of colorectal tumors is resulting from an accumulation of multiple genetic alterations in both oncogenes and tumor suppressor genes. In the majority of colorectal cancers, the APC gene is inactivated in an early stage of tumorigenesis. which triggers a casciade of other genetic alterations. It is hypothesized that exposure to dietary mutagens, as present in foods, may be of significant importance in these early mutations. In this perspective, the occurrence of heterocyclic aromatic amines (HCA) in processed meat is suspected to be relevant. HCA, firstly discovered and characterized some 25 years ago, are formed during the cooking of meat and are pyrolytic products from reactions involving different meat constituents like sugars, amino acids and creatine. HCA have proved to be highly mutagenic in bacteria, and carcinogenic in rodents and non-human primates. In humans, numerous epidemiological studies have demonstrated a relationship between $H C A$ intake and colorectall cancer risk (CRC), but these studies give no information about the metabolic and bioactivation pathways these HCA pass through in the human body. To obtain more insight in these processes, biomarkers have been developed that integrate several aspects that influence the ultimate risk. Chapter 2 describes the development and optimization of two methods that are widely used to determine biomarkers for HCA exposure and activation. The formation of covalently bound DNA adducts is regarded as an essential step in the carcinogenic process and these adducts can be seen as markers of internal dose and therefore be used as biomarkers of risk at target sites, e.g. DNA. Adduct levels can vary widely between individuals, due to differences in exposure levells, absorption, distribution, metabolic (in)activation, genetic susceptibility and DNA repair capacity. The ${ }^{32}$ P.postlabeling assay is a very sensitive method and is widely used for detection of DNA adducts. However, many different methods and modifications of basic methods have been developed since this technique was described for the first time, more than 20 years ago. As a result, large interlaboratory variations in DNA adduct analysis have arisen. Alternatively, the measurement of HCA compounds in urine reflects recent HCA exposure and bioactivation. GC-MS analysis has been widely applied for this purpose, because of its selectivity and sensitivity. Again, many different methods have been developed and described for this technique. For both ${ }^{32} \mathrm{P}$ postlabeling and GC-MS, selection and optimization of the most appropriate assay was necessary to achieve the research goals of our particular studies. Eventually, we succesisfully developed suitable methods for application in our studies. The detection limits under the most optimal conditions were 1 adduct per $10^{8}$ nucleotides for postlabeling and $5 \mathrm{pg}$ PhIP per ml urine for GC-MS analysis, making it possible to study HCA metabolism in vitro and in vivo.

Metabolic activation of HCA may proceed via two different pathways. The hepatic pathway involves $N$-oxidation to $N$-hydroxy metabolites, catalyzed by cytochome P4501A2 (CYP1A2), and subsequent O-acetylation to $N$-acetoxy arylamines, catalyzed by $N$-acetyltransferase 2 (NAT2). The extrahepatic pathway is dependent on the metabolic conversion of arachidonic acid (AA), during which HCA can serve as cosubstrates, thus being oxidized to free radical metabolites. This reaction is caltalyzed by the enzyme prostaglandin $H$ synthase (PHS), which is often termed cyclooxygenase (COX), featuring two distinct activities. In Chapter 3, the different routes for PhIP and IQ bioactivation were studied in vitro, using both electron spin resonance (ESR) spectroscopy and ${ }^{32} \mathrm{P}$-postlabeling to monitor the formation of primary and secondary HCA metabolites. Using ESR spectroscopy, both PhIP and IQ were found to inhibit the 
COX-mediated formation of oxygen radicals during the conversion of arachidonic acid to prostaglandins, possibly due to competition between the generation of reactive oxygen species (ROS) and HCA oxidation, or reaction of HCA with these ROS. The hepatic and extrahepatic pathway were represented by rat liver S9-mix and PHS, respectively, and led to different primary metabolites for both HCA. Formation of HCA radicals was indicated by the detection of glutathione-derived thiyl radicals. In this way, the generation of free radical metabolites was indirectly demonstrated for PhIP and $I Q$ in the PHS. catalyzed pathway, but not in the S9-catalyzed route. HCA bioactivation can eventually llead to metabolites that can covalently bind to DNA, thus forming DNA adducts that are mutagenic. DNA adducts that are formed in the colon may induce early mutations in crucial genes, which can eventually result in colorectal adenomas, as described in the Vogelstein model. ${ }^{32}$ P-postlabeling analysis showed identical DNA adduct profiles after S9- and PHS-activation of PhIP in the presence of single and double stranded salmon testes DNA, indicating the ultimate formation of a common reactive metabolite, presumably an arylnitrenium ion. For IQ, an additional spot was found after PHSactivation, which may result from direct DNA adduct formation by $1 Q$ free radicals. Overall, in both the ESR and postlabeling assays, $1 \mathrm{Q}$ showed stronger effects as compared to $\mathrm{PhIP}$. These results indicate that the PHS-catalyzed activation of HCA should be taken into account when the formation of genotoxic HCA metabolites which may induce mutagenic events, is investigated in vivo, especially in extrahepatic tissues like the colon.

The difference in DNA adduct forming capacity of PhiP and $1 Q$ was also observed in human adenocarcinoma colon cells (HCA-7), as described in Chapter 4. These cells highly express enzyme isoform COX-2, and can therefore be used to investigate HCA activation via the extrahepatic pathway, comprising onemelectron oxidation during the conversion of the polyunsaturated fatty acid (PUFA) AA to prostaglandin $E_{2}\left(P E_{2}\right)$. Next to $A A_{1}$ adidition of linoleic acid (LA) also resulted in $P G_{2}$ formation, demonstrating that HCA-7 cells are capable of converting LA into AA. DNA adducts were readily formed by both $\mathrm{PhIP}$ and $\mathrm{IQ}$, and their formation was stimulated by addition of the n-6 PUFA AA and the n-3 PUFA EPA, clearly demonstrating involvement of COX in this process. The promoting effect of both PUFA on DNA adduct formation by HCA is not in agreement with epidemiological findings, where n-6 PUFA exert beneficial effects, whereas n-3 PUFA show protective effects with respect to colorectal cancer risk. The stimulating effect was inverted by adding high amounts of PUFA, which might be explained by either fatty acid micelles entrapping the HCA, inhibition of COX activity by PUFA, or scavenging of HCA radicals by PUFA molecules. The role of $C O X, C O X-2$ in particular, and CYP1A2 was further investigated by using the specific enzyme inhibitors indomethacin (IM). NS-398 and phenethyl isothiocyanate (PEITC), respectively. Inhibition of PhIP-and IQ-DNA adduct formation by IM and NS-398 to nearly the same extent demonstrated involvement of mainly COX-2, not COX-1. PEITC also inhibited adduct formation, thus indicating that HCA-7 cells possess CYP450 activity, that may not be limited to CYPIA2. These study results confirm that COX, and especially COX -2 . could play an important role in HCA bioactivation in extrahepatic tissues, causing the formation of DNA adducts and subsequent mutagenic events. This might be a reason for the decrease in CRC risk that has been observed after long-term use of aspirin, which is known to inhibit COX. Furthermore, interaction with PUFA in COX-expressing cancer cells imply that other (food) compounds could be important in modulating colorectall cancer risk in wivo.

In humans, efficient absorption of HCA into the systemic circulation takes place after ingestion, leading to a high degree of bioavailability. The enzymes that are responsible for the hepatic activation of HCA, CYP1A2 and NAT2, show interindividual differences in activities, due to polymorphic distribution of the corresponding genes in the 
human population. However, since genotyping cannot be simply used to predict phenotypes, combined analysis of both geno-and phenotypes is considered necessary. in Chapter 5 , the influence of dietary exposure and variations in enzymatic activities (phenotypes) and genetic constitutions (genotypes) for CYP1A2 and NAT2 on PhIP metabolism was studied. For 10 consecutive days, 71 healthy wolunteers consumed daily portions of chicken, containing either a low $(1.7 \pm 0.6 \mathrm{ng} / \mathrm{g})$ or high $(7.4 \pm 2.0 \mathrm{ng} / \mathrm{g})$ dose of PhIP. $24 \mathrm{hr}$ urine samples were collected before, during and after the intervention period. Subjects were phenotyped for CYP1A2 and NAT2 by HPLC analysis of urinary caffeine metabolites, and genotyping for NAT2 and CYP1A2 was performed using PCRRFLP. CYP1A2 genotyping comprised analysis of the $-164 \mathrm{~A} \rightarrow \mathrm{C}$ polymorphism (CYP1A2*1F), one of the most cormon in Caucasians and suitable for routine assessment of the CYP1A2 genotype in humans. Urinary excretion levels, measured by GC-MS, were found to reflect the recent dietary exposure. NAT2 genotypes and phenotypes showed $79 \%$ concordance, and the bimodal phenotypic distribution could be clearly distinguished by the genotype. For CYP $1 A 2$, no significant correlation was found between the genotype and enzyme activities. From the different phenotypes and genolypes, the CYPIA2 $1 F$ polymorphism was significantly correlated to urinary PhIP excretion, and this correlation was strongly influenced by the genotype that occurred in only two individuals. These results demonstrate that slow oxidizers (possessing the $\mathrm{ClC}$ genotype) excreted higher amounts of urinary PhIP as compared to fast oxidizers. implying that these fast oxidizers are exposed to higher internal doses of genotoxic PhIP metabolites. Therefore, this polymorphism could play a role in colon cancer risk susceptibility in humans.

To assess the health risk associated with CYP1A2 and NAT2 genotypes and phenotypes, in Chapter 6 these parameters were studied in 94 patients at different risk of developing CRC, based on the occurrence and size of colorectal adenomas that were found and removed upon endoscopic examination. All individuals were phenotyped and genotyped for CYP1A2 and NAT2, using the same methodology as applied in the human intervention study described in Chapter 5. Although high enzyme activities for CYP1A2 and NAT2 have been correlated to an elevated CRC risk in some other studies, no such associations were found in the patients that were studied here. In contrast, the CYP1A2* $1 F$ polymorphism was found to be correlated to CRC risk when comparing different risk groups or combination of risk groups. This implies that individuals possessing the mutated CYP1A2 gene are at lower risk for developing CRC as compared to individuals possessing the wildtype constitution. With respect to the Vogelstein model, this genetic polymorphism may be of significance in the early stage of colorectal tumorigenesis most probably with respect to the induction of mutagenic events due to the bioactivation of food borne mutagens, and may thus influence the eventual colorectal cancer risk.

HCA-DNA adduct measurement in human studies

The ${ }^{32}$ P-postlabeling assay, as described in Chapter 2, was intended to be applied in both the human studies described in this thesis, thus evaluating DNA damaging effects of activated HCA molecules. As stated earlier, DNA adducts can be used as biomarkers of internal exposure and risk, giving an overall view of the metabolic fate of HCA in the human body.

In the intervention study with healthy volunteers (Chapter 5), attempts were made to detect HCA-DNA adducts in peripheral blood lymphocytes, serving as surrogate tissue for the colon. Also, in this way, it would be possible to study the peripheral availability of reactive HCA metabolites. However, no adducts were detected in DNA isolated from these cells. HCA-DNA adduct levels in a target tissue like the colon are expected to be higher than in lymphocytes, based on metabolic activity and as demonstrated in animal 
experiments. Therefore, the rectal biopsies obtained from the patients described in Chapter 6 were also tested for HCA-DNA adducts. Unfortunately. DNA isolated from normal mucosa nor adenoma tissue showed detectable adduct levels at our detection limit of 1 adduct per $10^{8}$ normal nucleotides. Alhough more sensitive methods for DNA adduct measurement have been developed, they are not applicable in standard biomonitoring studies due to the $u s e$ of ${ }^{14} \mathrm{C}$-labeled substrates.

Thus, it can be stated that HCA-DNA adducts in both the colon tissues of the patients and the lymphocytes of the volunteers, if present, occur at levels lower than 1 adduct $10^{8}$ nucleotides; the actual presence of these adducts can therefore not be excluded.

Future studies should focus on lowering the detection limit of the present postlabeling assay, or development and application of an alternative technique, enabling even more sensitive detection of HCA-DNA adducts.

In conclusion, the data presented in this thesis, show that HCA can be readily activated by two different pathways. Although the hepatic pathway has been studied and emphasized far more extensively, the free radical generating pathway may also be of significant influence in the onset of colorectal carcinogenesis. Therefore, metabolic activation of HCA via this route should be taken into account when investigating cancer risk induced by HCA exposure, especially in extrahepatic tissues such as the colon. Furthermore, it may be important to consider interactions with other compounds like PUFA, as these interactions can possibly modulate the eventual CRC risk. In humans. the CYP1A2*1F polymorphism influences HCA metabolism and can thus play an important role in the ultimate health risk related to HCA exposure.

Overall, although our study results presented in this thesis provide much information on the metabolic activation of $\mathrm{HCA}$ and the influence of variations in genes and corresponding enzymes involved herein, no final conclusion can be drawn with respect to HCA exposure and human colorectal cancer risk. Nevertheless, our HCA metabolism studies did demonstrate that the extrahepatic pathway should always be taken into account when investigating metabolic activation of HCA in humans. Furthermore, our human studies show that certain individuals are at higher risk for developing genotoxic damage and colorectal neoplasia as compared to others, and these risk groups should thus be careful with frequent consumption of well-done meat.

Future research should further investigate the importance of the CYP1A2 genotype in HCA risk assessment in humans. Finally, studies in larger populations are necessary to substantiate and extend our findings, and the development of very sensitive methods should make it possible to measure relevant biomarkers of internal exposure and risk in such populationis. 


\section{Samenvatting}

Het staat vast dat de mens dagelijks wordt blootgesteld aan een grote verscheidenheid aan genotoxische stoffen. Een aanzienlijk gedeelte van deze blootstelling kan worden toegeschreven aan voeding, en er is overtuigend bewijs dat de inname wan bepaalde voedingscomponenten een bijdrage zou kunnen leveren aan kanker risico's. Zo wordt de inname van rood en bereid vlees in verband gebracht met dikke darmkanker. Volgens het Vogelstein model is de ontwikkeling en progressie van dikke darmtumoren het resultaat van een opeenstapeling van meervoudige genetische veranderingen in $\mathbb{Z}$ owel oncogenen alls tumor suppressor genen. Bij de meerderheid van de dikke darmkanker gevallen is het A.PC gen geïnactiveerd in een vroeg stadium van tumorvorming, waardoor een cascade van andere genetische veranderingen wordt veroorzaakt. Het wordt verondersteld dat blootstelling aan mutagene stoffen, zoals die voorkomen in voeding, van groot belang kan zijn bij deze vroege mutaties. In dit verband is het voorkomen van heterocyclische aromatische amines ( $\mathrm{HCA})$ in bereid wlees waarschijnlijk van bellang. HCA werden ca. 25 jaar geleden ontdlekt en gekarakteriseerd, en worden gevormd tijdens de werhitting van vlees. Het zijm verbrandingsproducten van reacties waarbij verschillende vleesbestanddelen zoals suikers, aminozuren en creatine zijn betrokken. HCA zijn zeer mutageen in bacteriën en carcinogeen in knaagdieren en apen. Vele epidemiologische studies hebben een relatie aangetoond tussen inname van HCA en het risico op dikke darmkanker in de mens. Deze studies geven echter geen informatie over het metabolisme en de bioactivatie-routes van HCA in het lichaam. Om meer inzicht in deze processen te krijgen, zijn biomarkers ontwikkeld waarin verscheidene aspecten, die het uiteindelijke risico beïnvloeden, zijn geîntegreerd. Hoofdstuk 2 beschriff de ontwikkeling en optimalisatie van twee methoden die veelvuldig worden gebruikt om biomarkers voor HCA-blootstelling en -activatie te meten. De vorming van covalent gebonden DNA adducten wordt beschouwd als een essentiele stap in het carcinogene proces, en deze adducten kunnen gezien worden als markers van de interne dosis en kunnen dus gebruikt worden als biomarkers voor het risico op bepaalde doellocaties (b.v. DNA). Adductniveaus kunnen sterk variëren tussen mensen, als gevolg van verschillen in blootstelling, absorptie, verdeling, metabole (in)activatie. genetische gevoeligheid en DNA herstel capaciteit. De ${ }^{32}$ P-postlabeling methode is een zeer gevoelige en wordt veel gebruik: voor detectie van DNA adducten. Ongeverer 20 jaar geleden werd deze techniek woor het eerst beschreven, en sindsdien zijn vele verschillende methoden en aanpassingen van basismethoden ontwikkeld. Het gevolg hiervan is dat er tussen verschillende laboratoria grote verschillen zijn ontstaan ten aanzien van de DNA adduct analyse.

Het meten van HCA verbindingen in urine weersplegelt de recente $\mathrm{HCA}$ bllootstelling en bioactivatie. GC-MS analyse is hiervoor veelvuldig gebruilkt, vanwege de hoge selectiviteit en gevoeligheid. Ook hiervoor geldt dat vele verschillende methodes en aanpassingen zijn ontwikkeld en besichreven. Voor zowel ${ }^{32} \mathrm{P}$-postlabeling als GC-MS was het noodzakelijk om de meest geschikte methode te selecteren en optimaliseren. teneinde de onderzoeksdoelen in onze studies te bereiken. Uiteindelijk zijn we er in geslaagd am geschikte methaden te ontwikkelen voor toepassing in onze studies. De detectiegrenzen onder de meest optimale condities waren 1 adduct per $10^{8}$ nucleotiden voor de postlabeling en $5 \mathrm{pg}$ PhIP per ml urine voor de GC-MS analyse, wat het mogelijk maakte om hel HCA metabolisime zowel in vitro als in wivo te bestuderen. 
Metabole activatie van HCA kan verlopen via wee verschillende routes. De hepatische route betreft $N$-oxidatie tot $N$-hydroxy metabolieten en daarop volgend $O$ acetylering tot $N$-acetoxy arylamines, gekatalyseerd door respectievelijk cytochroom P4501A2 (CYP1A2) en N-acetyltransferase 2 (NAT-2). De extrahepatische route is afhankelijk van de metabole omzetting van arachidonzuur, waarbij HCA kunnen dienen als co-substraten en zo kunnen worden geoxideerd tot vrije radicaal metabolieten. Deze reactie wordt gekatalyseerd door het enzym prostaglandine H synthase (PHS), ook wel cyclooxygenase (COX) genoemd, dat wordt gekenmerkt door twee verschillende activiteiten. In Hoofdstuk 3 werden de twee werschillende routes woor de bioactivatie van $\mathrm{Ph} I \mathrm{P}$ en IQ in vitro bestudeerd, door gebruik te maken van zowel electron spin resonantie (ESR) spectroscopie en ${ }^{32} \mathrm{P}$-postlabeling om de vorming van primaire en secundaire HCA metabolieten te volgen. Met behulp van ESR spectroscopie kon worden aangetoond dat zowel PhIP als IQ de worming van zuurstof radicalen kunnen remmen, die ontstaan tijdens de COX-gemedieerde omzetting van arachidonzuur. Dit kan mogelijk verklaard worden door competitie tussen de vorming van reactieve zuurstof species en HCA oxidatie, of door reactie van HCA met de gevormde reactieve vormen van zuurstof. De hepatische en extrahepatische routes werden voorgesteld door respectievelijk S9mix uit rattenlever en PHS, en leidden tot verschillende primaire metabolieten voor beide HCA. De vorming van HCA radicalen werd aangetoond door de detectie van thiyl radicalen, gevormd uit glutathion. Op deze manier werd de worming wan vrije radicaal metabolieten uit PhIP en IQ op een indirecte manier aangetoond in de PHSgekatalyseerde route, maar niet in de $\$ 9$-gekatalyseerde route. HCA bioactivatie kan uiteindelijk leiden tot metabolieten die covalent kunnen binden aan DNA, resulterend in mutagene DNA adducten. In de dikke darm gevormde DNA adducten zouden vroege mutaties kunnen veroorzaken in cruciale genen, die uiteindelijk kunnen resulteren in colorectale adenomen, zoals beschreven in het Vogelstein model. Met behulp van ${ }^{32} \mathrm{P}$ postlabeling analyse kon worden aangetoond dat S9- en PHS-activatie van PhIP in aanwezigheid van enkelstrengs en dubbelstrengs DNA tot identieke DNA adduct profielen leidt. Dit duidt op de uiteindelijke vorming van een gemeenschappelijke reactieve metaboliet, vermoedelijk een arylnitrenium ion. Voor $I Q$ werd een additionele spot gevonden na PHS-activatie, die mogelijk afkomstig is van directe DNA adduct vorming door $I Q$ radicalen. Over het algemeen vertoonde $I Q$ sterkere effecten dan $P h \| P$ in zowel de ESR als de postlabeling analyses. De resultaten laten zien dat bij de bestudering van de vorming van genotoxische HCA metabolieten in vivo, rekening gehouden moet worden met de PHS-gekatalyseerde activatie van HCA. Deze metabolieten kunnen mogelijk mutagene effecten induceren, met name in extrahepatische weefsels zoals de dikke darm.

Het verschil in adduct vormende capaciteit tulssen PhIP en IQ werd ook gevonden in humane darmkanker cellen (HCA-7), zoals wordt beschreven in Hoofdstuk 4. In deze cellen komt de enzymatische isovorm COX-2 sterk tot expressie, en dit model kan daardoor gebruikt worden om de extrahepatische activatie van HCA te onderzoeken. Deze bestaat uit 1-electron oxidatie tijdens de omzetting van het meervoudig onverzadigde vetzuur (Engels: polyunsaturated fatty acid, PUFA) arachidonzuur naar prostaglandine $E_{2}\left(P G E_{2}\right)$. De toevoeging van zowel arachidonzuur als linolzuur leidde tot de vorming vam $\mathrm{PGE}_{2}$, wat aantoont dat $\mathrm{HCA}-7$ cellen in staat zijn om linolzuur om te zetten in arachidonzuur. Blootstelling van de cellen aan zowel PhIP als $I Q$ leidde tot de vorming van DNA adducten, en dit werd gestimuleerd door de toevoeging van het $n-6$ PUFA arachidonzuur en het n-3 PUFA EPA, wat duidelijk aangeeft dat COX betrokken is bij dit proces. Het stimulerende effect van beide PUFA op de DNA adduct vorming door HCA is niet in overeenstemming met de bevindingen in epidemiologische studies, waar n-6 PUFA bevorderende effecten en n-3 PUFA beschermende effecten vertonen met betrekking tot het risico op dikke darmkanker. Door toevoeging van hoge concentraties 
PUFA nam het stimulerende effect op de adductvorming weer af, wat mogelikk verklaard zou kunnen worden door insluiting van HCA moleculen door PUFA micellen, remming van COX activiteit door PUFA, of reactie van HCA radicalen met PUFA. De rol van COX, COX-2 in het bijzonder, en CYP1A2 werd verder onderzocht door respectievelijk gebruilk van de specifieke enzymremmers indomethacine (IM). NS-398 en fenethyl isothiocyanaat (PEITC). DNA adductvorming door PhIP en IQ werd na toevoeging van IM of NS-398 in nagenoeg dezelfde mate geremd, wat aangeeft dat voornamelijk COX-2, en niet COX-1, is betrokken bij dit proces. PEITC remde ook de adductvorming, wat dus betekent dat HCA-7 cellen ook CYP450 activiteit bezitten, die niet beperkt hoeft te zijn tot CYP1A2. Deze resultaten bevestigen dat $\mathrm{COX}$, en met name $\mathrm{COX}-2$, een belangrijke rol zouden kunnen spellen bij de bioactivatie van HCA in extrahepatische weefsels, resulterend in DNA adducten en de daaropwolgende mutagene effecten. Dit zou een verklaring kunnen zijn voor de waarneming dat het risico op dikke darmkanker daalt bij langdurig gebruik van aspirine, een bekende COX-remmer. Verder impliceert de interactie met PUFA in deze cellen met hoge COX-activiteit dat andere (voedings-) stoffen van invloed kunnen zijn op het dikke darmkanker risico in vivo.

In mensen vindt, na inname, efficiènte absorptie van HCA in de systeemcirculatie plaats, wat leidt tot een hoge mate van biologische beschikbaarheid. De enzymen die verantwoordelijk zijn voor de hepatische activatie van HCA, CYP1A2 en NAT2, vertonen interindividuele verschillen in activiteit als gevolg van een polymorfe verdeling van de bijbehorende coderende genen in de humane populatie. Omdat genotypering echter niet eenvoudigweg gebruikt kan worden om het fenotype te voorspellen, wardt een gecombineerde analyse van zowel geno- als fenotypes noodzakelijk geacht. In Hoofdstuk 5 werd de invloed van blootstelling via voeding, alsook de invloed van variaties in enzymatische activiteit (fenotype) en genetische samenstelling (genotype) op het metabolisme van PhIP bestudeerd. Gedurende 10 opeenvolgende dagen consumeerden 71 wrijwilligers dagelijkse porties kip met een lage $(1.7 \pm 0.6 \mathrm{ng} / \mathrm{g})$ of een hoge $(7.4 \pm 2.0 \mathrm{ng} / \mathrm{g})$ dosis PhIP. 24 uulurs urine samples werden vóór, tijdens en na de interventieperiode verzameld. Voor alle deelnemers werden de fenotypes bepaald met behulp van een HPLC analyse van urinaire caffeine metabolieten, en de genotypes met behulp van PCR-RFLP. Genotypering voor CYP\|A2 werd uitgevoerd door analyse wan het $-164 \mathrm{~A} \rightarrow \mathrm{C}$ polymorfisme (CYP1A2*1F), een van de meest voorkomende in West-Europeanen en daardoor geschikt voor routinebepaling van het CYP1A2 genotype in mensen. Urinaire excretiegehaltes, gemeten met behulp van GC-MS, bleken de recente blootstelling weer te geven. NAT2 genotypes en fenotypes vertoonden $79 \%$ overeenstemming, en de bimodale verdeling van fenolypes kon duidelijk worden onderscheiden door de genotypes. Voor CYP1A2 was er geen significante correlatie tussen het genotype en de enzymatische activiteit. Van de verschillende fenotypes en genotypes was alleen het CYP1A2*1F polymorfisme significant gecorreleerd aan de urinaire PhIP excretie, en dit verband werd sterk beïnvloed door hel genotype dat slechts in twee personen voorkwam. Deze resultaten geven aan dat langzame oxideerders (mensen met het $\mathrm{C} / \mathrm{C}$ genolype) gratere hoeveelheden urinair PhIP uitscheiden dan snelle oxideerders, wat impliceert dat deze laatste groep wordt blootgesteld aan een hogere interne dosis genotoxische Phip metabolieten. Dit polymorfisme zou dus een rol kunnen spelen in de gevoeligheid voor dikke darmkanker in de mens.

Om het gezondheidsrisico te bepalen dat samenhangt met CYP1A2 en NAT2 genotypes en fenotypes, werden deze parameters in Hoofdstuk 6 onderzocht in 94 patiënten. Deze patiënten werden ingedeeld in verschillende risico-klassen, op basis van aanwezigheid en afmeting van darmadenomen die waren gevonden en verwijderd bij endoscopisch onderzoek. Alle personen werden gefenotypeerd en gegenotypeerd voor CYP1A2 en NAT2 met behulp wan dezelfole methode als beschreven in Hoofdstuk 5 . 
Hoewel hoge enzymactiviteiten woor CYP1A2 en NAT2 in sommige andere studies in verband zijn gebracht met een werhoogd risico op dikke darmkanker, werd een dergelijk verband niet gewonden in de hier bestudeerde patiënten. Tegengesteld hieraan werd wel een correlatie gevonden tussem het CYP1A2*1F polymorfisme en kankerrisico in de dikke darm wanneer verschillende risicogroepen of combinaties van risicogroepen werden vergeleken. Dit impliceert dat mensen met een mutatie in het CYP1A2 gen een lager risico hebben op dikke darmkanker dan mensen met het wildtype. Ten aanzien van het Vogelstein model zou dit polymorfisme belangrijk kunnen zijn in een vroeg stadium van de tumorontwikkeling in de dlikke darm, waarschijnlijk met betrekking tot de inductie van mutagene effecten als gevolg van de bioactivatie van voedselmutagenen, en zo het witeindelijke dikke darmkankerrisico kunnen beïnloeden.

\section{HCA-DNA adduct metingen in humane studies}

De ${ }^{32}$ P-postlabeling methode, zoals beschreven in Hoofdstuk 2, was bedoeld om te worden toegepast in beide humane studies die beschreven zijn in dit proefschrift, om zo de schadelijke effecten van geactiveerde HCA moleculen op DNA te bestuderen. Zoals eerder gezegd kunnen DNA adducten gebruikt worden als biomarkers van interne blootstelling en risico, en geven ze en algemeen beeld van het metabole lot van HCA in het menselijk lichaam. In de interwentiestudie met humane vrijwilligers (Hoofdstuk 5) werden pogingen ondernomen om HCA-DNA adducten te meten in lymfocyten in perifeer bloed, als surrogaatweefsel woor de dikke darm. Op deze manier zou het ook mogelijk zijn om de perifere beschikbaarheid van reactieve HCA metabolieten te onderzoeken. Detectie van adducten in het DNA van deze cellen bleek echter niet mogelijk. Op basis van metabole activiteit en data uit proefdierstudies werd verwacht dat adductniveaus in doelwitweefsel zoals de dikke darm hoger zijn dan in lymfocyten. Daarom werden de rectumbiopten van de patiënten beschreven in Hoofdstuk 6 ook onderzocht op HCA-DNA adducten. Helaas werden in het DNA van zowel normaal weefsel als adenoomweefsel geen meetbare adductniveaus aangetroffen bij een detectiegrens van 1 adduct per $10^{8}$ nucleotiden. Hoewell gevoeligere methoden for DNA. adduct metingen wel zijn ontwikkeld, zijn deze niet bruikbaar in normale biomonitoringsstudies vanwege het gebruik van radioactief gelabelde substraten.

Het kan dus gesteld worden dat HCA-DNA adducten in zowell het dikke darmweefsel wan de patiênten als in de lymfocyten wan de vrijwilligers, indien aanwezig, voorkomen op niveaus lager dan 1 adduct/10 $0^{8}$ nucleotiden; de feitelike aanwezigheid van deze adducten kan derhalve niet worden uitgesloten.

Toekomstige studies zouden zich moeten toeleggen op de verlaging van de detectiegrens van de huidige postlabeling assay " of op de ontwikkeling en toepassing van een alternatieve techniek die een nog gevoeligiere detectie van HCA-DNA adducten mogelijk zou maken.

Concluderend kan gesteld worden dat de data die in dit proefschrift zijn gepresenteerd, aantonen dat HCA via twee verschiltende routes geactiveerd kunnen worden. Hoewel de hepatische route tot nu toe veel uitgebreider bestudeerd en benadrukt is, kan de vije radicalen genererende route ook van significant belang zijn bij het begin van het carcinogene proces in die dikke darm. Daarom zou ook rekening gehouden moeten worden met de metabole activatie van HCA via deze route wanneer het aan HCA blootstelling gerelateerde kankerrisico wordt onderzocht, met name in extrahepatische weefsels zoals de dikke darm. Verder zou het wan belang kunnen zijn om interacties met andere verbindingen zaals PUFA in aanmerking te nemen, omdat deze interacties van invloed zouden kunnen zijn op het uiteindelijke risico op dikke darmkanker. In de mens is het CYP1A2*1F polymorfisme van invloed op het HCA metabolisme, en dit zou dus een 
belangrijke rol kunnen spelen in het uiteindelijke gezondheidsrisico dat gerelateerd is aan HCA blootstelling.

In het algemeen kan geen definitieve conclusie worden getrokken over de relatie tussen blootstelling aan HCA en het risico op dikke darmkankerrisico in de mens, hoewel de studies die in dit proefschrift gepresenteerd worden veel informatie verschaffen over de metabole activatie van HCA en de invloed van variaties in genen en bijbehorende enzymen die hierbij betrokken zijn. Niettemin laten de studies met betrekking tot HCA metabolisme zien dat de extrahepatische route altijd in beschouwing moet worden genomen als de metabole activatie van HCA in de mens wordt bestudeerd. Verder laten de humane studies zien dat bepaalde mensen een hoger risico hebben op het ontwikkelen van genotoxische schade en adenomen in de dikke darm dan anderen, en deze risicogroepen zouden derhalve voorzichtig moeten zijn met het frequent consumeren van doorbakken vlees.

Toekomstig onderzoek zou het belang van het CYP1A2 genotype in de risicobepaling van HCA werder moeten onderzoeken. Tenslotte zijn studies in grotere groepen belangrijk om onze bevindingen te onderbouwen en wit te breiden, en de ontwikkeling van zeer gevoelige methoden zou het mogelijk moeten maken om belangrijke biomarkers van interne blootstelling en risico te meten in dergelijke populaties. 


\title{
Dankwoord
}

\author{
"It is never too late to be what you might have been" - Geonge Eliot
}

Aan het eind van het werhaal rest mij nog een aantal personen te bedanken, zonder wie dit proefschrift er niet in de huidige vorm (of helemaal niet) zou liggen.

Allereerst mijn promotor, prof. Jos Kleinjans, en mijn co-promotor, dr. Theo de Kok. Jos, jouw kritische en enthousiasmerende kijk op het onderzoek hebben me vaak de juiste impuls gegeven om door te gaan op de ingeslagen weg. Bedankt voor alles, ook voor het delen van overige gemeenschappelijke interesses zoals goede jazz en 'mojitos'! Theo, ik kon altijd bij je terecht met vragen en problemen. We hebben valak lange gesprekken gevoerd en (gelukkig) niet alleen over HCA. Mijn kennismaking met je 'fecale humor' en ons avontuur in het Gentse nachtleven waren op zijn minst bijzonder te noemen!

Veel dank ben ik ook verschuldigd aan dr. Leopold Engels: de studie beschreven in hoofdstuk 6 was absoluut onmogelijk geweest zonder zijn grote inspanning en enthousiasme. Ook het verpleegkundig personee van de afdeling Gastroenterologie en dr. Vos en de secretaresses van de afdeling Pathologie van het Maaslandziekenhuis in Sittard wil ik graag bedanken voor hun bereidwillige medewerking, evenals alle patienten die belangeloos hebben meegewerkt aan de studie.

Ook de proefpersonen van de interventiestudie wil ik bedanken voor het eten van alle kip, doneren van bloed en verzamelen van urine. Het keskenpersoneel van het AZM: bedankt woor de prettige samenwerking bij de bereiding van de grote hoeveelheden kip. Natuurlijk ook dank aan de collega's van de capgroep Gezondheidsrisico Analyse en Toxicologie (GRAT) voor alle hulp, samenwerking en gezelligheid. Een aantal hiervan wil ik hier even persconlïk vermelden. Marcel van Herwijnen: bedankt voor het vele celkweekwerk. Naast alle gezellige uren op het lab (en in de prikkamer!), hebben we ook nog eens vele uren samen doorgebracht in de trein; ik ben heel blij dat je mijn paranimf wilt (en kunt) zijn ! Lou Maas: onze gesprekken over muziek kumnen weer worden voortgezet; bedankt voor de introductie in de postlabeling, de genotyperingen en de radio op het E-llab: postlabelen zonder muziek is onmogelijk ! Edwin Moonen (Moeene): bedankt voor je medewerking als "urine-koerier" en de enorme hoeveelheid uren die je hebt gestoken in het GC-MS en HPLC-werk: het is ons toch gelukt! Danielle Pachen en Liesbeth Brouwer: bedankt voor het chauffeuren naar alle proefpersonen. Roger Godschalk voor de statistische hulp. Ingrid Vermeer: je hebt me 5 jaar geleden de allereerste beginselen van het 'AlO-zijn' bijgebracht, bedankt daarvoor.

Bedankt ook alle stagiaires die in de loop der jaren hun bijdragen hebben geleverd: Marieke, Karen, Inge, Michael en wooral Eva van Rooil en Marloes van Zwam. Gerrit Alink en Yvonne Dommels (WU) , bedankt woor de fijne samenwerking.

Heleen Huyten voor de hulpvaardigheid en goede service op het B-lab.

Leden van de beoordelingscommissie: Prof. E. Mariman, Prof. M. Daemen, Dr. H. van Kranen. Prof. F. Ramaekers en Prof. I. Rietjens; bedankt woor het beoordelen van mijn proefschrift.

De collega's van de vakgroep Farmacologie \& Toxicologie: Agnes, Rachel, Gert-Jan, Mariken, Els en Chantal, bedankt voor alle gezelligheid tijdens en buiten werktijd. 
Mark Walravens voor de technische hulp bil het kaftontwerp en Karel Brouns voor het uitlenen van de laptop.

Heren wan Texan Tail en The Wild Specialties: bedankt voor alle geweldige muzikale avonturen die zorg(d)en voor de broodnodige afleiding en ontspanning: Let 'er roll !

Roy van der Putten: geweldig dat je mijn paranimf bent; I leel alright tonight ! (Schoon)familie en vrienden, bedankt voor de belangstelling en steun; ik weet dat het niet makkelijk was om te begrijpen waar ik al die tijd precies mee bezig was, maar om dit boekje ging het dus allemaial....

Pap en mam, jullie hebben me de gelegenheid gegeven om te kunnen studeren en me altijd wrij gelaten in mijn keuzes, heel erg bedankt!

En als laatste natuurlijk Chantal. Lieve Tall (mevrouw Moonen), enorm bedankt voor je nimmer aflatende steun, begrip en geduld; it's a wonderful night for a moondance.....

Bedankt allemaal !

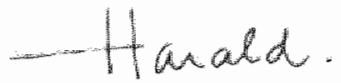




\section{Curriculum vitae}

Harald Johan Joseph Moonen werd geboren op 27 april 1974 te Weert. Na het behalen van het WNO diploma aan de Phillips van Horne Scholengemeenschap te Weert in 1992. begon hij zijn studie Chemische Technologie aan de Technische Universiteit in Eindhoven. Tijdens dieze studie werden stage-onderzoeken verricht in Braziliè en bij de capaciteitsgroep Gezondheidsrisico Analyse en Toxicologie (GRAT) aan de Universiteit Maastricht. In augustus 1998 behaalde hij het ingenieursdiploma.

In november 1998 begon hij als assistent in opleiding bij de capacitieitsgroep GRAT. alwaar het onderzoek beschreven in dit proefschrift werd uitgevoerd. Tijdens deze periode werd tevens het certificaat 'Stralingshygiêne, deskundigheidsniveau 5b' behaald. Vanaf oktober 2003 is Harald werkzaam als post-doc bij de capaciteitsgroep GRAT aan de Universiteit Maastricht.

\section{List of publications}

\section{ARTICLES}

De Kok , T.M.C.M., Moonen, H.J.J., Van Delft, J., Van Schooten, F.J. Methodologies for bulky DNA adduct analysis and biomonitoring of environmental and occupational exposures. Journal of Chromatography B, 778(1-2): 345-55, 2002.

Moonen, H.J.J., Briedé, J.J., Van Maanen, J.M.S., Kleinjans, J.C.S., De Kok, T.M.C.M. Generation of free radicals and induction of DNA adducts by activation of heterocyclic aromatic amines via different metabolic pathways in vitro. Molecular Carcinogenasis, 35(4): 196-203, 2002.

Moonen, H.J.J., Dommels, Y.E.M., Van Zwam, M. Van Herwinen, M.H.M. Kleinjans, J.C.S. Alink, G.M., De Kok, T.M.C.M. Effects of polyunsaturated fatty acids on DNA adduct formation by heterocycic aromatic amines in human adenocarcinoma colon cells. Submitted for publication

Moonen, H.J.J. Moonen, E.J.C., Maas, L., Kleinjans, J.C.S., De Kok, T.M.C.M. NAT2 and CYP1A2 genotype/phenotype relations and urinary excretion of 2-amino-1 methyl-6phenylimidazo[4,5-b]pyridine (PhIP) in a human dietary intervention study. Submitted for publication

Moonen, H.J.J., Engels, L.G.J.B., Kleinjans, J.C.S., De Kok, T.M.C.M. Relationship between the CYP1A2-164A $\rightarrow C$ polymorphism (CYP1A2* $1 F$ ) and risk for colorectal neoplasia in humans. Submitted for publication 


\section{ABSTRACTS}

H.J.J. Moonen, T.M.C.M. de Kok, F.J. van Schooten, J.C.S. Kleinjans. The role of dietary heterocycic aromatic amimes in colorectal cancer. Proceedings of the scientific meeting of the Nethertands Society of Toxicology, Kerkrade, The Netherlands, December 2000

H.J.U. Moonen, T.M.C.M. De Kok, J.C.S. Kleinjans. In vitro DNA adduct formation by heterocylic amines, activated via different metabolic pathways. Proceedings of the 31 st Annual Meeting of the European Environmental Mutagen Society (EEMS), Ghent; Belgium, September 2001.

H.J.J. Moonen, T.M.C.M. De Kok J.C.S. Kleinjans. In witro DNA adduct formation by heterocylic amines, activated via different metabolic pathways. Proceedings of the scientific meeting of the Netherlands Society of Toxicology. Nimegen. The Netherlands, November 2001 .

H.J.d. Moonen, J.J. Briede, J.M.S. van Maanen, J.C.S. Kleinjans, T.M.C.M. De Kok. In vitro activation of 2-amino-3-methylimidazo[4,5-f]quinoline $(\mid \mathrm{Q})$ and 2-amino-1-methyl-6phenyl-imidazo[4,5-b]pyridine (PhIP) via different metabolic pathways. Proceedings of the 93rd Annual Meeting of the American Association for Cancer Research (AACR), San Francisco, USA, April 2002.

H. Moonen, Y. Dommels, M. van Zwam, M. van Herwijnen, G. Alink, I. Rietjens, d. Kleinjans, T. de Kok. Effect of polyunsaturated fatty acids on DNA adduct formation by heteracyclic aromatic amines in HCA-7 cells. 1 st Seminar of the European Graduate School, Maastricht, The Netherlands, November 2002.

H. Moonen, Y. Dommels, M. van Zwam, M. van Herwijnen, G. Allink, I. Rietjens, J. Kleinjans, $T$. de Kok. Effect of polyunsaturated fatty acids on DNA adduct formation by heterocyclic aromatic amines in HCA-7 cells. Proceedings of the scientific meeting of the Netherlands Society of Toxicology, De Bilt, The Netherlands, January 2003.

H.J.J. Moonen, M. van Zwam, M. van Herwijnen, J.C.S. Klleinjans, T.M.C.M. de Kok. Effects of polyunsaturated fatty acids on DNA adduct formation by heterocyclic aromatic amines in HCA-7 cells. Proceedings of the 42nd Annual Meeting of the Society of Toxicology (SOT), Salt Lake City, USA, March 2003.

J. Kleinjans, H. Moonen, M. van Herwijnen, E. Moonen, Th. De Kok. Different metabolic pathways of heterocyclic aromatic amines in man. Proceedings of the 4 th International Conference on Environmental Mutagens in Human Populations (ICEMHP). Florianopolis, Brazil, May 2003.

H.J.J. Moonen, L.G.J.B. Engels, J.C.S. Kleinjans and T.M.C.M. de Kok.

Relationship between the CYP1A2-164A $\rightarrow C$ polymorphism (CYP1A2*1F) and risk for colorectall neoplasia in humans. Proceedings of the Annual Meeting of the Netherlands Society of Gastroenterology, Veldhoven. The Netherlands, October 2003. 